\title{
Stimulating fits
}

Citation for published version (APA):

Rijkers, K. (2011). Stimulating fits. [Doctoral Thesis, Maastricht University]. Datawyse / Universitaire Pers Maastricht. https://doi.org/10.26481/dis.20110114kr

\section{Document status and date:}

Published: 01/01/2011

DOI:

10.26481/dis.20110114kr

Document Version:

Publisher's PDF, also known as Version of record

\section{Please check the document version of this publication:}

- A submitted manuscript is the version of the article upon submission and before peer-review. There can be important differences between the submitted version and the official published version of record.

People interested in the research are advised to contact the author for the final version of the publication, or visit the DOI to the publisher's website.

- The final author version and the galley proof are versions of the publication after peer review.

- The final published version features the final layout of the paper including the volume, issue and page numbers.

Link to publication

\footnotetext{
General rights rights.

- You may freely distribute the URL identifying the publication in the public portal. please follow below link for the End User Agreement:

www.umlib.nl/taverne-license

Take down policy

If you believe that this document breaches copyright please contact us at:

repository@maastrichtuniversity.nl

providing details and we will investigate your claim.
}

Copyright and moral rights for the publications made accessible in the public portal are retained by the authors and/or other copyright owners and it is a condition of accessing publications that users recognise and abide by the legal requirements associated with these

- Users may download and print one copy of any publication from the public portal for the purpose of private study or research.

- You may not further distribute the material or use it for any profit-making activity or commercial gain

If the publication is distributed under the terms of Article $25 \mathrm{fa}$ of the Dutch Copyright Act, indicated by the "Taverne" license above, 


\section{STIMULATING FITS}


(c) 2011 Kim Rijkers, Maastricht

Layout: Tiny Wouters

Cover illustration: Els Franken

Production: Datawyse | Universitaire Pers Maastricht

ISBN: 9789461590251 


\section{STIMULATING FITS}

PROEFSCHRIFT

ter verkrijging van de graad van doctor aan de Universiteit Maastricht, op gezag van de Rector Magnificus, Prof. mr. G.P.M.F. Mols, volgens het besluit van het College van Decanen, in het openbaar te verdedigen op vrijdag 14 januari 2011 om 12.00 uur

door

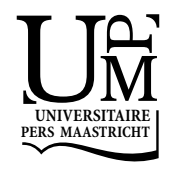




\section{Promotores:}

Prof. dr. J.S.H. Vles

Prof. dr. H.W.M. Steinbusch

Co-promotores:

Dr. H.J.M. Majoie

Dr. G. Hoogland

Beoordelingscommissie:

Prof. dr. J.J. Van Overbeeke (voorzitter)

Prof. dr. F.C.S. Ramaekers

Prof. dr. M. De Baets

Prof. dr. O. Van Nieuwenhuizen (Universitair Medisch Centrum Utrecht)

Dott.ssa A. Vezzani (Instituto di Richerche Farmacologiche 'Mario Negri', Milaan, Italië) 


\section{Contents}

$\begin{array}{lll}\text { Chapter } 1 & \text { General introduction } & 7\end{array}$

Chapter 2 The role of interleukin-1 in seizures and epilepsy: a critical review 27

$\begin{array}{lll}\text { Chapter } 3 & \text { Neuroimmunological changes in epilepsy } & 61\end{array}$

Chapter 4 Polymorphisms in CACNA1E and Camk2d are associated with $\quad 77$ seizure susceptibility of Sprague Dawley rats

Chapter 5 Acute seizure-suppressing effect of vagus nerve stimulation $\quad 91$ in the amygdala kindled rat

Chapter 6 Rat vagus nerve stimulation model of seizure suppression: nNOS and $\triangle$ fos $B$ changes

Chapter 7 Horner's syndrome: a complication of experimental carotid artery surgery in rats

Chapter 8 General discussion and conclusion

Summary

Samenvatting

List of publications

Dankwoord 

Chapter 1

General introduction 
$8 \mid$ Chapter 1 


\section{Background}

Vagus nerve stimulation (VNS) is used to treat medically refractory epilepsy. Despite years of basic and clinical research it is still not clear why patients develop epileptic seizures and why VNS can reduce these seizures. In this thesis the results of scientific experiments aimed at exploring the pathophysiology of epilepsy and at establishing the effectiveness of VNS in a clinically relevant animal model for epilepsy are described.

\section{Epilepsy}

Epilepsy is a syndrome that is characterized by recurrent unprovoked seizures which are due to occasional, excessive or abnormal synchronous firing of neurons ${ }^{1}$. Patients are diagnosed after clinical observation and electro-encephalographic (EEG) recording of brain activity. It is the second most common neurological disorder after stroke, affecting approximately $1 \%$ of the world's population ${ }^{2}$.

Epileptic seizures that originate in a specific part of the brain are referred to as partial seizures while seizures in which both hemispheres participate are referred to as generalized seizures. Partial seizures can be subdivided into simple, in which consciousness remains unaffected (e.g. clonic movement in one limb), and complex in which consciousness is impaired (e.g. complex partial seizure). Often a partial seizure secondarily spreads through the brain evolving into a generalized seizure. This is called secondary generalization.

\section{Pathophysiology of epilepsy}

\section{Interleukin 1}

Why neurons start to fire synchronously in epilepsy patients is not known. The most important risk factors for developing epilepsy are febrile seizures $(\mathrm{FS})^{3}$, brain trauma ${ }^{4}$ and stroke ${ }^{5}$. These conditions are associated with increased levels of the proinflammatory cytokine interleukin- 1 beta $(\mathrm{IL}-1 \beta)^{6-8}$. It is thought that IL-1 $\beta$ contributes to, or even initiates epileptogenesis?.

For long it was thought that the brain is deprived of immune cells, being protected by the blood brain barrier (BBB). Research over the past twenty years has revealed that the brain has an immune system of its own, mainly represented by microglial cells. These cells are able to produce IL- 1 and other immunological mediators, and do so when neurons are threatened, for instance in stroke ${ }^{7}$, traumatic brain injury ${ }^{8}$ and epilepsy ${ }^{10-12}$. The seizure-induced IL-1 $\beta$ expression ${ }^{13-17}$ most likely results from the release of heath shock proteins (HSP) during the seizure that activate Toll-like 
receptors (TLR) which in turn induce IL-1 $\beta$ production via activation of nuclear factor

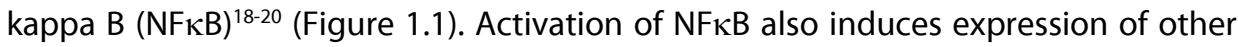
proteins, amongst others the ceramide transporter (CERT, also known as the Goodpasture antigen binding protein) a protein involved in intracellular transport of ceramide $^{21}$.

Besides local seizure-induced IL-1 $\beta$ production it has been shown recently that the BBB is leaky in many neurological conditions including epileptic seizures, exposing the cells to circulating cytokines as well ${ }^{22,23}$ (Figure 1.1).

After entering the central nervous system (CNS) via either the leaky BBB or local production, IL-1 $\beta$ can affect functioning of neurons after binding to its receptor (IL-1 receptor type I, IL-1RI). This is followed by association with an accessory protein (AcP) after which intracellular signal transduction cascades are activated. These cascades can affect amongst others $\mathrm{N}$-methyl-D-aspartic acid receptor (NMDA-R) phosphorylation, IL-6 production, $\mathrm{Ca}^{2+}$ influx, $\mathrm{K}^{+}$efflux, alpha-amino-3-hydroxy-5methyl-4-isoxazole-propionic acid receptor (AMPA-R) function and the balance between gamma-aminobutyric acid (GABA) and glutamate ${ }^{24-32}$. Some of these IL-1 $\beta$ dependent mechanisms bring the neuron in a state more favorable for depolarisation, for example NMDA-R phosphorylation ${ }^{29}$, augmented $\mathrm{Ca}^{2+}$ influx ${ }^{31}$ and restrained $\mathrm{K}^{+}$efflux ${ }^{33}$, and may contribute to increased seizure susceptibility and the actual development of a subsequent seizure by causing cellular hyperexcitability (Figure 1.1).

\section{Calcium}

In addition to IL-1 $\beta$, several other mechanisms appear to play a role in seizure generation and the pathophysiology of epilepsy. A well-established factor in this regard is intracellular free calcium. The process of epileptogenesis, the process that transforms a normal brain into a hyperexcitable brain, is characterized by high intracellular calcium levels. While irreversible elevations in intracellular free calcium levels result in neuronal death, a prolonged but reversibly high intracellular calcium concentration can trigger pathological neuronal plasticity, leading to the development of epilepsy ${ }^{34}$ (Figure 1.1).

Stroke, brain injury and several other conditions associated with epilepsy are characterized by high intracellular calcium levels. These high calcium levels are the result of excessive release of glutamate, leading to activation of the NMDA-R and calcium influx ${ }^{35}$ (Figure 1.1). Glutamate excitotoxicity occurs in all stroke or traumatic brain injury patients, and is unclear why some of them develop epilepsy, while the majority does not. 


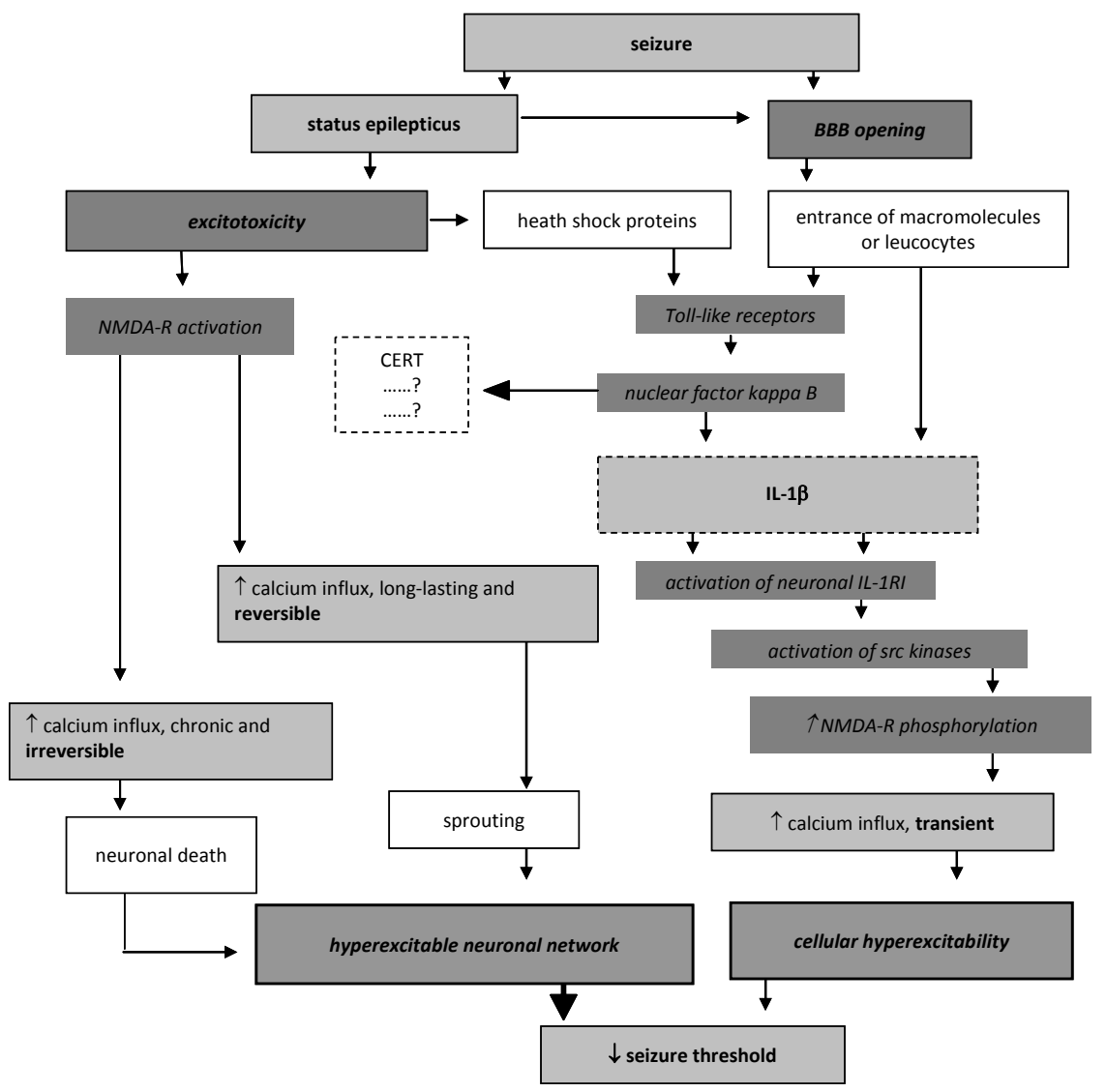

Figure 1.1 Scheme depicting seizure-induced actions of IL-1 $\beta$ in the brain. If a seizure evolves in a status epilepticus this can cause glutamate excitotoxicity, that is associated with the release of heath shock proteins (HSPs). HSPs are endogenous ligands for the Toll like receptors which in turn induce $\mathrm{NF \kappa B}$ production. $\mathrm{NF \kappa B}$ stimulates the neurons to produce IL-1 $\beta$. Simultaneously, the blood brain barrier becomes disrupted during a seizure and during status epilepticus. This leads to entrance of macromolecules and leucocytes from the general circulation which either activate microglial IL-1 $\beta$ expression, or express IL-1 $\beta$ themselves.

When this seizure-induced IL-1 $\beta$ signal is picked up by IL-1 receptors on neurons, a cascade of events is initiated: firstly upregulation of the Src family of kinases occurs, which increase the degree of phosphorylation of the NDMA-R, in turn leading to augmented calcium influx. This ultimately causes cellular hyperexcitability for as long as the NMDA-R are letting more calcium in. In many epilepsy models, especially those that are based on status epilepticus, other cascades contribute to hyperexcitability as well. Glutamate excitotoxicity that occurs during status epilepticus leads to excess activation of NMDA-R, resulting in massive calcium influx into the neurons. Neuronal death occurs if the intracellular calcium concentrations remain chronically elevated, while reversible high calcium levels cause sprouting. Neuronal death and sprouting lead to network changes, ultimately resulting in network hyperexcitability. If both network hyperexcitability and cellular hyperexcitability are present, it is likely that network hyperexcitability contributes more to epileptogenesis than cellular hyperexcitability caused by IL-1 $\beta$. When a seizure is less severe with regard to excitotoxicity, the contribution of seizure-induced IL-1 $\beta$ may be relatively bigger. 


\section{Antiepileptic treatment}

The majority of epilepsy patients is seizure free with classic antiepileptic drugs such as carbamazepine and valproate, but $25 \%$ is medically refractory ${ }^{36,37}$. For them, several treatment options are available. First of all the ketogenic diet can be used to treat children with refractory epilepsy, resulting in $>50 \%$ seizure frequency reduction in $38 \%$ of children versus in $6 \%$ of controls ${ }^{38}$. Secondly, resective neurosurgery is an option in a small number of patients that can be cured from epilepsy by removing the part of the brain where the seizures originate without damaging eloquent brain areas. In the majority of medically refractory epilepsy patients this is not possible.

Consequently, there are still many medically refractory epilepsy patients. Scientists have been searching for other ways to treat these patients; over the past 25 years this has lead to the development of several different antiepileptic drugs such as lamotrigine, zonisamide and levetiracetam ${ }^{39-43}$, but also to neuromodulative treatments such as deep brain stimulation ${ }^{44}$ and VNS.

Evaluation of the effectiveness of an antiepileptic treatment in general relies on seizure-diaries that are kept by patients or caretakers. A patient that has $>50 \%$ reduction in seizure frequency after treatment compared to baseline is generally considered a responder.

\section{Vagus nerve stimulation}

VNS consists of continuous cyclic electrical stimulation of the left vagus nerve in the neck. During a $<60$-minute surgical procedure, a helical electrode (Figure 1.2) is wrapped around the nerve and connected to a subcutaneously placed pulse generator (Figure 1.3). Actual stimulation (a 30 -second train of $30 \mathrm{~Hz}, 0.25-0.5 \mathrm{~ms}$ block pulses with an intensity of $0.25-2.5 \mathrm{~mA}$ ) is followed by a 5 -minute stimulationfree interval.

Randomized controlled trials report $>50 \%$ seizure frequency reduction in $22-39 \%$ of adult patients within the first three months of treatment ${ }^{45,46}$. After correcting these data for placebo effect and natural course of the disease, $>50 \%$ seizure frequency reduction is reached in $11.7 \%$.

Stimulation-induced side effects are generally mild, consisting of vocal cord paralysis (hoarseness) a strange feeling in the throat (can be painful), neck pain and difficulty swallowing ${ }^{47}$. Surgical complications consist of infection, bleeding, (transient) vocal cord paralysis, and Horner's syndrome. Hardware failure can occur as well, most often lead damage ${ }^{48,49}$. VNS does not have the negative effects on mood, cognition and behavior often found after antiepileptic drug treatment. VNS on the contrary even appears to have a positive effect on mood in epilepsy patients ${ }^{50}$. This observation was followed by studies on VNS in depressive patients but a true antidepressant effect has not been established ${ }^{51}$. Behavioral function also appears to improve after VNS $^{52}$. 


\section{The vagus nerve}

The vagus nerve is the $10^{\text {th }}$ cranial nerve, and mainly known by its parasympathetic function. Besides this efferent visceromotor function, that is carried out by only $20 \%$ of the vagus nerve fibers, the nerve contains efferent motor fibers, afferent exteroceptive sensory fibers, afferent viscerosensory fibers, and afferent taste fibers. The majority of nerve fibers ( $90 \%$ of the afferents and $70 \%$ of the efferents) are unmyelinated C-fibers ${ }^{53}$.

The efferent parasympathetic fibers that innervate organs in the thoracic and abdominal cavity, originate in the visceromotor dorsal nucleus of the vagus nerve (DMV). The efferent motor fibers that innervate muscles of the larynx and pharynx, originate in the nucleus ambiguus (AMB). The afferent viscerosensory and pure sensory fibers end in the nucleus of the solitary tract (NTS), while the afferent exteroceptive sensory fibers end in the spinal trigeminal nucleus (Table 1.1).

Fibers originating in or projecting to the $A M B, D M V$ and NTS, respectively, unite dorsally from the olivary nucleus and leave/enter the brain stem between the olivary nucleus and the cerebellar peduncle. Just prior to leaving the skull through the jugular foramen, the superior ganglion of the vagus nerve is found, containing the cell bodies of the exteroceptive nerve fibers. These fibers transmit sensory information from the infratentorial dura mater and skin of the external acustic meatus and part of the concha of the ear to the spinal trigeminal nucleus. The vagus nerve subsequently exits the skull via the jugular foramen, together with the glossopharyngeal and accessory nerves and sigmoid and inferior petrosal sinusses. Immediately outside the skull the nodose ganglion is found, containing cell bodies of the viscerosensory and pure sensory fibers that transmit information from the organs and larynx/pharynx to the NTS (Figure 1.4).

The vagus nerve subsequently courses between the internal and communal carotid artery and the internal and communal jugular vein in the neck where it gives off four (groups of) branches. 1) The motor fibers that innervate the pharyngeal muscles as well as sensory fibers that originate in the pharynx mucosa and in trachea, esophagus and epiglottis constitute the pharyngeal branches. 2) The motor fibers that innervate the $\mathrm{m}$. cricothyroideus and the sensory fibers that originate in the laryngeal mucosa constitute the superior laryngeal nerve. 3) The recurrent laryngeal nerve that contains fibers that innervate all muscles of the larynx except the $\mathrm{m}$. cricothyroideus, as well as fibers that transmit sensory information from the mucosa of the pharynx below the level of the vocal cords to the NTS. 4) The parasympathetic fibers that originate in the DMV course via the superior and inferior cervical cardiac branches to the heart. The superior branches leave the vagus nerve at variable levels but in general at the level of the parotid gland. They end in a large parasympathetic plexus of the heart: the cardiac plexus. One of these branches also contains viscerosensible fibers that transmit information regarding the aortic wall-tension and can cause blood pressure to fall. The inferior cardiac branches either leave the vagus 
nerve itself or branch off the recurrent laryngeal nerve and also end in the cardiac plexus.

After these four groups of branches have left the vagus nerve, it loses its character as a single nerve and subdivides into a number of plexi and rami: the pulmonal plexus, the esophageal plexus, the gastric rami, the hepatic rami, the coeliac rami and the renal rami.

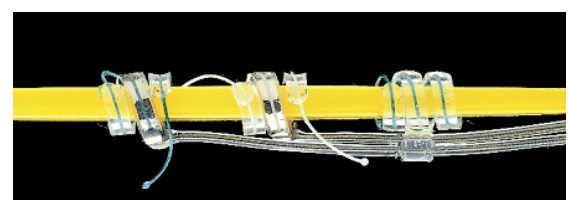

Figure 1.2 Bipolar electrode used for vagus nerve stimulation in humans. (Courtesy of Cyberonics, Inc.)

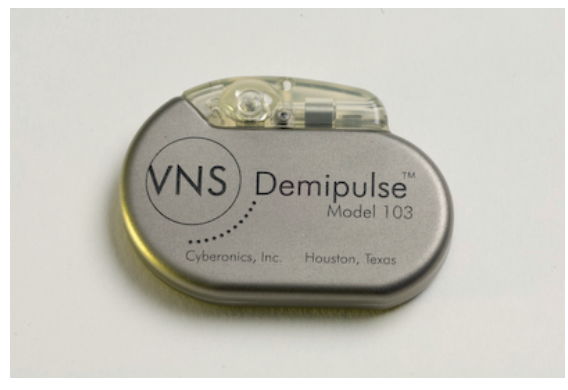

Figure 1.3 Pulse generator (Courtesy of Cyberonics Inc.)

Table $1.1 \quad$ Functions of the vagus nerve.

\begin{tabular}{|c|c|c|c|c|c|}
\hline Afferents & Nucleus & Vargus target organs & Nerve efferents & s Nucleus & Target organs \\
\hline Exteroceptive & $\begin{array}{l}\text { spinal } \\
\text { trigeminal } \\
\text { nucleus }\end{array}$ & $\begin{array}{l}\text { dura mater posterior fossa } \\
\text { skin concha ear } \\
\text { skin meatus acusticus externus }\end{array}$ & Motor & AMB & $\begin{array}{l}\text { larynx-pharynx } \\
\text { muscles }\end{array}$ \\
\hline Viscerosensory & NTS & organs in thorax and abdomen & Visceromotor & DMV & $\begin{array}{l}\text { organs in thorax } \\
\text { and abdomen }\end{array}$ \\
\hline Sensory & NTS & $\begin{array}{l}\text { pharynx } \\
\text { epiglottis } \\
\text { oesophagus } \\
\text { trachea }\end{array}$ & & & \\
\hline
\end{tabular}

With regard to the mechanisms of action of VNS and to the IL- $1 \beta$-hypothesis in epilepsy, a recently discovered function of the vagus nerve is of particular interest. The vagus nerve carries out the cholinergic anti-inflammatory reflex, by which the CNS can modulate peripheral IL-1 $\beta$ expression ${ }^{54}$. Afferent vagus nerve fibers signal the CNS when circulating macrophages produce more IL-1 $\beta$ (and other proinflammatory markers). As a result of this afferent vagal signal, the efferent vagus nerve is activated. This results in the release of acetylcholine, which immediately triggers the $\alpha 7$ subunit of the nicotinic receptor on activated macrophages. These in turn decrease peripheral IL-1 $\beta$ production. It is not clear whether activation of the afferent vagus nerve induces a similar immunosuppressive effect inside the CNS as well. 


\section{Vagus Nerve (X): Schema}

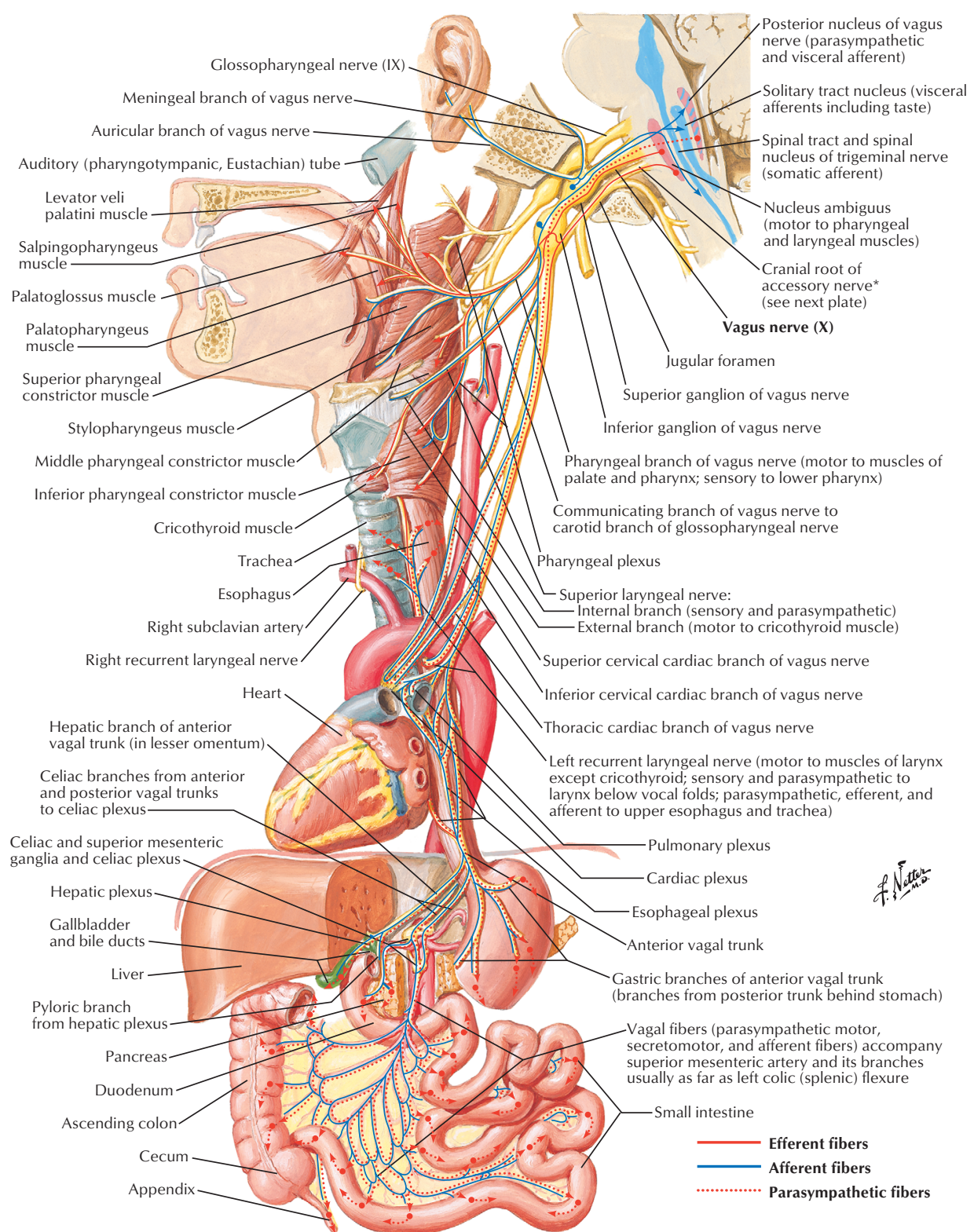

Figure 1.4 Anatomy of the vagus nerve. Netter illustration used with permission of Elsevier, Inc. All rights reserved. www.netterimages.com. 
C-fiber activation is not required for obtaining an anticonvulsive effect ${ }^{55}$. This implies that only $14 \%$ of vagus nerve fibers, consisting of myelinated $A$ and $B$ fibers that are normally involved in mediating reflexes ${ }^{56}$, are responsible for the anticonvulsive effect.

\section{Animal models for epilepsy}

Animal models are and have been used to test novel antiepileptic drugs and to unravel the pathophysiology of epilepsy. Several types of animal models are available. They can roughly be divided into seizure models and epilepsy models.

\section{Seizure models}

Chemical seizure models are models in which a single seizure is induced by administration of a chemical substance such as kainate, phenylenetetrazol or bicuculline. In electrical seizure models a single seizure is induced by electrical stimulation of the brain, for instance through ear-clip electrodes or corneal electrodes. Infection induced seizure models are models in which a single seizure is provoked using pertussis vaccine or shigella dysenteria toxin. In fever induced seizure models lipopolysaccharide is injected to provoke fever followed by administration of a subconvulsive dose of kainate to provoke a single seizure. Major drawback of the seizure models is the fact that they mimic a single seizure, not epilepsy.

\section{Epilepsy models}

In chemical epilepsy models a status epilepticus is induced by administration of a high dose of a chemical substance such as kainate, pilocarpine or bicuculline. Spontaneous seizures start to develop later. In this latent period between status epilepticus and the first spontaneous seizure, epileptogenesis takes place. Status epilepticus can also be provoked by electrical stimulation of the hippocampus or amygdala. Similarly to the chemical epilepsy models, in these electrical epilepsy models spontaneously recurring seizures start later, after epileptogenesis has taken place in the latent period. These models are especially useful to study epileptogenesis itself. Major drawback of both electrical and chemical epilepsy models is the fact that either the chemical and the status epilepticus themselves can cause major neuronal damage by glutamate excitotoxicity that is generally not present in the brains of humans with epilepsy.

In kindling, chemicals or electrical stimulation are used as well but instead of using these stimuli to provoke a severe status epilepticus, repetitive subthreshold stimuli (either chemical or electrical) are administered at fixed intervals. These stimuli 
eventually lead to a decreased seizure-threshold which results in the occurrence of a seizure upon administration of the (previously subthreshold) stimulus. The disadvantages of the kindling models are that there is no seizure-free latent phase to study epileptogenesis in, and that most seizures occur after stimulation and not spontaneously, as is the case in the human situation. Spontaneous seizures do occur, but at a low frequency, generally too low to be useful in an experimental setup to evaluate treatment effects.

A number of genetic epilepsy models are available. Most of them model absence epilepsy.

Exposing rat pups to hyperthermia evokes febrile seizures (FS) in a subpopulation of rats. A subpopulation of these FS rats develops spontaneous seizures in later adult life. The advantage of this animal model is that it is directly linked to the situation in humans, where a significant number of temporal lobe epilepsy (TLE) patients have a history of febrile seizures, making FS the most important risk factor for developing temporal lobe epilepsy (still the majority of patients that suffer from FS will never develop epilepsy). The disadvantage is that a large number of rats is required in order to collect a sufficient number of epileptic animals to study treatment effects in.

\section{Amygdala kindling}

In the experiments that have been carried out for this thesis, the amygdala kindled (AK) rat was used ${ }^{57}$. This is one of the electrical animal models for epilepsy that is based on daily subthreshold stimulation of the left basolateral amygdala (Figure 1.5) and has been used frequently in the past and present to study the pathophysiology of $\mathrm{TLE}^{58}$ and to study treatment effects of novel antiepileptic drug $\mathrm{s}^{59}$. For kindling, animals are implanted with an electrode in the left amygdala and connected to an external stimulator and a stimulus consisting of $50 \mathrm{~Hz}, 0.2 \mathrm{~ms}$ block pulses with an intensity of $400 \mu \mathrm{A}$ is administered to the amygdala for two seconds. These twice daily kindling stimuli provoke seizures of increasing severity, graded on a five-point scale first described by Racine (Table 1.2) ${ }^{57}$.

The kindling model was chosen for a number of reasons. First of all we aimed at a model that mimics the clinical features of the most frequently occurring type of epilepsy, TLE ${ }^{57}$. Furthermore, seizures evoked by kindling are often resistant to phenytoin, a phenomenon often encountered in human TLE as well ${ }^{60}$. Thirdly we aimed at a model that mimics the histopathological changes seen in TLE ${ }^{61}$. Fourthly we wanted to avoid all models that are associated with major neuronal damage since this would interfere with our immunological studies involving IL-1 $\beta^{62}$. Since we did not have the video/EEG equipment to monitor the animals continuously, 24 hours per day, 7 days per week, that is required when animals that have spontaneously recurring seizures are used, we chose a model for chronic epilepsy in which all seizures are provoked. 


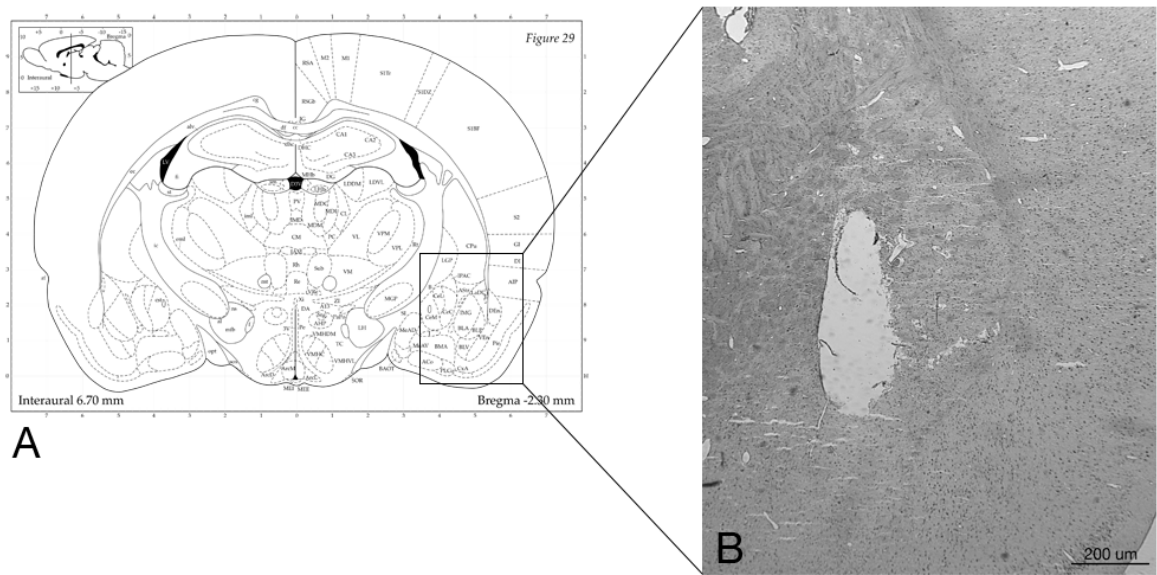

Figure 1.5 Amygdala kindling: Coronal section of a rat brain $(A)$ showing the location of the electrode tip in a microscopic picture of a brain slice in which the basolateral amygdala is visualized using hematoxylin-eosin (B).

Table 1.2 Racine's scale.

$\begin{array}{ll}\text { Stage } & \text { Seizure behavior } \\ \mathbf{1} & \text { mild facial clonus } \\ 2 & \text { severe facial clonus } \\ 3 & \text { unilateral forelimb clonus } \\ 4 & \text { bilateral forelimb clonus, rearing } \\ 5 & \text { rearing, loss of balance, falling }\end{array}$

\section{Animal models for vagus nerve stimulation}

The first animal study on VNS was published in $1952^{63}$. Between that year and 1997, the year of FDA approval, it had been tested in a number of animal studies in which single seizures were treated with a short train of VNS, when the animal was anesthetized ${ }^{64-68}$. Only one study dating from this period was conducted in freely moving animals suffering from experimental epilepsy ${ }^{69}$. These studies generally confirm the effectiveness of VNS and do not focus on possible mechanism of action. The first studies in which the mechanism of action of VNS was explored date from the late 1990-s, when Krahl et al. described that the locus coeruleus played a crucial role in the anticonvulsant effect of $\mathrm{VNS}^{70}$. The same group showed a couple of years later that C-fiber activation was not required for the anticonvulsive effect of $\mathrm{VNS}^{55}$. The third paper on this subject from the same period by Zagon and Kemeny focused on the hyperpolarizing effect of VNS on cortical neurons as a possible mode of action ${ }^{71}$. Even though more studies on VNS in animal models have been published, all the others focus on the effectiveness and not on the mechanism of action ${ }^{72-79}$; all studies 
except one using Genetic Absence Epilepsy Rats from Strassbourg (GAERS) ${ }^{76}$ show that VNS is effective in reducing the severity or duration of one or more seizures.

Apart from the studies in animal models for seizures, a number of papers has been published in which VNS was applied in otherwise healthy animals to evaluate the effect on the EEG pattern ${ }^{63}$, cognitive function and memory ${ }^{80-82}$ or for feasibility purposes $^{83}$. The past five years more scientists have shown interest in the anticonvulsive mode of action of VNS, resulting in a number of papers focusing on VNS-induced activity in the locus coeruleus ${ }^{84}$, thalamus ${ }^{85,86}, \mathrm{NTS}^{87,88}$, $\operatorname{cortex}^{89,90}$ and hippocampus ${ }^{91,92}$.

In the experiments that were carried out for this thesis, VNS was performed using a custom-made circular electrode (Figure 1.6) that was wrapped around both left carotid artery and vagus nerve of the rats. The lead of the electrode was tunneled subcutaneously and fixed to the cranium of the rat with a connector for connecting the animal to an external stimulator.
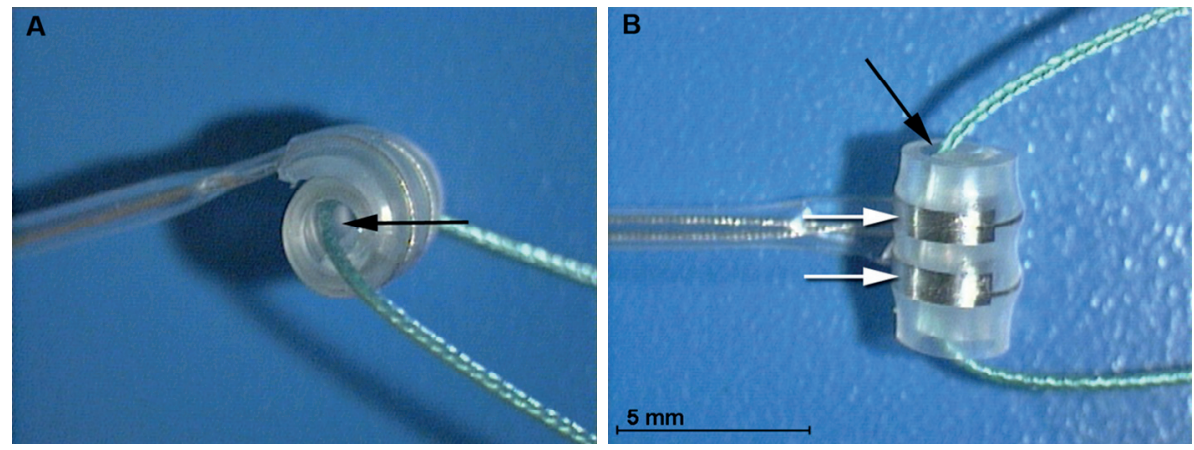

Figure 1.6 Vagus nerve electrode (photograph by P. Van Venrooij and V. Duysens, developers of the electrode at Medtronic Bakken Research Center, Maastricht, The Netherlands). A: lateral view; B: ventral view. Green suture is used for surgical placement. 


\section{Scope and aims of the study}

The aims of the present study were to gain more insight into the pathophysiology of epilepsy with regard to both IL-1 $\beta$ and calcium, and to develop a clinically relevant animal model in which the mode of action of VNS can be studied.

Chapters 2, 3 and 4 are dedicated to the pathophysiology of epilepsy while the studies regarding VNS are described in Chapters 5, 6 and 7.

In Chapter 2 the existing literature concerning the role of IL-1 in epilepsy is reviewed. Based on these data a hypothesis regarding the involvement of IL-1 in the pathophysiology of epilepsy is presented.

In Chapter 3 the involvement of the immune system in the kindling model is investigated. We demonstrate that IL-1 $\beta$ is not chronically expressed in this animal model, probably because the model is not associated with neuronal damage.

Some people develop seizures after stroke or traumatic brain injury, while others do not. In a similar way, some rats need a low number of kindling stimuli to develop epilepsy while others need many more. Apparently seizure thresholds can vary between individuals. In Chapter 4 we demonstrate that polymorphisms in genes that are involved in calcium homeostasis may contribute to the individual seizure susceptibility in rats.

In Chapter 5 we demonstrate that VNS affects seizures induced by kindling. This means that the VNS-treated kindled rat is a clinically relevant animal model in which the mechanism of action of VNS can be studied. The primary and secondary projection nuclei of the vagus nerve in the brain stem appear to be involved, as we immunohistochemically demonstrate in Chapter 6.

A rare complication of VNS in humans is Horner's syndrome. In Chapter 7 we describe Horner's syndrome as a complication of vagus nerve electrode placement in rats.

Finally, in Chapter $\mathbf{8}$ a summary of the findings described in this thesis is given, and implications of these findings are discussed. 


\section{References}

1. Fisher RS, van Emde Boas W, Blume W, Elger C, Genton P, Lee P, Engel J Jr. Epileptic seizures and epilepsy: definitions proposed by the International League Against Epilepsy (ILAE) and the International Bureau for Epilepsy (IBE). Epilepsia. 2005;46:470-2.

2. Sander JW. The epidemiology of epilepsy revisited. Curr Opin Neurol. 2003;16:165-70.

3. Scantlebury MH, Heida JG. Febrile seizures and temporal lobe epileptogenesis. Epilepsy Res. 2010; 89:27-33.

4. Kharatishvili I, Pitkanen A. Posttraumatic epilepsy. Curr Opin Neurol. 2010;23:183-8.

5. Lossius MI, Ronning OM, Mowinckel P, Gjerstad L. Incidence and predictors for post-stroke epilepsy. A prospective controlled trial. The Akershus stroke study. Eur J Neurol. 2002;9:365-8.

6. Haspolat S, Mihci E, Coskun M, Gumuslu S, Ozben T, Yegin O. Interleukin-1beta, tumor necrosis factor-alpha, and nitrite levels in febrile seizures. J Child Neurol. 2002;17:749-51.

7. Minami M, Kuraishi Y, Yabuuchi K, Yamazaki A, Satoh M. Induction of interleukin-1 beta mRNA in rat brain after transient forebrain ischemia. J Neurochem. 1992;58:390-2.

8. Taupin V, Toulmond S, Serrano A, Benavides J, Zavala F. Increase in IL-6, IL-1 and TNF levels in rat brain following traumatic lesion. Influence of pre- and post-traumatic treatment with Ro5 4864, a peripheral-type ( $p$ site) benzodiazepine ligand. J Neuroimmunol. 1993;42:177-85.

9. Vezzani A, Balosso S, Ravizza T. The role of cytokines in the pathophysiology of epilepsy. Brain Behav Immun. 2008;22:797-803.

10. Sheng JG, Boop FA, Mrak RE, Griffin WS. Increased neuronal beta-amyloid precursor protein expression in human temporal lobe epilepsy: association with interleukin-1 alpha immunoreactivity. J Neurochem. 1994;63:1872-9.

11. Baranzini SE, Laxer K, Bollen A, Oksenberg JR. Gene expression analysis reveals altered brain transcription of glutamate receptors and inflammatory genes in a patient with chronic focal (Rasmussen's) encephalitis. J Neuroimmunol. 2002;128:9-15.

12. Ravizza T, Boer K, Redeker S, Spliet WG, van Rijen PC, Troost D, Vezzani A, Aronica E. The IL-1beta system in epilepsy-associated malformations of cortical development. Neurobiol Dis. 2006;24: 128-43.

13. Vezzani A, Conti M, De Luigi A, Ravizza T, Moneta D, Marchesi F, De Simoni MG. Interleukin-1beta immunoreactivity and microglia are enhanced in the rat hippocampus by focal kainate application: functional evidence for enhancement of electrographic seizures. J Neurosci. 1999;19:5054-65.

14. Rizzi M, Perego C, Aliprandi M, Richichi C, Ravizza T, Colella D, Velískǒvá J, Moshé SL, De Simoni MG, Vezzani A. Glia activation and cytokine increase in rat hippocampus by kainic acid-induced status epilepticus during postnatal development. Neurobiol Dis. 2003;14:494-503.

15. Ravizza T, Vezzani A. Status epilepticus induces time-dependent neuronal and astrocytic expression of interleukin-1 receptor type I in the rat limbic system. Neuroscience. 2006;137:301-8.

16. Marini H, Altavilla D, Bellomo M, Adamo EB, Marini R, Laureanti F, Bonaccorso MC, Seminara $P$, Passaniti M, Minutoli L, Bitto A, Calapai G, Squadrito F. Modulation of IL-1 beta gene expression by lipid peroxidation inhibition after kainic acid-induced rat brain injury. Exp Neurol. 2004; 188:178-86.

17. Eriksson C, Tehranian R, Iverfeldt K, Winblad B, Schultzberg M. Increased expression of mRNA encoding interleukin-1beta and caspase-1, and the secreted isoform of interleukin-1 receptor antagonist in the rat brain following systemic kainic acid administration. J Neurosci Res. 2000;60: 266-79.

18. Maelfait J, Vercammen E, Janssens S, Schotte P, Haegman M, Magez S, Beyaert R. Stimulation of Tolllike receptor 3 and 4 induces interleukin-1 beta maturation by caspase-8. J Exp Med. 2008;205: 1967-73.

19. Beg AA. Endogenous ligands of Toll-like receptors: implications for regulating inflammatory and immune responses. Trends Immunol. 2002;23:509-12.

20. Henshall DC, Murphy BM. Modulators of neuronal cell death in epilepsy. Curr Opin Pharmacol. 2008; 8:75-81.

21. Mencarelli C, Losen M, Hammels C, De Vry J, Hesselink MK, Steinbusch HW, De Baets MH, MartínezMartínez P. The ceramide transporter (CERT) and the Goodpasture antigen binding protein (GPBP). One protein - one function? J Neurochem. 2010;113:1369-86. 
22. van Vliet EA, da Costa Araujo S, Redeker S, van Schaik R, Aronica E, Gorter JA. Blood-brain barrier leakage may lead to progression of temporal lobe epilepsy. Brain. 2007;130:521-34.

23. Fabene PF, Navarro Mora G, Martinello M, Rossi B, Merigo F, Ottoboni L, Bach S, Angiari S, Benati D, Chakir A, Zanetti L, Schio F, Osculati A, Marzola P, Nicolato E, Homeister JW, Xia L, Lowe JB, McEver RP, Osculati F, Sbarbati A, Butcher EC, Constantin G. A role for leukocyte-endothelial adhesion mechanisms in epilepsy. Nat Med. 2008;14:1377-83.

24. Ringheim GE, Burgher KL, Heroux JA. Interleukin- 6 mRNA expression by cortical neurons in culture: evidence for neuronal sources of interleukin-6 production in the brain. J Neuroimmunol. 1995;63:113-23.

25. Yu B, Shinnick-Gallagher P. Interleukin-1 beta inhibits synaptic transmission and induces membrane hyperpolarization in amygdala neurons. J Pharmacol Exp Ther. 1994;271:590-600.

26. Wang S, Cheng Q, Malik S, Yang J. Interleukin-1beta inhibits gamma-aminobutyric acid type A $(\mathrm{GABA}(\mathrm{A}))$ receptor current in cultured hippocampal neurons. J Pharmacol Exp Ther. 2000;292: 497-504.

27. Miller LG, Galpern WR, Dunlap K, Dinarello CA, Turner TJ. Interleukin-1 augments gammaaminobutyric acidA receptor function in brain. Mol Pharmacol. 1991;39:105-8.

28. Strijbos PJ, Rothwell NJ. Interleukin-1 beta attenuates excitatory amino acid-induced neurodegeneration in vitro: involvement of nerve growth factor. J Neurosci. 1995;15:3468-74.

29. Viviani B, Bartesaghi S, Gardoni F, Vezzani A, Behrens MM, Bartfai T, Binaglia M, Corsini E, Di Luca M, Galli $C L$, Marinovich $M$. Interleukin-1 beta enhances NMDA receptor-mediated intracellular calcium increase through activation of the Src family of kinases. J Neurosci. 2003;23:8692-700.

30. Meini A, Benocci A, Frosini M, Sgaragli G, Pessina G, Aldinucci C, Youmbi GT, Palmi M. Nitric oxide modulation of interleukin-1 [beta]-evoked intracellular Ca2+ release in human astrocytoma U-373 MG cells and brain striatal slices. J Neurosci. 2000;20:8980-6.

31. Zhu G, Okada M, Yoshida S, Mori F, Ueno S, Wakabayashi K, Kaneko S. Effects of interleukin-1beta on hippocampal glutamate and GABA releases associated with $\mathrm{Ca}(2+)$-induced $\mathrm{Ca}(2+)$ releasing systems. Epilepsy Res. 2006;71:107-16.

32. Lai AY, Swayze RD, El-Husseini A, Song C. Interleukin-1 beta modulates AMPA receptor expression and phosphorylation in hippocampal neurons. J Neuroimmunol. 2006;175:97-106.

33. Zhang R, Yamada J, Hayashi Y, Wu Z, Koyama S, Nakanishi H. Inhibition of NMDA-induced outward currents by interleukin-1 beta in hippocampal neurons. Biochem Biophys Res Commun. 2008; 372:816-20.

34. DeLorenzo RJ, Sun DA, Deshpande LS. Erratum to "Cellular mechanisms underlying acquired epilepsy: the calcium hypothesis of the induction and maintenance of epilepsy." Pharmacol. Ther. 2005;105:229-66. Pharmacol Ther. 2006;111:288-325.

35. Fujikawa DG. Prolonged seizures and cellular injury: understanding the connection. Epilepsy Behav. 2005;7 Suppl 3:S3-11.

36. Kwan P, Brodie MJ. Early identification of refractory epilepsy. N Engl J Med. 2000;342:314-9.

37. Devinsky O. Patients with refractory seizures. N Engl J Med. 1999;340:1565-70.

38. Neal EG, Chaffe H, Schwartz RH, Lawson MS, Edwards N, Fitzsimmons G, Whitney A, Cross JH. The ketogenic diet for the treatment of childhood epilepsy: a randomised controlled trial. Lancet Neurol. 2008;7:500-6.

39. Shorvon SD, Lowenthal A, Janz D, Bielen E, Loiseau P. Multicenter double-blind, randomized, placebo-controlled trial of levetiracetam as add-on therapy in patients with refractory partial seizures. European Levetiracetam Study Group. Epilepsia. 2000;41:1179-86.

40. LaRoche SM, Helmers SL. The new antiepileptic drugs: scientific review. JAMA. 2004;291:605-14.

41. Sander JW. The use of antiepileptic drugs--principles and practice. Epilepsia. 2004;45 Suppl 6:28-34.

42. Marson AG, Al-Kharusi AM, Alwaidh M, Appleton R, Baker GA, Chadwick DW, Cramp C, Cockerell OC, Cooper PN, Doughty J, Eaton B, Gamble C, Goulding PJ, Howell SJ, Hughes A, Jackson M, Jacoby A, Kellett M, Lawson GR, Leach JP, Nicolaides P, Roberts R, Shackley P, Shen J, Smith DF, Smith PE, Smith CT, Vanoli A, Williamson PR; SANAD Study group. The SANAD study of effectiveness of valproate, lamotrigine, or topiramate for generalised and unclassifiable epilepsy: an unblinded randomised controlled trial. Lancet. 2007;369:1016-26. 
43. Marson AG, Al-Kharusi AM, Alwaidh M, Appleton R, Baker GA, Chadwick DW, Cramp C, Cockerell OC, Cooper PN, Doughty J, Eaton B, Gamble C, Goulding PJ, Howell SJ, Hughes A, Jackson M, Jacoby A, Kellett M, Lawson GR, Leach JP, Nicolaides P, Roberts R, Shackley P, Shen J, Smith DF, Smith PE, Smith CT, Vanoli A, Williamson PR; SANAD Study group. The SANAD study of effectiveness of carbamazepine, gabapentin, lamotrigine, oxcarbazepine, or topiramate for treatment of partial epilepsy: an unblinded randomised controlled trial. Lancet. 2007;369:1000-15.

44. Fisher R, Salanova V, Witt T, Worth R, Henry T, Gross R, Oommen K, Osorio I, Nazzaro J, Labar D, Kaplitt M, Sperling M, Sandok E, Neal J, Handforth A, Stern J, DeSalles A, Chung S, Shetter A, Bergen D, Bakay R, Henderson J, French J, Baltuch G, Rosenfeld W, Youkilis A, Marks W, Garcia P, Barbaro N, Fountain N, Bazil C, Goodman R, McKhann G, Babu Krishnamurthy K, Papavassiliou S, Epstein C, Pollard J, Tonder L, Grebin J, Coffey R, Graves N; SANTE Study Group. Electrical stimulation of the anterior nucleus of thalamus for treatment of refractory epilepsy. Epilepsia. 2010;51:899-908.

45. A randomized controlled trial of chronic vagus nerve stimulation for treatment of medically intractable seizures. . Neurology. 1995;45:224-30.

46. Handforth A, DeGiorgio CM, Schachter SC, Uthman BM, Naritoku DK, Tecoma ES, Henry TR, Collins SD, Vaughn BV, Gilmartin RC, Labar DR, Morris GL 3rd, Salinsky MC, Osorio I, Ristanovic RK, Labiner DM, Jones JC, Murphy JV, Ney GC, Wheless JW. Vagus nerve stimulation therapy for partial-onset seizures: a randomized active-control trial. Neurology. 1998;51:48-55.

47. Kersing W, Dejonckere PH, van der Aa HE, Buschman HP. Laryngeal and vocal changes during vagus nerve stimulation in epileptic patients. J Voice. 2002;16:251-7.

48. Rijkers K, Berfelo MW, Cornips EM, Majoie HJ. Hardware failure in vagus nerve stimulation therapy. Acta Neurochir (Wien). 2008;150:403-5.

49. Smyth MD, Tubbs RS, Bebin EM, Grabb PA, Blount JP. Complications of chronic vagus nerve stimulation for epilepsy in children. J Neurosurg. 2003;99:500-3.

50. Majoie HJ, Berfelo MW, Aldenkamp AP, Evers SM, Kessels AG, Renier WO. Vagus nerve stimulation in children with therapy-resistant epilepsy diagnosed as Lennox-Gastaut syndrome: clinical results, neuropsychological effects, and cost-effectiveness. J Clin Neurophysiol. 2001;18:419-28.

51. Rush AJ, Marangell LB, Sackeim HA, George MS, Brannan SK, Davis SM, Howland R, Kling MA, Rittberg BR, Burke WJ, Rapaport MH, Zajecka J, Nierenberg AA, Husain MM, Ginsberg D, Cooke RG. Vagus nerve stimulation for treatment-resistant depression: a randomized, controlled acute phase trial. Biol Psychiatry. 2005; 58:347-54.

52. Aldenkamp AP, Majoie HJ, Berfelo MW, Evers SM, Kessels AG, Renier WO, Wilmink J. Long-term effects of 24-month treatment with vagus nerve stimulation on behaviour in children with LennoxGastaut syndrome. Epilepsy Behav. 2002;3:475-9.

53. Asala SA, Bower AJ. An electron microscope study of vagus nerve composition in the ferret. Anat Embryol (Berl). 1986;175:247-53.

54. Tracey KJ. The inflammatory reflex. Nature. 2002;420:853-9.

55. Krahl SE, Senanayake SS, Handforth A. Destruction of peripheral C-fibers does not alter subsequent vagus nerve stimulation-induced seizure suppression in rats. Epilepsia. 2001;42:586-9.

56. Paintal AS. Vagal sensory receptors and their reflex effects. Physiol Rev. 1973;53:159-227.

57. Racine RJ. Modification of seizure activity by electrical stimulation. II. Motor seizure. Electroencephalogr Clin Neurophysiol. 1972;32:281-94.

58. Mclntyre DC, Gilby KL. Parahippocampal networks, intractability, and the chronic epilepsy of kindling. Adv Neurol. 2006;97:77-83.

59. Loscher W, Reissmuller E, Ebert U. Anticonvulsant efficacy of gabapentin and levetiracetam in phenytoin-resistant kindled rats. Epilepsy Res. 2000;40:63-77.

60. Loscher W. Animal models of intractable epilepsy. Prog Neurobiol. 1997;53:239-58.

61. Cavazos JE, Golarai G, Sutula TP. Mossy fiber synaptic reorganization induced by kindling: time course of development, progression, and permanence. J Neurosci. 1991;11:2795-803.

62. Brandt C, Ebert U, Loscher W. Epilepsy induced by extended amygdala-kindling in rats: lack of clear association between development of spontaneous seizures and neuronal damage. Epilepsy Res. 2004;62:135-56.

63. Zanchetti A, Wang SC, Moruzzi G. The effect of vagal afferent stimulation on the EEG pattern of the cat. Electroencephalogr Clin Neurophysiol. 1952;4:357-61. 
64. Woodbury DM, Woodbury JW. Effects of vagal stimulation on experimentally induced seizures in rats. Epilepsia. 1990;31 Suppl 2:S7-19.

65. Zabara J. Inhibition of experimental seizures in canines by repetitive vagal stimulation. Epilepsia. 1992;33:1005-12.

66. McLachlan RS. Suppression of interictal spikes and seizures by stimulation of the vagus nerve. Epilepsia. 1993;34:918-23.

67. Naritoku DK, Terry WJ, Helfert RH. Regional induction of fos immunoreactivity in the brain by anticonvulsant stimulation of the vagus nerve. Epilepsy Res. 1995;22:53-62.

68. Takaya M, Terry WJ, Naritoku DK. Vagus nerve stimulation induces a sustained anticonvulsant effect. Epilepsia. 1996;37:1111-6.

69. Lockard JS, Congdon WC, DuCharme LL. Feasibility and safety of vagal stimulation in monkey model. Epilepsia. 1990;31 Suppl 2:S20-6.

70. Krahl SE, Clark KB, Smith DC, Browning RA. Locus coeruleus lesions suppress the seizure-attenuating effects of vagus nerve stimulation. Epilepsia. 1998;39:709-14.

71. Zagon A, Kemeny AA. Slow hyperpolarization in cortical neurons: a possible mechanism behind vagus nerve simulation therapy for refractory epilepsy? Epilepsia. 2000;41:1382-9.

72. Fernandez-Guardiola A, Martinez A, Valdes-Cruz A, Magdaleno-Madrigal VM, Martinez D, FernandezMas R. Vagus nerve prolonged stimulation in cats: effects on epileptogenesis (amygdala electrical kindling): behavioral and electrographic changes. Epilepsia. 1999;40:822-9.

73. Krahl SE, Senanayake SS, Handforth A. Right-sided vagus nerve stimulation reduces generalized seizure severity in rats as effectively as left-sided. Epilepsy Res. 2003;56:1-4.

74. Munana KR, Vitek SM, Tarver WB, Saito M, Skeen TM, Sharp NJ, Olby NJ, Haglund MM. Use of vagal nerve stimulation as a treatment for refractory epilepsy in dogs. J Am Vet Med Assoc. 2002;221: 977-83.

75. Sunderam S, Osorio I, Watkins JF, 3rd, Wilkinson SB, Frei MG, Davis RE. Vagal and sciatic nerve stimulation have complex, time-dependent effects on chemically-induced seizures: a controlled study. Brain Res. 2001;918:60-6.

76. Dedeurwaerdere S, Vonck K, Claeys P, Van Hese P, D'Have M, Grisar T, Naritoku D, Boon P. Acute vagus nerve stimulation does not suppress spike and wave discharges in "Genetic Absence Epilepsy Rats from Strasbourg". Epilepsy Res. 2004;59:191-8.

77. Dedeurwaerdere S, Vonck K, De Herdt V, Waterschoot L, De Smedt T, Raedt R, Wyckhuys T, Legros B, Van Hese P, Van Laere K, Delbeke J, Wadman W, Boon P. Neuromodulation with levetiracetam and vagus nerve stimulation in experimental animal models of epilepsy. Acta Neurol Belg. 2006;106:91-7.

78. Yang HJ, Peng KR, Hu SJ, Liu Y. Inhibiting effect of vagal nerve stimulation to seizures in epileptic process of rats. Neurosci Bull. 2007;23:336-40.

79. Sahin D, Ilbay G, Imal M, Bozdogan O, Ates N. Vagus nerve stimulation suppresses generalized seizure activity and seizure-triggered postictal cardiac rhythm changes in rats. Physiol Res. 2009;58:345-50.

80. Clark KB, Krahl SE, Smith DC, Jensen RA. Post-training unilateral vagal stimulation enhances retention performance in the rat. Neurobiol Learn Mem. 1995;63:213-6.

81. Clark KB, Smith DC, Hassert DL, Browning RA, Naritoku DK, Jensen RA. Posttraining electrical stimulation of vagal afferents with concomitant vagal efferent inactivation enhances memory storage processes in the rat. Neurobiol Learn Mem. 1998;70:364-73.

82. Clark KB, Naritoku DK, Smith DC, Browning RA, Jensen RA. Enhanced recognition memory following vagus nerve stimulation in human subjects. Nat Neurosci. 1999;2:94-8.

83. Dedeurwaerdere S, Cornelissen B, Van Laere K, Vonck K, Achten E, Slegers G, Boon P. Small animal positron emission tomography during vagus nerve stimulation in rats: a pilot study. Epilepsy Res. 2005;67:133-41.

84. Groves DA, Bowman EM, Brown VJ. Recordings from the rat locus coeruleus during acute vagal nerve stimulation in the anaesthetised rat. Neurosci Lett. 2005;379:174-9.

85. Ito S, Craig AD. Vagal-evoked activity in the parafascicular nucleus of the primate thalamus. J Neurophysiol. 2005;94:2976-82.

86. Zhang JL, Zhang SP, Zhang HQ. Antiepileptic effect of electroacupuncture vs. vagus nerve stimulation in the rat thalamus. Neurosci Lett. 2008;441:183-7. 
87. Osharina V, Bagaev V, Wallois F, Larnicol N. Autonomic response and Fos expression in the NTS following intermittent vagal stimulation: Importance of pulse frequency. Auton Neurosci. 2006;126127:72-80.

88. Cunningham JT, Mifflin SW, Gould GG, Frazer A. Induction of c-Fos and DeltaFosB immunoreactivity in rat brain by Vagal nerve stimulation. Neuropsychopharmacology. 2008;33:1884-95.

89. Roosevelt RW, Smith DC, Clough RW, Jensen RA, Browning RA. Increased extracellular concentrations of norepinephrine in cortex and hippocampus following vagus nerve stimulation in the rat. Brain Res. 2006;1119:124-32.

90. Zhang JL, Zhang SP, Zhang HQ. Antiepileptic effects of electroacupuncture vs vagus nerve stimulation on cortical epileptiform activities. J Neurol Sci. 2008;270:114-21.

91. Biggio F, Gorini G, Utzeri C, Olla P, Marrosu F, Mocchetti I, Follesa P. Chronic vagus nerve stimulation induces neuronal plasticity in the rat hippocampus. Int J Neuropsychopharmacol. 2009;12:1209-21.

92. Revesz D, Tjernstrom M, Ben-Menachem E, Thorlin T. Effects of vagus nerve stimulation on rat hippocampal progenitor proliferation. Exp Neurol. 2008;214:259-65. 



\section{Chapter 2}

The role of interleukin-1 in seizures and epilepsy:

a critical review

K Rijkers, HJ Majoie, G Hoogland, G Kenis, M De Baets, JS Vles

Experimental Neurology 2009;216:258-271 


\section{Abstract}

Interleukin-1 (IL-1) has a multitude of functions in the central nervous system. Some of them involve mechanisms that are related to epileptogenesis. The role of $\mathrm{IL}-1$ in seizures and epilepsy has been investigated in both patients and animal models. This review aims to synthesize, based on the currently available literature, the consensus role of IL-1 in epilepsy.

Three lines of evidence suggest a role for IL-1: brain tissue from epilepsy patients and brain tissue from animal models shows increased IL-1 expression after seizures, and IL-1 has proconvulsive properties when applied exogeneously. However, opposing results have been published as well. More research is needed to fully establish the role of IL-1 in seizure generation and epilepsy, and to explore possible new treatment strategies that are based on interference with intracellular signaling cascades that are initiated when IL-1 binds to its receptor. 


\section{Introduction}

In the last decade, the immune system has attracted the attention of many investigators in epilepsy research. This has resulted in a still rapidly growing amount of information, on involvement of various immunological factors in seizures and epileptogenesis. The pro-inflammatory cytokine interleukin-1 (IL-1) is one of the immunological factors receiving much attention in this regard. Data from both clinical and preclinical research indicate a role for this cytokine in epilepsy.

The aim of this review is to establish, based on literature so far available, whether IL-1 is related to increased seizure susceptibility and plays a key role in epileptogenesis, or if it is merely a biochemical epiphenomenon of a seizure. If epileptogenesis depends on IL-1, this cytokine is an important target for the development of new anti-epileptic or anti-epileptogenic therapies.

\section{Interleukin-1}

Cytokines, soluble mediators that are produced by virtually all cells of the immune system and many other cells, regulate the activity of the immune system. Generally, cytokines are synthesized and secreted rapidly in response to an antigenic stimulus. They have half-lives in the range of minutes.

Interleukin-1 beta (IL-1 $\beta$ ) belongs to the so-called IL-1 family, which further consists of interleukin-1 alpha (IL-1 $\alpha$ ) and interleukin-1 receptor antagonist (IL-1 ra). Recently, eight new ligands were added: IL-18 ${ }^{1}$, IL-33 ${ }^{2}$ and IL-1F5 - IL-1F10 ${ }^{3}$. IL- $1 \beta$ is one of the pro-inflammatory cytokines. Together with other pro-inflammatory cytokines such as tumor necrosis factor alpha (TNF- $\alpha$ ), interleukin-6 (IL-6) and interleukin-8 (IL-8), IL-1 $\beta$ can induce acute inflammation (cytokine cascade, high fever, C-reactive protein (CRP) production) in response to infection. IL- $1 \alpha$ and IL-1 $\beta$ exert identical agonist actions by binding to a receptor called interleukin- 1 receptor type I (IL-1RI). IL-1 $\alpha$ has lower affinity for this receptor than IL-1 $\beta$, and mainly regulates intracellular events ${ }^{4}$. After binding its ligand, IL-1RI associates with an accessory protein (AcP) which activates intracellular signal transduction cascades. Type II interleukin-1 receptor (IL-1RII) binds IL- $1 \alpha$ and IL- $1 \beta$ as well, but does not initiate signal transduction because it lacks an intracellular domain and is thus referred to as decoy receptor. IL-1 ra is a highly selective, competitive receptor antagonist that binds to IL-1RI as well. Unlike IL-1 $\alpha$ and IL-1 $\beta$, IL-1ra is unable to trigger the association with AcP and consequently, signal transduction cannot take place. High molar excess (100- to 1000 - fold) of IL-1 ra is needed to counteract the effects of IL-1 $\beta$.

Thus, at cellular level, the IL-1 response can be controlled by two mechanisms: 1 ) the ratio of IL-1RI/IL-1RII, and 2) the concentration of IL-1 agonists (IL-1 $\alpha$ and IL-1 $\beta$ ) versus that of IL-1ra.

Four IL-1 ligands are formed as precursors: pro-IL-1 $\alpha$, pro-IL-1 $\beta$, pro-IL-18 and pro-IL-1ra. Pro-IL-1 $\alpha$ and pro-IL-1ra are biologically active, while pro-IL-1 $\beta$ and 
pro-IL-18 need to be cleaved first. Cleaving takes places by the enzyme caspase-1 (=interleukin-1 converting enzyme, ICE).

\section{Interleukin-1 in the central nervous system - Where is it located?}

IL-1 in the central nervous system (CNS) either comes from outside, or is locally produced by CNS cells. Systemic IL-1 levels are usually very low, but rapidly increase in case of inflammation (e.g. during systemic infection). In this situation, diffusion of IL-1 into the CNS occurs at the circumventricular organs (lining the third ventricle) that lack a blood-brain barrier (BBB). Diffusion can occur outside these circumventricular organs, and despite low systemic IL-1 levels as well, in case of a leaky or temporarily opened BBB (e.g. after an epileptic seizure ${ }^{5}$ ).

Low basal expression of IL-1RI is found throughout the CNS, on all CNS cells ${ }^{6}$. In case of neuronal injury, IL-1 is rapidly produced by microglia and other CNS cells ${ }^{7}$. Common neurological and psychiatric conditions, such as stroke ${ }^{8}$, traumatic brain injury ${ }^{9}$, spinal cord injury ${ }^{10}$, multiple sclerosis ${ }^{11}$, Down syndrome and Alzheimer disease $^{12}$ are associated with increased CNS production of IL-1 $\beta$.

When IL-1 is expressed in the brain, its signal propagates via 3 pathways, described by Vitkovic et al.: 1) extracellular diffusion and circulating cerebrospinal fluid (CSF), 2) neuronal projections and 3) gap junctions that connect glial cells ${ }^{13}$.

Apart from the presence of IL-1 in the CNS (either from diffusion or local production), the CNS can also modulate peripheral IL-1 expression through the cholinergic antiinflammatory reflex ${ }^{14}$. An important structure in this reflex is the vagus nerve: its afferent fibers signal the CNS when circulating macrophages produce more IL-1 $\beta$ (and other pro-inflammatory markers). As a result of this afferent vagal signal, the efferent vagus nerve is activated. This results in the release of acetylcholine which immediately triggers the $\alpha 7$ subunit of the nicotinic receptor on activated macrophages. These in turn decrease IL-1 $\beta$ production. It is not clear whether activation of the afferent vagus nerve induces a similar immunosuppressive effect within the CNS as well.

\section{Interleukin-1 in the central nervous system - What are the effects?}

II- $1 \beta$ has a multitude of actions in the CNS, summarized by Allan et al. ${ }^{15}$. Binding of IL-1 $\beta$ to the IL-1RI on any of the CNS cell types has both neuroprotective and neurotoxic effects. Neuroprotective effects take place when IL-1 $\beta$ is present in low concentrations, while under pathological circumstances, when IL-1 $\beta$ levels are higher, processes leading to neurotoxicity are facilitated by IL-1 $\beta$.

When IL-1 $\beta$ binds the neuronal IL-1RI, it has many effects on, for instance, N-methylD-aspartic acid receptor (NMDA-R) function, IL-6 production, $\mathrm{Ca}^{2+}$ influx, alphaamino-3-hydroxy-5-methyl-4-isoxazolepropionic acid receptor (AMPA-R) function and the balance between gamma-aminobutyric acid (GABA) and glutamate ${ }^{16-24}$. When excessively activated, these IL-1 $\beta$ effects are generally considered to increase 
neuronal excitability, and the risk of excitotoxicity. At the cellular level, increased neuronal excitability means that less current is needed to depolarize the neuron and can be caused by an increased inward current and/or a decreased outward current. Experimental evidence has shown that, when hippocampal neurons are held at $40 \mathrm{mV}$, and then exposed to NMDA and IL-1 $\beta$ simultaneously, the inward current is increased ${ }^{25,26}$, and the outward current is decreased ${ }^{25}$, compared with hippocampal neurons that are subjected to NMDA alone, or to NMDA, IL-1 $\beta$ and IL-1ra. The amplitude of the inward current increases because more $\mathrm{Ca}^{2+}$ can enter the cell via both the NMDA-R channel and voltage-dependent $\mathrm{Ca}^{2+}$ channels ${ }^{25}$. In the presence of IL-1 $\beta$, NMDA-R subunits are phosphorylated which leads to increased $\mathrm{Ca}^{2+}$ influx ${ }^{21}$. The amplitude of the outward current is reduced due to IL-1 $\beta$-mediated inhibition of $\mathrm{Ca}^{2+}$-dependent $\mathrm{K}^{+}$channels ${ }^{26}$.

As mentioned above, activation of neuronal IL-1RI is not always associated with risk of excitotoxicity. For instance, IL-1 $\beta$ originating from hippocampal neurons may be involved in long-term potentiation (LTP), an experimental correlate of memory formation ${ }^{27-29}$, yet externally applied IL-1 $\beta$ inhibits LTP29,30.

IL-1 $\beta$ can have both neurotoxic and physiologic effects on glial cells as well. In astrocytes $^{22,31-35}$ and microglia ${ }^{36,37}$, IL-1RI activation initiates the expression of many genes, ultimately resulting in astrogliosis ${ }^{15,20}$, dampening of the neuroinflammatory response, and modulation of BBB permeability ${ }^{38}$.

Through binding the IL-1RI on oligodentrocytes, IL-1 $\beta$ appears to have mainly neuroprotective effects ${ }^{39}$ that contribute to myelination and to CNS repair ${ }^{40}$. However, neurotoxic effects of IL-1RI activation on oligodendrocytes have been reported as well ${ }^{41,42}$.

Apart from these direct effects of IL-1 $\beta$ on the different CNS cell types, proinflammatory cytokines in general influence tryptophan metabolism, ultimately leading to an increase of the neurotoxic metabolite quinolinic acid, an NMDA receptor agonist ${ }^{43}$.

\section{Interleukin-1 \& epilepsy}

Based on these findings, IL-1 $\beta$ originating peripherally or in the CNS, can modulate neuronal excitability, and thus potentially contribute to seizure development or epileptogenesis.

The aim of the current review is to determine, based on the currently available literature, whether IL-1 is involved in the process of epileptogenesis, as was suggested recently ${ }^{44}$, or whether it is merely an epiphenomenon. If IL-1 is related to increased seizure-susceptibility and/or to epileptogenesis, the modulation of IL-1 may play a role in the mechanism of action of some of the currently available antiepileptic treatments, such as vagus nerve stimulation (VNS) and ACTH/ dexamethasone treatment. Moreover, it may be a potential target for development of new anti-epileptic treatment strategies. 
To establish whether there is evidence for a specific role for IL-1 in increased seizure susceptibility and epileptogenesis we reviewed all currently available literature on this topic. This review concentrates on data from original papers, directly relevant to the topic, published in peer-reviewed journals and written in English. Data were obtained after searching Pubmed, The Cochrane Library and Embase using 'epilepsy AND IL-1', 'epilepsy AND interleukin-1', 'seizures AND IL-1' and 'seizures AND interleukin-1' as key words and after citation tracking in March 2008.

The Pubmed search resulted in 101 hits for 'seizures AND IL-1', 97 hits for 'seizures AND interleukin-1', 120 hits for 'epilepsy AND IL-1' and 114 hits for 'epilepsy AND interleukin-1'. The Embase search resulted in 22 hits for 'seizures AND IL-1', 27 hits for 'seizures AND interleukin-1', 19 hits for 'epilepsy AND IL-1' and 26 hits for 'epilepsy AND interleukin-1'. The Cochrane Library search resulted in 0 hits. After counting out overlap, 90 papers were left, 36 of which on human material and 54 on animal material.

\section{In epilepsy patients, plasma interleukin-1 levels show no consistent change}

The relation between cytokine levels in the CNS and in plasma, has not been established yet. Nevertheless, in search of clinically applicable biochemical markers, several scientists have attempted to determine IL-1 levels in plasma and IL-1 production in whole blood of patients that suffer from CNS disease. Concerning seizures and epilepsy, 16 papers have been published on this subject.

Blood cells of epilepsy patients do not consistently produce more IL-1 in response to inflammatory stimulation than blood cells of controls ${ }^{45-49}$. Moreover, no consistent changes have been found in plasma levels of any of the IL-1 family members in patients with epilepsy (see Table 2.1), nor in children with febrile seizures (FS) ${ }^{46,49-58}$. Anti-epileptic treatment does not affect IL- $1 \alpha$ and IL-1 $\beta$ production by mononuclear cells $^{48}$, nor plasma levels of IL-1 $\beta$ and IL-1 ra ${ }^{49}$. Although no data are available on IL-1 levels after vagus nerve stimulation (VNS) in epileptic patients, VNS did not affect plasma IL-1 $\beta$ levels in depressed patients ${ }^{59}$. Anti-inflammatory drugs are sometimes used to treat (childhood) epilepsy. No data are available on IL-1 changes after such treatment. However, recently a systematic review has been published in which no evidence was found for the efficacy or safety of corticosteroid treatment for childhood epilepsy ${ }^{60}$.

Perhaps these results reflect the real situation. On the other hand, differences in methods may account for the inconsistent results as well. For example, ELISA kits that were used varied in sensitivity and detection levels (see Table 2.1). Other limitations are: differences in time interval between FS or epileptic seizure and time of blood collection, short half-life of IL-1, small patient number, the use of different controls and of different epilepsy syndromes or causes of seizures, the lack of information on comorbidity or drug use. 
Nevertheless, it is important to continue determination of plasma IL-1 levels in epilepsy patients. If consistent differences are found between patients and controls, between different types of epilepsies or between responders to anti-epileptic treatment and non-responders, IL-1 could be used as biochemical marker or predictor, e.g. for response to anti-epileptic treatment.

\section{Interleukin-1 is present in the brain of epilepsy patients, but not in cerebrospinal fluid}

The majority of CSF is produced by the choroid plexus (60\%), but it also consists of fluid derived from the capillary bed (30\%), and 'metabolic water' (10\%). Metabolic water contains substances that have not been recaptured following liberation by CNS cells. Therefore, the association between CNS cytokine levels and CSF cytokine levels is a stronger one than the association between CNS cytokine levels and plasma cytokine levels. However, IL-1 determination in CSF is difficult. This is illustrated by the fact that of the seven studies published on this subject (summarized in Table $2.2)^{51-54,56,57,61}$, only four report on detectable IL-1 $\beta$ levels ${ }^{51-53}$. Of these four, three studies were unable to find statistically significant differences between patients and controls, while one reported on increased IL-1 $\beta$ levels in children with $\mathrm{FS}^{53}$. Reasons for these scarce results are similar to the reasons mentioned above on plasma studies: ELISA kits that were used varied in sensitivity and detection limit (see Table 2.2), studies differed in time interval between seizure and time of CSF collection, IL-1 has a short half life, small patient number, the use of different controls and of patients suffering from different epilepsy syndromes, and the lack of information on comorbidity or drug use. Moreover, ELISA kits are generally developed for determinations in plasma, not in CSF.

Changes in IL-1 mRNA expression in brain tissue of epilepsy patients gives the most direct information on involvement of IL-1 in epilepsy. However, brain tissue is more difficult to obtain than CSF or plasma, and therefore even less studies $(n=3)$ have been published on this subject ${ }^{62-64}$.

These three studies have revealed that several of the IL-1 family members are present in epileptic brain tissue in temporal lobe epilepsy $(T L E)^{62,63}$, chronic focal encephalitis (CFE, also known as Rasmussen encephalitis) ${ }^{63}$, and in epileptogenic cortical malformations ${ }^{64}$. In TLE, the IL-1 $\alpha$ positive cells had morphological characteristics of microglia and were mainly located adjacent to neurons in layer $\mathrm{V}$ of the temporal cortex, while in the cortical malformations IL-1 positive astrocytes and neurons were found as well. In this last study, the number of IL-1 $\beta$ positive cells was positively correlated with seizure frequency, while the number of IL-1ra positive cells was negatively correlated with epilepsy duration prior to surgery. These important findings were not mentioned in the other two papers. No expression of IL-1 $\beta$, IL-1RI, IL-1RII and IL-1 ra was found in perilesional cortex from the same patients or in cortex tissue from autopsy specimens. 


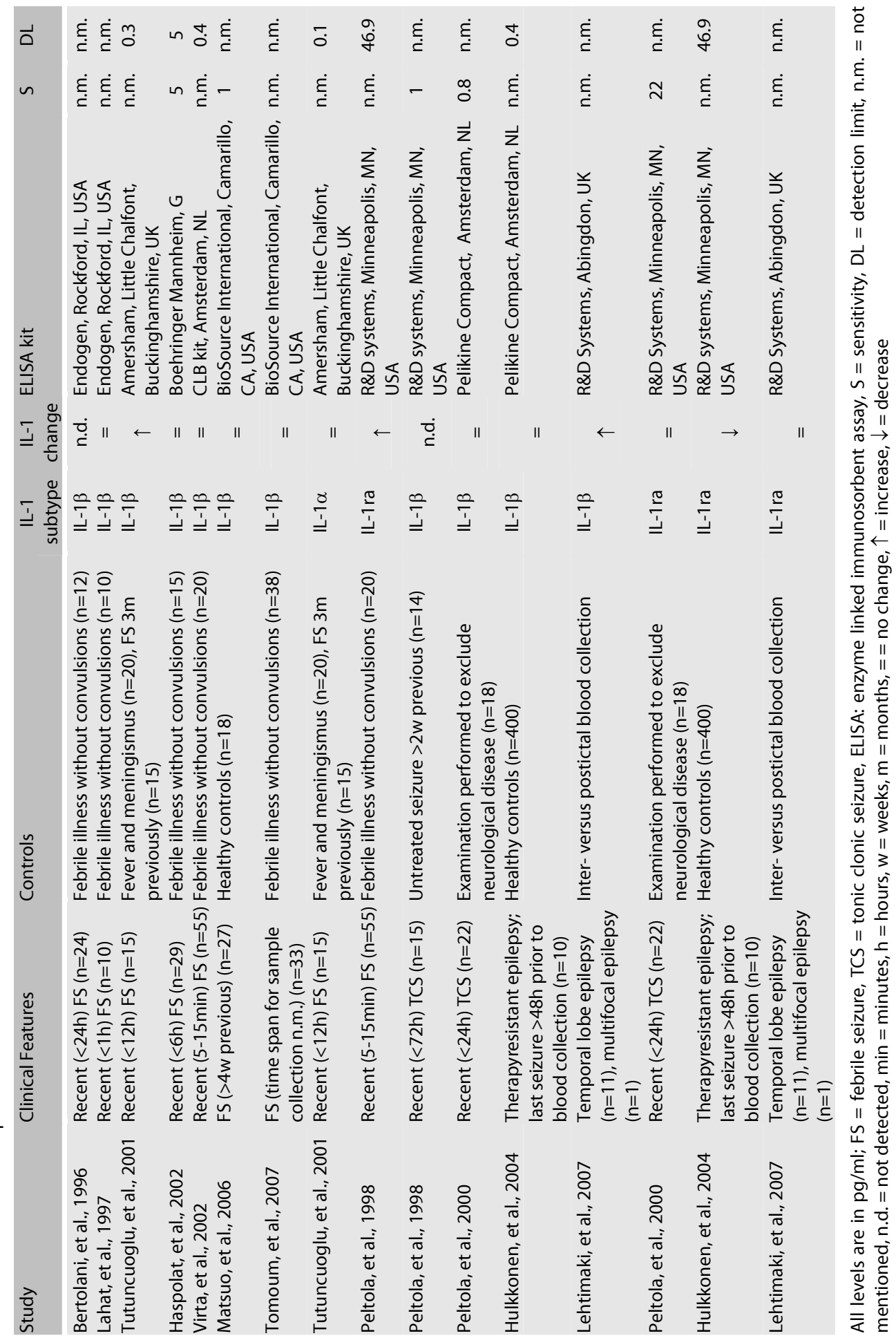




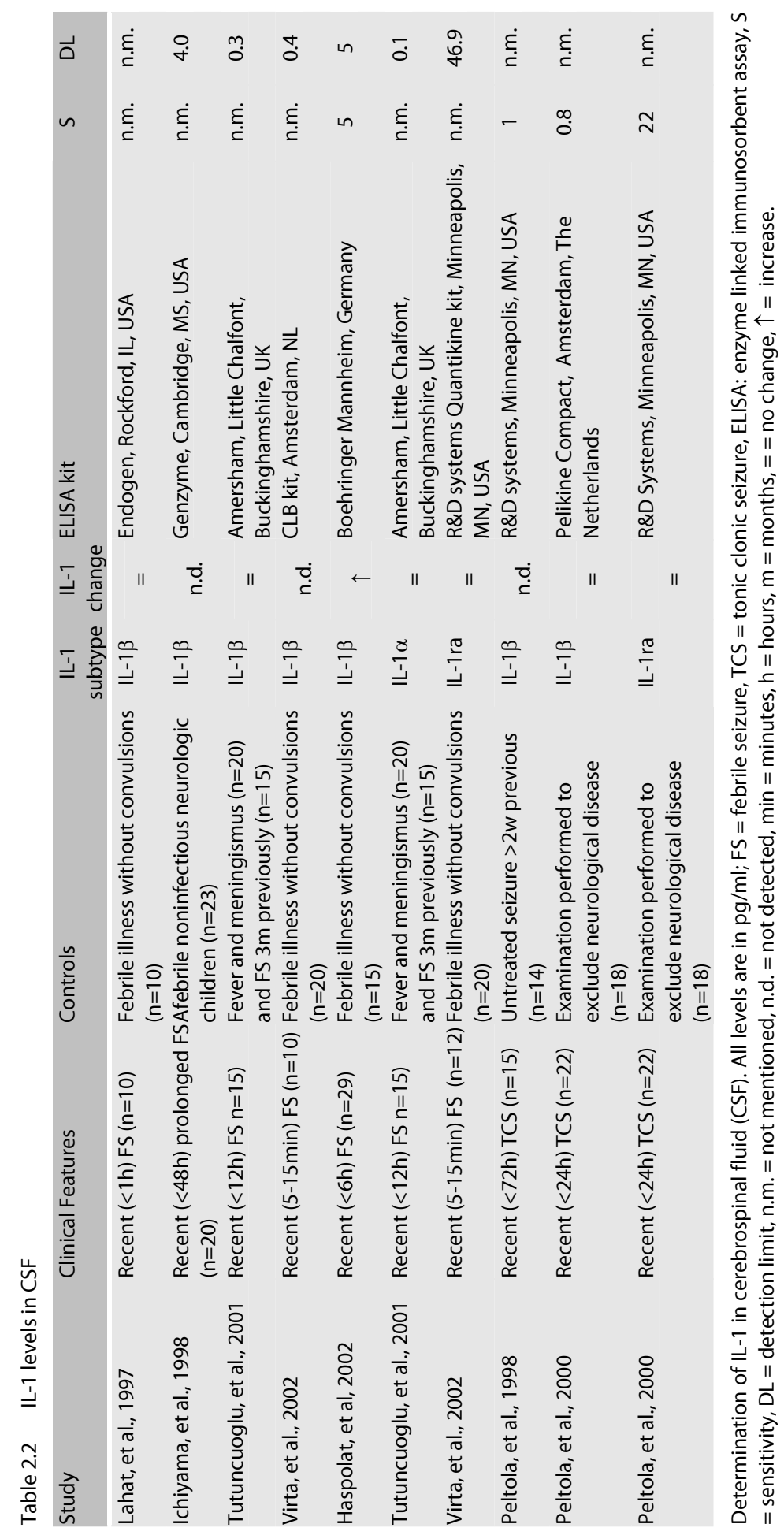


Entrance of IL-1 through a leaky BBB (caused by a recent seizure) may have been the source of the increased IL- $1 \alpha^{62}$ and IL-1 $\beta^{64}$. This assumption would be more likely if IL-1 was expressed in the parenchyma surrounding blood vessels as well as in neurons and astrocytes around blood vessels, similar to the post-seizure localization of albumin in the study by Van Vliet et al. ${ }^{5}$. This was not specifically mentioned in these two studies.

As already addressed by the authors of these papers, it is not clear whether the IL-1 expression is intrinsic to the lesions or induced by the seizures. The fact that normal perilesional cortex samples did not express IL-1 suggests that seizures alone are unlikely to be responsible. However, time interval between sample collection and last seizure (which is not mentioned) may have been too long for seizure-induced IL-1 to be still present.

\section{Single nucleotide polymorphisms in interleukin-1 genes may be associated with epilepsy}

Genes for IL-1 $\alpha$, IL-1 $\beta$ and IL-1ra are all located in a gene cluster on the long arm of chromosome 2 (2q12-13 region). Many common polymorphisms in this gene cluster have been described, and some of them are associated with increased levels of circulating cytokines. Because of the association of FS with inflammation, polymorphisms in the IL-1 gene cluster have been studied in relation to FS. Because of the suggested association between FS and TLE, the frequency of some of these polymorphisms has been investigated in TLE patients as well. All studies that have been performed so far, are association studies. Linkage studies have not yet been published.

The polymorphisms that have been studied are: two C-to-T transitions, one at position -511 (IL-1B-511, promotor region, designated as rs16944), and one at position +3953 (IL-1B+3953, exon 5, designated as rs1143634) of the IL-1 $\beta$ gene, and two common polymorphisms, one at position -889 (IL-1A-889) of the IL-1 $\alpha$ gene, giving rise to alleles 1 and 2 , and one in the second intron of the IL-1RN gene (encoding IL-1ra).

No consistent data are available on the frequency of any of these polymorphisms in $\mathrm{FS}^{46,65-70}$.

The studies on these polymorphisms in relation to epilepsy are summarized in Table 2.3. Kauffman et al. ${ }^{71}$ recently systematically analyzed the data from the studies on the frequency of IL-1B-511 allele $2(T)$ in TLE ${ }^{66,69,72-77}$. They calculated a significantly increased risk of developing TLE with hippocampal sclerosis for IL-1B-511 allele 2 homozygotes ${ }^{71}$. Interestingly, this polymorphism is associated with increased IL-1 $\beta$ expression $^{78}$.

The role of polymorphisms in the IL-1A-889 gene, in the IL-1B+3953 gene and in the IL-1RN gene in epilepsy is still undetermined ${ }^{72,74,77,79}$. More studies, in larger patient groups with the same genetic background and similar control groups are needed. 


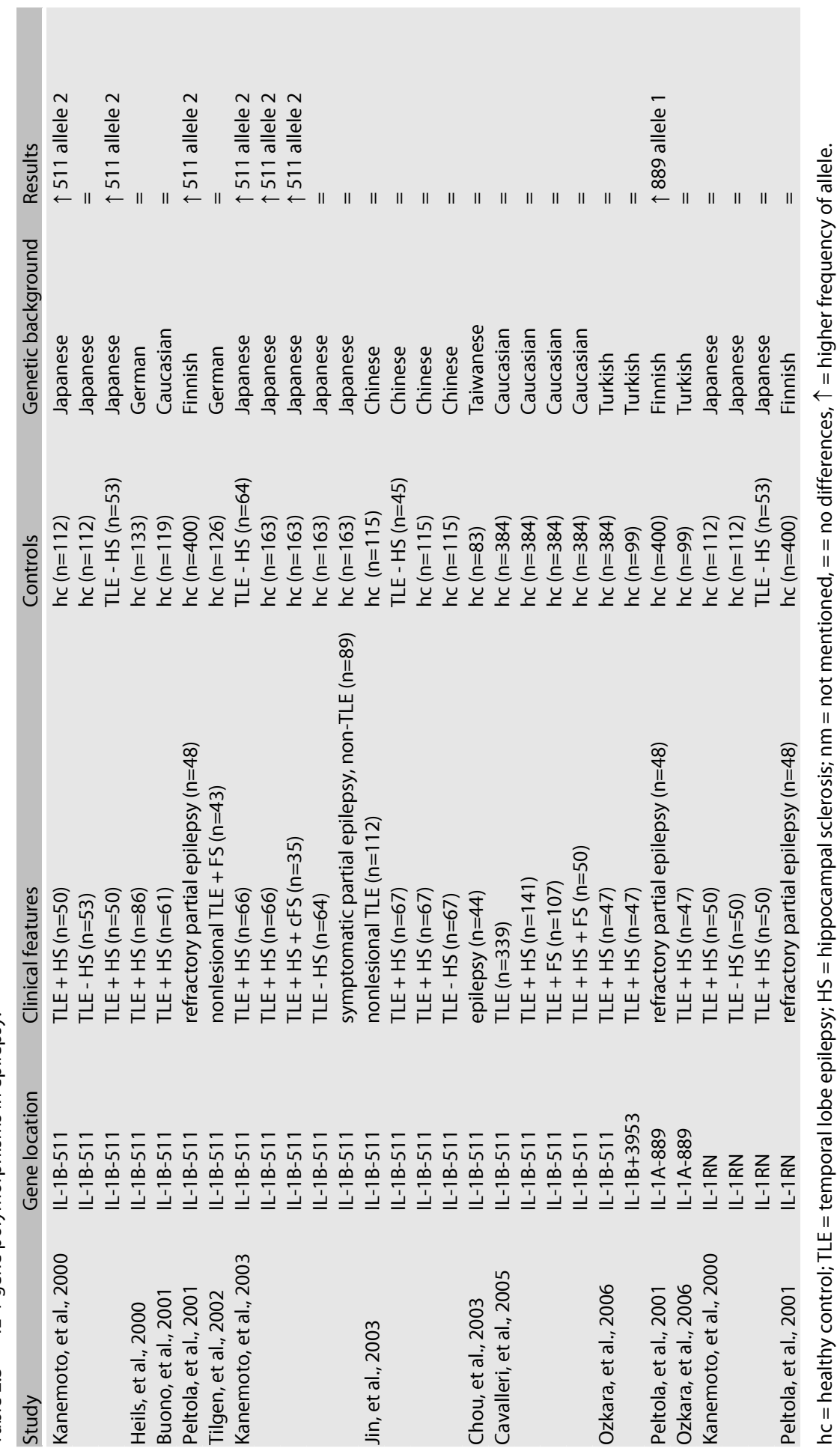




\section{Interleukin-1 is present in most animal models for seizures and epilepsy}

IL-1 mRNA or IL-1 protein expression in the brains of experimental animal models for seizures and for epilepsy, has been investigated by a number of groups. The 19 different animal models that have been used for this, comprise both models for seizures and models for epilepsy, in which either chemical, electrical, or other stimuli are used to induce seizures.

\section{Chemically induced seizures are associated with increased CNS IL-1 expression}

The 15 studies in which seizures were induced by administration of a chemical substance (often a neurotoxin) are summarized in Table 2.4. They all report about increased cerebral levels of IL- $1 \alpha, \mathrm{IL}-1 \beta$ or IL-1 $\mathrm{ra}^{80-94}$. Protein levels as well as mRNA expression levels were increased, and in most studies these increases were acute and transient. The location of IL-1 expression correlated with the location of neuronal injury, with which many of the chemical seizure models are associated. Chronic increases were found in trimethyltin (TMT)-induced seizures ${ }^{90}$ (IL-1 $\alpha$ mRNA levels remained increased up to eight days after the seizure) and in sarin-induced seizures ${ }^{91}$ (IL-1 $\beta$ levels remained increased up to 30 days after the seizure). While it is most likely that these long-lasting increases in IL-1 $\alpha$ mRNA expression and IL-1 $\beta$ protein levels are related to the ongoing neuronal injury associated with TMT and sarin intoxication, they may contribute to seizure development as well.

\section{Electrically-induced seizures are associated with increased CNS IL-1 expression}

More IL-1 $\beta$ mRNA was found in the cortex of rats between four and 12 hours after a single seizure induced by electrical stimulation through ear-clip electrodes, than in rats that were not stimulated ${ }^{95}$. No data are available on the cells that expressed IL-1 $\beta$ mRNA, nor on associated neuronal injury. Therefore no conclusions on the role of IL-1 in this type of seizure can be drawn from this single study.

\section{Infection-induced seizures are associated with increased CNS-IL-1 expression}

Shigella Dysenteriae infection and whole-cell pertussis vaccination are associated with seizures and other neurological symptoms in humans. In mice, S. Dysenteriae infection and pertussis vaccination are associated with increased sensitivity to pentylenetetrazol (PTZ, a GABA antagonist) ${ }^{96}$ and with seizures ${ }^{97}$, respectively. Both experimental paradigms are associated with increased levels of IL-1 $\beta$ mRNA and IL-1 $\beta$ protein in plasma ${ }^{96}$, hippocampus and hypothalamus ${ }^{97}$. These studies have not clarified what the time span between infection, seizures and IL-1 $\beta$ expression was or what cells were involved. Moreover, the increased IL-1 $\beta$ expression may be related to the generalized encephalopathy that both experimental conditions are associated with. Whether it has contributed to seizure development, can not be concluded from these studies. 


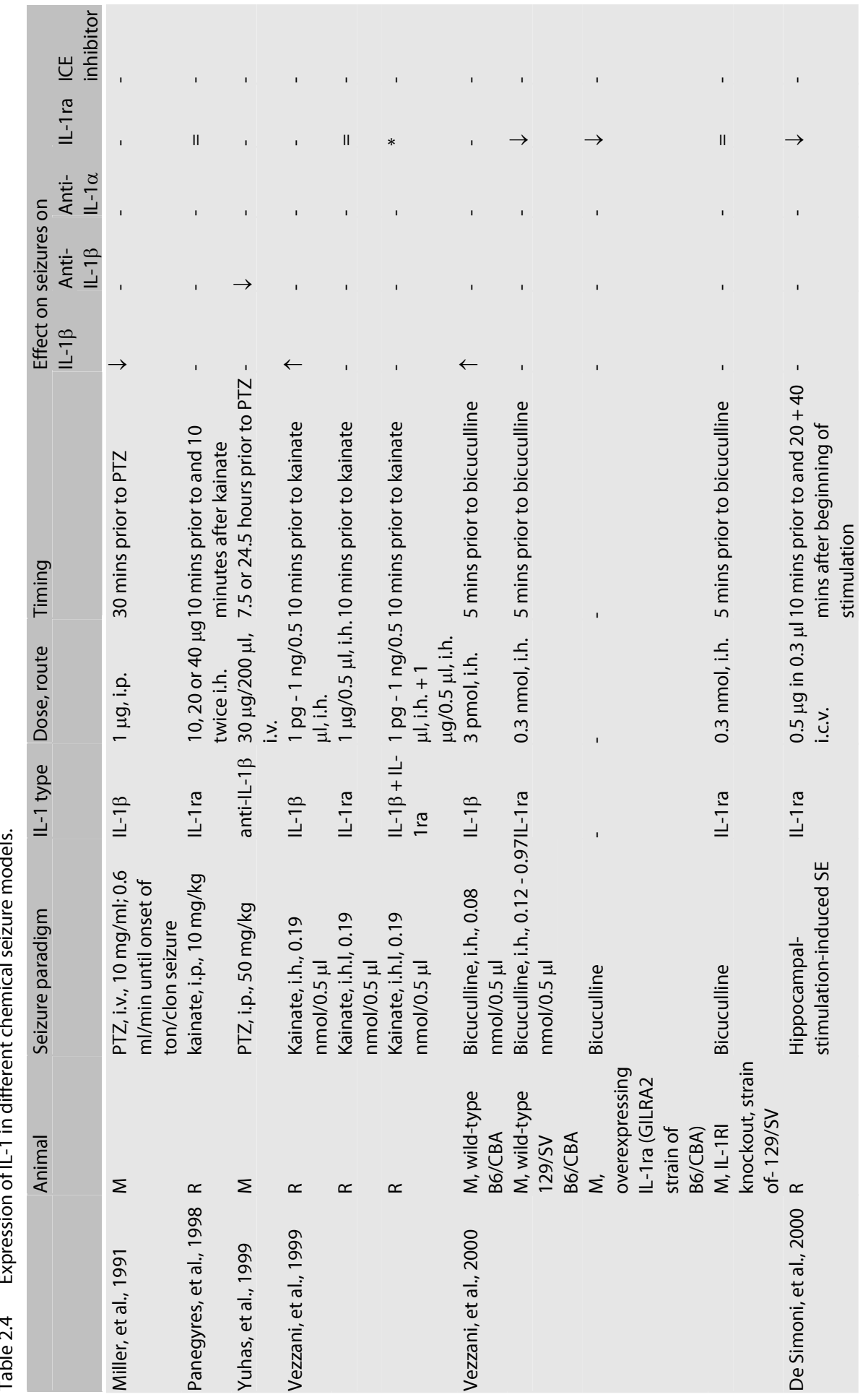




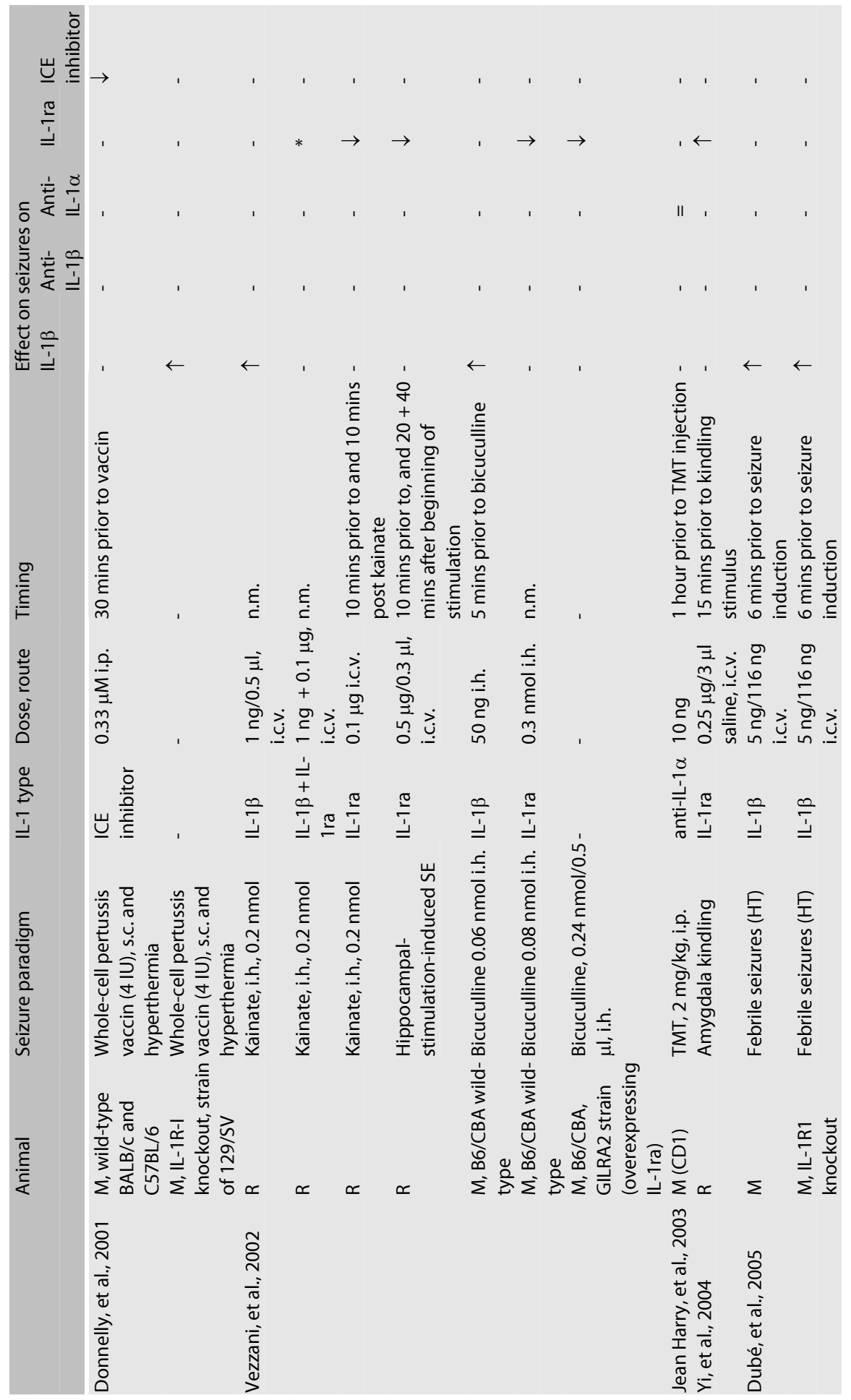




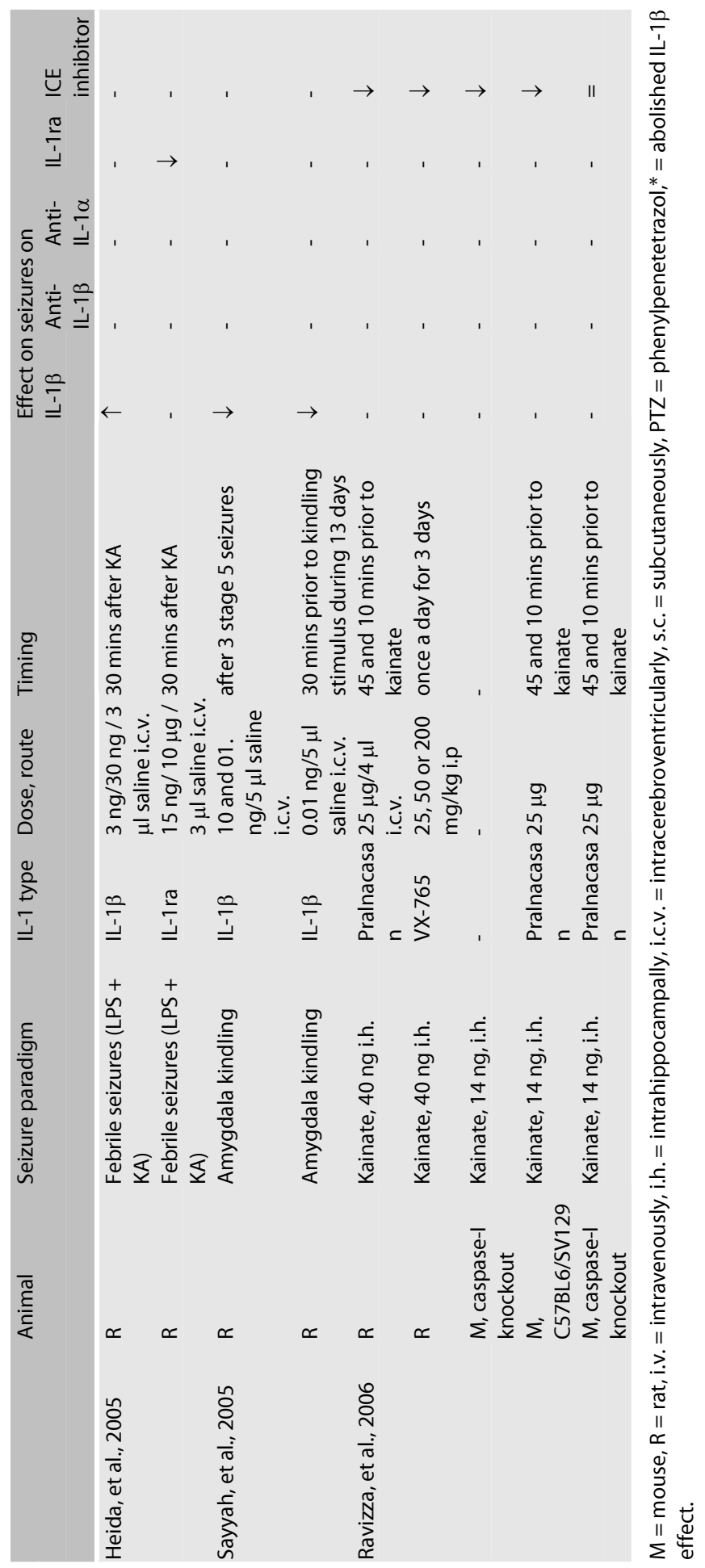




\section{Fever-induced seizures are associated with increased CNS IL-1 expression}

Injection of lipopolysaccharide (LPS, the coating of gram negative bacteria) induces fever. If LPS is injected in combination with a low (subconvulsant) dose of kainate (KA), approximately $50 \%$ of rats show seizures. These rats display significantly higher hippocampal and hypothalamic IL-1 $\beta$ protein levels (cell types not mentioned) than the rats that do not show seizures within two hours after KA administration, while IL-1 ra protein levels remain unchanged ${ }^{98}$. These results suggest that the increased $\mathrm{IL}-1 \beta$ protein levels are associated with the development of FS because they are most pronounced in the hippocampus, the structure thought to be mainly involved. The reason for the lack of IL-1ra expression may be related to the relatively short time span between FS and measurements; from the other studies in which IL-1 ra is increased in response to seizures, the earliest IL-1 ra responses are often found more than two hours after the seizure.

\section{Chemically induced epilepsies are associated with increased CNS IL-1 expression}

The two chemicals KA and pilocarpine have been used to study IL-1 expression after chemically induced epilepsy. The effect of KA-induced epilepsy on the IL-1 system was reviewed previously by Oprica et al. in $2003^{99}$. All KA studies and pilocarpine studies report on increased CNS levels of the different IL-1 family members ${ }^{80,83,100-118}$. KA-induced neuronal injury may have been the main cause of all IL-1 expression, because IL-1 was mainly found in regions that showed the most extensive neuronal injury, such as hippocampus and piriform cortex ${ }^{83,102,105-107,109-112,114,118}$, and because microglia were the main source ${ }^{83,101,104-106,114}$. In pilocarpine treated rats, IL-1 $\beta$ staining paralleled that of fluoro-Jade-B (marker of neuronal degeneration) and was found in glial cells as well ${ }^{113}$.

Due to the association with chemical-induced neuronal injury, the IL-1 expression that was found in these studies can not be directly linked to the development of epilepsy itself. Moreover, no IL-1 $\beta$ was found in the latent period after the pilocarpine-induced status epilepticus (SE), while during this period, epileptogenesis takes place. This suggests that there is no major role for IL-1 during epileptogenesis in this model. Additionally, IL-1 $\beta$ mRNA expression does not appear to be necessary for KA-induced seizures, because dexamethasone pretreatment suppressed KAinduced IL-1 $\beta$ mRNA expression, but not the KA-induced seizure ${ }^{80}$.

\section{Not all electrically induced epilepsies are associated with increased CNS IL-1 expression}

Both seizures induced by amygdala kindling (AK) and spontaneous seizures that occur after SE induced by electrical stimulation, are associated with increased expression of several of the IL-1 family members ${ }^{119-121}$. No data are available on the morphology of the IL-1 positive cells. Interestingly, in a subgroup of rats that received kindling stimuli during the dark period, normal kindling took place but no changes in IL-1 $\alpha$ mRNA or IL-1 $\beta$ mRNA expression were observed ${ }^{120}$. This last finding 
suggests that IL-1 is not necessary for the development of AK seizures. The results from these studies are particularly interesting in determining the role of IL-1 expression in epileptogenesis, because AK is not associated with neuronal injury ${ }^{122}$. SE induced by electrical stimulation of the ventral hippocampus is associated with both acutely and chronically increased levels of IL-1ra and IL-1 $\beta^{121}$. This chronic expression may be related to epileptogenesis, which takes place during this period in this model. However, spontaneous recurring seizures after ventral hippocampus stimulation induced $\mathrm{SE}$, are associated with neuronal injury and neuronal loss ${ }^{123}$ and the increased IL-1 $\beta$ and IL-1 ra protein expression may be related to that as well. This is supported by the finding that IL-1 $\beta$ positive cells have glial morphology. Moreover, the occurrence of spontaneous epileptic seizures prior to sacrificing the animals is not mentioned in the paper; the authors have stated that the rats had not experienced a seizure two hours prior to death, but this does not exclude the hypothesis that the 'chronic' IL-1 $\beta$ expression 60 days after SE is a result of spontaneous seizures more that two hours prior to death.

\section{Not all genetic epilepsies are associated with increased CNS IL-1 expression}

Six to 24 hours after a seizure, hypothalamic IL-1 $\alpha$ mRNA expression is increased in two strains of audiogenic mice ${ }^{124}$. This hypothalamic IL-1 $\alpha$ mRNA increase resembles c-fos activation in one of the strains (Frings mice) ${ }^{125}$, a finding that supports the hypothesis that IL-1 $\alpha$ mRNA expression is related to acute neuronal activation related to the development of seizures.

No changes in IL-1 expression were found in two other strains of genetically seizure susceptible animals: kindled Wistar audiogenic rats show no increased levels of hippocampal IL-1 $\beta$ mRNA ${ }^{126}$ and the complex partial seizures provoked by tossing of the El-mouse are not associated with IL-1 $\beta$ mRNA expression either ${ }^{127}$. Pretreating the El mice with turpentine (as a model for sterile inflammation) leads to increased duration of the postconvulsive period and to detectable levels of cortical IL-1 $\beta$ mRNA, but did not affect seizures or seizure threshold. Although these results suggest that IL-1 $\beta$ mRNA expression is no prerequisite for the development of seizures, the time interval at which IL-1 $\beta$ mRNA has been determined is relatively long (24 hours). On the other hand, the finding that co-administration of turpentine increases cortical IL-1 $\beta$ mRNA as well as the postconvulsive period suggests that IL-1 $\beta$ mRNA does contribute to seizure-related processes.

\section{Conclusion}

All seizure and epilepsy models described above are associated with enhanced cerebral IL-1 $\beta$ expression, except a subgroup of rats in one study using the AK model ${ }^{120}$, a subgroup of KA-treated rats that was treated with dexamethasone ${ }^{80}$, and two studies using genetic models ${ }^{126,127}$. Many of the results are based on experiments in only one or two research groups, and have not yet been reproduced by others. Nevertheless, from these results it can be concluded that IL-1 is expressed as a result 
of experimental seizures, especially if these seizures are associated with neuronal injury. However, the presence of IL-1 after one or more seizures does not imply that it is involved in epileptogenesis. More insight into possible mechanisms may come from intervention studies, in which the effect of exogenously applied IL-1 $\beta$, IL-1 ra and caspase- 1 inhibitors on excitability, seizures and epilepsy has been evaluated. These studies are discussed in the following part.

\section{The effect of interleukin-1 on epilepsy}

\section{Interleukin-1 $\beta$ has both inhibitory and excitatory effects}

All studies on the effect of exogenously applied IL-1 $\beta$ and IL-1ra on excitability, seizures or epilepsy are summarized in Table 2.5. Three of them describe inhibitory effects of $\mathrm{IL}-1 \beta$ on PTZ seizures ${ }^{19}$ and on seizures provoked by amygdala kindling ${ }^{120,128}$. These findings suggest that IL-1 $\beta$ has anticonvulsive properties, while the finding that kindling rate was slowed by IL-1 $\beta$ even suggests that IL-1 $\beta$ has antiepileptogenic properties ${ }^{128}$.

However, the majority of studies that have evaluated the effect of one of the IL-1 family members on seizures or epilepsy find either no effect ${ }^{88,129}$, or a proconvulsive effect of IL-1 $\beta^{81,83,97,98,130,131}$, and an anticonvulsive effect of IL-1 ra $81,98,121,130$ and of caspase 1-inhibition ${ }^{97,132}$.

Only i.c.v., but not i.h., injections with IL-1ra reduced KA-induced seizures ${ }^{83,129,130}$. Assuming that $40 \mu \mathrm{g}$ of IL-1ra (the maximal dose used ${ }^{129}$ ), is sufficient to block all hippocampal IL-1 $\beta$ activity, these results indicate that not only hippocampal, but also extrahippocampal IL-1 $\beta$ contributes to KA-induced seizures. On the other hand, an other study revealed that i.h. applied IL-1 ra effectively blocked bicuculline-induced seizures, and that mice overexpressing IL-1ra did not develop seizures after bicuculline treatment ${ }^{81}$. These results suggest that, in bicuculline-induced seizures, hippocampal IL-1 $\beta$ alone contributes to the development of seizures. An anticonvulsive effect of i.c.v. applied IL-1 ra was also found in electrical stimulationinduced SE rats ${ }^{121}$. Seizures elicited by whole-cell pertussis vaccine ${ }^{97}$ and by KA ${ }^{132}$ were both suppressed by decreasing IL-1 $\beta$-activity through caspase- 1 inhibition.

In the majority of studies reporting on anticonvulsive effects of IL-1ra, the administration of exogenous IL-1 $\beta$ worsened seizures. This was confirmed in KAinduced seizures ${ }^{83,130}$, in bicuculline-induced seizures ${ }^{81,130}$, in whole-cell pertussisvaccine induced seizures ${ }^{97}$ and in $\mathrm{FS}^{98,131}$. 


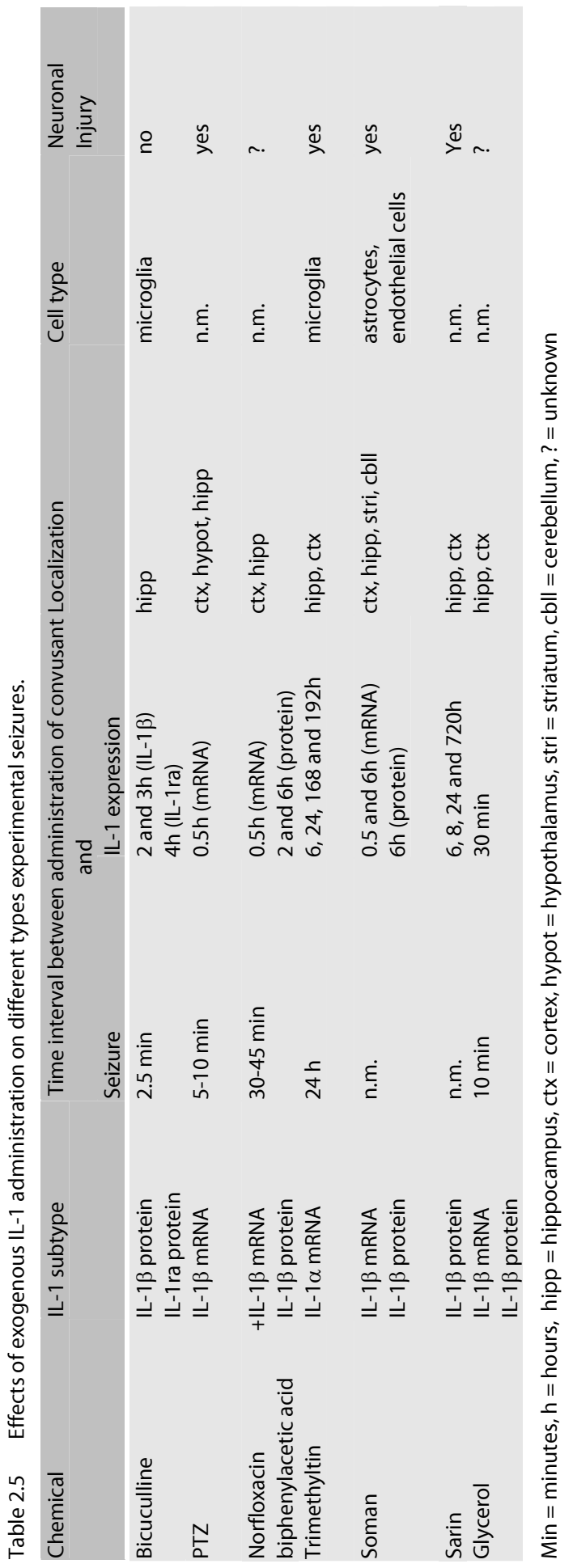




\section{Pharmacological seizure suppression is associated with decreased interleukin-1 expression}

In a number of animal studies, summarized in Table 2.6, the effect of antiepileptic treatment on IL-1 has been investigated.

Most of these studies show both seizure suppression and decreased IL-1 expression as a result of treatment $80,89,107,111,112$, often in association with reduced neurodegeneration ${ }^{107,111,112}$. On the contrary, dexamethasone treatment prior to KA administration abolished the normally induced IL-1 $\beta$ expression but did not affect the KA-induced seizures ${ }^{80}$. This suggests that IL-1 $\beta$ expression is not necessary for the development of KA-induced seizures, a finding in line with the results of Dinkel et al. ${ }^{110}$. They described a KA-induced corticosterone peak which was followed by reduced IL-1 $\beta$ expression. As a result, adrenalectomized rats (lacking the KA-induced corticosterone peak) had higher IL-1 $\beta$ levels. Despite the increased IL-1 $\beta$ expression, adrenalectomized rats showed smaller KA-induced lesions in this study. In contrast with the inhibiting effect of a single corticosterone peak on IL-1 $\beta$ expression, chronically elevated corticosterone levels were associated with increased IL-1 $\beta$ expression and increased KA-induced lesion size. This suggests that chronically elevated corticosterone levels worsen KA-induced neurotoxicity due to neuroinflammatory changes. This is in line with the findings of Bruccoleri et al., who found augmentation of TMT-induced cerebral IL-1 $\alpha$ expression after chronic dexamethasone pretreatment in mice ${ }^{84}$.

In summary, it can be concluded that different anticonvulsive drugs that have been studied in this regard, including NMDA antagonists, GABA agonists and levetiracetam, decrease both seizure severity and IL-1 $\beta$ expression. The results of studies using other types of medication, like dexamethasone or indomethacine, are inconsistent. Perhaps this is related to the fact that these last drugs are not anticonvulsive drugs, but act on the immune system and only indirectly influence seizures.

\section{Implications}

Clearly, experimental seizures are associated with post-ictally increased IL-1 $\beta$ levels in the CNS. However, these seizures are often accompanied by extensive neuronal injury, which may account for IL-1 production by microglia ${ }^{7}$. At the cellular level, Tolllike receptors (TLRs), activated by seizure-induced heath shock proteins (HSPs), induce the activation of nuclear factor kappa $B(N F \kappa B)$, which finally results in IL-1 $\beta$ production ${ }^{133-135}$. Thus, increased CNS levels of IL-1 after experimental seizures may be an epiphenomenon of neuronal injury alone, especially when IL-1 is found in the structures that are most severely affected. Epilepsies in humans are sometimes associated with neuronal injury as well, especially after prolonged SE. This neuronal 
injury is thought to be the result of excitotoxicity related to massive release of glutamate, activation of NDMDA-R and subsequent influx of $\mathrm{Ca}^{2+}$ that causes cell death $^{136}$.

Even though in these cases IL-1 $\beta$ may be the result of neuronal injury, the cascades of events that are initiated when IL-1 $\beta$ binds to IL-1RI, may contribute to increased seizure-susceptibility (Figure 2.1). Increased neuronal NFKB activity has indeed been found in animal models for epilepsy ${ }^{137-140}$, and in the glial scar in the hippocampus of TLE patients ${ }^{141}$. As a transcription factor it is involved in many intracellular processes, for instance induction of iNOS and subsequent formation of NO, that may contribute to seizure generation ${ }^{142-144}$. Moreover, IL-1 $\beta$ directly increases NMDA-R function, and $\mathrm{Ca}^{2+}$ influx, and inhibits $\mathrm{K}^{+}$efflux, all contributing to increased neuronal excitability and thus to seizure susceptibility ${ }^{21-23,25,26}$.

Some epilepsies in humans are associated with neuronal injury that is present already prior to the occurrence of seizures, for instance post stroke epilepsy and epilepsy after traumatic brain injury ${ }^{145,146}$ (Figure 2.1). Both conditions are associated with increased CNS IL-1 $\beta$ levels ${ }^{8,9}$. This IL-1 $\beta$ is predominantly found in microglial cells in the lesioned area. It is conceivable that IL-1 $\beta$ released by microglia, activates neuronal IL-1RI, resulting in a decreased seizure threshold due to the mechanisms described above $21-23,25,26$.

Apart from experimental seizures and epilepsies that are associated with neuronal injury, there is evidence that suggests that IL-1 also plays a role in experimental epilepsies and epilepsies in humans that are not associated with neuronal injury $62,64,119,120$.

It is still unclear what the source of this IL-1 expression is. The seizure-induced BBB opening leads to the entrance of marcomolecules such as albumin ${ }^{5}$. IL-1 $\beta$ may be produced locally (by perivascular microglia) in a reaction to these macromolecules. During $\mathrm{BBB}$ opening, reactive astrocytes produce prostaglandins that activate microglia which in turn express IL-1 $\beta$ (Figure 2.1). In addition, circulating IL-1 $\beta$ may diffuse into the brain if the BBB is opened. Alternatively, CNS cells may express IL-1 $\beta$ prior to seizure onset.

Irrespective of the source, none of the data that are currently available, prove that postictally increased CNS IL-1 levels, have contributed to the development of this seizure. 


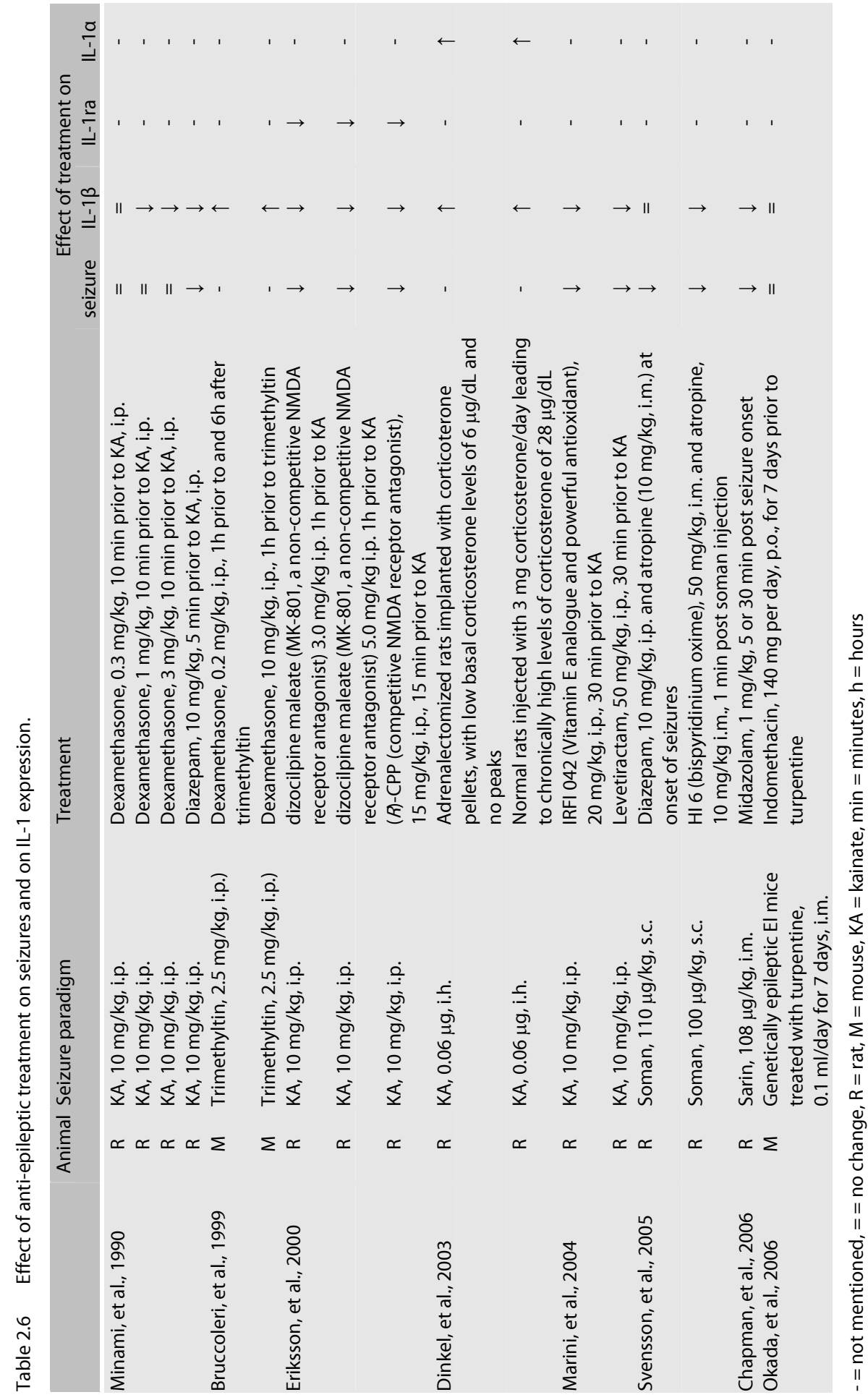




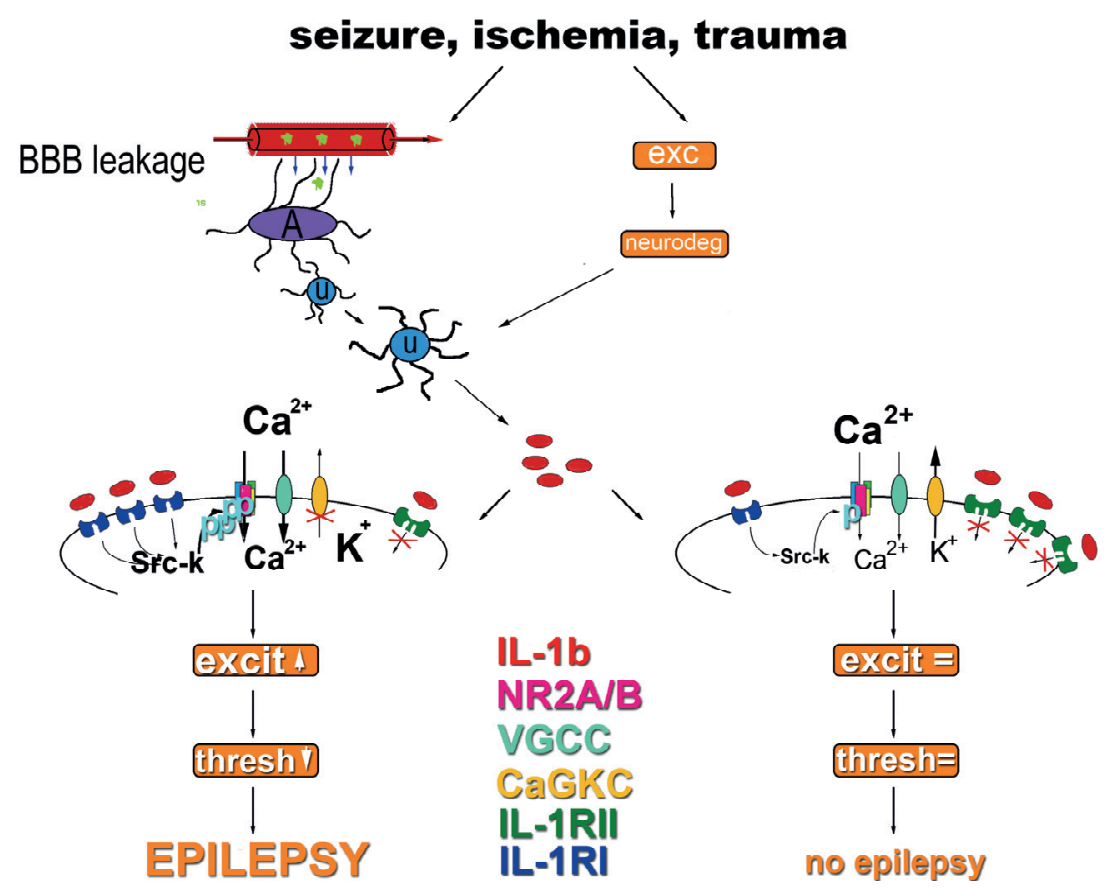

Figure 2.1 Many CNS conditions such as a seizure, cerebral ischemia and neurotrauma are associated with BBB leakage and extravasation of CNS-foreign proteins such as albumin. Increased cerebral blood flow can contribute to this extravasation. During BBB opening, perivascular astrocytes activate microglia, which in turn produce IL-1 $\beta$. Simultaneously, excitotoxic damage, caused by the seizure, ischemia or neurotrauma itself, and leading to neurodegenerative changes, causes microglial IL-1 $\beta$ expression as well.

Whether this increased IL-1 $\beta$ expression leads to decreased seizure thresholds and ultimately to epilepsy, may depend on the amount of neuronal IL-1RI and IL-1RII that is present. In case IL-1RI outnumbers IL-1RII (left side of the figure), IL-1 $\beta$ activates IL-1RI which leads to increased phosphorylation (P) of the NR2A/B subunits of the NMDA-R through Src-kinases, resulting in increased influx of $\mathrm{Ca}^{2+}$. Moreover, IL-1 $\beta$ augments the $\mathrm{Ca}^{2+}$ influx though activation of the voltage-dependent $\mathrm{Ca}^{2+}$ channel (VGCC), while it inhibits $\mathrm{K}^{+}$efflux though the $\mathrm{Ca}^{2+}$ dependent $\mathrm{K}^{+}$channels $\left(\mathrm{K}_{\mathrm{Ca} 2+} \mathrm{C}\right)$. These $\mathrm{IL}-1 \beta$-induced changes result in increased inward currents and decreased outward currents, leading to increased excitability and decreased seizure thresholds, contributing to the development of a subsequent seizure and to epilepsy.

In case IL-1RII outnumbers IL-1RI (right side of the figure), the IL-1 $\beta$ signal is not processed and does not lead to changes in inward and outward currents. In this situation, neuronal excitability and seizure threshold remain unchanged and thus, IL-1 $\beta$ does not contribute to the development of a subsequent seizure.

BBB: blood brain barrier, $\mu$ glia: microglia, I: II-1RI, II: IL-1RII, P: phosphorylation, NR2A/B: NR2A and NR2B subunits of the NMDA-R, VGCC: voltage-gated calcium channel, $\mathrm{K}_{\mathrm{Ca} 2+} \mathrm{C}$ : calciumgated potassium channel. 
CNS IL-1 $\beta$ expression is not restricted to neurological diseases that are associated with epilepsy, but has also been found in $\mathrm{MS}^{11}, \mathrm{DS}$ and $\mathrm{AD}^{12}$. A plausible explanation for IL-1 $\beta$ expression in these different conditions, is the fact that they are all associated with neuronal injury. The question is, if you attribute seizure-susceptibility to increased IL-1 $\beta$ expression, why some of these neurological conditions are associated with an increased frequency of epilepsy, while others are not. Moreover, most people that suffer from stroke or traumatic brain injury do not develop epilepsy; those that do develop epilepsy are apparently more vulnerable to excitotoxic changes, or these changes are more marked in those that do develop epilepsy. In line with this, is the finding that some patients suffer from a single seizure, while in other patients the first seizure is followed by epileptogenic changes that lead to subsequent seizures, and thus to epilepsy.

The reason for these differences may (in part) lie in the IL-1Rs. In animal experiments, different excitotoxic stimuli lead to different responses in IL-1RI or IL-1RII expression ${ }^{103,147}$. It is plausible that these differences occur in human neurological diseases as well, and if so, they may explain why some conditions result in seizures, while others do not. If IL-1RII is quickly upregulated after release of microglial IL-1 $\beta$, the neuronal IL-1RI is not activated and subsequent signal transduction pathways that may contribute to increased seizure-susceptibility, are not activated (Figure 2.1). Interindividual variability in IL-1R upregulation may explain why some patients with stroke or traumatic brain injury develop epilepsy, while others do not. There is no literature available on differences in IL-1RI and IL-1RII expression in epilepsy, but this could play an important role in establishing these potential effects.

\section{Future directions}

The currently available literature on IL-1 and epilepsy does not show conclusive evidence on the critical involvement of IL-1 in seizure generation. However, it is clear that IL-1 has the ability to modulate neuronal excitability and contribute to astrogliosis, which may lead to facilitated seizure generation and epileptogenesis. The hypothesis that IL-1 is merely a biochemical epiphenomenon of a seizure is therefore unlikely.

Consequently, inhibition of IL-1 $\beta$ may be a new target for anticonvulsive therapy. In this respect, future studies in IL-1 and epilepsy research should be aimed at selectively managing the temporal and local IL-1 $\beta$-excess that coincides with a seizure.

IL-1 production and activity are regulated by many factors, such as caspase-1, IL-1RI and IL-1RII, IL-1 ra and by other factors that regulate the action of these regulators (e.g. pro-caspase- 1 has to be cleaved first $)^{15}$. This means that there are many ways to interfere with IL-1 $\beta$ activity, of which the anti-convulsive effects can be explored. 
These future studies will provide clinically relevant data if animal models for epilepsies are used that are not associated with extensive neuronal injury (such as the amygdala kindled rat, or genetic epilepsy models). Finally, the contribution of other members of the IL-1 family should not be overlooked, for IL-18 has been referred to as 'key player in neuroinflammation' as well ${ }^{148}$. 


\section{References}

1. Dinarello CA, Novick D, Puren AJ, Fantuzzi G, Shapiro L, Muhl H, Yoon DY, Reznikov LL, Kim SH, Rubinstein M. Overview of interleukin-18: more than an interferon-gamma inducing factor. J Leukoc Biol. 1998;63:658-64.

2. Schmitz J, Owyang A, Oldham E, Song Y, Murphy E, McClanahan TK, Zurawski G, Moshrefi M, Qin J, Li X, Gorman DM, Bazan JF, Kastelein RA. IL-33, an interleukin-1-like cytokine that signals via the IL-1 receptor-related protein ST2 and induces $\mathrm{T}$ helper type 2-associated cytokines. Immunity. 2005;23:479-90.

3. Dunn E, Sims JE, Nicklin MJ, O'Neill LA. Annotating genes with potential roles in the immune system: six new members of the IL-1 family. Trends Immunol. 2001;22:533-6.

4. Lonnemann G, Endres S, Van der Meer JW, Cannon JG, Koch KM, Dinarello CA. Differences in the synthesis and kinetics of release of interleukin 1 alpha, interleukin 1 beta and tumor necrosis factor from human mononuclear cells. Eur J Immunol. 1989;19:1531-6.

5. van Vliet EA, da Costa Araujo S, Redeker S, van Schaik R, Aronica E, Gorter JA. Blood-brain barrier leakage may lead to progression of temporal lobe epilepsy. Brain. 2007;130:521-34.

6. Allan SM, Rothwell NJ. Cytokines and acute neurodegeneration. Nat Rev Neurosci. 2001;2:734-44.

7. Allan SM, Rothwell NJ. Inflammation in central nervous system injury. Philos Trans R Soc Lond B Biol Sci. 2003;358:1669-77.

8. Minami M, Kuraishi Y, Yabuuchi K, Yamazaki A, Satoh M. Induction of interleukin-1 beta mRNA in rat brain after transient forebrain ischemia. J Neurochem. 1992;58:390-2.

9. Taupin V, Toulmond S, Serrano A, Benavides J, Zavala F. Increase in IL-6, IL-1 and TNF levels in rat brain following traumatic lesion. Influence of pre- and post-traumatic treatment with Ro5 4864, a peripheral-type ( $p$ site) benzodiazepine ligand. J Neuroimmunol. 1993;42:177-85.

10. Yang L, Blumbergs PC, Jones NR, Manavis J, Sarvestani GT, Ghabriel MN. Early expression and cellular localization of proinflammatory cytokines interleukin-1 beta, interleukin-6, and tumor necrosis factoralpha in human traumatic spinal cord injury. Spine. 2004;29:966-71.

11. Bauer J, Berkenbosch F, Van Dam AM, Dijkstra CD. Demonstration of interleukin-1 beta in Lewis rat brain during experimental allergic encephalomyelitis by immunocytochemistry at the light and ultrastructural level. J Neuroimmunol. 1993;48:13-21.

12. Griffin WS, Stanley LC, Ling C, White L, MacLeod V, Perrot LJ, White CL 3rd, Araoz C. Brain interleukin 1 and S-100 immunoreactivity are elevated in Down syndrome and Alzheimer disease. Proc Natl Acad Sci U S A. 1989;86:7611-5.

13. Vitkovic L, Konsman JP, Bockaert J, Dantzer R, Homburger V, Jacque C. Cytokine signals propagate through the brain. Mol Psychiatry. 2000;5:604-15.

14. Tracey KJ. The inflammatory reflex. Nature. 2002;420:853-9.

15. Allan SM, Tyrrell PJ, Rothwell NJ. Interleukin-1 and neuronal injury. Nat Rev Immunol. 2005;5:629-40.

16. Ringheim GE, Burgher KL, Heroux JA. Interleukin- 6 mRNA expression by cortical neurons in culture: evidence for neuronal sources of interleukin-6 production in the brain. J Neuroimmunol. 1995; 63:113-23.

17. Yu B, Shinnick-Gallagher P. Interleukin-1 beta inhibits synaptic transmission and induces membrane hyperpolarization in amygdala neurons. J Pharmacol Exp Ther. 1994;271:590-600.

18. Wang S, Cheng Q, Malik S, Yang J. Interleukin-1beta inhibits gamma-aminobutyric acid type A $(\mathrm{GABA}(\mathrm{A}))$ receptor current in cultured hippocampal neurons. J Pharmacol Exp Ther. 2000;292: 497-504.

19. Miller LG, Galpern WR, Dunlap K, Dinarello CA, Turner TJ. Interleukin-1 augments gammaaminobutyric acidA receptor function in brain. Mol Pharmacol. 1991;39:105-8.

20. Strijbos PJ, Rothwell NJ. Interleukin-1 beta attenuates excitatory amino acid-induced neurodegeneration in vitro: involvement of nerve growth factor. J Neurosci. 1995;15:3468-74.

21. Viviani B, Bartesaghi S, Gardoni F, Vezzani A, Behrens MM, Bartfai T, Binaglia M, Corsini E, Di Luca M, Galli CL, Marinovich M. Interleukin-1 beta enhances NMDA receptor-mediated intracellular calcium increase through activation of the Src family of kinases. J Neurosci. 2003;23:8692-700. 
22. Meini A, Benocci A, Frosini M, Sgaragli G, Pessina G, Aldinucci C, Youmbi GT, Palmi M. Nitric oxide modulation of interleukin-1[beta]-evoked intracellular Ca2+ release in human astrocytoma U-373 MG cells and brain striatal slices. J Neurosci. 2000;20:8980-6.

23. Zhu G, Okada M, Yoshida S, Mori F, Ueno S, Wakabayashi K, Kaneko S. Effects of interleukin-1beta on hippocampal glutamate and GABA releases associated with $\mathrm{Ca}(2+)$-induced $\mathrm{Ca}(2+)$ releasing systems. Epilepsy Res. 2006;71:107-16.

24. Lai AY, Swayze RD, El-Husseini A, Song C. Interleukin-1 beta modulates AMPA receptor expression and phosphorylation in hippocampal neurons. J Neuroimmunol. 2006;175:97-106.

25. Yang S, Liu ZW, Wen L, Qiao HF, Zhou WX, Zhang YX. Interleukin-1beta enhances NMDA receptormediated current but inhibits excitatory synaptic transmission. Brain Res. 2005;1034:172-9.

26. Zhang R, Yamada J, Hayashi Y, Wu Z, Koyama S, Nakanishi H. Inhibition of NMDA-induced outward currents by interleukin-1 beta in hippocampal neurons. Biochem Biophys Res Commun. 2008;372: 816-20.

27. Schneider H, Pitossi F, Balschun D, Wagner A, del Rey A, Besedovsky HO. A neuromodulatory role of interleukin-1beta in the hippocampus. Proc Natl Acad Sci U S A. 1998;95:7778-83.

28. Avital A, Goshen I, Kamsler A, Segal M, Iverfeldt K, Richter-Levin G, Yirmiya R. Impaired interleukin-1 signaling is associated with deficits in hippocampal memory processes and neural plasticity. Hippocampus. 2003;13:826-34.

29. Ross FM, Allan SM, Rothwell NJ, Verkhratsky A. A dual role for interleukin-1 in LTP in mouse hippocampal slices. J Neuroimmunol. 2003;144:61-7.

30. Togashi H, Mori K, Itoh Y, Matsumoto M, Ueno K, Ohashi S, Otani H, Yoshioka M. Involvement of interleukin-1 beta/nitric oxide pathway in the postischemic impairment of long-term potentiation of the rat hippocampus. Neurosci Lett. 2001;313:133-6.

31. Ye ZC, Sontheimer H. Cytokine modulation of glial glutamate uptake: a possible involvement of nitric oxide. Neuroreport. 1996;7:2181-5.

32. Ilyin SE, Gonzalez-Gomez I, Romanovicht A, Gayle D, Gilles FH, Plata-Salaman CR. Autoregulation of the interleukin-1 system and cytokine-cytokine interactions in primary human astrocytoma cells. Brain Res Bull. 2000;51:29-34.

33. Meeuwsen S, Persoon-Deen C, Bsibsi M, Ravid R, van Noort JM. Cytokine, chemokine and growth factor gene profiling of cultured human astrocytes after exposure to proinflammatory stimuli. Glia. 2003;43:243-53.

34. John GR, Lee SC, Song X, Rivieccio M, Brosnan CF. IL-1-regulated responses in astrocytes: relevance to injury and recovery. Glia. 2005;49:161-76.

35. Marcus JS, Karackattu SL, Fleegal MA, Sumners C. Cytokine-stimulated inducible nitric oxide synthase expression in astroglia: role of Erk mitogen-activated protein kinase and NF-kappaB. Glia. 2003;41:152-60.

36. Basu A, Krady JK, Enterline JR, Levison SW. Transforming growth factor beta1 prevents IL-1betainduced microglial activation, whereas TNFalpha- and IL-6-stimulated activation are not antagonized. Glia. 2002;40:109-20.

37. Tichauer J, Saud K, von Bernhardi R. Modulation by astrocytes of microglial cell-mediated neuroinflammation: effect on the activation of microglial signaling pathways. Neuroimmunomodulation. 2007;14:168-74.

38. Argaw AT, Zhang Y, Snyder BJ, Zhao ML, Kopp N, Lee SC, Raine CS, Brosnan CF, John GR. IL-1beta regulates blood-brain barrier permeability via reactivation of the hypoxia-angiogenesis program. $J$ Immunol. 2006;177:5574-84.

39. Vela JM, Molina-Holgado E, Arevalo-Martin A, Almazan G, Guaza C. Interleukin-1 regulates proliferation and differentiation of oligodendrocyte progenitor cells. Mol Cell Neurosci. 2002;20: 489-502.

40. Mason JL, Suzuki K, Chaplin DD, Matsushima GK. Interleukin-1beta promotes repair of the CNS. J Neurosci. 2001;21:7046-52.

41. Bhat NR, Zhang $P$, Bhat AN. Cytokine induction of inducible nitric oxide synthase in an oligodendrocyte cell line: role of p38 mitogen-activated protein kinase activation. J Neurochem. 1999;72:472-8.

42. Brogi A, Strazza M, Melli M, Costantino-Ceccarini E. Induction of intracellular ceramide by interleukin1 beta in oligodendrocytes. J Cell Biochem. 1997;66:532-41. 
43. Myint AM, Kim YK, Verkerk R, Scharpe S, Steinbusch H, Leonard B. Kynurenine pathway in major depression: evidence of impaired neuroprotection. J Affect Disord. 2007;98:143-51.

44. Vezzani A, Baram TZ. New roles for interleukin-1 Beta in the mechanisms of epilepsy. Epilepsy Curr. 20077:45-50.

45. Helminen $M$, Vesikari T. Increased interleukin-1 (IL-1) production from LPS-stimulated peripheral blood monocytes in children with febrile convulsions. Acta Paediatr Scand. 1990;79:810-6.

46. Matsuo M, Sasaki K, Ichimaru T, Nakazato S, Hamasaki Y. Increased IL-1 beta production from dsRNAstimulated leukocytes in febrile seizures. Pediatr Neurol. 2006;35:102-6.

47. Straussberg R, Amir J, Harel L, Punsky I, Bessler H. Pro- and anti-inflammatory cytokines in children with febrile convulsions. Pediatr Neurol. 2001;24:49-53.

48. Pacifici R, Paris L, Di Carlo S, Bacosi A, Pichini S, Zuccaro P. Cytokine production in blood mononuclear cells from epileptic patients. Epilepsia. 1995;36:384-7.

49. Hulkkonen J, Koskikallio E, Rainesalo S, Keranen T, Hurme M, Peltola J. The balance of inhibitory and excitatory cytokines is differently regulated in vivo and in vitro among therapy resistant epilepsy patients. Epilepsy Res. 2004;59:199-205.

50. Bertolani MF, Portolani M, Marotti F, Sabbattini AM, Chiossi C, Bandieri MR, Cavazzuti GB. A study of childhood febrile convulsions with particular reference to HHV-6 infection: pathogenic considerations. Childs Nerv Syst. 1996;12:534-9.

51. Lahat E, Livne M, Barr J, Katz Y. Interleukin-1beta levels in serum and cerebrospinal fluid of children with febrile seizures. Pediatr Neurol. 1997;17:34-6.

52. Tutuncuoglu S, Kutukculer N, Kepe L, Coker C, Berdeli A, Tekgul H. Proinflammatory cytokines, prostaglandins and zinc in febrile convulsions. Pediatr Int. 2001;43:235-9.

53. Haspolat S, Mihci E, Coskun M, Gumuslu S, Ozben T, Yegin O. Interleukin-1beta, tumor necrosis factor-alpha, and nitrite levels in febrile seizures. J Child Neurol. 2002;17:749-51.

54. Virta M, Hurme M, Helminen M. Increased plasma levels of pro- and anti-inflammatory cytokines in patients with febrile seizures. Epilepsia. 2002;43:920-3.

55. Tomoum HY, Badawy NM, Mostafa AA, Harb MY. Plasma interleukin-1beta levels in children with febrile seizures. J Child Neurol. 2007;22:689-92.

56. Peltola J, Hurme M, Miettinen A, Keranen T. Elevated levels of interleukin-6 may occur in cerebrospinal fluid from patients with recent epileptic seizures. Epilepsy Res. 1998;31:129-33.

57. Peltola J, Palmio J, Korhonen L, Suhonen J, Miettinen A, Hurme M, Lindholm D, Keränen T. Interleukin-6 and interleukin-1 receptor antagonist in cerebrospinal fluid from patients with recent tonic-clonic seizures. Epilepsy Res. 2000;41:205-11.

58. Lehtimaki K, Keranen T, Huuhka M, Palmio J, Hurme M, Leinonen E, Peltola J. Increase in plasma proinflammatory cytokines after electroconvulsive therapy in patients with depressive disorder. J Ect. 2008;24:88-91.

59. Corcoran C, Connor TJ, O'Keane V, Garland MR. The effects of vagus nerve stimulation on pro- and anti-inflammatory cytokines in humans: a preliminary report. Neuroimmunomodulation. 2005;12: 307-9.

60. Gayatri NA, Ferrie CD, Cross H. Corticosteroid including ACTH for childhood epilepy other than epileptic spasms. Cochrane Database Syst Rev. 2007:CD005222..

61. Ichiyama T, Nishikawa M, Yoshitomi T, Hayashi T, Furukawa S. Tumor necrosis factor-alpha, interleukin-1 beta, and interleukin-6 in cerebrospinal fluid from children with prolonged febrile seizures. Comparison with acute encephalitis/encephalopathy. Neurology. 1998;50:407-11.

62. Sheng JG, Boop FA, Mrak RE, Griffin WS. Increased neuronal beta-amyloid precursor protein expression in human temporal lobe epilepsy: association with interleukin-1 alpha immunoreactivity. J Neurochem. 1994;63:1872-9.

63. Baranzini SE, Laxer K, Bollen A, Oksenberg JR. Gene expression analysis reveals altered brain transcription of glutamate receptors and inflammatory genes in a patient with chronic focal (Rasmussen's) encephalitis. J Neuroimmunol. 2002;128:9-15.

64. Ravizza T, Boer K, Redeker S, Spliet WG, van Rijen PC, Troost D, Vezzani A, Aronica E. The IL-1 beta system in epilepsy-associated malformations of cortical development. Neurobiol Dis. 2006;24: 128-43.

65. Virta M, Hurme M, Helminen M. Increased frequency of interleukin-1beta (-511) allele 2 in febrile seizures. Pediatr Neurol. 2002;26:192-5. 
66. Tilgen N, Pfeiffer H, Cobilanschi J, Rau B, Horvath S, Elger CE, Propping P, Heils A. Association analysis between the human interleukin 1beta $(-511)$ gene polymorphism and susceptibility to febrile convulsions. Neurosci Lett. 2002;334:68-70.

67. Kira R, Torisu H, Takemoto M, Nomura A, Sakai Y, Sanefuji M, Sakamoto K, Matsumoto S, Gondo K, Hara T. Genetic susceptibility to simple febrile seizures: interleukin-1beta promoter polymorphisms are associated with sporadic cases. Neurosci Lett. 2005;384:239-44.

68. Haspolat S, Baysal Y, Duman O, Coskun M, Tosun O, Yegin O. Interleukin-1alpha, interleukin-1beta, and interleukin-1Ra polymorphisms in febrile seizures. J Child Neurol. 2005;20:565-8.

69. Chou IC, Tsai CH, Hsieh YY, Peng CT, Tsai FJ. Association between polymorphism of interleukin1 beta-511 promoter and susceptibility to febrile convulsions in Taiwanese children. Acta Paediatr. 2003;92:1356.

70. Tsai FJ, Hsieh YY, Chang CC, Lin CC, Tsai CH. Polymorphisms for interleukin 1 beta exon 5 and interleukin 1 receptor antagonist in Taiwanese children with febrile convulsions. Arch Pediatr Adolesc Med. 2002;156:545-8.

71. Kauffman MA, Moron DG, Consalvo D, Bello R, Kochen S. Association study between interleukin 1 beta gene and epileptic disorders: a HuGe review and meta-analysis. Genet Med. 2008;10:83-8.

72. Kanemoto K, Kawasaki J, Miyamoto T, Obayashi H, Nishimura M. Interleukin (IL)1 beta, IL-1alpha, and IL-1 receptor antagonist gene polymorphisms in patients with temporal lobe epilepsy. Ann Neurol. 2000;47:571-4.

73. Kanemoto K, Kawasaki J, Yuasa S, Kumaki T, Tomohiro O, Kaji R, Nishimura M. Increased frequency of interleukin-1beta-511T allele in patients with temporal lobe epilepsy, hippocampal sclerosis, and prolonged febrile convulsion. Epilepsia. 2003;44:796-9.

74. Peltola J, Keranen T, Rainesalo S, Hurme M. Polymorphism of the interleukin-1 gene complex in localization-related epilepsy. Ann Neurol. 2001;50:275-6.

75. Heils A, Haug K, Kunz WS, Fernandez G, Horvath S, Rebstock J, Propping P, Elger CE. Interleukin-1 beta gene polymorphism and susceptibility to temporal lobe epilepsy with hippocampal sclerosis. Ann Neurol. 2000;48:948-50.

76. Buono RJ, Ferraro TN, O'Connor MJ, Sperling MR, Ryan SG, Scattergood T, Mulholland N, Gilmore J, Lohoff FW, Berrettini WH. Lack of association between an interleukin 1 beta (IL-1 beta) gene variation and refractory temporal lobe epilepsy. Epilepsia. 2001;42:782-4.

77. Ozkara C, Uzan M, Tanriverdi T, Baykara O, Ekinci B, Yeni N, Kafadar A, Buyru N. Lack of association between IL-1beta/alpha gene polymorphisms and temporal lobe epilepsy with hippocampal sclerosis. Seizure. 2006;15:288-91.

78. Chen H, Wilkins LM, Aziz N, Cannings C, Wyllie DH, Bingle C, Rogus J, Beck JD, Offenbacher S, Cork MJ, Rafie-Kolpin M, Hsieh CM, Kornman KS, Duff GW. Single nucleotide polymorphisms in the human interleukin-1B gene affect transcription according to haplotype context. Hum Mol Genet. 2006; 15:519-29.

79. Peltola J, Eriksson K, Keranen T. Cytokines and seizures. Arch Neurol. 2001;58:1168-9.

80. Minami M, Kuraishi Y, Yamaguchi T, Nakai S, Hirai Y, Satoh M. Convulsants induce interleukin-1 beta messenger RNA in rat brain. Biochem Biophys Res Commun. 1990;171:832-7.

81. Vezzani A, Moneta D, Conti M, Richichi C, Ravizza T, De Luigi A, De Simoni MG, Sperk G, AndellJonsson S, Lundkvist J, Iverfeldt K, Bartfai T. Powerful anticonvulsant action of IL-1 receptor antagonist on intracerebral injection and astrocytic overexpression in mice. Proc Natl Acad Sci U S A. 2000;97:11534-9.

82. Bruccoleri A, Brown H, Harry GJ. Cellular localization and temporal elevation of tumor necrosis factoralpha, interleukin-1 alpha, and transforming growth factor-beta 1 mRNA in hippocampal injury response induced by trimethyltin. J Neurochem. 1998;71:1577-87.

83. Vezzani A, Conti M, De Luigi A, Ravizza T, Moneta D, Marchesi F, De Simoni MG. Interleukin-1beta immunoreactivity and microglia are enhanced in the rat hippocampus by focal kainate application: functional evidence for enhancement of electrographic seizures. J Neurosci. 1999;19:5054-65.

84. Bruccoleri A, Pennypacker KR, Harry GJ. Effect of dexamethasone on elevated cytokine mRNA levels in chemical-induced hippocampal injury. J Neurosci Res. 1999;57:916-26.

85. Bruccoleri A, Harry GJ. Chemical-induced hippocampal neurodegeneration and elevations in TNFalpha, TNFbeta, IL-1alpha, IP-10, and MCP-1 mRNA in osteopetrotic (op/op) mice. J Neurosci Res. 2000;62:146-55. 
86. Svensson I, Waara L, Johansson L, Bucht A, Cassel G. Soman-induced interleukin-1 beta mRNA and protein in rat brain. Neurotoxicology. 2001;22:355-62.

87. Williams AJ, Berti R, Yao C, Price RA, Velarde LC, Koplovitz I, Schultz SM, Tortella FC, Dave JR. Central neuro-inflammatory gene response following soman exposure in the rat. Neurosci Lett. 2003; 349:147-50.

88. Jean Harry G, Bruccoleri A, Lefebvre d'Hellencourt C. Differential modulation of hippocampal chemical-induced injury response by ebselen, pentoxifylline, and TNFalpha-, IL-1alpha-, and IL-6neutralizing antibodies. J Neurosci Res. 2003;73:526-36.

89. Svensson I, Waara L, Cassel G. Effects of HI 6, diazepam and atropine on soman-induced IL-1 beta protein in rat brain. Neurotoxicology. 2005;26:173-81.

90. Maier WE, Brown HW, Tilson HA, Luster MI, Harry GJ. Trimethyltin increases interleukin (IL)-1 alpha, IL-6 and tumor necrosis factor alpha mRNA levels in rat hippocampus. J Neuroimmunol. 1995;59: 65-75.

91. Chapman S, Kadar T, Gilat E. Seizure duration following sarin exposure affects neuro-inflammatory markers in the rat brain. Neurotoxicology. 2006;27:277-83.

92. Zhang LR, Li XT, Tang WL, Wang YM, Cheng NN, Chen BY. Changes in brain interleukin-1beta following the coadministration of norfloxacin with biphenylacetic acid in rats. Eur J Pharmacol. 2006; 543:21-6.

93. Dhote F, Peinnequin A, Carpentier P, Baille V, Delacour C, Foquin A, Lallement G, Dorandeu F. Prolonged inflammatory gene response following soman-induced seizures in mice. Toxicology. 2007;238:166-76.

94. Donnelly S, Loscher C, Mills KH, Lynch MA. Glycerol-induced seizure: involvement of IL-1beta and glutamate. Neuroreport. 1999;10:1821-5.

95. Okada K, Matsunaga K, Yuhi T, Kuroda E, Yamashita U, Tsuji S. The long-term high-frequency repetitive transcranial magnetic stimulation does not induce mRNA expression of inflammatory mediators in the rat central nervous system. Brain Res. 2002;957:37-41.

96. Yuhas Y, Shulman L, Weizman A, Kaminsky E, Vanichkin A, Ashkenazi S. Involvement of tumor necrosis factor alpha and interleukin-1 beta in enhancement of pentylenetetrazole-induced seizures caused by Shigella dysenteriae. Infect Immun. 1999;67:1455-60.

97. Donnelly S, Loscher CE, Lynch MA, Mills KH. Whole-cell but not acellular pertussis vaccines induce convulsive activity in mice: evidence of a role for toxin-induced interleukin-1beta in a new murine model for analysis of neuronal side effects of vaccination. Infect Immun. 2001;69:4217-23.

98. Heida JG, Pittman QJ. Causal links between brain cytokines and experimental febrile convulsions in the rat. Epilepsia. 2005;46:1906-13.

99. Oprica M, Eriksson C, Schultzberg M. Inflammatory mechanisms associated with brain damage induced by kainic acid with special reference to the interleukin-1 system. J Cell Mol Med. 2003;7: 127-40.

100. Minami M, Kuraishi Y, Satoh M. Effects of kainic acid on messenger RNA levels of IL-1 beta, IL-6, TNF alpha and LIF in the rat brain. Biochem Biophys Res Commun. 1991;176:593-8.

101. Yabuuchi K, Minami M, Katsumata S, Satoh M. In situ hybridization study of interleukin-1 beta mRNA induced by kainic acid in the rat brain. Brain Res Mol Brain Res. 1993;20:153-61.

102. Dalton T, Pazdernik TL, Wagner J, Samson F, Andrews GK. Temporalspatial patterns of expression of metallothionein-I and -III and other stress related genes in rat brain after kainic acid-induced seizures. Neurochem Int. 1995;27:59-71.

103. Nishiyori A, Minami M, Takami S, Satoh M. Type 2 interleukin-1 receptor mRNA is induced by kainic acid in the rat brain. Brain Res Mol Brain Res. 1997;50:237-45.

104. Eriksson C, Winblad B, Schultzberg M. Kainic acid induced expression of interleukin-1 receptor antagonist mRNA in the rat brain. Brain Res Mol Brain Res. 1998;58:195-208.

105. Eriksson C, Van Dam AM, Lucassen PJ, Bol JG, Winblad B, Schultzberg M. Immunohistochemical localization of interleukin-1 beta, interleukin-1 receptor antagonist and interleukin-1 beta converting enzyme/caspase- 1 in the rat brain after peripheral administration of kainic acid. Neuroscience. 1999;93:915-30. 
106. Eriksson C, Tehranian R, Iverfeldt K, Winblad B, Schultzberg M. Increased expression of mRNA encoding interleukin-1 beta and caspase-1, and the secreted isoform of interleukin-1 receptor antagonist in the rat brain following systemic kainic acid administration. J Neurosci Res. 2000;60: 266-79.

107. Eriksson C, Zou LP, Ahlenius S, Winblad B, Schultzberg M. Inhibition of kainic acid induced expression of interleukin-1 beta and interleukin-1 receptor antagonist mRNA in the rat brain by NMDA receptor antagonists. Brain Res Mol Brain Res. 2000;85:103-13.

108. Lehtimaki KA, Peltola J, Koskikallio E, Keranen T, Honkaniemi J. Expression of cytokines and cytokine receptors in the rat brain after kainic acid-induced seizures. Brain Res Mol Brain Res. 2003;110:253-60.

109. Rizzi M, Perego C, Aliprandi M, Richichi C, Ravizza T, Colella D, Velískǒvá J, Moshé SL, De Simoni MG, Vezzani A. Glia activation and cytokine increase in rat hippocampus by kainic acid-induced status epilepticus during postnatal development. Neurobiol Dis. 2003;14:494-503.

110. Dinkel K, MacPherson A, Sapolsky RM. Novel glucocorticoid effects on acute inflammation in the CNS. J Neurochem. 2003;84:705-16.

111. Marini $H$, Altavilla D, Bellomo $M$, Adamo EB, Marini $R$, Laureanti $F$, Bonaccorso MC, Seminara $P$, Passaniti M, Minutoli L, Bitto A, Calapai G, Squadrito F. Modulation of IL-1 beta gene expression by lipid peroxidation inhibition after kainic acid-induced rat brain injury. Exp Neurol. 2004;188:178-86.

112. Marini H, Costa C, Passaniti M, Esposito M, Campo GM, lentile R, Adamo EB, Marini R, Calabresi P, Altavilla D, Minutoli L, Pisani F, Squadrito F. Levetiracetam protects against kainic acid-induced toxicity. Life Sci. 2004;74:1253-64.

113. Voutsinos-Porche B, Koning E, Kaplan H, Ferrandon A, Guenounou M, Nehlig A, Motte J. Temporal patterns of the cerebral inflammatory response in the rat lithium-pilocarpine model of temporal lobe epilepsy. Neurobiol Dis. 2004;17:385-402.

114. Penkowa M, Florit S, Giralt M, Quintana A, Molinero A, Carrasco J, Hidalgo J. Metallothionein reduces central nervous system inflammation, neurodegeneration, and cell death following kainic acidinduced epileptic seizures. J Neurosci Res. 2005;79:522-34.

115. MacPherson A, Dinkel K, Sapolsky R. Glucocorticoids worsen excitotoxin-induced expression of proinflammatory cytokines in hippocampal cultures. Exp Neurol. 2005;194:376-83.

116. Oprica M, Spulber SD, Aronsson AF, Post C, Winblad B, Schultzberg M. The influence of kainic acid on core temperature and cytokine levels in the brain. Cytokine. 2006;35:77-87.

117. Hay C, de Belleroche J. Induction of immediate early genes, interleukin-1 beta and ornithine decarboxylase messenger RNA in spinal cord by seizures. Biochem Soc Trans. 1994;22:148S.

118. Ravizza T, Rizzi M, Perego C, Richichi C, Veliskova J, Moshe SL, De Simoni MG, Vezzani A. Inflammatory response and glia activation in developing rat hippocampus after status epilepticus. Epilepsia. 2005;46 Suppl 5:113-7.

119. Plata-Salaman CR, Ilyin SE, Turrin NP, Gayle D, Flynn MC, Romanovitch AE, Kelly ME, Bureau Y, Anisman H, Mclntyre DC. Kindling modulates the IL-1beta system, TNF-alpha, TGF-beta1, and neuropeptide mRNAs in specific brain regions. Brain Res Mol Brain Res. 2000;75:248-58.

120. Yi PL, Tsai CH, Lin JG, Lee CC, Chang FC. Kindling stimuli delivered at different times in the sleepwake cycle. Sleep. 2004;27:203-12.

121. De Simoni MG, Perego C, Ravizza T, Moneta D, Conti M, Marchesi F, De Luigi A, Garattini S, Vezzani A. Inflammatory cytokines and related genes are induced in the rat hippocampus by limbic status epilepticus. Eur J Neurosci. 2000; 12:2623-33.

122. Brandt C, Ebert U, Loscher W. Epilepsy induced by extended amygdala-kindling in rats: lack of clear association between development of spontaneous seizures and neuronal damage. Epilepsy Res. 2004;62:135-56.

123. Du F, Eid T, Lothman EW, Kohler C, Schwarcz R. Preferential neuronal loss in layer III of the medial entorhinal cortex in rat models of temporal lobe epilepsy. J Neurosci. 1995;15:6301-13.

124. Gahring LC, White HS, Skradski SL, Carlson NG, Rogers SW. Interleukin-1alpha in the brain is induced by audiogenic seizure. Neurobiol Dis. 1997;3:263-9.

125. Klein BD, Fu YH, Ptacek LJ, White HS. c-Fos immunohistochemical mapping of the audiogenic seizure network and tonotopic neuronal hyperexcitability in the inferior colliculus of the Frings mouse. Epilepsy Res. 2004;62:13-25. 
126. Pereira MG, Gitai DL, Paco-Larson ML, Pesquero JB, Garcia-Cairasco N, Costa-Neto CM. Modulation of $\mathrm{B} 1$ and $\mathrm{B} 2$ kinin receptors expression levels in the hippocampus of rats after audiogenic kindling and with limbic recruitment, a model of temporal lobe epilepsy. Int Immunopharmacol. 2008;8:200-5.

127. Okada K, Yamashita U, Tsuji S. Cyclooxygenase system contributes to the maintenance of post convulsive period of epileptic phenomena in the genetically epileptic El mice. J Uoeh. 2006;28: 265-75.

128. Sayyah M, Beheshti S, Shokrgozar MA, Eslami-far A, Deljoo Z, Khabiri AR, Haeri Rohani A. Antiepileptogenic and anticonvulsant activity of interleukin-1 beta in amygdala-kindled rats. Exp Neurol. 2005;191:145-53.

129. Panegyres PK, Hughes J. The neuroprotective effects of the recombinant interleukin-1 receptor antagonist rhlL-1ra after excitotoxic stimulation with kainic acid and its relationship to the amyloid precursor protein gene. J Neurol Sci. 1998;154:123-32.

130. Vezzani A, Moneta D, Richichi C, Aliprandi M, Burrows SJ, Ravizza T, Perego C, De Simoni MG. Functional role of inflammatory cytokines and antiinflammatory molecules in seizures and epileptogenesis. Epilepsia. 2002;43 Suppl 5:30-5.

131. Dube C, Vezzani A, Behrens M, Bartfai T, Baram TZ. Interleukin-1 beta contributes to the generation of experimental febrile seizures. Ann Neurol. 2005;57:152-5.

132. Ravizza T, Lucas SM, Balosso S, Bernardino L, Ku G, Noe F, Malva J, Randle JC, Allan S, Vezzani A. Inactivation of caspase-1 in rodent brain: a novel anticonvulsive strategy. Epilepsia. 2006;47:1160-8.

133. Henshall DC, Murphy BM. Modulators of neuronal cell death in epilepsy. Curr Opin Pharmacol. 2008; 8:75-81.

134. Beg AA. Endogenous ligands of Toll-like receptors: implications for regulating inflammatory and immune responses. Trends Immunol. 2002;23:509-12.

135. Maelfait J, Vercammen E, Janssens S, Schotte P, Haegman M, Magez S, Beyaert R. Stimulation of Tolllike receptor 3 and 4 induces interleukin-1 beta maturation by caspase-8. J Exp Med. 2008;205: 1967-73.

136. Fujikawa DG. Prolonged seizures and cellular injury: understanding the connection. Epilepsy Behav. 2005;7 Suppl 3:S3-11.

137. Rong Y, Baudry M. Seizure activity results in a rapid induction of nuclear factor-kappa B in adult but not juvenile rat limbic structures. J Neurochem. 1996;67:662-8.

138. Matsuoka Y, Kitamura Y, Okazaki M, Terai K, Taniguchi T. Kainic acid-induced activation of nuclear factor-kappaB in rat hippocampus. Exp Brain Res. 1999;124:215-22.

139. Yu Z, Zhou D, Bruce-Keller AJ, Kindy MS, Mattson MP. Lack of the p50 subunit of nuclear factorkappaB increases the vulnerability of hippocampal neurons to excitotoxic injury. J Neurosci. 1999; 19:8856-65.

140. Lerner-Natoli M, Montpied P, Rousset MC, Bockaert J, Rondouin G. Sequential expression of surface antigens and transcription factor NFkappaB by hippocampal cells in excitotoxicity and experimental epilepsy. Epilepsy Res. 2000;41:141-54.

141. Crespel A, Coubes P, Rousset MC, Brana C, Rougier A, Rondouin G, Bockaert J, Baldy-Moulinier M, Lerner-Natoli M. Inflammatory reactions in human medial temporal lobe epilepsy with hippocampal sclerosis. Brain Res. 2002;952:159-69.

142. Murashima YL, Yoshii M, Suzuki J. Role of nitric oxide in the epileptogenesis of EL mice. Epilepsia. 2000;41 Suppl 6:S195-9.

143. Gonzalez-Hernandez T, Garcia-Marin V, Perez-Delgado MM, Gonzalez-Gonzalez ML, Rancel-Torres N, Gonzalez-Feria L. Nitric oxide synthase expression in the cerebral cortex of patients with epilepsy. Epilepsia. 2000;41:1259-68.

144. Kamida T, Takeda Y, Fujiki M, Abe T, Abe E, Kobayashi H. Nitric oxide synthase and NMDA receptor expressions in cavernoma tissues with epileptogenesis. Acta Neurol Scand. 2007;116:368-73.

145. Burn J, Dennis M, Bamford J, Sandercock P, Wade D, Warlow C. Epileptic seizures after a first stroke: the Oxfordshire Community Stroke Project. BMJ. 1997;315:1582-7.

146. Frey LC. Epidemiology of posttraumatic epilepsy: a critical review. Epilepsia. 2003;44(Suppl 10):11-7.

147. Docagne F, Campbell SJ, Bristow AF, Poole S, Vigues S, Guaza C, Perry VH, Anthony DC. Differential regulation of type I and type II interleukin-1 receptors in focal brain inflammation. Eur J Neurosci. 2005;21:1205-14. 
The role of interleukin-1 in seizures and epilepsy $\mid 59$

148. Felderhoff-Mueser U, Schmidt OI, Oberholzer A, Buhrer C, Stahel PF. IL-18: a key player in neuroinflammation and neurodegeneration? Trends Neurosci. 2005;28:487-93. 



\section{Chapter 3}

\section{Neuroimmunological changes in epilepsy?}

Rijkers K, Hoogland G, Mencenali C, Aalbers MW, Huijbers M, Philippens M, Martinez-Martinez P, Vles JSH, Steinbusch HMW, Majoie HJM 


\section{Abstract}

Although interleukin-1 beta (IL-1 $\beta$ ) can affect cellular excitability, and is upregulated after seizures, it is still unclear to what extent this contributes to epileptogenesis. Studies on IL-1 $\beta$ involvement in epilepsy have mainly been conducted in models that are associated with neuronal damage induced by excitotoxicity. This can have major impact on network excitability and can directly affect IL-1 $\beta$ expression via activation of amongst others nuclear factor kappa $B(N F \kappa B)$. To study to what extent IL-1 $\beta$ is upregulated in the absence of neuronal damage we determined chronic IL-1 $\beta$ expression in the amygdala kindled rat. Moreover, to get more insight in NFKB activity, we determined the expression of the ceramide transfer protein (CERT) since the expression of this protein is associated with NFKB activity.

Rats were implanted in the left basolateral amygdala with kindling electrodes. Half of them were fully kindled while the other half served as sham. Animals were sacrificed 48 hours after the last generalized seizure after which IL-1 $\beta$ and CERT were determined in hippocampus and cortex. Two anti-IL-1 $\beta$ antibodies and one antibody directed against CERT were used.

No IL-1 $\beta$ was detected in the brains of kindled animals nor in shams. Some IL-1 $\beta$ immunopositive cells were observed in the cortex area where the kindling electrode pierced the dura. No differences in intensity of CERT staining were observed between kindled animals and shams.

IL-1 $\beta$ is not chronically upregulated in fully kindled rats. This may be related to the fact that kindling is not

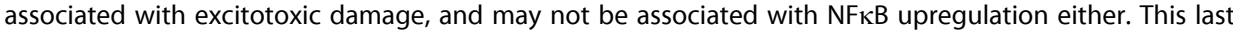
assumption is supported by the fact that we did not observe differences in CERT staining either. Further studies aimed at $\mathrm{NF \kappa B}$ are needed to elucidate this. 


\section{Introduction}

The brain shows increased expression of the pro-inflammatory cytokine interleukin-1 beta (IL-1 $\beta$ ) after experimental seizures and epilepsy'. It is thought that this IL-1 $\beta$ plays a key role in the development of seizures and epilepsy².

Neuronal injury in general leads to rapid production of IL-1 $\beta^{3}$. In line with this, seizure-induced IL-1 $\beta$ is predominantly found brain structures that show most severe seizure-induced neuronal damage $\mathrm{e}^{4-14}$. On the cellular level, this IL-1 $\beta$ expression ${ }^{5,7,9,11,15}$ can be induced by the release of heat shock proteins (HSP) during the seizure that activate Toll-like receptors (TLR) which in turn induce IL-1 $\beta$ production via activation of nuclear factor kappa $B(N F \kappa B)^{16-18}$, see Figure 3.1. Activation of NFKB also induces expression of the ceramide transfer protein (CERT, also known as the Goodpasture antigen binding protein) a transporter involved in transporting ceramide from its production-site the endoplasmatic reticulum to the Golgi ${ }^{19}$.

Many patients with epilepsy have never suffered from severe neuronal damage. Brain MRI is normal in $23 \%$ of epilepsy patients ${ }^{20}$. The majority of these MRI-negative epilepsy patients have focal cortical dysplasia ${ }^{21}$, a developmental abnormality unrelated to excitotoxic damage or neuronal death ${ }^{22}$. Still, brain tissue of these focal cortical dysplasia patients and from experimental epilepsies that are not associated with neuronal injury show IL-1 $\beta$ expression as well ${ }^{23-26}$. It has been hypothesized that central nervous system (CNS) IL-1 $\beta$ expression can result from seizure-induced opening of the blood-brain barrier (BBB) and subsequent entrance of macromolecules ${ }^{27}$ as well, while IL-1 $\beta$ expressing leucocytes can enter the CNS too after seizure-induced changes in the expression of vascular cell adhesion molecules ${ }^{28}$ (Figure 3.1).

On the cellular level IL-1 $\beta$ has properties that support its presumed key role in epileptogenesis. When IL-1 $\beta$ binds to its type I receptor (IL-1RI), several cascades are initiated. Immediately Src kinases are activated which in turn increase the degree of phosphorylation of the NMDA-R. This results in increased $\mathrm{Ca}^{2+}$ influx ${ }^{29,30}$, immediately leading to cellular hyperexcitability (Figure 3.1). Slower transcriptional pathways result in the transcription of proinflammatory genes (including $\mathrm{IL}-1 \beta$ ) and may affect excitability on the long run as well ${ }^{31}$.

The role of IL-1 $\beta$ in seizures and epilepsy has mainly been studied in animal models that are associated with glutamate excitotoxicity and related neuronal damage'. Studies on BBB integrity after seizures have been performed on these types of animal models as well ${ }^{27,28}$.

Glutamate excitotoxicity occurs when glutamate (being released during the (prolonged) seizure) activates the NMDA-R, leading to massive calcium influx. Chronically elevated intracellular calcium levels can be toxic to the cell and cause neuronal death. If the high calcium levels are reversible, neuronal death is prevented 


\section{and sprouting can occur ${ }^{32}$. Both neuronal death and sprouting contribute to network hyperexcitability (Figure 3.1).}

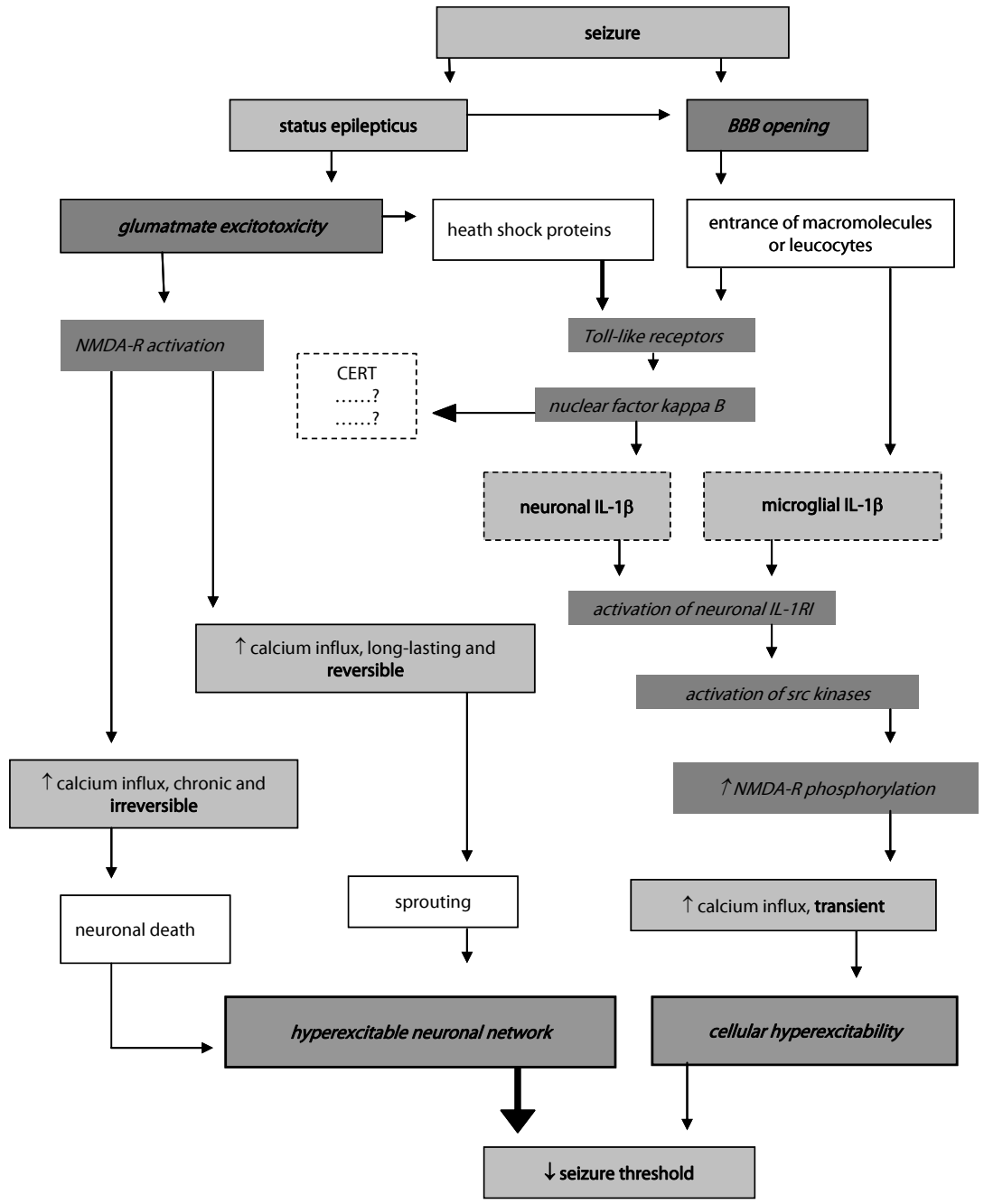

Figure 3.1 Scheme depicting seizure-induced actions of IL-1 $\beta$ in the brain. If a seizure evolves in a status epilepticus this can cause glutamate excitotoxicity, that is associated with the release of heath shock proteins (HSPs). HSPs are endogenous ligands for the Toll like receptors which in turn induce $N F \kappa B$ production. $N F \kappa B$ stimulates the neurons to produce IL-1 $\beta$. Simultaneously, the blood brain barrier becomes disrupted during a seizure and during status epilepticus. This leads to entrance of macromolecules and leucocytes from the general circulation which either activate microglial IL-1 $\beta$ expression, or express IL-1 $\beta$ themselves.

When this seizure-induced IL-1 $\beta$ signal is picked up by IL- 1 receptors on neurons, a cascade of events is initiated: firstly upregulation of the Src family of kinases occurs, which increases the degree of phosphorylation of the NDMA-R, in turn leading to augmented calcium influx. This ultimately causes cellular hyperexcitability for as long as the NMDA-R are letting more calcium in. 
In many epilepsy models, especially those that are based on status epilepticus, other cascades contribute to hyperexcitability as well. Glutamate excitotoxicity that occurs during status epilepticus leads to activation of NMDA-R, resulting in massive calcium influx into the neurons. Neuronal death occurs if the intracellular calcium concentrations remain chronically elevated, while reversibly high calcium levels cause sprouting. Neuronal death and sprouting lead to network changes, ultimately resulting in network hyperexcitability. If both network hyperexcitability and cellular hyperexcitability are present, it is likely that network hyperexcitability contributes more to epileptogenesis than cellular hyperexcitability caused by IL-1 $\beta$. In the absence of glutamate excitotoxicity, the contribution of seizure-induced IL-1 $\beta$ may be relatively bigger.

Even though both excessive glutamate release and IL-1 $\beta$ expression lead to increased calcium influx via the NMDA-R, the contribution of glutamate is likely to be much bigger than the contribution of IL-1 $\beta$, especially in cases associated with neuronal damage (Figure 3.1). We therefore hypothesize that in these cases, network hyperexcitability is established by cascades that are initiated after glutamateinduced enhancement of NMDA-R functioning. IL-1 $\beta$-induced enhancement of NMDA-R functioning may on the other hand play an important role in cases where seizures occur but excessive glutamate release remains limited.

Since the majority of studies on the role of IL-1 $\beta$ in epilepsy has been performed using animal models that are associated with excitotoxic neuronal damage, the question still remains to what extent IL-1 $\beta$ contributes to epileptogenesis in cases that are not associated with neuronal damage but comprise an important part of the patient population ${ }^{20}$.

We hypothesized that, if IL-1 $\beta$ is required for epileptogenesis, it must be expressed chronically during epileptogenesis, also in the absence of neuronal damage. We further hypothesized that, if IL-1 $\beta$ is indeed chronically expressed in the absence of neuronal damage, this expression may depend on both BBB disruption (which remains present up to one week after experimental seizures ${ }^{27}$ ) and $\mathrm{NF \kappa B}$ activation (Figure 3.1).

We have therefore investigated, using immunohistochemistry, whether IL-1 $\beta$ is chronically expressed in an animal model for chronic epilepsy that is not associated with glutamate excitotoxicity-associated neuronal cell death ${ }^{33-36}$, the amygdala kindled rat $^{37}$. As a second readout parameter for NFKB activation we have determined the ceramide transfer protein $^{38}$ (CERT, also known as the Goodpasture antigen binding protein ${ }^{19}$ ). 


\section{Materials and Methods}

\section{Animals}

Male 12-weeks old Sprague-Dawley (SD) rats purchased from Harlan (Horst, The Netherlands) were housed under controlled conditions $\left(21 \pm 2^{\circ} \mathrm{C}\right.$ ambient temperature, a 12 hour light/dark schedule, background noise provided by radio, and ad libitum food and water. The animals were allowed to adapt to the laboratory for one week before surgery. Adequate measures were taken to minimize pain and discomfort. All experimental procedures were conducted in accordance with international standards as defined by the European Communities Council Directive of November $24^{\text {th }} 1986$ and approved by the Animal Ethics Committee of Maastricht University.

\section{Surgery}

Twenty-five rats were implanted with a set of kindling/EEG electrodes. Thirty minutes prior to surgery all rats received $0.1 \mathrm{ml}$ buprenorfine hydrochloride (Temgesic ${ }^{\circledR}$, Schering-Plough Inc., Amstelveen, The Netherlands) for perioperative pain relief. All surgical procedures were performed under general isoflurane anesthesia (5\% for induction and $2.5 \%$ for maintenance).

The set of electrodes for kindling/EEG was implanted stereotaxically (Dual Manipulator Lab Standard Stereotaxic, Stoelting Inc., Wood Dale, IL, USA). The amygdala stimulating/recording electrode ${ }^{39}$ (Department of Instrument Development, Engineering \& Evaluation of Maastricht University) was implanted in the left basolateral amygdala (coordinates derived from a rat stereotaxic atlas ${ }^{40}$ relative to bregma: $-2.5 \mathrm{~mm}$ posteriorly, $4.8 \mathrm{~mm}$ laterally, and $9.6 \mathrm{~mm}$ ventrally). Three monopolar stainless steel electrodes were implanted in the cerebral cortex at $1 \mathrm{~mm}$ depth. One of three $3.8 \mathrm{~mm}$ laterally on the right and $2.5 \mathrm{~mm}$ posteriorly to bregma, was used for EEG, one $4.8 \mathrm{~mm}$ laterally to the left and $5 \mathrm{~mm}$ posterior to bregma for reference, and one $3.8 \mathrm{~mm}$ laterally on the right and $5 \mathrm{~mm}$ posterior to bregma for ground. Connectors for the kindling/EEG electrodes were fixed on the skull using dental acrylic.

\section{Amygdala kindling}

As described previously ${ }^{41}$, ten days after surgery the pre-kindling afterdischarge threshold (pre-KADT) was assessed in all rats. It was defined as the stimulus amplitude necessary to elicit a two-second discharge with a high frequency and high voltage in the amygdala, evoked by stimulating the amygdala with a series of pulses delivered at an interstimulus interval of two minutes using steps of $10 \mu \mathrm{A}$ starting at $10 \mu \mathrm{A}(50 \mathrm{~Hz}, 0.2 \mathrm{~ms}$ square wave delivered by a WPI Accupulser A310 connected to a WPI Stimulus Isolation Unit A360 (World Precision Instruments, Sarasota, FL, USA). 
Kindling was started the next day. The amygdala was stimulated twice per day (first stimulus between 8 and 10 am, second stimulus between 2 and 4 pm; interstimulus interval at least 6 hours) with a two-second $50 \mathrm{~Hz}$ stimulus ( $400 \mu \mathrm{A}, 0.2 \mathrm{~ms}$ square wave pulses). $400 \mu \mathrm{A}$ was chosen as stimulus intensity since it was at least $200 \%$ above pre-KADT for all rats. Seizure stage was determined based on Racine's fivepoint scale ${ }^{37}$ in which stage one seizures are characterized by unilateral eye closure (mild facial clonus), stage two by bilateral eye closure and chewing (severe facial clonus), stage three by unilateral forelimb clonus, stage four by rearing and stage five by loss of balance and falling. After five consecutive stage five seizures, the animals were considered fully kindled. Subsequently, the amygdala was stimulated once per day for two more weeks.

All rats were videotaped (Minolta DiMage G400, Konica Minolta Inc., Tokyo, Japan) during delivery of the kindling stimulus and for as long as the behavioral seizure lasted. Videos were analyzed offline by two blinded observers who assessed seizure severity based on Racine's scale.

\section{EEG analysis}

The EEG recordings from the amygdala and cortex were performed using a Vangard system (Vangard Systems, Cleveland Clinic Foundation, Cleveland, USA). Recordings were made with a sample frequency of $200 \mathrm{~Hz}$, frequency band of $0.5-70 \mathrm{~Hz}$ and with a $50 \mathrm{~Hz}$ notch filter. The total seizure duration was determined by a blinded observer and defined as the duration of rhythmic activity (spikes, sharp waves or slow waves) on the EEG. A seizure was considered to have ended when these wave forms occurred less than once per ten seconds.

\section{Histochemistry and immunohistochemistry}

Forty-eight hours after the last seizure the rats received an overdose of pentobarbital (Nembutal) followed by transcardial perfusion with tyrode buffer (in $\mathrm{mM}: 136.9 \mathrm{NaCl}$, 2.7 KCl, $0.2 \mathrm{MgCl}_{2}, 11.9 \mathrm{NaHCO}_{3}, 0.3 \mathrm{NaH}_{2} \mathrm{PO}_{4}, 5.0$ glucose, equilibrated with $5 \% \mathrm{CO}_{2}$ / $95 \% \mathrm{O}_{2}$ ), and then with fixative (4\% paraformaldehyde dissolved in $0.1 \mathrm{M}$ phosphate buffer, pH 7.6).

The brains were removed and postfixed in the same fixative $\left(4^{\circ} \mathrm{C}, 48 \mathrm{~h}\right)$, cryoprotected in $20 \%$ sucrose $/ 0.1 \mathrm{M}$ phosphate buffer at $\left(4^{\circ} \mathrm{C}, 24 \mathrm{~h}\right)$ and rapidly frozen and stored at $80^{\circ} \mathrm{C}$ until further processing.

Coronal $10 \mu \mathrm{m}$ serial sections through the hippocampus were cut on a cryostat, mounted on gelatin-coated glass slides, and stored at $-20^{\circ} \mathrm{C}$ until processing for (immuno)histochemistry. Standard haematoxylin-eosin (Merck, Germany) staining was used to identify the location of the tip of the kindling electrode.

For IL-1 $\beta$-immunohistochemistry, two antibodies against IL-1 $\beta$ were used: one polyclonal antibody generated in goat to rat IL-1 $\beta$ (Santa Cruz Biotechnology Inc., Santa Cruz, CA, USA) and one monoclonal antibody generated in mice to 
recombinant rat IL-1 $\beta$, referred to as SILK $22^{42}$ and kindly provided by Dr. A.-M. van Dam (Vrije Universiteit, Amsterdam, The Netherlands).

For the polyclonal antibody, sections were rinsed in $0.1 \mathrm{M}$ phosphate buffer (PB), Trisbuffered saline (TBS), and TBS containing $0.3 \%$ Triton (TBS-T) and $0.3 \% \mathrm{H}_{2} \mathrm{O}_{2}$. Subsequently sections were rinsed in TBS-T and incubated in $0.3 \%$ normal donkey serum (NDS) dissolved in TBS-T for one hour. Then they were incubated for 24 hours at room temperature with the goat polyclonal anti rat IL-1 $\beta$ antibody (sc-1252, Santa Cruz Biotechnology Inc., Santa Cruz, CA, USA), diluted 1:100 in TBS-T containing $0.03 \%$ NDS. The next day, sections were rinsed in TBS and incubated for one hour with the rabbit anti goat peroxidase conjugated secondary antibody (Jackson ImmunoResearch Laboratories, Inc., West Grove, PA, USA), diluted 1:100 in TBS. The staining was visualized using diaminobenzidine. One glass containing four sections in which the primary antibody was omitted, was included to confirm specificity of immunoreactivity.

For the SILK 22 antibody, sections were rinsed in TBS followed by TBS containing $0.3 \% \mathrm{H}_{2} \mathrm{O}_{2}$. Subsequently sections were rinsed in TBS-T and incubated for 20 minutes in TBS-T containing 2\% NDS. Then they were incubated for 24 hours at $4{ }^{\circ} \mathrm{C}$ with the mouse monoclonal against recombinant rat IL-1 $\beta$ antibody diluted 1:50 in TBS-T containing $0.2 \%$ NDS. The next day, sections were rinsed in TBS and incubated for two hours with the donkey anti mouse biotin conjugated secondary antibody (Jackson ImmunoResearch Laboratories, Inc., West Grove, PA, USA), diluted 1:400 in TBS-T. Subsequently, sections were rinsed in TBS-T and incubated for two hours with avidin-biotin (Vectastain ABC-kit, Vector Laboratories Inc., Burlingame, CA, USA), diluted 1:400 in TBS-T. The staining was visualized using diaminobenzidine. One glass containing four sections in which the primary antibody was omitted, was included to confirm specificity of immunoreactivity.

For CERT immunohistochemistry, sections were incubated for 12 minutes in 4\% paraformaldehyde containing $0.2 \%$ gluteraldehyde $25 \%$ and $15 \%$ picric acid at $4{ }^{\circ} \mathrm{C}$. Then, sections were rinsed in TBS-T and incubated for five minutes in sodium citrate buffer $\left(\mathrm{pH} \mathrm{6.0)}\right.$ at $60^{\circ} \mathrm{C}$ in the water bath. Sections were thereafter cooled at room temperature for five minutes after which they were rinsed in TBS-T. Then the rabbit polyclonal against human CERT primary antibody (anti Goodpasture binding protein antibody A300-668A, BioConnect B.V. Huissen, The Netherlands) diluted 1:100 in TBS containing $5 \%$ bovine serum antigen was added. After 48 hours of incubation at $4^{\circ} \mathrm{C}$, sections were rinsed in TBS-T and incubated for one hour at room temperature with the donkey anti rabbit biotin conjugated (D23, Jackson ImmunoResearch Laboratories Inc., West Grove, PA, USA) diluted 1:800 in TBS-T. Sections were rinsed in TBS-T and incubated for 90 minutes with avidin-biotin (Vectastain ABC-kit, VectorLaboratories Inc., Burlingame, CA, USA) diluted 1:400. The staining was visualized using diaminobenzidine containing $8 \% \mathrm{NiCl}$. One glass containing four sections in which the primary antibody was omitted, was included to confirm specificity of immunoreactivity. 


\section{Microscopy: IL-1 $\beta$}

IL-1 $\beta$ immunoreactivity (ir) in the left hippocampus and cortex was assessed qualitatively by microscopic inspection of four sections per rat 12 kindled and 8 shams) between bregma levels -2.8 and -3.1 using the Olympus AX-70 microscope (Olympus, Tokyo, Japan).

\section{Microscopy: CERT}

CERT ir in the dendate gyrus (DG), cornu ammonis 1 (CA1) and cornu ammonis 3 (CA3) was measured by a semi-quantitative method. Briefly, within each section between 3.1 and 6.0 millimeters posterior to bregma two to eight photographs per animal (five kindled animals and three controls) were taken including the left DG (2 areas), CA1, CA3, cortex and corpus callosum with the Olympus AX-70 microscope connected to a digital camera (F-view; Olympus, Tokyo, Japan). To correct for potential variability in lighting conditions, all images were collected under identical conditions. Photographs were analyzed using NIH ImageJ software (http://rsb.info.nih.gov/ij/). Using a trial and error method, a threshold value to optimally discern the stained cells was selected and kept the same for all measurements (adapted threshold). Subsequently the gray value of the respective areas was calculated for each area separately. The gray value of the corpus callosum of each section was used to correct for small variations in background staining.

\section{Statistical analysis}

Differences in pre-KADT between kindled animals and shams (to assess homogeneity of the two groups) and in CERT ir signal between kindled animals and shams were calculated using Mann Whitney $\mathrm{U}$ testing.

\section{Results}

In total, 25 rats were operated on. Five rats did not complete the experiments because of anesthesia-related death $(n=1)$, loss of kindling/EEG electrode $(n=1)$, defected kindling/EEG electrode $(n=2)$, not reaching the fully kindled state $(n=1)$. Twelve rats were kindled according to the above-mentioned protocol, while eight rats served as sham.

\section{Amygdala kindling}

Kindled rats needed $16 \pm 5$ stimuli to reach the fully kindled state. Pre-KADT levels did not significantly differ between kindled rats (mdn $119 \mu \mathrm{A}$, range 30 - 275) and shams (mdn $44 \mu \mathrm{A}$, range $38-80$ ). 


\section{Immunohistochemistry}

HE staining was compared to the rat stereotactic atlas ${ }^{40}$ and revealed that in all animals the kindling electrode tip was located in the left basolateral amygdala.

\section{$I L-1 \beta$}

Both antibodies showed IL-1 $\beta$ ir cells in the cortex areas where the electrodes pierced the dura mater. The majority of these cells was found superficially at the level of the cortex damage (Figures 3.2A and 3.2B), while some IL-1 $\beta$ ir cells were found in deeper cortex layers, predominantly perivascularly (Figures $3.2 \mathrm{C}$ and 3.2D). These large ir cells had the appearance of macrophages. No IL-1 $\beta$ ir cells were present in the hippocampus.

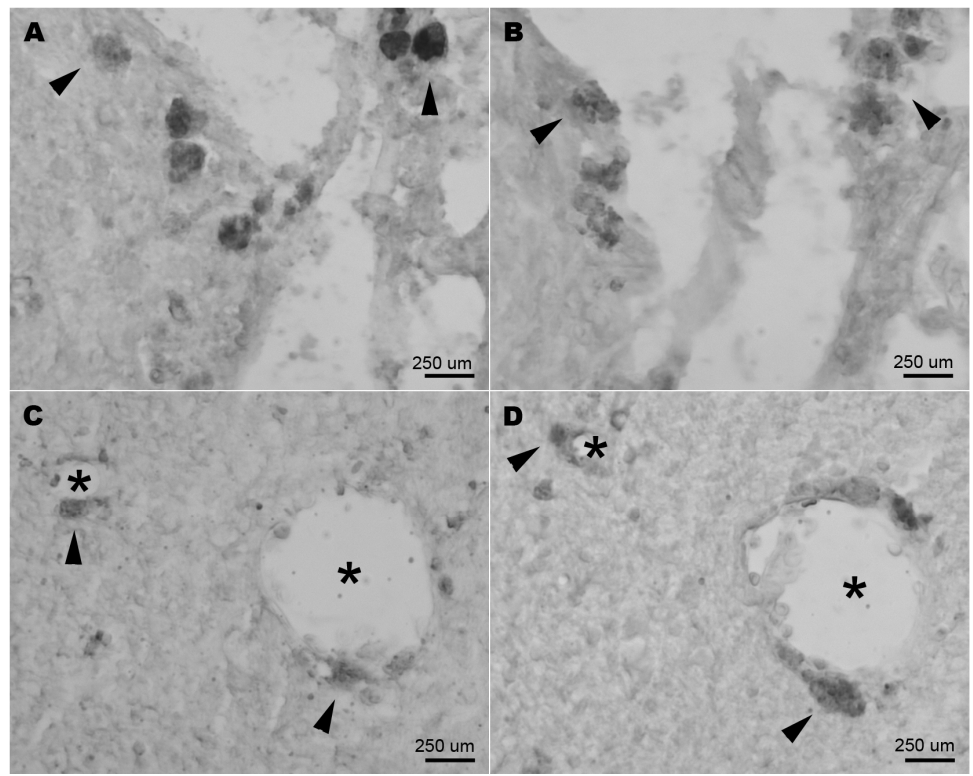

Figure 3.2 Microscopic images of IL-1 $\beta$ stained sections at $10 \mathrm{x}$ magnification and depicting IL-1 $\beta$ immunopositive cells in the cortex at the level of the electrode damage ( $A$ and $B$ ) and in deeper cortical layers ( $C$ and $D)$, visualized using the polyclonal antibody ( $A$ and $C$ ) and the monoclonal antibody (B and D).

Arrowheads point at some of the IL-1 $\beta$ ir cells. Asteriks are located inside vessels. A and B are adjacent sections $(10 \mu \mathrm{m})$ of one kindled animal, $C$ and $D$ are adjacent sections of one sham animal.

\section{CERT}

Cells in the cortex, DG, CA1 and CA3 showed CERT immunoreactivity (Figure 3.3). The intensity of this signal did not significantly differ in any of the regions between kindled animals and shams. 


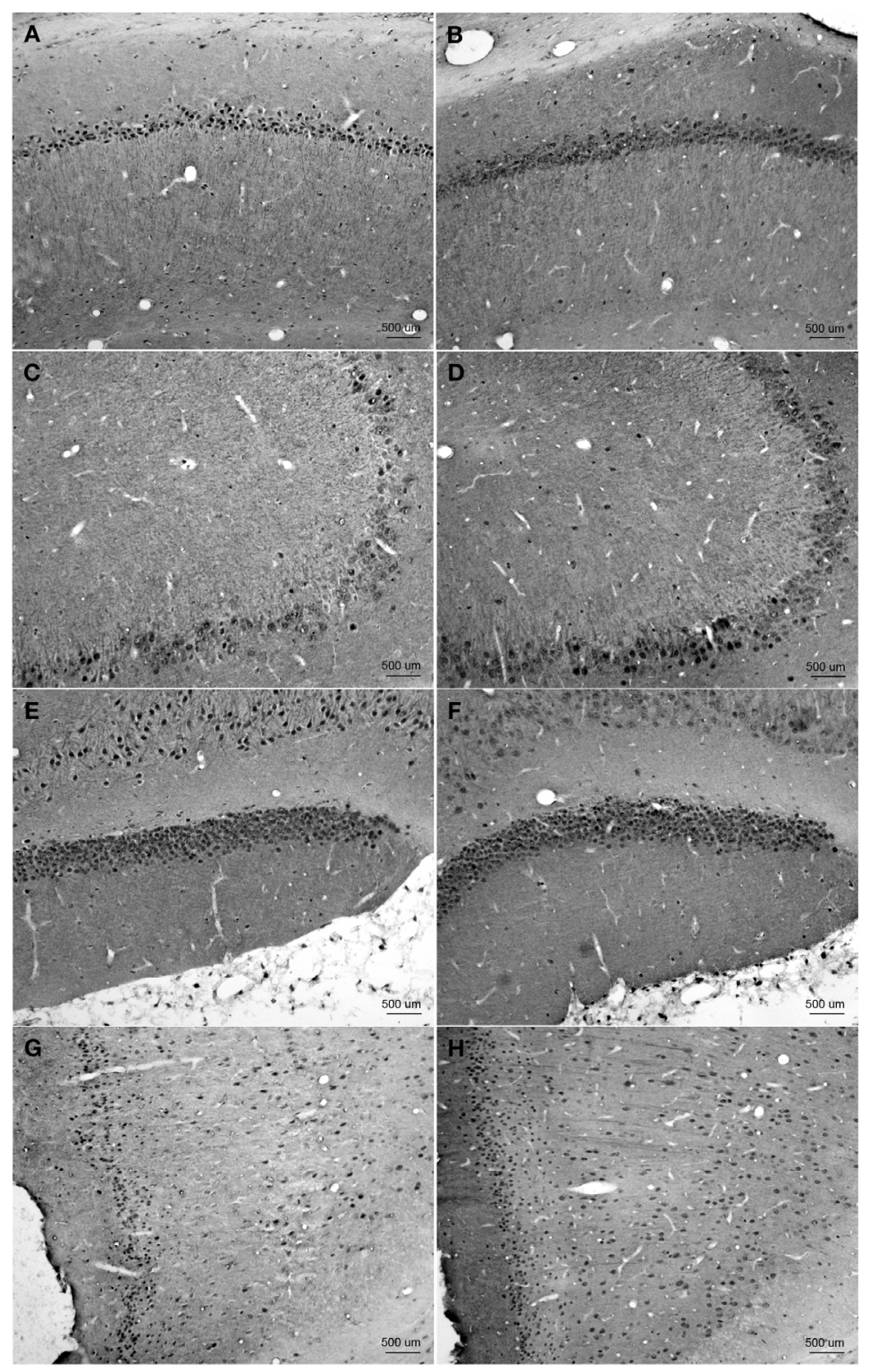

Figure 3.3 Microscopic images of CERT-stained sections photographed at $4 \mathrm{x}$ magnification and depicting CA1 (A, B), CA3 (C, D), ventral DG (E, F) and cortex (G and H) of kindled (B, D, F and $H$ ) and sham animals (A, C, E and $G$ ), at $3.8 \mathrm{~mm}$ posterior to bregma. 


\section{Discussion}

It has recently been hypothesized that IL-1 $\beta$ is crucially involved in seizure generation and epileptogenesis ${ }^{43}$. This hypothesis is supported by studies in which IL-1 $\beta$ was blocked during seizure generation, resulting in seizure suppression ${ }^{44-50}$. Several studies have shown that IL-1 $\beta$ is expressed in limbic structures immediately after a seizure ${ }^{1}$. This IL-1 $\beta$ either comes from outside the brain as a result of seizureinduced BBB leakage ${ }^{27}$ associated with altered expression of cell-adhesion molecules ${ }^{28}$, or is expressed by the brain upon $\mathrm{NF \kappa B}$ activation as response to release of HSPs during the seizure.

The question is whether IL-1 $\beta$ that is found after a seizure has critically contributed to the development of the seizure. Scientific evidence for that hypothesis is not yet conclusive ${ }^{1}$, but on a molecular basis there are reasons supporting this hypothesis because IL- $1 \beta$ has the ability to augment NMDA-R function, leading to increased $\mathrm{Ca}^{2+}$ influx, and to inhibited $\mathrm{K}^{+}$efflux; changes that have been shown to directly affect neuronal excitability and seizure susceptibility ${ }^{30,51-53}$.

The hypothesis that IL-1 $\beta$ is critically involved in seizure generation is based on the assumption that seizure-induced IL-1 $\beta$ is present for as long as necessary to create effects that ultimately result in a chronic epileptogenic state. The seizure-induced peak in IL-1 $\beta$ expression is found between 5 and 10 hours after a seizure after which it quickly decreases to disappear between 24 and 48 hours $^{6,54}$. In a number of studies, chronic IL-1 $\beta$ expression has been described as well, up to 8 days after trimetyltininduced seizures ${ }^{55}, 30$ days after sarin-induced seizures ${ }^{56}$ and in the latent phase three to seven days after status epilepticus induced by electrical stimulation of the ventral hippocampus ${ }^{57}$ as well as in the chronic phase $(60 \text { days })^{50}$.

In contrast to these four chronic studies, we did not find IL-1 $\beta$ expression 48 hours after a seizure in fully kindled animals. This time point was chosen specifically to avoid IL-1 $\beta$ expression that has been the result of excitotoxicity alone, and detect changes that are related to chronic seizure-induced NFKB activation or disruption of BBB integrity. The staining was not false negative because locally around the kindling/EEG electrodes some IL-1 $\beta$ immunopositive cells were found. Morphologically these cells resembled macrophages. In the negative controls these cells were not stained, and therefore we concluded that this signal was IL-1 $\beta$ specific. No other studies have been published in which IL-1 $\beta$ expression was determined 48 hours after a seizure in amygdala kindled animals. In only two other studies acute IL-1 $\beta$ expression in kindled rats was investigated, and the results of these studies are contradictory ${ }^{23,24}$ since both describe seizure-induced increases in IL-1 $\beta$ expression while $\mathrm{Yi}$ et al. also describe that if rats are kindled during the night, $I I-1 \beta$ is not expressed at all ${ }^{24}$.

The lack of IL-1 $\beta 48$ hours after a seizure suggests that both mechanisms for the induction and maintenance of IL-1 $\beta$ (NFKB and BBB leakage) are not actively present anymore. To further investigate this with regard to $\mathrm{NF \kappa B}$, we determined a second 
readout parameter for NFKB activation, namely CERT expression ${ }^{38}$. CERT transports ceramide from its production site the ER, to the Golgi ${ }^{19}$. It is a fundamental protein and is present in all CNS cells. The antibody used in the current study only detects neuronal CERT expression, as has been shown previously using double stainings with Neu-N, GFAP and Ox-42 ${ }^{58}$. In line with its fundamental role we observed basal CERT expression throughout the brains of both kindled and sham animals. Similar to our IL-1 $\beta$ findings, we did not observe any differences between kindled animals and shams regarding neuronal CERT expression either. Since the same brain tissue that was used in the current study has been used successfully for other immunohistochemistry studies before ${ }^{41}$ and because our lab is experienced in performing CERT immunohistochemistry ${ }^{58}$, we are convinced of the validity of our results in the current study. To our knowledge, no other studies have been published on CERT expression after seizures or epilepsy.

Future studies are aimed at studying BBB integrity and NFKB activation in the kindling model at different time-points after seizures. No data are currently available on BBB integrity after kindling, nor on $N F \kappa B$ expression. If $N F \kappa B$ appears to be upregulated, other NFKB-induced proteins and cascades than those related to IL-1 $\beta$ may have contributed to epileptogenesis. Perhaps these unidentified mechanisms also play a role in other experimental epilepsies, since seizures can occur in the absence of IL-1 $\beta$, as has been shown in two genetic epilepsy models ${ }^{59,60}$, and in one study using the kainate model ${ }^{61}$.

\section{Conclusion}

IL-1 $\beta$ nor CERT are chronically upregulated after a generalized seizure in fully kindled rats. Previous studies using seizure models that are associated with excitotoxic neuronal damage, suggest that seizure-induced IL-1 $\beta$ upregulation occurs as a result of HSP-induced activation of $\mathrm{NF \kappa B}$, and as a result of $\mathrm{BBB}$ disruption. Since kindling is not associated with excitotoxic neuronal damage, subsequent NFKB activation may not be present either. This hypothesis implies that other, currently unidentified mechanisms, may be responsible for epileptogenesis in this model. Further studies are necessary to elucidate these questions. 


\section{References}

1. Rijkers K, Majoie HJ, Hoogland G, Kenis G, De Baets M, Vles JS. The role of interleukin-1 in seizures and epilepsy: A critical review. Exp Neurol. 2009;216:258-71.

2. Vezzani A, Baram TZ. New roles for interleukin-1 Beta in the mechanisms of epilepsy. Epilepsy Curr. 2007;7:45-50.

3. Allan SM, Tyrrell PJ, Rothwell NJ. Interleukin-1 and neuronal injury. Nat Rev Immunol. 2005;5:629-40.

4. Dalton T, Pazdernik TL, Wagner J, Samson F, Andrews GK. Temporalspatial patterns of expression of metallothionein-I and -III and other stress related genes in rat brain after kainic acid-induced seizures. Neurochem Int. 1995;27:59-71.

5. Vezzani A, Conti M, De Luigi A, Ravizza T, Moneta D, Marchesi F, De Simoni MG. Interleukin-1beta immunoreactivity and microglia are enhanced in the rat hippocampus by focal kainate application: functional evidence for enhancement of electrographic seizures. J Neurosci. 1999;19:5054-65.

6. Eriksson C, Van Dam AM, Lucassen PJ, Bol JG, Winblad B, Schultzberg M. Immunohistochemical localization of interleukin-1 beta, interleukin-1 receptor antagonist and interleukin-1beta converting enzyme/caspase-1 in the rat brain after peripheral administration of kainic acid. Neuroscience. 1999;93:915-30.

7. Eriksson C, Tehranian R, Iverfeldt K, Winblad B, Schultzberg M. Increased expression of mRNA encoding interleukin-1beta and caspase-1, and the secreted isoform of interleukin-1 receptor antagonist in the rat brain following systemic kainic acid administration. J Neurosci Res. 2000;60: 266-79.

8. Eriksson C, Zou LP, Ahlenius S, Winblad B, Schultzberg M. Inhibition of kainic acid induced expression of interleukin-1 beta and interleukin-1 receptor antagonist mRNA in the rat brain by NMDA receptor antagonists. Brain Res Mol Brain Res. 2000;85:103-13.

9. Rizzi M, Perego C, Aliprandi M, Richichi C, Ravizza T, Colella D, Velískǒvá J, Moshé SL, De Simoni MG, Vezzani A. Glia activation and cytokine increase in rat hippocampus by kainic acid-induced status epilepticus during postnatal development. Neurobiol Dis. 2003;14:494-503.

10. Dinkel K, MacPherson A, Sapolsky RM. Novel glucocorticoid effects on acute inflammation in the CNS. J Neurochem. 2003;84:705-16.

11. Marini H, Altavilla D, Bellomo $M$, Adamo EB, Marini R, Laureanti $F$, Bonaccorso MC, Seminara $P$, Passaniti M, Minutoli L, Bitto A, Calapai G, Squadrito F. Modulation of IL-1 beta gene expression by lipid peroxidation inhibition after kainic acid-induced rat brain injury. Exp Neurol. 2004;188:178-86.

12. Marini H, Costa C, Passaniti M, Esposito M, Campo GM, lentile R, Adamo EB, Marini R, Calabresi P, Altavilla D, Minutoli L, Pisani F, Squadrito F. Levetiracetam protects against kainic acid-induced toxicity. Life Sci. 2004;74:1253-64.

13. Penkowa M, Florit S, Giralt M, Quintana A, Molinero A, Carrasco J, Hidalgo J. Metallothionein reduces central nervous system inflammation, neurodegeneration, and cell death following kainic acidinduced epileptic seizures. J Neurosci Res. 2005;79:522-34.

14. Ravizza T, Rizzi M, Perego C, Richichi C, Veliskova J, Moshe SL, De Simoni MG, Vezzani A. Inflammatory response and glia activation in developing rat hippocampus after status epilepticus. Epilepsia. 2005;46 Suppl 5:113-7.

15. Ravizza T, Vezzani A. Status epilepticus induces time-dependent neuronal and astrocytic expression of interleukin-1 receptor type I in the rat limbic system. Neuroscience. 2006;137:301-8.

16. Maelfait J, Vercammen E, Janssens S, Schotte P, Haegman M, Magez S, Beyaert R. Stimulation of Tolllike receptor 3 and 4 induces interleukin-1 beta maturation by caspase-8. J Exp Med. 2008;205: 1967-73.

17. Beg AA. Endogenous ligands of Toll-like receptors: implications for regulating inflammatory and immune responses. Trends Immunol. 2002;23:509-12.

18. Henshall DC, Murphy BM. Modulators of neuronal cell death in epilepsy. Curr Opin Pharmacol. 2008; 8:75-81.

19. Mencarelli C, Losen M, Hammels C, De Vry J, Hesselink MK, Steinbusch HW, De Baets MH, MartínezMartínez P. The ceramide transporter (CERT) and the Goodpasture antigen binding protein (GPBP). One protein - one function? J Neurochem. 2010;113:1369-86. 
20. Berg AT, Vickrey BG, Langfitt JT, Sperling MR, Walczak TS, Shinnar S, Bazil CW, Pacia SV, Spencer SS; Multicenter Study of Epilepsy Surgery. The multicenter study of epilepsy surgery: recruitment and selection for surgery. Epilepsia. 2003;44:1425-33.

21. McGonigal A, Bartolomei F, Régis J, Guye M, Gavaret M, Trébuchon-Da Fonseca A, Dufour $H$, Figarella-Branger D, Girard N, Péragut JC, Chauvel P. Stereoelectroencephalography in presurgical assessment of MRI-negative epilepsy. Brain. 2007;130:3169-83.

22. Bentivoglio M, Tassi L, Pech E, Costa C, Fabene PF, Spreafico R. Cortical development and focal cortical dysplasia. Epileptic Disord. 2003;5 Suppl 2:S27-34.

23. Plata-Salamán CR, llyin SE, Turrin NP, Gayle D, Flynn MC, Romanovitch AE, Kelly ME, Bureau Y, Anisman $\mathrm{H}$, Mclntyre DC. Kindling modulates the IL-1 beta system, TNF-alpha, TGF-beta1, and neuropeptide mRNAs in specific brain regions. Brain Res Mol Brain Res. 2000;75:248-58.

24. Yi PL, Tsai CH, Lin JG, Lee CC, Chang FC. Kindling stimuli delivered at different times in the sleepwake cycle. Sleep. 2004;27:203-12.

25. Sheng JG, Boop FA, Mrak RE, Griffin WS. Increased neuronal beta-amyloid precursor protein expression in human temporal lobe epilepsy: association with interleukin-1 alpha immunoreactivity. J Neurochem. 1994;63:1872-9.

26. Ravizza T, Boer K, Redeker S, Spliet WG, van Rijen PC, Troost D, Vezzani A, Aronica E. The IL-1beta system in epilepsy-associated malformations of cortical development. Neurobiol Dis. 2006;24: 128-43.

27. van Vliet EA, da Costa Araujo S, Redeker S, van Schaik R, Aronica E, Gorter JA. Blood-brain barrier leakage may lead to progression of temporal lobe epilepsy. Brain. 2007;130:521-34.

28. Fabene PF, Navarro Mora G, Martinello M, Rossi B, Merigo F, Ottoboni L, Bach S, Angiari S, Benati D, Chakir A, Zanetti L, Schio F, Osculati A, Marzola P, Nicolato E, Homeister JW, Xia L, Lowe JB, McEver RP, Osculati F, Sbarbati A, Butcher EC, Constantin G. A role for leukocyte-endothelial adhesion mechanisms in epilepsy. Nat Med. 2008;14:1377-83.

29. Balosso S, Maroso M, Sanchez-Alavez M, Ravizza T, Frasca A, Bartfai T, Vezzani A. A novel nontranscriptional pathway mediates the proconvulsive effects of interleukin-1beta. Brain. 2008;131: 3256-65.

30. Viviani B, Bartesaghi S, Gardoni F, Vezzani A, Behrens MM, Bartfai T, Corsini E, Di Luca M, Galli CL, Marinovich M. Interleukin-1beta enhances NMDA receptor-mediated intracellular calcium increase through activation of the Src family of kinases. J Neurosci. 2003;23:8692-700.

31. Dinarello CA. Biologic basis for interleukin-1 in disease. Blood. 1996;87:2095-147.

32. DeLorenzo RJ, Sun DA, Deshpande LS. Erratum to "Cellular mechanisms underlying acquired epilepsy: the calcium hypothesis of the induction and maintenance of epilepsy." [Pharmacol. Ther. 105(3) (2005) 229-266]. Pharmacol Ther. 2006;111:288-325.

33. Gawlowicz M, Reichert M, Wojcierowski J, Czuczwar SJ, Borowicz KK. Apoptotic markers in various stages of amygdala kindled seizures in rats. Pharmacol Rep. 2006;58:512-8.

34. Khurgel M, Switzer RC, 3rd, Teskey GC, Spiller AE, Racine RJ, Ivy GO. Activation of astrocytes during epileptogenesis in the absence of neuronal degeneration. Neurobiol Dis. 1995;2:23-35.

35. Brandt C, Ebert U, Loscher W. Epilepsy induced by extended amygdala-kindling in rats: lack of clear association between development of spontaneous seizures and neuronal damage. Epilepsy Res. 2004;62:135-56.

36. Osawa $\mathrm{M}$, Uemura S, Kimura $\mathrm{H}$, Sato $\mathrm{M}$. Amygdala kindling develops without mossy fiber sprouting and hippocampal neuronal degeneration in rats. Psychiatry Clin Neurosci. 2001;55:549-57.

37. Racine RJ. Modification of seizure activity by electrical stimulation. II. Motor seizure. Electroencephalogr Clin Neurophysiol. 1972;32:281-94.

38. Granero F, Revert F, Revert-Ros F, Lainez S, Martinez-Martinez P, Saus J. A human-specific TNFresponsive promoter for Goodpasture antigen-binding protein. FEBS J. 2005;272:5291-305.

39. Temel Y, Visser-Vandewalle V, van der Wolf M, Spincemaille GH, Desbonnet L, Hoogland G, Steinbusch HW. Monopolar versus bipolar high frequency stimulation in the rat subthalamic nucleus: differences in histological damage. Neurosci Lett. 2004;367:92-6.

40. Paxinos GW, C. The Rat brain in stereotaxic coordiates. fourth ed. London: Academic press; 1998.

41. Rijkers K, Aalbers M, Hoogland G, van Winden L, Vles J, Steinbusch H, Majoie M. Acute seizuresuppressing effect of vagus nerve stimulation in the amygdala kindled rat. Brain Res. 2010;1319: 155-63. 
42. van Dam AM, Poole S, Schultzberg M, Zavala F, Tilders FJ. Effects of peripheral administration of LPS on the expression of immunoreactive interleukin-1 alpha, beta, and receptor antagonist in rat brain. Ann N Y Acad Sci. 1998;840:128-38.

43. Vezzani A, Balosso S, Ravizza T. The role of cytokines in the pathophysiology of epilepsy. Brain Behav Immun. 2008;22:797-803.

44. Ravizza T, Noe F, Zardoni D, Vaghi V, Sifringer M, Vezzani A. Interleukin Converting Enzyme inhibition impairs kindling epileptogenesis in rats by blocking astrocytic IL-1beta production. Neurobiol Dis. 2008;31:327-33.

45. Ravizza T, Lucas SM, Balosso S, Bernardino L, Ku G, Noe F, Malva J, Randle JC, Allan S, Vezzani A. Inactivation of caspase-1 in rodent brain: a novel anticonvulsive strategy. Epilepsia. 2006;47:1160-8.

46. Donnelly $\mathrm{S}$, Loscher $\mathrm{CE}$, Lynch MA, Mills $\mathrm{KH}$. Whole-cell but not acellular pertussis vaccines induce convulsive activity in mice: evidence of a role for toxin-induced interleukin-1beta in a new murine model for analysis of neuronal side effects of vaccination. Infect Immun. 2001;69:4217-23.

47. Vezzani A, Moneta D, Richichi C, Aliprandi M, Burrows SJ, Ravizza T, Perego C, De Simoni MG. Functional role of inflammatory cytokines and antiinflammatory molecules in seizures and epileptogenesis. Epilepsia. 2002;43 Suppl 5:30-5.

48. Vezzani A, Moneta D, Conti M, Richichi C, Ravizza T, De Luigi A, De Simoni MG, Sperk G, AndellJonsson S, Lundkvist J, Iverfeldt K, Bartfai T. Powerful anticonvulsant action of IL-1 receptor antagonist on intracerebral injection and astrocytic overexpression in mice. Proc Natl Acad Sci U S A. 2000;97:11534-9.

49. Heida JG, Pittman QJ. Causal links between brain cytokines and experimental febrile convulsions in the rat. Epilepsia. 2005;46:1906-13.

50. De Simoni MG, Perego C, Ravizza T, Moneta D, Conti M, Marchesi F, De Luigi A, Garattini S, Vezzani A. Inflammatory cytokines and related genes are induced in the rat hippocampus by limbic status epilepticus. Eur J Neurosci. 2000; 12:2623-33.

51. Zhang R, Yamada J, Hayashi Y, Wu Z, Koyama S, Nakanishi H. Inhibition of NMDA-induced outward currents by interleukin-1beta in hippocampal neurons. Biochem Biophys Res Commun. 2008; 372:816-20.

52. Yang S, Liu ZW, Wen L, Qiao HF, Zhou WX, Zhang YX. Interleukin-1beta enhances NMDA receptormediated current but inhibits excitatory synaptic transmission. Brain Res. 2005;1034:172-9.

53. Zhu G, Okada M, Yoshida S, Mori F, Ueno S, Wakabayashi K, Kaneko S. Effects of interleukin-1beta on hippocampal glutamate and GABA releases associated with $\mathrm{Ca}(2+)$-induced $\mathrm{Ca}(2+)$ releasing systems. Epilepsy Res. 2006;71:107-16.

54. Voutsinos-Porche B, Koning E, Kaplan H, Ferrandon A, Guenounou M, Nehlig A, Motte J. Temporal patterns of the cerebral inflammatory response in the rat lithium-pilocarpine model of temporal lobe epilepsy. Neurobiol Dis. 2004;17:385-402.

55. Maier WE, Brown HW, Tilson HA, Luster MI, Harry GJ. Trimethyltin increases interleukin (IL)-1 alpha, IL-6 and tumor necrosis factor alpha mRNA levels in rat hippocampus. J Neuroimmunol. 1995;59: 65-75.

56. Chapman S, Kadar T, Gilat E. Seizure duration following sarin exposure affects neuro-inflammatory markers in the rat brain. Neurotoxicology. 2006;27:277-83.

57. Ravizza T, Gagliardi B, Noe F, Boer K, Aronica E, Vezzani A. Innate and adaptive immunity during epileptogenesis and spontaneous seizures: evidence from experimental models and human temporal lobe epilepsy. Neurobiol Dis. 2008;29:142-60.

58. Mencarelli C, Hammels C, Van Den Broeck J, Losen M, Steinbusch H, Revert F, Saus J, Hopkins DA, De Baets MH, Steinbusch HW, Martinez-Martinez P. The expression of the Goodpasture antigen-binding protein (ceramide transporter) in adult rat brain. J Chem Neuroanat. 2009;38:97-105.

59. Okada K, Yamashita U, Tsuji S. Cyclooxygenase system contributes to the maintenance of post convulsive period of epileptic phenomena in the genetically epileptic El mice. J Uoeh. 2006;28: 265-75.

60. Pereira MG, Gitai DL, Paco-Larson ML, Pesquero JB, Garcia-Cairasco N, Costa-Neto CM. Modulation of $\mathrm{B} 1$ and $\mathrm{B} 2$ kinin receptors expression levels in the hippocampus of rats after audiogenic kindling and with limbic recruitment, a model of temporal lobe epilepsy. Int Immunopharmacol. 2008;8:200-5.

61. Minami M, Kuraishi Y, Yamaguchi T, Nakai S, Hirai Y, Satoh M. Convulsants induce interleukin-1 beta messenger RNA in rat brain. Biochem Biophys Res Commun. 1990;171:832-7. 


\section{Chapter 4}

\section{Polymorphisms in CACNA1E and Camk2d are} associated with seizure susceptibility of Sprague Dawley rats

Rijkers K, Mescheriakova J, Majoie M, Lemmens E, Xander van Wijk, Philippens M, Van Kranen-Mastenbroek v, Schijns O, Vles J, Hoogland G 


\section{Abstract}

Seizures are associated with high intracellular calcium levels. However, conditions characterized by high intracellular calcium levels, such as stroke or traumatic brain injury, do not always evoke epilepsy. We hypothesized that polymorphisms in calcium-related genes CACNA1E and Camk2d contribute to the individual variability in seizure susceptibility.

The distribution of one single nucleotide polymorphism (SNP) in the CACNA1E gene and one in the Camk2d gene were determined in Sprague-Dawley rats that were subjected to amygdala kindling or hyperthermia-induced seizures.

The pre-kindling afterdischarge threshold was significantly lower in rats with the CACNA1E GG genotype $(45.2 \pm 6.7 \mu \mathrm{A})$ than in the GT genotyped animals $(79.3 \pm 53.7 \mu \mathrm{A})$. Among hyperthermia treated rats, the Camk2d G allele was more frequent among rats that did not display behavioral seizures during hyperthermia (67\%) than in animals that did show behavioral seizures during hyperthermia $(52 \%$, $\left.\chi^{2}(1)=3.847, p=0.05\right)$.

SNPs in CACNA1E and Camk2d genes are associated with individual variability in seizure susceptibility in two experimental seizure models. 


\section{Introduction}

Epileptogenesis, the process that transforms a normal brain into a hyperexcitable brain, is characterized by high intracellular calcium levels. While irreversible elevations in intracellular free calcium levels result in neuronal death, a prolongued but reversibly high intracellular calcium concentration in the first place lowers the threshold for neurons to depolarize, which results in lower seizure thresholds. This in turn can trigger pathological neuronal plasticity, leading to the development of epilepsy'. This hypothesis explains the induction and maintenance of acquired epilepsy, for instance after traumatic brain injury or stroke. Both conditions are associated with an increased risk of epilepsy, but it is not always clear why some patients develop epilepsy after stroke or traumatic brain injury, while the majority does not (http://www.who.int). Animal models also show individual differences in seizure-susceptibility. For instance, $65-96 \%$ of rat pups that are exposed to hyperthermia develop seizures and only $35 \%$ of these rats develop spontaneous epileptic seizures within 3 - 6 months $^{2-5}$. In an other model, the amygdala kindled (AK) rat, strain-specific and rat-specific variabilities in seizure susceptibility have been described as well ${ }^{6,7}$.

The aim of the current study was to investigate whether genetic differences in genes that are involved in calcium homeostasis are related to individual variability in seizure susceptibility. To investigate this, we have explored the occurrence of SNPs in calcium related genes among two rat models of provoked seizures that are not

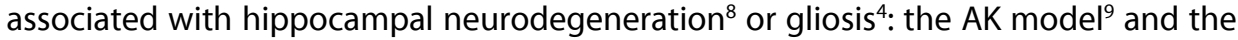
hyperthermia (HT) model ${ }^{5}$. The AK model was used to study both seizure susceptibility (using pre-kindling afterdischarge thresholds, pre-KADT) and vulnerability to epileptogenesis (using kindling rate), while the HT model was used to study seizure susceptibility only.

The Spague Dawley ${ }^{6 / m}$ (SD) rat genome probably contains thousands of SNPs, 53 of them have been characterized ${ }^{10}$. At least two of these SNPs are located in calciumrelated genes: the CACNA1E gene encoding the $\alpha 1$ e subunit of the voltage-gated calcium channel (VGCC) and the Camk2d gene that encodes the delta chain of calcium/calmodulin dependent kinase II (Camkll). Previous research in other epilepsy models has demonstrated altered expression levels of these proteins. For example, genetic absence epilepsy rats from Strassbourg (GEARS) and genetically epilepsy prone rats show an altered expression of the VGCC $\alpha 1$ e subunit ${ }^{11,12}$. In several other epilepsy models reduced CamKII expression was found during and immediately after seizures ${ }^{13-17}$ while CamKII is increasingly phosphorylated for several hours after status epilepticus ${ }^{18}$. So far, no studies have been published in which SNPs in the CACNA1E or Camk2d gene in relation to seizures or epilepsy have been analyzed. 


\section{Materials \& Methods}

\section{Animals}

Male SD rats, purchased from Harlan (Horst, the Netherlands), were kept under controlled conditions $\left(21 \pm 2{ }^{\circ} \mathrm{C}\right.$ ambient temperature, a 12 hour light/dark schedule, background noise provided by radio and food and water available ad libitum). The animals were allowed to adapt to the laboratory for one week before surgery or hyperthermia. All experimental procedures were approved by the animal ethics committee of Maastricht University and complied with governmental legislation.

\section{Amygdala kindling}

\section{Surgery}

The set of electrodes for kindling/EEG was implanted stereotactically (Dual Manipulator Lab Standard Stereotact, Stoelting Inc., Wood Dale, USA) as described previously ${ }^{7}$. Briefly, a bipolar platinum/iridium stimulating/recording electrode ${ }^{19}$ (designed by the department of Instrument Development, Engineering \& Evaluation of Maastricht University, Maastricht, The Netherlands) was implanted in the left basolateral amygdala (coordinates relative to bregma: $-2.5 \mathrm{~mm}$ posteriorly, $4.8 \mathrm{~mm}$ laterally, and $9.6 \mathrm{~mm}$ ventrally ${ }^{20}$ ) together with three monopolar stainless steel electrodes that were implanted in the cortex at $1 \mathrm{~mm}$ depth. One of these cortical electrodes was used for EEG, one for reference, and one for ground. The electrode connectors were fixed on the skull using dental acrylic.

\section{Amygdala kindling procedure}

Kindling was performed as described previously ${ }^{7}$. Briefly, ten days after surgery the pre-KADT was assessed. Pre-KADT, defined as the stimulus amplitude necessary to elicit a two-second discharge with a high frequency and high voltage on the amygdala electrode, was assessed by stimulating the amygdala with increasing intensitiy starting at $10 \mu \mathrm{A}(10 \mu \mathrm{A}$ increment and two-minute interstimulus interval). Stimuli were delivered at $50 \mathrm{~Hz}, 0.2 \mathrm{~ms}$ square wave using a WPI Accupulser A310 connected to a WPI Stimulus Isolation Unit A360 (World Precision Instruments, Sarasota, FL, USA). The EEG recordings from the amygdala and cortical electrodes were performed using a Vangard system (Vangard Systems, Cleveland Clinics Foundation, Cleveland, USA). Recordings were made with a sample frequency of 200 $\mathrm{Hz}$, frequency band of $0.5-70 \mathrm{~Hz}$ and with a $50 \mathrm{~Hz}$ notch filter.

Kindling started the following day by administering two stimuli per day (each stimulus two s, $50 \mathrm{~Hz}, 400 \mu \mathrm{A}, 0.2 \mathrm{~ms}$ square wave) to the amygdala, once between 8 and $10 \mathrm{am}$, and again between 2 and $4 \mathrm{pm}$ (interstimulus interval $\geq 6$ hours). All rats were video monitored and recorded (Minolta DiMage G400, Konica Minolta Inc., Tokyo, Japan) during delivery of the kindling stimulus and for as long as the 
behavioral seizure lasted. Videos were analyzed offline by two blinded observers who graded seizure severity according to Racine's scale ${ }^{9}$. Once the animals had reached the fully kindled state, i.e. five consecutive stage five seizures, they continued to receive one kindling stimulus a day for two more weeks. Finally post-KADT was assessed in a similar manner as the pre-KADT. The kindling rate was defined as the number of stimuli needed to reach the fully kindled state.

\section{Hyperthermia}

HT was induced as described previously ${ }^{3,5}$. Briefly, 9-day old male rat pups were placed in a cylinder into which a stream of heated air was blown causing an increase in core temperature to $41-42.5^{\circ} \mathrm{C}$. Core temperatures were measured before and every 2.5 min during the 30 min HT. As reported previously ${ }^{4,21,22}$ during HT exposure a subset of rats displayed behavioral seizures that were characterized by arrest of hyperkinesia, followed by falling to the side or back with body flexion and clonic contractions of the limbs (referred to as $\mathrm{HT}+$ ). This behavior has previously been shown to correlate with hippocampal EEG discharges ${ }^{5,23}$. Other rats did not display this stereotyped behavior and were referred to as HT-.

\section{Genotyping}

Rat tail specimens of about $0.5-1 \mathrm{~cm}(40-50 \mathrm{mg})$ were collected from sacrificed animals and stored at $-80^{\circ} \mathrm{C}$ until molecular analysis. Of the 53 SNPs that were found when two SD rats from Harlan were compared ${ }^{10,24}$, we selected one in the CACNA1E gene (SNP in intron 7 at position 13:069472098; RGSC v3.4, NCBI assay id: ss48531400) and one in the Camk2d gene (SNP in intron 6 at position 2:224024428; RGSC v3.4, NCBI assay id: ss48531499).

For SNP analysis, genomic DNA was extracted from the tail specimen using a Qiagen DNeasy ${ }^{\circledR}$ Tissue Kit (Qiagen, Hilden, Germany), which was then submitted to a PCRrestriction fragment length polymorphism (RFLP) protocol as follows: first, a PCR reaction was carried out in a volume of $50 \mu$ containing $200 \mathrm{ng}$ genomic DNA, $0.5 \mu \mathrm{M}$ of each primer, $0.2 \mathrm{mM}$ dNTPs, $1 \mathrm{U}$ Taq DNA polymerase (Roche Applied Sciences, The Netherlands), and 1x PCR buffer with $1.5 \mathrm{mM} \mathrm{MgCl}_{2}$ (for PCR conditions see Table 4.1). Next, SNP dependent fragments were generated by digestion of the PCR products with restriction endonucleases according to the manufacturer's recommendations (Table 4.2). Finally, the fragments were resolved by gel electrophoresis on a $3 \%$ agarose gel containing gel star, and visualized by UV light using a Biorad Geldoc 2000 system with Quantity One software (Figure 4.1).

\section{Statistical analysis}

Statistical analyses were performed using the Statistical Package for Social Sciences (SPSS) 16.0 for Mac software. The pre-KADT, $\triangle$ ADT (post-KADT minus pre-KADT expressed as percentage of pre-KADT) and kindling rate were calculated for each 
CACNA1E and CamK2 genotype carrier and for all 9 CACNA1E/Camk2d genotype combinations. Differences between genotype groups were analyzed using one-way ANOVA with a Games-Howell post-hoc test. Carrier differences were analyzed using a Mann Whitney U test.

To calculate if the genotype distribution differed between HT+ and HT- rats, the Likelihood Ratio was determined, and to assess if the allele frequency differed between HT+ and HT- rats we performed a Pearson's chi-square test and calculated odd's ratios.

Values are expressed as mean \pm standard deviations. A $p$ value $\leq 0.05$ was considered significant.

Table 4.1 Primer sequences and conditions for amplification of CACNA1E and Camk2d SNP flanking fragments.

\begin{tabular}{|c|c|c|c|c|c|c|c|}
\hline SNP & Forward & Reverse & Denaturation & PCR cycle & $\begin{array}{l}\text { No of } \\
\text { cycles }\end{array}$ & Extension & $\begin{array}{l}\text { Amplicon } \\
\text { size (bp) }\end{array}$ \\
\hline CACNA1E & $\begin{array}{l}\text { 5'ATA TTA } \\
\text { AGC CAG GCA } \\
\text { TाT GG-3' }\end{array}$ & $\begin{array}{l}\text { 5'-CTG GGC AGG } \\
\text { AAT GTA TGA G-3' }\end{array}$ & $\begin{array}{l}10 \mathrm{~min} \\
95^{\circ} \mathrm{C}\end{array}$ & $\begin{array}{l}45 \mathrm{~s} \\
94{ }^{\circ} \mathrm{C} \\
50 \mathrm{~s} \\
55^{\circ} \mathrm{C} \\
60 \mathrm{~s} \\
72{ }^{\circ} \mathrm{C}\end{array}$ & 35 & $\begin{array}{l}5 \mathrm{~min} \\
72^{\circ} \mathrm{C}\end{array}$ & 322 \\
\hline Camk2d & $\begin{array}{l}\text { 5'-CСА CTT } \\
\text { САT CTG TGT } \\
\text { TTA CCC-3' }\end{array}$ & $\begin{array}{l}5^{\prime}-\mathrm{AAA} \text { GGC ACA } \\
\text { TAA TCA CAT CG-3' }\end{array}$ & $\begin{array}{l}10 \mathrm{~min} \\
95^{\circ} \mathrm{C}\end{array}$ & $\begin{array}{l}45 \mathrm{~s} \\
94^{\circ} \mathrm{C} \\
50 \mathrm{~s} \\
59^{\circ} \mathrm{C} \\
60 \mathrm{~s} \\
72^{\circ} \mathrm{C}\end{array}$ & 35 & $\begin{array}{l}5 \mathrm{~min} \\
72{ }^{\circ} \mathrm{C}\end{array}$ & 421 \\
\hline
\end{tabular}

Table 4.2 CACNA1E and Camk2d SNP detection by restriction fragment length polymorphism.

\begin{tabular}{llccc} 
SNP & Restriction & \multicolumn{2}{c}{ Fragments $^{\mathrm{a}}(\mathrm{bp})$} \\
& endonuclease & $\mathrm{GG}$ & $\mathrm{GT}$ & $\pi$ \\
CACNA1E $^{\mathrm{b}}$ & Mael & $138,113,71$ & $209,138,113,71$ & 209,113 \\
Camk2d $^{c}$ & Msel & $163,115,86$, & $163,131,115,86$, & $131,115,86$, \\
& & 29,28 & $32,29,28$ & $32,29,28$
\end{tabular}

a fragments calculated from NCBI database sequences

${ }^{\mathrm{b}} \mathrm{G} / \mathrm{T}$ at position 142 of the amplicon (genomic location 13:069472098; NCBI assay id: s\$48531400)

${ }^{\mathrm{C}} \mathrm{G} / \mathrm{T}$ at position 189 of the amplicon (genomic location 2:224024428; NCBI assay id: ss48531499) 

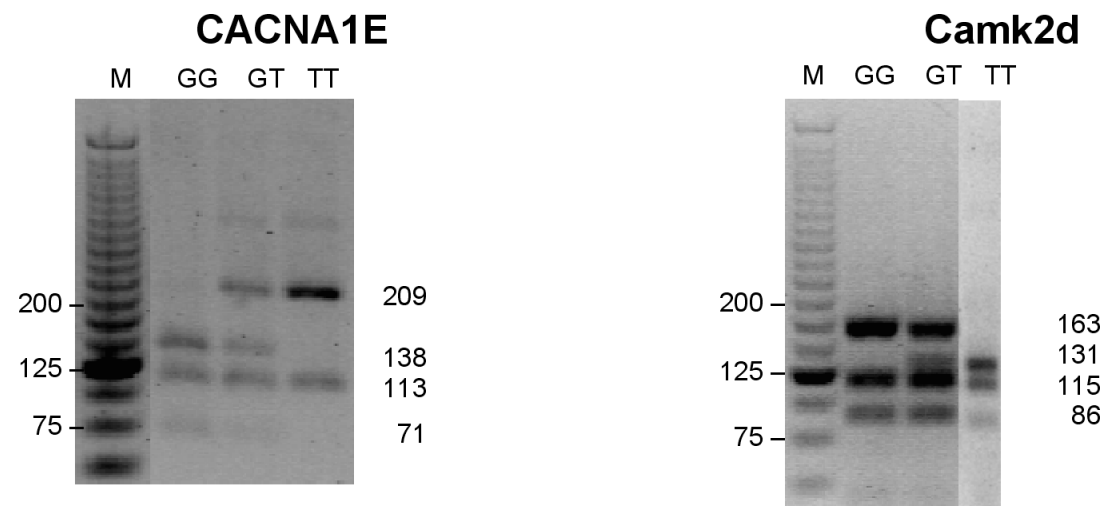

Figure 4.1 Representative agarose gels showing RFLP products visualized by UV and a digital camera connected to a computer with Quantity One software (Geldoc 2000, Biorad). M = marker, numbers indicate basepairs.

\section{Results}

\section{Amygdala kindling}

Forty-five rats were implanted with electrodes. Thirty-four were kindled and six served as sham. Histological analysis (haematoxylin-eosin) revealed that in all rats except five the kindling electrode was located inside the basolateral amygdala. The five rats in which the electrode was not inside the basolateral amygdala were excluded from analysis. In four kindled rats we were unable to determine the CACNA1E and Camk2d genotype.

\section{CACNATE}

The CACNA1E GT genotype was more common (67\%) than the $\Pi(22 \%)$ and GG (11\%) genotype. The pre-KADT was significantly lower in GG rats $(45.2 \pm 6.7 \mu \mathrm{A})$ than in GT rats $(79.3 \pm 53.7 \mu \mathrm{A}$, Figure $4.2 \mathrm{~A})$. There were no statistically significant differences between the three genotypes regarding $\triangle$ ADT or kindling rate. There were also no statistically significant differences between the occurrence of the $\mathrm{G}$ or $\mathrm{T}$ allele regarding pre-KADT, $\triangle$ ADT or kindling rate.

\section{Camk2d}

The GG and GT genotypes were most common (44 and 45\%, respectively) while TT occurred in $11 \%$ of the animals. There were no statistically significant differences between the three genotypes regarding pre-KADT (Figure 4.2B), $\triangle \mathrm{ADT}$ or kindling rate. There were also no statistically significant differences between the occurrence of the $\mathrm{G}$ or $\mathrm{T}$ allele regarding pre-KADT, $\triangle \mathrm{ADT}$ or kindling rate. 


\section{Combination of CACNA1E and Camk2d}

The GT (for CACNA1E) in combination with GT (for Camk2d) was most frequent (30\%), followed by $28 \%$ GT GG, $11 \%$ TT GT, $8 \%$ GG GG, $8 \%$ TT GG, 6\% GT TT, 3\% TT TT, $3 \%$ GG TT and 3\% GG GT. There were no statistically significant differences between the nine genotype combinations regarding pre-KADT, $\triangle$ ADT or kindling rate.
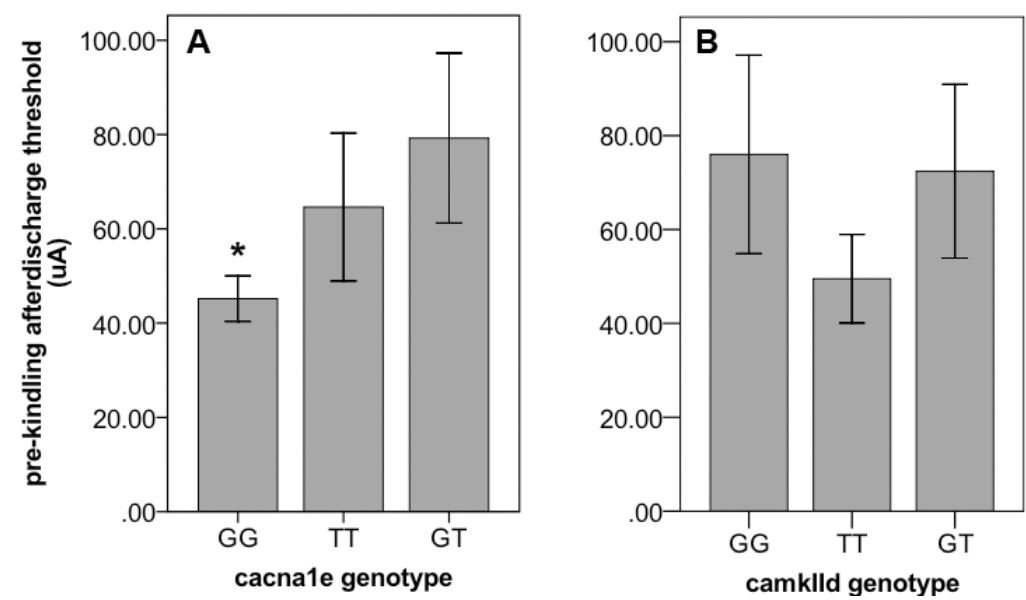

Figure 4.2 Average pre-KADT \pm standard deviation of CACNA1E (A) and Camk2d (B) GG, TT and GTgenotyped animals * $\mathrm{p}<0.05$ compared to GT.

\section{Hyperthermia-induced seizures}

In total 112 rats were included this experiment. In 20 cases we were unable to determine the CACNA1E or Camk2d genotype leaving 92 rats (26 HT+ and 66 HT-, Table 4.3).

\section{CACNATE}

The most common CACNA1E genotype was $\Pi$ ( $64 \%$ ), followed by GT (29\%) and GG (7\%). The genotype and carrier distribution were not different between HT+ and HTanimals (Table 4.3). Even though the $\mathrm{G}$ allele was more often associated with seizures after hyperthermia (41\%) than the T allele (25\%, odds ratio 2.01$)$, this difference did not reach the level of statistical significance.

\section{Camk2d}

The most common Camk2d genotype was GT (53\%), followed by GG (37\%) and TT (10\%). The Camk2d genotype distribution did not significantly differ between HT+ and HT- animals (Table 4.3). Regarding carrying frequency in HT+ animals the T allele was present in $48 \%$, while in HT- rats the T allele was present in $32 \%$, a difference that 
approaches the level of statistical significance $\left(\chi^{2}(1)=3.847, p=0.05\right)$. The odds ratios illustrate as well that in $\mathrm{HT}+$ rats the T allele is 2.0 times more likely to occur than the $\mathrm{G}$ allele. Vice versa, $37 \%$ of $\mathrm{T}$ allele carriers are $\mathrm{HT}+$ versus $23 \%$ of $\mathrm{G}$ allele carriers (odds ratio 1.9). Even though more $T$ carriers (34\%) than $G$ carriers (25\%, odds ratio 1.56) are $\mathrm{HT}+$, this difference is not statistically significant.

Table 4.3 Distribution of CACNA1E and Camk2d SNPs in hyperthermia rats without (HT-) and with $(\mathrm{HT}+)$ seizures.

\begin{tabular}{lccccc} 
SNP & \multicolumn{3}{c}{ Genotype } & Allele \\
CACNA1E & GG & TT & GT & G & T \\
HT- $(n=66)$ & & & & & \\
HT+ $(n=26)$ & $3(5)$ & $45(68)$ & $18(27)$ & $24(18)$ & $108(82)$ \\
Camk2d & $3(12)$ & $14(54)$ & $9(34)$ & $15(29)$ & $37(71)$ \\
HT- $(n=66)$ & & & & \\
HT+ $(n=26)$ & $28(42)$ & $4(6)$ & $34(52)$ & $90(68)$ & $42(32)^{\mathrm{a}}$ \\
& $6(23)$ & $5(19)$ & $15(58)$ & $27(52)$ & $25(48)$
\end{tabular}

Numbers indicate the frequencies of the genotypes, alleles and carriers of CACNA1E and Camk2d among $\mathrm{HT}+$ and $\mathrm{HT}$ - rats, in absolute numbers and percentages between brackets.

${ }^{\mathrm{a}} \chi^{2}(1)=3.847, \mathrm{p}=0.05$

\section{Combination of CACNA1E and Camk2d}

Amongst all HT rats the $\Pi \mathrm{GT}(30 \%)$ was most frequent, followed by $29 \% \pi \mathrm{TG}, 20 \%$ GT GT, 7\% GT GG, 5\% GT TT, 3\% TT TT, 3\% GG GG, 2\% GG TT and 1\% GG GT. No difference in genotype distribution were noted between $\mathrm{HT}+$ and HT- rats (Figure 4.3).

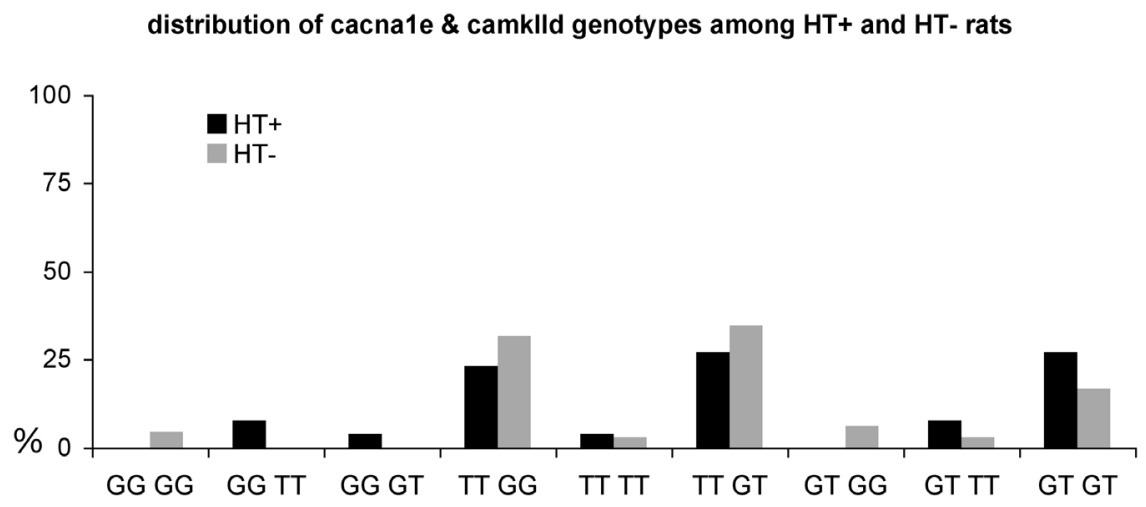

Figure 4.3 Distribution (\%) of the 9 possible combinations of CACNA1E and Camk2d genotype in animals that did ( $\mathrm{HT}+$ ) and animals that did not (HT-) display behavioural seizures during hyperthermia treatment. 


\section{Discussion}

In this study we analyzed the distribution of CACNA1E and Camk2d SNPs in two SD rat models for seizures. First of all we observed a large variability in CACNA1E genotype frequency between the two experimental groups. The AK population consisted of $67 \%$ GT genotyped animals, while $65 \%$ of the HT population was genotyped as $\Pi$. This is a remarkable finding considering the fact that all rats were obtained in a relatively short time period (between 2005 and 2008) and from the same company (Harlan, Horst, The Netherlands). An explanation may relate to the fact that animals used in the kindling experiments came from different litters than animals used in the HT experiments. Camk2d genotypes were equally distributed since in both studies GT was the most common genotype (45\% in AK and 53\% in HT), followed by GG (44\% in AK and 37\% in HT) and TT (both 11\%).

\section{CACNA1E}

In the current study we found that CACNA1E GG genotyped SD rats are characterized by a significantly lower pre-KADT than GT genotyped animals. The pre-KADT can be regarded as an indirect measure of seizure susceptibility. In order to develop seizures, the kindling-stimulus intensity has to be higher than the pre-KADT ${ }^{9}$. This implies that rats with a low pre-KADT require a lower stimulus intensity to become epileptic than rats with a high pre-KADT. Vulnerability to epileptogenesis was not associated with CACNA1E genotype since kindling rate was not significantly different among the three genotypes.

Previous studies have shown that pre-KADT is influenced by a number of factors including rat strain, sex, postoperative recovery time ${ }^{25}$ and the location of the stimulating electrode ${ }^{26}$. Since these factors were constant in the current study, it is tempting to suggest that the CACNA1E genotype can affect pre-KADT. The observations in the HT group are consistent with those in the AK group: even though not statistically significant, HT+ animals were more often GG genotyped, the G allele frequency was higher among HT+ rats (29\%) than among HT- rats (17\%), and the $\mathrm{G}$ allele was more often associated with $\mathrm{HT}+(41 \%)$ than the $\mathrm{T}$ allele $(25 \%$, odds ratio 2.01).

Phenotypes associated with the different CACNA1E genotypes are still to be identified. The intronic CACNA1E SNP can affect protein function in two ways. First of all it can induce alternative splicing of the mRNA. It fell beyond the scope of the current study, but future studies using quantified real-time PCR can further elucidate this. Secondly it is possible that the CACNA1E SNP itself is not responsible for the phenotype, because this SNP coincides with an other SNP (T/C) at the end of the CACNA1E amplicon, at 290 nucleotides from the currently analysed SNP. Of this second SNP the $C$ coincides with the $T$ of the first SNP. Based on our results it is 
unclear which one of these two SNPs functionally contributes to seizure susceptibility.

It has been shown that $\Pi$ genotyped humans are at higher risk of developing type II diabetes due to impaired insulin synthesis ${ }^{27}$. With regard to epilepsy the function of the VGCC $\alpha 1$ e subunit has not been elucidated and so far findings are contradictory. On the one hand the $\alpha 1$ e subunit of the VGCC is less expressed in GEARS ${ }^{11}$. On the other hand, VGCC $\alpha 1$ e upregulation is suggested to play a role in the mechanism underlying the increased seizure susceptibility of genetically epilepsy-prone rats ${ }^{12}$.

\section{Camk2d}

These data also show that SNPs in the Camk2d gene are associated with an increased seizure susceptibility since the T allele was found more often in HT+ than in HT-.

The phenotype of the intronic Camk2d SNP can affect protein function in the same two ways as were explained for CACNA1E: via alternative splicing or by coinciding with an other SNP. In contrast to the CACNA1E SNP, such a coinciding SNP has not been identified for the Camk2d SNP but may be present as well.

The Camkll protein has been investigated in relation to epilepsy in many different epilepsy models. These studies consistently show a reduced Camkll expression during and immediately after a seizure ${ }^{13-17}$. More recently it has been shown that Camkll is increasingly phosphorylated up to several hours after a status epilepticus ${ }^{18}$. No other traits associated with SNPs in the rat Camk2d gene have been reported so far, while a recent study has demonstrated Camkll involvement in neonatal seizures in rats, where a transient increase in Camkll is found after hypoxia-induced seizures ${ }^{28}$. In humans two polymorphisms of the Camk2d gene have been described. These polymorphisms have solely been investigated in relation to type II diabetes, where no relation was found ${ }^{29}$. It therefore remains to be determined what the phenotype of the SNP is and if this polymorphism contributes to seizure susceptibility.

\section{CACNA1E \& Camk2d}

Analyzing the combined CACNA1E and Camk2d genotypes revealed that none of the rats with the GG-GG combination and the GT-GG combination developed seizures after hyperthermia (Figure 4.3). This may indicate a protective effect of these genotype combinations, allthough the small number of rats with these genotypes ( $n=3$ for GG GG and $n=4$ for GT-GG) may have contributed to this finding as well. In the kindling model this analysis did not reveal any correlation between combined genotypes and seizure susceptibility. 


\section{Conclusion}

In this study we have shown that polymorphisms in the CACNA1E and Camk2d genes are associated with individual variability in seizure susceptibility in two experimental seizure models. Both SNPs are located in introns, and not in de coding DNA. Even though they could functionally contribute to the association that we found in the current study through alternative splicing, it is possible that these SNPs only represent markers for other linked and functional polymorphisms that remain to be demonstrated. Therefore, future studies must be aimed at replication of our findings and at elucidating the physiological phenotype associated with these SNPs, in order to get more insight in epileptogenesis. 


\section{References}

1. DeLorenzo RJ, Sun DA, Deshpande LS. Erratum to "Cellular mechanisms underlying acquired epilepsy: the calcium hypothesis of the induction and maintenance of epilepsy." [Pharmacol. Ther. 105(3) (2005) 229-266]. Pharmacol Ther. 2006;111:288-325.

2. Dube C, Richichi C, Bender RA, Chung G, Litt B, Baram TZ. Temporal lobe epilepsy after experimental prolonged febrile seizures: prospective analysis. Brain. 2006;129:911-22.

3. Lemmens EM, Lubbers T, Schijns OE, Beuls EA, Hoogland G. Gender differences in febrile seizureinduced proliferation and survival in the rat dentate gyrus. Epilepsia. 2005;46:1603-12.

4. Jansen JF, Lemmens EM, Strijkers GJ, Prompers JJ, Schijns OE, Kooi ME, Beuls EA, Nicolay K, Backes WH, Hoogland G. Short- and long-term limbic abnormalities after experimental febrile seizures. Neurobiol Dis. 2008;32:293-301.

5. Baram TZ, Gerth A, Schultz L. Febrile seizures: an appropriate-aged model suitable for long-term studies. Brain Res Dev Brain Res. 1997;98:265-70.

6. Loscher W, Cramer S, Ebert U. Differences in kindling development in seven outbred and inbred rat strains. Exp Neurol. 1998;154:551-9.

7. Rijkers K, Aalbers M, Hoogland G, van Winden L, Vles J, Steinbusch H, Majoie M. Acute seizuresuppressing effect of vagus nerve stimulation in the amygdala kindled rat. Brain Res. 2010;1319: 155-63.

8. Brandt C, Ebert U, Loscher W. Epilepsy induced by extended amygdala-kindling in rats: lack of clear association between development of spontaneous seizures and neuronal damage. Epilepsy Res. 2004;62:135-56.

9. Racine RJ. Modification of seizure activity by electrical stimulation. II. Motor seizure. Electroencephalogr Clin Neurophysiol. 1972;32:281-94.

10. Smits BM, Guryev V, Zeegers D, Wedekind D, Hedrich HJ, Cuppen E. Efficient single nucleotide polymorphism discovery in laboratory rat strains using wild rat-derived SNP candidates. BMC Genomics. 2005;6:170.

11. de Borman B, Lakaye B, Minet A, Zorzi W, Vergnes M, Marescaux C, Grisar T. Expression of mRNA encoding alpha1E and alpha1G subunit in the brain of a rat model of absence epilepsy. Neuroreport. 1999;10:569-74.

12. N'Gouemo P, Yasuda R, Faingold CL. Seizure susceptibility is associated with altered protein expression of voltage-gated calcium channel subunits in inferior colliculus neurons of the genetically epilepsy-prone rat. Brain Res. 2010;1308:153-7.

13. Bronstein JM, Micevych P, Popper P, Huez G, Farber DB, Wasterlain CG. Long-lasting decreases of type Il calmodulin kinase expression in kindled rat brains. Brain Res. 1992;584:257-60.

14. Kochan LD, Churn SB, Omojokun O, Rice A, DeLorenzo RJ. Status epilepticus results in an N-methylD-aspartate receptor-dependent inhibition of $\mathrm{Ca} 2+/$ calmodulin-dependent kinase II activity in the rat. Neuroscience. 2000;95:735-43.

15. Churn SB, Kochan LD, DeLorenzo RJ. Chronic inhibition of $\mathrm{Ca}(2+)$ /calmodulin kinase II activity in the pilocarpine model of epilepsy. Brain Res. 2000;875:66-77.

16. Blair RE, Sombati S, Churn SB, Delorenzo RJ. Epileptogenesis causes an N-methyl-d-aspartate receptor/Ca2+-dependent decrease in Ca2+/calmodulin-dependent protein kinase II activity in a hippocampal neuronal culture model of spontaneous recurrent epileptiform discharges. Eur J Pharmacol. 2008;588:64-71.

17. Singleton MW, Holbert WH, 2nd, Lee AT, Bracey JM, Churn SB. Modulation of CaM kinase II activity is coincident with induction of status epilepticus in the rat pilocarpine model. Epilepsia. 2005;46: 1389-400.

18. Gurd JW, Rawof S, Zhen Huo J, Dykstra C, Bissoon N, Teves L, Wallace MC, Rostas JA. Ischemia and status epilepitcus result in enhanced phosphorylation of calcium and calmodulin-stimulated protein kinase II on threonine 253. Brain Res. 2008;1218:158-65.

19. Temel Y, Visser-Vandewalle V, van der Wolf M, Spincemaille GH, Desbonnet L, Hoogland G, Steinbusch HW. Monopolar versus bipolar high frequency stimulation in the rat subthalamic nucleus: differences in histological damage. Neurosci Lett. 2004;367:92-6.

20. Paxinos GW, C. The Rat brain in stereotaxic coordiates. fourth ed. London: Academic press; 1998. 
21. Lemmens EM, Schijns OE, Beuls EA, Hoogland G. Cytogenesis in the dentate gyrus after neonatal hyperthermia-induced seizures: what becomes of surviving cells? Epilepsia. 2008;49:853-60.

22. Lemmens EM, Aendekerk B, Schijns OE, Blokland A, Beuls EA, Hoogland G. Long-term behavioral outcome after early-life hyperthermia-induced seizures. Epilepsy Behav. 2009;14:309-15.

23. Dube C, Chen K, Eghbal-Ahmadi M, Brunson K, Soltesz I, Baram TZ. Prolonged febrile seizures in the immature rat model enhance hippocampal excitability long term. Annals of neurology. 2000;47: 336-44.

24. Guryev V, Berezikov E, Cuppen E. CASCAD: a database of annotated candidate single nucleotide polymorphisms associated with expressed sequences. BMC Genomics. 2005;6:10.

25. $\mathrm{Ng} \mathrm{MS}$, Hwang $P$, Burnham WM. Afterdischarge threshold reduction in the kindling model of epilepsy. Epilepsy Res. 2006;72:97-101.

26. Racine RJ. Modification of seizure activity by electrical stimulation. I. After-discharge threshold. Electroencephalogr Clin Neurophysiol. 1972;32:269-79.

27. Holmkvist J, Tojjar D, Almgren P, Lyssenko V, Lindgren CM, Isomaa B, Tuomi T, Berglund G, Renström $\mathrm{E}$, Groop L. Polymorphisms in the gene encoding the voltage-dependent $\mathrm{Ca}(2+)$ channel $\mathrm{Ca}(\mathrm{V}) 2.3$ (CACNA1E) are associated with type 2 diabetes and impaired insulin secretion. Diabetologia. 2007;50:2467-75.

28. Rakhade SN, Zhou C, Aujla PK, Fishman R, Sucher NJ, Jensen FE. Early alterations of AMPA receptors mediate synaptic potentiation induced by neonatal seizures. J Neurosci. 2008;28:7979-90.

29. Gloyn AL, Desai M, Clark A, Levy JC, Holman RR, Frayling TM, Hattersley AT, Ashcroft SJ. Human calcium/calmodulin-dependent protein kinase II gamma gene (CAMK2G): cloning, genomic structure and detection of variants in subjects with type II diabetes. Diabetologia. 2002;45:580-3. 
Chapter 5

\section{Acute seizure-suppressing effect of vagus nerve stimulation in the amygdala kindled rat}

Rijkers K, Aalbers M, Hoogland G, van Winden L, Vles J, Steinbusch H, Majoie M Brain Research 2010;1319:155-163 


\section{Abstract}

Vagus nerve stimulation (VNS) is a moderately effective antiepileptic treatment. Clinically relevant animal models that are suitable to study the mechanism of action of VNS are not available. The aim of the current study was to develop a clinically relevant animal model for VNS-treated epilepsy that can be used to study the mechanism of action of VNS.

The anticonvulsive effect of VNS was studied in fully kindled rats by measuring behavioral and electrophysiological parameters. Afferent vagus nerve activation was confirmed by quantifying nNOS immunopositive cells in the nucleus of the solitary tract (NTS).

VNS rats had more nNOS immunopositive cells $/ \mathrm{mm}^{2}$ in the NTS than shams. VNS induced a $>25 \%$ decrease in stage 5 duration (S5D) in 32\% of rats. Prior to VNS this type of responders suffered from seizures with a longer total seizure duration (TSD) than non-responders. In $21 \%$ of rats VNS resulted in a $>25 \%$ decrease in TSD. This type of responders had a shorter TSD prior to VNS than non-responders. In $29 \%$ of rats VNS resulted in $>200 \%$ increase in stage 5 latency (S5L). This type of responders had higher kindling rates than non-responders.

We conclude that the VNS-treated kindled rat is a clinically relevant animal model because it is a chronic epilepsy model that responds to VNS with effects that are comparable to the effects of VNS in epilepsy patients. In addition, this study demonstrates that VNS-treated kindled rats can be used to study the mode of action of VNS using immunohistochemical techniques. 


\section{Introduction}

Vagus nerve stimulation (VNS) is a type of neuromodulation therapy that has been used to treat refractory epilepsy patients since $1988^{1}$. Average seizure frequency reduction is $12.8 \%$, while $11.7 \%$ of patients have $>50 \%$ seizure frequency reduction ${ }^{2-4}$. Besides this chronic effect on seizure frequency reduction observed after 3-6 months of VNS treatment, VNS has an acute seizure-suppressing effect as well. Acute activation of the pulse generator can abort $20 \%$ of seizures in patients who experience auras or simple partial seizures, while placebo-activation aborts approximately $10 \% \%^{5-7}$.

Even though VNS has been applied in a number of animal models ${ }^{8-25}$, including three studies in freely moving, awake animals suffering from experimental epilepsy ${ }^{17,18,22}$, a study using a clinically relevant animal model and experimental design has not been conducted so far.

The aims of the current study were to develop a clinically relevant animal model for VNS-treated epilepsy that can be used to study the mechanism of action of VNS, and to characterize rats that responded to VNS.

Therefore we applied VNS in fully amygdala kindled (AK) rats, and evaluated its acute seizure suppressing effect by measuring behavioral and electrophysiological parameters. The AK rat has been developed as an epilepsy model several years ago and has been used to study the effectiveness of several anti-epileptic drugs ${ }^{6}$. After establishing the effectiveness of VNS, responders were further analyzed regarding epilepsy-related parameters before VNS. To confirm afferent vagus nerve activation, we quantified neuronal NO synthetase (nNOS) immunoreactivity (ir) in the nucleus of the solitary tract (NTS), the primairy projection site of the vagal afferents.

\section{Experimental procedure}

\section{Animals}

Male, 12-weeks old adult Sprague-Dawley rats, purchased from Harlan (Horst, The Netherlands) were kept under controlled conditions $\left(21 \pm 2^{\circ} \mathrm{C}\right.$ ambient temperature, a 12 hour light/dark schedule, background noise provided by radio, and food and water available ad libitum). The animals were allowed to adapt to the laboratory for one week before surgery. All experimental procedures were approved by the animal ethics committee of Maastricht University and complied with governmental legislation. Adequate measures were taken to minimize pain and discomfort.

\section{Surgery}

Fifteen rats were implanted with a set of electrodes for kindling and EEG registration (AK; untreated controls). An additional group of thirty-three rats underwent surgery 
to implant two types of electrodes: one electrode for VNS and one set of kindling/EEG electrodes. Sixteen of these rats were kindled and treated with VNS (VNS), while 17 were kindled but not treated (sVNS). Thirty minutes prior to surgery all rats received $0.1 \mathrm{ml}$ buprenorfinehydrochloride (Temgesic ${ }^{\circledR}$, Schering-Plough Inc., Amstelveen, The Netherlands) subcutaneously for peri-operative pain relief. All surgical procedures were performed under general isoflurane anesthesia (5\% for induction and $2.5 \%$ for maintenance).

\section{Vagus nerve electrode}

A detailed description of the surgical procedure was published previously ${ }^{26}$. Briefly, the left carotid artery and vagus nerve were exposed. The vagus nerve was found on the surface of the carotid artery. A custom made circular bipolar electrode ( $P$. van Venrooij \& V. Duysens, Medtronic Bakken Research Center, Maastricht, The Netherlands) was wrapped around both carotid artery and vagus nerve.

\section{Electrodes for kindling/EEG}

A set of electrodes for kindling/EEG was implanted stereotactically (Dual Manipulator Lab Standard Stereotact, Stoelting Inc., Wood Dale, USA). This set consisted of a bipolar stimulating/recording electrode (Department of Instrument Development, Engineering \& Evaluation of Maastricht University \& Dr. Y. Temel, Maastricht, The Netherlands) that was implanted in the basolateral amygdala (coordinates relative to bregma: $-2.5 \mathrm{~mm}$ posteriorly, $4.8 \mathrm{~mm}$ laterally, and $9.6 \mathrm{~mm}$ ventrally ${ }^{27}$ ) and three monopolar stainless steel electrodes that were implanted in the cortex at $11 \mathrm{~mm}$ depth. One of these cortical electrodes was used for EEG, one for reference, and one for ground. Connectors for the kindling/EEG and VNS electrodes were fixed on the skull using dental acrylic.

\section{Amygdala kindling}

Ten days after surgery the pre-kindling afterdischarge threshold ADT (pre-KADT) was assessed in all rats by stimulating the amygdala with a series of pulses of increasing intensity starting at $10 \mu \mathrm{A}(50 \mathrm{~Hz}, 0.2 \mathrm{~ms}$ block pulse). Stimuli were delivered through a WPI Accupulser A310 connected to a WPI Stimulus Isolation Unit A360 (World Precision Instruments, Sarasota, FL, USA).

Kindling was started the next day. The amygdala was stimulated twice-a-day (first stimulus between 8 and 10 am, second stimulus between 2 and 4 pm; interstimulusinterval $>6$ hours) with a two-second $50 \mathrm{~Hz}$ stimulus ( $400 \mu \mathrm{A}, 0.2 \mathrm{~ms}$ block pulses). Seizure stage was determined based on Racine's five-point scale ${ }^{28}$. After five consecutive stage five seizures, the animals were considered to be fully kindled. Subsequently, the amygdala was stimulated once a day for two more weeks. 
All rats were videotaped (Minolta DiMage G400, Konica Minolta Inc., Tokyo, Japan) during delivery of the kindling stimulus and for as long as the behavioral seizure lasted. Videos were analyzed offline by two blinded observers who assessed kindling rate (number of stimuli needed to reach the fully kindled state), seizure severity based on Racine's scale, stage 5 duration (S5D) and stage 5 latency (S5L; the interval between kindling stimulus and start of the behavioral stage 5 seizure).

Twenty-four hours after the last kindling stimulus post-kindling ADT (post-KADT) was determined using the same method as described above for pre-KADT. The difference between pre-KADT and post-KADT was defined as $\triangle$ ADT.

\section{EEG analysis}

The EEG registrations from the amygdala and cortical electrodes were performed using a Vangard system (Vangard Systems, Cleveland Clinics Foundation, Cleveland, USA). Recordings were made with a sample frequency of $200 \mathrm{~Hz}$, frequency band of $0.5-70 \mathrm{~Hz}$ and with a $50 \mathrm{~Hz}$ notch filter.

Total seizure duration (TSD) was determined by a blinded observer and defined as the duration of rhythmic activity (spikes, sharp waves or slow waves) on the EEG. A seizure was considered to have ended when the frequency of the spikes, sharp waves or slow waves was $<0.1 \mathrm{~Hz}$.

Afterdischarge activity was determined as high frequency, high voltage activity in the amygdala following electrical stimulation. It was not per se accompanied by epileptiform activity in the cortex or amygdala, nor by epileptic behavior. ADT was defined as the stimulus amplitude necessary to elicit a 2-second discharge with a high frequency and high voltage.

\section{Vagus nerve stimulation}

For VNS, rats were connected to an external pulse-generator (Pulse ${ }^{\mathrm{TM}}$ Model 102 Generator, Cyberonics Inc., Houston, Texas) and stimulated with $30 \mathrm{~Hz}, 1.0 \mathrm{~mA}$ amplitude, 0.5 ms block pulses, using a 30s/12s ON/OFF cycle. VNS was administered for three minutes starting one minute prior to the last kindling stimulus. The sVNS rats were handled in exactly the same way as the VNS rats, apart from the fact that the current was not turned on in the sVNS group.

\section{Histology and immunohistochemistry}

Twenty-four hours after post-KADT determination (i.e. 48 hours after the last seizure), the rats received an overdose of pentobarbital (Nembutal), followed by perfusion with tyrode buffer (in mM: $136.9 \mathrm{NaCl}, 2.7 \mathrm{KCl}, 0.2 \mathrm{MgCl}_{2}, 11.9 \mathrm{NaHCO}_{3}, 0.3 \mathrm{NaH}_{2} \mathrm{PO}_{4}$, $\left.\begin{array}{llllll}5.0 & \text { glucose, equilibrated with } 30 \% & \mathrm{CO}_{2} / 70 \% & \mathrm{O}_{2}\end{array}\right)$, and then with $4 \%$ paraformaldehyde dissolved in 0.1 $\mathrm{M}$ phosphate buffer, $\mathrm{pH}$ 7.6. 
The brains were removed and postfixed in the same fixative $\left(4^{\circ} \mathrm{C}, 48 \mathrm{~h}\right)$, cryoprotected in $20 \%$ sucrose/ $0.1 \mathrm{M}$ phosphate buffer $\left(4^{\circ} \mathrm{C}, 24 \mathrm{~h}\right)$ and rapidly frozen and stored at $-80^{\circ} \mathrm{C}$ until further processing. The vagus nerve was exposed in order to visually check electrode position.

Coronal $10 \mu \mathrm{m}$ serial sections through the brainstem and hippocampus were cut on a cryostat, mounted on gelatin-coated glass slides, and stored at $-20^{\circ} \mathrm{C}$ until processing for (immuno)histochemistry.

\section{Histology}

Standard haematoxilyn-eosin ( $\mathrm{HE}$, Merck, Germany) staining of coronal sections containing the amygdala electrode was used to visualize the location of the electrode tip. The evaluation of the location of the electrode tip was based on a stereotaxic atlas ${ }^{27}$.

\section{Immunohistochemistry}

For nNOS immunohistochemistry, sections were rinsed in tris-buffered saline (TBS: $0.1 \mathrm{M}$ Tris-base, $0.15 \mathrm{M} \mathrm{NaCl}, \mathrm{pH}$ 7.4) and incubated overnight with anti-nNOS antibody (rabbit anti-nNOS, ImmunoStar, Inc., Hudson, WI, USA) diluted 1:400, followed the next day by incubation for 90 minutes with the secondary antibody (donkey anti-rabbit alexa 488, Invitrogen Inc., Eugene, Oregon, USA) diluted 1:100. Sections were rinsed in TBS and cover-slipped with $80 \%$ glycerol in TBS.

\section{Microscopic analysis}

Microscopic analysis of nNOS stained sections was performed with a MicroBrightField (MBF) Bioscience Stereo Investigator stereology system (MBF Bioscience Inc., Williston, VT, USA), consisting of a modified Olympus BX50 fluorescence microscope (Olympus, Tokyo, Japan) with Olympus UPlanApo objectives 10x (N.A.=0.40) and 20x (oil; N.A.=0.80), three-axis high-accuracy computer-controlled stepping motor specimen stage (4x4 Grid Encoded Stage; Ludl Electronic Products, Hawthorne, NY, USA), linear z-axis position encoder (Ludl), MBF-CX9000 CCD color camera (1.200x1.800 pixels) and controlling software (MBF Bioscience).

In 5 VNS rats and 5 sVNS rats the NTS was studied at levels between bregma -12.7 and $-13.1 \mathrm{~mm}$. In 9 remaining rats ( 3 VNS and 6 sVNS), the caudalmost portion of the brain stem (including the NTS) was not included in the brain stem slices and could not be analyzed. Every 10th section was analyzed with the Fractionator probe of the Stereolnvestigator software (MBF Bioscience Inc., Williston, VT, USA). The NTS was delineated and all nNOS ir cells in this area were counted and expressed as the number of cells per $\mathrm{mm}^{2}$. 


\section{Statistical analysis}

Statistical analysis was performed using SPSS v16.0 for MacOSX. In general, outliers were defined as values diverging more than two standard deviations from the mean and were excluded from further analysis. A p-value of $<0.05$ was considered statistically significant. Data are expressed as mean $\pm \mathrm{sd}$ or as median + range.

To assess rater reliability, the amount of measurement error for the two observers concerning S5D and seizure severity was determined by calculating the intraclass correlation coefficient $(\text { ICC })^{29}$ and the weighted kappa $\left(\kappa_{\omega}\right)^{30,31}$, respectively.

In order to estimate the treatment effect, S5D, TSD and S5L during VNS were expressed as percentage of their respective means over five preceding seizures. Additionally, the difference in average S5D, TSD, S5L, kindling rate, pre-KADT, postKADT and $\triangle A D T$ between the three experimental groups was statistically tested by a one-way ANOVA followed by the Games-Howell procedure as post-hoc test. Wilcoxon signed ranks test was used to compare pre-KADT and post-KADT.

Responders were identified as those rats that responded to VNS treatment by either a decrease in seizure severity based on Racine's scale, or $>25 \%$ decrease in TSD or S5D, or $>200 \%$ increase in S5L.

The difference in number of nNOS ir cells $/ \mathrm{mm}^{2}$ between VNS and sVNS rats was calculated using a Mann-Whitney $U$ test, and between the left and right NTS by Wilcoxon signed ranks test.

Responder characteristics were determined by comparing the average kindling rate, pre-KADT, post-KADT, $\triangle A D T, S 5 D, T S D$ and S5L between responders and nonresponders using the independent samples $t$-test for normally distributed values and the Mann-Whitney $U$ test for non-normally distributed values.

\section{Results}

Forty-eight rats were operated on. Seventeen rats did not complete the experiments because of anesthesia-related death $(n=2)$, severe post-operative dyspnea due to glottisedema $(n=2)$, loss of AK electrode $(n=9)$, defective AK electrode $(n=2)$, or not reaching the fully kindled state $(n=2)$. We observed left sided Horner's syndrome immediately after surgical placement of the vagus nerve electrode in 20 of 33 rats $^{5}$. Thirty-one rats (12 AK, 8 VNS and 11 sVNS) completed the experiments and were used for further analysis.

In all VNS-rats, the VNS electrode was located around the vagus nerve and carotid artery during post-mortem examination, while in 3 sVNS rats, the electrode was found detached from artery and nerve but still in close proximity to these structures. Kindling rates did not significantly differ between VNS rats ( $19 \pm 4$ stimuli), sVNS rats $(16 \pm 4)$ and $A K$ rats (16 \pm 5 stimuli). 


\section{VNS effects}

\section{Seizure severity}

The amount of measurement error for the two observers concerning seizure severity was low $\left(\kappa_{\omega}\right.$ 0.96). Seizure severity during VNS treatment (stage 5 ) did not differ from the average seizure severity of the 5 seizure preceding VNS (stage 5).

\section{Stage 5 duration}

Determination of S5D by two observers resulted in a low amount of measurement error (ICC 0.918). We therefore averaged the S5Ds of the two observations and used this number for analysis. The S5D of the five seizures preceding VNS or sham treatment did not significantly differ between VNS $(25 \pm 6)$, sVNS $(25 \pm 6)$ and AK rats ( $23 \pm 9$ s). Animals with $>25 \%$ reduced S5D upon VNS treatment were considered responders (S5D-responder), and represented $50 \%$ of VNS, $18 \%$ of sVNS and $9 \%$ of AK rats (Figure 5.1A). We attributed the S5D reductions in sVNS and AK rats as normal fluctuations, and the corrected responder rate in the VNS group was therefore $32 \%$. Further analysis of the S5D-responders in the VNS group showed that their average TSD prior to VNS was significantly longer than the TSD of non-responders (Table 5.1).

Table 5.1 Characteristics of S5D responders and S5D non-responders.

$\begin{array}{lccl}\text { factor } & \text { responder } & \text { non-responder } & \text { p-value } \\ \text { kindling rate } & 18 \mathrm{stimuli}(14-21) & 19.5 \text { stimuli }(15-26) & 0.77 \\ \text { pre-KADT } & 72.5 \mu \mathrm{A}(37.5-82.5) & 56.25 \mu \mathrm{A}(37.5-112.5) & 0.559 \\ \text { post-KADT } & 66.25 \pm 42.5 \mu \mathrm{A} & 37.5 \pm 13.22 \mu \mathrm{A} & 0.244 \\ \text { ADT change } & 7.5 \mu \mathrm{A}(-32.5-57.5) & 23.75 \mu \mathrm{A}(7.5-57.5) & 0.468 \\ \text { mean S5D } & 24.45 \mathrm{~s}(16.4-32.3) & 28.05 \mathrm{~s}(19.6-29) & 1 \\ \text { mean TSD } & 254.45 \pm 30.41 \mathrm{~s} & 113.85 \pm 30.16 \mathrm{~s} & 0.001\end{array}$

Differences between S5D responders and S5D non-responders regarding kindling rate, pre-kindling afterdischarge threshold (pre-KADT), post-kindling afterdischarge threshold (post-KADT), difference between pre- and post-KADT (ADT change), mean stage 5 duration prior to VNS treatment (mean S5D) and mean total seizure duration prior to VNS treatment (mean TSD). $\mu \mathrm{A}=$ micro Ampère, $\mathrm{s}=$ seconds. Values for responders and non-responders are either means \pm standard deviations (analysed with an independent-samples $t$-test), or medians with range (analysed with Mann-Whitney $U$ test). 2-tailed pvalue.

\section{Seizure duration}

The mean TSD prior to VNS or sham treatment did not significantly differ between VNS rats (184 $\pm 80 \mathrm{~s})$, sVNS rats (246 $\pm 66 \mathrm{~s})$ and AK rats (181 $\pm 76 \mathrm{~s})$. Animals with a $>25 \%$ reduced TSD upon VNS treatment were considered responders (TSDresponder), and represented $57 \%$ of VNS, $36 \%$ of sVNS, and $9 \%$ of AK rats Figure 5.1B). The TSD reductions in sVNS rats and AK rats were considered normal fluctuations in TSD. Therefore the corrected responder rate based on TSD reduction is $21 \%$. Further analysis of the TSD-responders in the VNS group showed that their 
average TSD prior to VNS was significantly shorter than that of non-responders (Table 5.2).

Table 5.2 Characteristics of TSD responders and TSD non-responders.

$\begin{array}{lccc}\text { factor } & \text { responder } & \text { non-responder } & \text { p-value } \\ \text { kindling rate } & 20.5 \pm 4.51 \text { stimuli } & 17 \pm 3 \text { stimuli } & 0.301 \\ \text { pre-KADT } & 56.25 \mu \mathrm{A}(37.5-82.5) & 62.5 \mu \mathrm{A}(37.5-125) & 0.719 \\ \text { post-KADT } & 27.5 \mu \mathrm{A}(25-40) & 95 \mu \mathrm{A}(35-110) & 0.074 \\ \text { ADT change } & 23.75 \mu \mathrm{A}(7.5-57.5) & 2.5 \mu \mathrm{A}(-32.5-12.5) & 0.157 \\ \text { mean S5D } & 28.05 \mathrm{~s}(16.4-29) & 29.6 \mathrm{~s}(19.3-32.3) & 0.289 \\ \text { mean TSD } & 134.5 \mathrm{~s}(86.8-218) & 266.6 \mathrm{~s}(244.2-289) & 0.034\end{array}$

Differences between TSD responders and TSD non-responders regarding kindling rate, pre-kindling afterdischarge threshold (pre-KADT), post-kindling afterdischarge threshold (post-KADT), difference between pre- and post-KADT (ADT change), mean stage 5 duration prior to VNS treatment (mean S5D) and mean total seizure duration prior to VNS treatment (mean TSD). $\mu \mathrm{A}=$ micro Ampère, $s=$ seconds. Values for responders and non-responders are either means \pm standard deviations (analysed with an independent-samples $t$-test), or medians with range (analysed with Mann-Whitney $U$ test). 2-tailed $p$ value.

\section{Stage 5 latency}

The mean S5L of the five seizures preceding VNS or sham treatment did not significantly differ between VNS ( $6 \pm 6 \mathrm{~s})$, sVNS ( $2 \pm 2 \mathrm{~s})$ and AK rats $(4 \pm 3 \mathrm{~s})$. After the last kindling stimulus, those rats that were treated with VNS had a longer S5L $(9 \pm 8 \mathrm{~s})$ than sVNS $(1 \pm 1 \mathrm{~s})$ and AK rats $(3 \pm 3 \mathrm{~s})$. There was a trend towards statistical significance between VNS treated rats and sVNS treated rats $(p=0.056)$.

Animals in which S5L increased with $>200 \%$ upon VNS treatment, were considered responders (S5L-responder), and represented 38\% of VNS, none of sVNS and $8 \%$ of AK rats (Figure 5.1C). The corrected responder rate based on $\mathrm{S} 5 \mathrm{~L}$ increase was therefore $30 \%$. Further analysis of S5L-responders in the VNS group showed that their kindling rate was significantly slower than that of non-responders (Table 5.3).

Table 5.3 Characteristics of S5L responders and S5L non-responders.

$\begin{array}{lccc}\text { factor } & \text { responder } & \text { non-responder } & \text { p-value } \\ \text { kindling rate } & 22.3 \mathrm{stimuli}(\text { range } 20-26) & 17 \mathrm{stimuli}(14-20) & 0.035 \\ \text { pre-KADT } & 62.5 \mu \mathrm{A}(37.5-82.5) & 62.5 \mu \mathrm{A}(37.5-125) & 0.651 \\ \text { post-KADT } & 25 \mu \mathrm{A}(25-35) & 55 \mu \mathrm{A}(30-110) & 0.051 \\ \text { ADT change } & 37.5 \mu \mathrm{A}(2.5-57.5) & 11 \mu \mathrm{A}(-32.5-57.5) & 0.549 \\ \text { mean S5D } & 27.4 \mathrm{~s}(16.4-29.6) & 28.7 \mathrm{~s}(19.3-32.3) & 0.655 \\ \text { mean TSD } & 218 \mathrm{~s}(112.8-244.2) & 156.2 \mathrm{~s}(86.8-289) & 0.881\end{array}$

Differences between S5L responders and S5L non-responders regarding kindling rate, pre-kindling afterdischarge threshold (pre-KADT), post-kindling afterdischarge threshold (post-KADT), difference between pre- and post-KADT (ADT change), mean stage 5 duration prior to VNS treatment (mean S5D) and mean total seizure duration prior to VNS treatment (mean TSD). $\mu A=$ micro Ampère, $s=$ seconds. Values for responders and non-responders are medians with range, and analysed with Mann-Whitney $U$ test). 2-tailed $p$-value. 


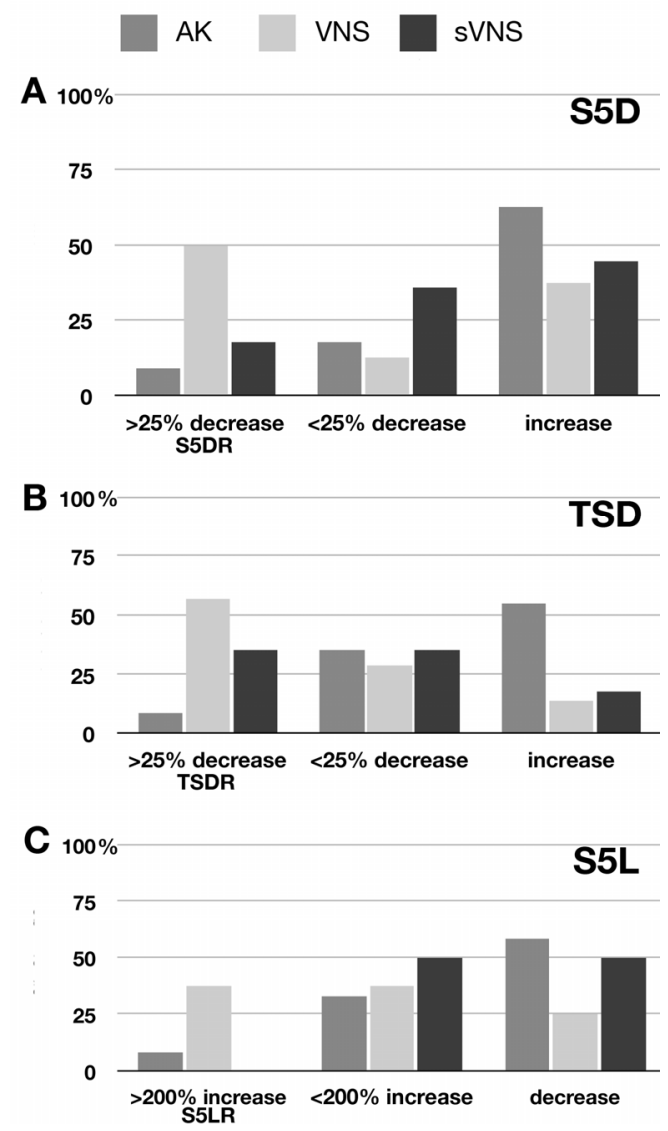

Figure 5.1 Distribution of responders.

Stage 5 duration responders (S5DR) were defined as rats that showed $>25 \%$ reduction in S5D after the last AK stimulus compared to the mean of the previous 5 S5D.

Total seizure duration responders (TSDR) were defined as rats that showed $>25 \%$ reduction in TSD after the last AK stimulus compared to the mean of the previous 5 TSD.

Stage five latency responders (S5LR) were defined as rats that showed $>200 \%$ increase in the latency period between kindling stimulus and start of the convulsive seizure compared to the mean of the previous $5 \mathrm{~S} 5 \mathrm{~L}$.

Y-axis: percentage of animals, X-axis: S5DR, TSDR and S5LR (>25\% decrease for S5D and TSD and $>200 \%$ increase for S5L) and S5D non-responders, TSD non-responders and S5L non-responders ( $<25 \%$ decrease and increase for TSD and S5D and $<200 \%$ decrease or increase for $\mathrm{S} 5 \mathrm{~L})$.

\section{Afterdischarge thresholds}

The pre-KADT did not differ between the three groups. Within each treatment group, the post-KADT was lower than pre-KADT (VNS: $p=0.03$, sVNS: $p=0.004$ and AK: $p=0.001)$. The post-KADT did not statistically differ between the experimental groups. 


\section{(Immuno)histochemistry}

HE staining revealed that in all animals, the kindling electrode tip was located in the amygdala.

VNS treated rats had more nNOS ir cells $/ \mathrm{mm}^{2}$ in the right NTS $(153,75-233)$ than sVNS treated rats $(100,43-142 ; \mathrm{p}<0.001)$. Similarly, higher nNOS ir cell density was found in the left NTS of VNS rats $(140,61-261)$ than in the left NTS of sVNS rats $(105,38-148$; $p<0.001$, Figures $5.2 \& 5.3)$.

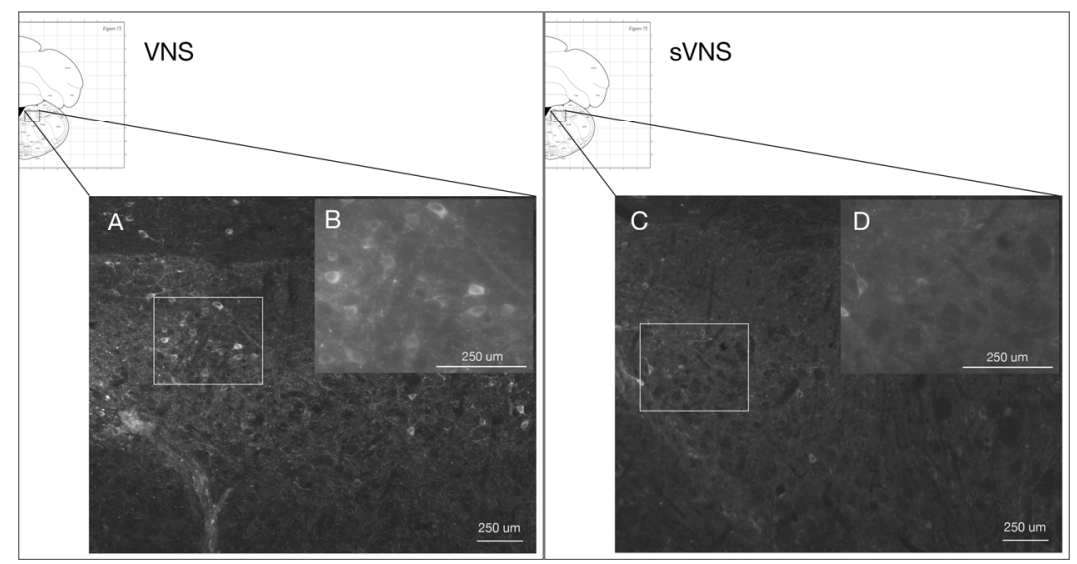

Figure 5.2 Photographs A and B show a relatively high background staining as well as nNOS stained neurons throughout the NTS, while $C$ and D show less background staining and less nNOS stained neurons.

nNOS immunohistochemistry of the left NTS at bregma -12.9

A: left NTS of a VNS treated rat at 10x magnification.

B: left NTS of a VNS treated rat at 40x magnification.

C: left NTS of a sVNS treated rat at 10x magnification.

D: left NTS of a sVNS treated rat at 40x magnification.

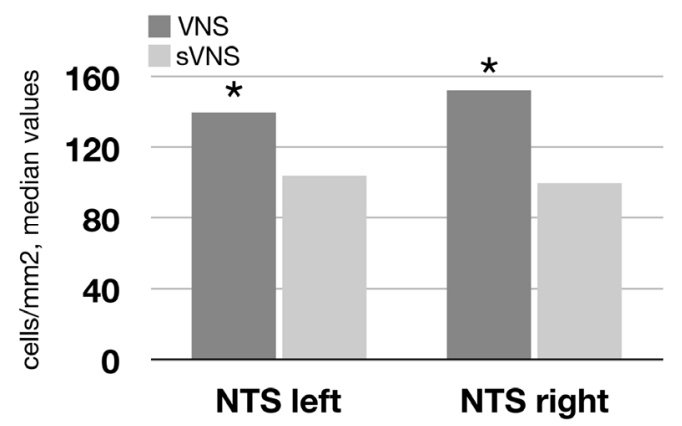

Figure 5.3 Median number of nNOS expressing cells in the nucleus of the solitary tract (NTS). $y$-axis: nNOS expressing cells in the NTS per $\mathrm{mm}^{2}$ of NTS, median values; $x$-axis: left and right NTS of VNS and sVNS treated rats. ${ }^{*}: p<0.001$, Mann Whitney $U$ 


\section{Discussion}

\section{Technical notes}

In humans VNS is performed with an electrode that is placed around the vagus nerve alone. In several studies using epileptic rats VNS has been applied in a similar way ${ }^{10,11,13.16,17,19,20,21,24}$. However, manipulation of the vagus nerve can lead to nerve damage, chronically followed by Wallerian degeneration of the axons and subsequent structural changes at the level of the NTS and dorsal motor nucleus of the vagus nerve ${ }^{32}$. To prevent this type of damage we chose to minimize the amount of nerve manipulation by wrapping the electrode around both the carotid artery and vagus nerve, a technique previously used by Folessa et al. ${ }^{33}$. Similar to Follesa et al., brain circulation was not measured in the current study. Therefore it is not know what the effect of placement of an electrode around the carotid artery alone is on brain circulation. Since we did not observe statistically significant differences on any of the epilepsy-related parameters between untreated controls and sham controls, we believe that placement of this electrode alone does not affect brain circulation in such a way that it influences seizure severity.

By minimizing the amount of vagus nerve manipulation, it was necessary to manipulate the surrounding structures. This led to the occurrence of Horner's syndrome in 20 of 33 rats, which did not affect the seizures ${ }^{26}$.

Similar to other studies that have described the anticonvulsive effect of VNS in epileptic rats $10,11,13,16,19,20,21$, we did not measure the electrode impedance prior to applying the VNS stimulus. The contact surface between electrode and vagus nerve in the current study is approximately $0.06 \mathrm{~mm}^{2}$, while in humans this is $7.2 \mathrm{~mm}^{2}$ (Cyberonics, Inc., Houston, Texas). The expected impedance in a correctly placed Pulse $^{\mathrm{TM}}$ Model 102 Generator (Cyberonics, Inc., Houston, Texas) system in humans is $<4 \mathrm{kOhm}$. Using the same pulse generator connected to a $0.06 \mathrm{~mm}^{2}$ electrode, an impedance value $>4 \mathrm{kOhm}$ can be expected. This measurement will therefore not inform us about the integrity of the system. Furthermore, measuring the impedance implicates that an electrical stimulus is applied. For methodological issues, the impedance should have been measured in both VNS and sVNS rats. This could have interfered with the immunohistochemical changes in the NTS that may have occurred as a result of the impedance stimulus.

The fact that we did not measure the impedance implies that it is unclear whether all rats received the exact same stimulation. In all rats, $1 \mathrm{~mA}$ was the maximally tolerated stimulus since at higher intensities they started to cough or vocalize.

\section{The effectiveness of acute VNS}

In humans, the effectiveness of an anticonvulsive treatment is quantified by measuring the seizure frequency using seizure diaries. In the kindling model as it was used in the current study, seizure frequency cannot be measured since the rats do 
not suffer from spontaneous seizures. When the kindling model is used to evaluate antiepileptic drugs, parameters such as seizure severity (according to Racine's scale), TSD, S5L and post-KADT are used to study an anticonvulsive effect. Here, we added 2 other new parameters: S5D and $\triangle$ ADT.

Pharmacological treatment with anti-epileptic drugs such as gabapentin and levetiracetam can reduce seizure stage in fully kindled rats ${ }^{34}$. We did not observe a decrease in seizure stage during VNS. Recently, Wyckhuys et al. were also unable to affect seizure stage in fully kindled rats using hippocampal deep brain stimulation ${ }^{35}$, a treatment option that can be effective in epilepsy patients ${ }^{36,37}$.

Our findings are in contrast with an earlier study on VNS in fully kindled rats, where 2 out of 6 rats showed suppression of a stage 5 seizure ${ }^{17}$. This difference may be explained by the rat strains that were used, since we used Sprague Dawley rats while Dedeurwaerdere et al. used a fast-kindling rat strain that was created through selective breeding. Fast and slow-kindling rats show large differences in their response to GABA-ergic drugs ${ }^{38}$. Similar differences in pharmacological response may play a role in the VNS effect as well. A second explanation may be related to VNS protocol: we used continuous cyclic stimulation of the vagus nerve starting one minute prior to the kindling stimulus and lasting until 2 minutes thereafter, while Dedeurwaerdere et al. stimulated the vagus nerve for 60 seconds, starting 2 minutes after the kindling stimulus ${ }^{17}$. We chose to start VNS prior to the kindling stimulus in an attempt to mimic the clinical situation, where the patient can activate the pulsegenerator when perceiving an upcoming seizure prior to generalization.

Although seizure stage was not affected, VNS reduced S5D with $>25 \%$ in $32 \%$ of the rats. This parameter has never been used to evaluate the effect of VNS, which may be related to the subjective interpretation of seizure behavior. By using two blinded, independent observers that showed low inter-observer variability we have shown that S5D can be used as an objective parameter to evaluate VNS treatment effects.

A second effect of VNS on seizure duration was found by electrophysiological measurement of TSD. In $21 \%$ of the VNS-treated rats we found $>25 \%$ reduction in TSD. This effect of VNS is modest compared to that of pharmacological treatments, in which often a TSD reduction of $>50 \%$ is seen in the majority of animals ${ }^{34}$.

Using a third, behavioral, parameter, we again found that VNS affected kindlinginduced seizures in a significant number of rats: $29 \%$ of the VNS-treated rats showed a $>200 \%$ increase in S5L. Similar effects were found after hippocampal deep brain stimulation in kindled rats $^{35}$, but not after VNS in AK rats in the study of Dedeurwaerdere et al. ${ }^{17}$. Again, the latter may be explained by differences in rat strain or in VNS protocol.

Here we identified treatment responders based on arbitrarily chosen effects, such as a $25 \%$ reduction in TSD and a $200 \%$ increase in S5L. Although this approach resulted in responder rates that are comparable to the effects in epilepsy patients, additional studies are necessary to validate these parameters. In epilepsy patients, a seizure 
frequency reduction of $>50 \%$ is used identify a responder. This parameter has been arbitrarily chosen as well, but has proven its effectiveness over the years.

Despite the differences in experimental setup, our results as well as those of Dedeurwaerdere et al. ${ }^{17}$ illustrate that acute VNS can affect different characteristic of a seizure, but it does not have the power to prevent or terminate a seizure in all fully kindled animals. This is partly in line with clinical practice where $10 \%$ of VNS treated patients can completely abort a seizure by acute activation of the VNS device, while more patients report on having a shorter seizure or shorter recovery time $e^{5-7}$.

The finding that different characteristics of a seizure can be affected by acute VNS suggests that chronic VNS may have more effects than seizure frequency reduction alone. Indeed, many patients that are designated as non-responder based on seizure frequency reduction report on beneficial effects of VNS on other seizure characteristics, such as seizure severity or recovery time. Possibly hampered by their subjective nature, these additional effects of VNS have been reported in a small number of prospective studies ${ }^{39,40}$.

\section{Afferent vagus nerve activation}

It is generally thought that the anticonvulsive effect of VNS is the result of afferent vagus nerve activation. We chose an immunohistochemical approach to confirm activation of afferent vagus nerve fibers instead of electrophysiology to avoid the risks associated with implanting an extra set of electrodes for recording purposes. Immunohistochemical detection of changes in neuronal activity is often done using markers such as c-fos, fos-b, or $\Delta$ fos-b. Indeed, c-fos staining of the NTS immediately after VNS has confirmed NTS activation ${ }^{9,41,42}$, while chronic cyclic VNS induces $\Delta$ FosB expression in the NTS ${ }^{41}$. In the current study we sacrificed the rats 48 hours after VNS. At this time point, c-fos is not present anymore ${ }^{41}$, while fos-b and $\Delta$ fos-b are less likely to be detected due to the short half life of fos-b and expected lack of accumulation of $\Delta$ fos-b after a single VNS stimulus in our study, respectively ${ }^{43}$. We therefore used nNOS, an enzyme that is known to be present under normal conditions in the NTS ${ }^{44,45}$. Its activity in the NTS increases between 2 and 10 days after manipulating the vagus nerve ${ }^{46}$, but not immediately after $\mathrm{VNS}^{41}$. In the current study we have shown that 48 hours after VNS, more nNOS-ir cells are present in the NTS of VNS treated rats than in that of sVNS rats.

\section{Responder identification}

VNS did not elicit a uniform anticonvulsive effect in the current study. Some animals displayed a reduced S5D, while others responded to VNS with a reduction in TSD or an increased S5L. According to the current standards of seizure frequency reduction, a minority of epilepsy patients responds to VNS ${ }^{2-4}$. Improved effectiveness may come from identifying responders prior to advancing with VNS. For this reason, we characterized responders based on behavioral and electrophysiological parameters 
that were measured prior to treatment. This analysis did not identify a single predictive parameter but learned that S5D-responders are characterized by a longer TSD, TSD-responders by a shorter TSD and S5L-responders by a slower kindling rate than non-responders. Future experiments in which similar VNS responder characterization studies are carried out may ultimately lead to clinical identification of suitable candidates for VNS.

\section{Conclusion}

The VNS-treated kindled rat is a clinically relevant animal model because it is a chronic epilepsy model that responds to VNS with a reduction in TSD and S5D, and an increase in S5L in a subpopulation of rats. These effects are comparable to the anticonvulsive effects of VNS in epilepsy patients. Future translational studies may identify responders and non-responders when analyzing more than seizure frequency reduction alone.

This study has furthermore shown that VNS-treated kindled rats can be used to study the mode of action of VNS using immunohistochemical techniques. Future studies must be aimed at identifying afferent vagus nerve projection nuclei that are critically involved in the anticonvulsive effect of VNS. Perhaps one of these is the optimal target for anticonvulsive or antiepileptic deep brain stimulation. 


\section{References}

1. Penry JK, Dean JC. Prevention of intractable partial seizures by intermittent vagal stimulation in humans: preliminary results. Epilepsia. 1990;31 Suppl 2:S40-3.

2. The Vagus Nerve Stimulation Group. A randomized controlled trial of chronic vagus nerve stimulation for treatment of medically intractable seizures. Neurology. 1995;45:224-30.

3. Handforth A, DeGiorgio CM, Schachter SC, Uthman BM, Naritoku DK, Tecoma ES, Henry TR, Collins SD, Vaughn BV, Gilmartin RC, Labar DR, Morris GL 3rd, Salinsky MC, Osorio I, Ristanovic RK, Labiner DM, Jones JC, Murphy JV, Ney GC, Wheless JW. Vagus nerve stimulation therapy for partial-onset seizures: a randomized active-control trial. Neurology. 1998 Jul;51(1):48-55.

4. Landy HJ, Ramsay RE, Slater J, Casiano RR, Morgan R. Vagus nerve stimulation for complex partial seizures: surgical technique, safety, and efficacy. J Neurosurg. 1993;78:26-31.

5. Ben-Menachem E, Mañon-Espaillat R, Ristanovic R, Wilder BJ, Stefan H, Mirza W, Tarver WB, Wernicke JF. Vagus nerve stimulation for treatment of partial seizures: 1. A controlled study of effect on seizures. First International Vagus Nerve Stimulation Study Group. Epilepsia. 1994;35:616-26.

6. Boon P, Vonck K, Van Walleghem P, D'Havé M, Goossens L, Vandekerckhove T, Caemaert J, De Reuck J. Programmed and magnet-induced vagus nerve stimulation for refractory epilepsy. J Clin Neurophysiol. 2001;18:402-7.

7. Morris GL 3rd. A retrospective analysis of the effects of magnet-activated stimulation in conjunction with vagus nerve stimulation therapy. Epilepsy Behav. 2003;4:740-5.

8. McLachlan RS. Suppression of interictal spikes and seizures by stimulation of the vagus nerve. Epilepsia. 1993;34:918-23.

9. Naritoku DK, Terry WJ, Helfert RH. Regional induction of fos immunoreactivity in the brain by anticonvulsant stimulation of the vagus nerve. Epilepsy Res. 1995;22:53-62.

10. Sunderam S, Osorio I, Watkins JF 3rd, Wilkinson SB, Frei MG, Davis RE. Vagal and sciatic nerve stimulation have complex, time-dependent effects on chemically-induced seizures: a controlled study. Brain Res. 2001;918:60-6.

11. Woodbury DM, Woodbury JW. Effects of vagal stimulation on experimentally induced seizures in rats. Epilepsia. 1990;31 Suppl 2:S7-19.

12. Zabara J. Inhibition of experimental seizures in canines by repetitive vagal stimulation. Epilepsia. 1992;33:1005-12.

13. Zagon A, Kemeny AA. Slow hyperpolarization in cortical neurons: a possible mechanism behind vagus nerve simulation therapy for refractory epilepsy? Epilepsia. 2000;41:1382-9.

14. Zanchetti A, Wang SC, Moruzzi G. The effect of vagal afferent stimulation on the EEG pattern of the cat. Electroencephalogr Clin Neurophysiol. 1952;4:357-61.

15. Zhang $\mathrm{JL}$, Zhang SP, Zhang HQ. Antiepileptic effect of electroacupuncture vs. vagus nerve stimulation in the rat thalamus. Neurosci Lett. 2008;441:183-7.

16. Zhang JL, Zhang SP, Zhang HQ. Antiepileptic effects of electroacupuncture vs vagus nerve stimulation on cortical epileptiform activities. J Neurol Sci. 2008;270:114-21.

17. Dedeurwaerdere S, Gilby K, Vonck K, Delbeke J, Boon P, Mclntyre D. Vagus nerve stimulation does not affect spatial memory in fast rats, but has both anti-convulsive and pro-convulsive effects on amygdala-kindled seizures. Neuroscience. 2006;140:1443-51.

18. Fernández-Guardiola A, Martínez A, Valdés-Cruz A, Magdaleno-Madrigal VM, Martínez D, FernándezMas R. Vagus nerve prolonged stimulation in cats: effects on epileptogenesis (amygdala electrical kindling): behavioral and electrographic changes. Epilepsia. 1999;40:822-9.

19. Krahl SE, Clark KB, Smith DC, Browning RA. Locus coeruleus lesions suppress the seizure-attenuating effects of vagus nerve stimulation. Epilepsia. 1998;39:709-14.

20. Krahl SE, Senanayake SS, Handforth A. Destruction of peripheral C-fibers does not alter subsequent vagus nerve stimulation-induced seizure suppression in rats. Epilepsia. 2001;42:586-9.

21. Krahl SE, Senanayake SS, Handforth A. Right-sided vagus nerve stimulation reduces generalized seizure severity in rats as effectively as left-sided. Epilepsy Res. 2003;56:1-4

22. Lockard JS, Congdon WC, DuCharme LL. Feasibility and safety of vagal stimulation in monkey model. Epilepsia. 1990;31 Suppl 2:S20-6. 
23. Muñana KR, Vitek SM, Tarver WB, Saito M, Skeen TM, Sharp NJ, Olby NJ, Haglund MM. Use of vagal nerve stimulation as a treatment for refractory epilepsy in dogs. J Am Vet Med Assoc. 2002;221: 977-83.

24. Takaya M, Terry WJ, Naritoku DK. Vagus nerve stimulation induces a sustained anticonvulsant effect. Epilepsia. 1996;37:1111-6.

25. Dedeurwaerdere S, Vonck K, Claeys P, Van Hese P, D'Have M, Grisar T, Naritoku D, Boon P. Acute vagus nerve stimulation does not suppress spike and wave discharges in "Genetic Absence Epilepsy Rats from Strasbourg". Epilepsy Res. 2004;59:191-8.

26. Aalbers MW, Rijkers K, van Winden LA, Hoogland G, Vles JS, Majoie HJ. Horner's syndrome: A complication of experimental carotid artery surgery in rats. Auton Neurosci. 2009;147:64-9.

27. Paxinos GW, C. The Rat brain in stereotaxic coordiates. fourth ed. London: Academic press; 1998.

28. Racine RJ. Modification of seizure activity by electrical stimulation. II. Motor seizure. Electroencephalogr Clin Neurophysiol. 1972;32:281-94.

29. Shrout PE, Fleiss JL. Intraclass correlations: uses in assessing rater reliability. Psychol Bull. 1979;86: 420-8.

30. Cohen J. A Coefficient of Agreement for Nominal Scales. Educational and Psychological Measurement. 1960;20:37-46.

31. Cohen J. Weighted kappa: nominal scale agreement with provision for scaled disagreement or partial credit. Psychol Bull. 1968;70:213-20.

32. Hopkins DA, Plumier JC, Currie RW. Induction of the $27-\mathrm{kDa}$ heat shock protein (Hsp27) in the rat medulla oblongata after vagus nerve injury. Exp Neurol. 1998;153:173-83.

33. Follesa P, Biggio F, Gorini G, Caria S, Talani G, Dazzi L, Puligheddu M, Marrosu F, Biggio G. Vagus nerve stimulation increases norepinephrine concentration and the gene expression of BDNF and bFGF in the rat brain. Brain Res. 2007;1179:28-34.

34. Loscher W, Reissmuller E, Ebert U. Anticonvulsant efficacy of gabapentin and levetiracetam in phenytoin-resistant kindled rats. Epilepsy Res. 2000;40:63-77.

35. Wyckhuys T, De Smedt T, Claeys P, Raedt R, Waterschoot L, Vonck K, Van den Broecke C, Mabilde C, Leybaert L, Wadman W, Boon P. High frequency deep brain stimulation in the hippocampus modifies seizure characteristics in kindled rats. Epilepsia. 2007;48:1543-50.

36. Boon P, Vonck K, De Herdt V, Van Dycke A, Goethals M, Goossens L, Van Zandijcke M, De Smedt T, Dewaele I, Achten R, Wadman W, Dewaele F, Caemaert J, Van Roost D. Deep brain stimulation in patients with refractory temporal lobe epilepsy. Epilepsia. 2007;48:1551-60.

37. Velasco AL, Velasco F, Velasco M, Trejo D, Castro G, Carrillo-Ruiz JD. Electrical stimulation of the hippocampal epileptic foci for seizure control: a double-blind, long-term follow-up study. Epilepsia. 2007;48:1895-903.

38. Mclntyre DC, Poulter MO, Gilby K. Kindling: some old and some new. Epilepsy Res. 2002;50:79-92.

39. Majoie HJ, Berfelo MW, Aldenkamp AP, Evers SM, Kessels AG, Renier WO. Vagus nerve stimulation in children with therapy-resistant epilepsy diagnosed as Lennox-Gastaut syndrome: clinical results, neuropsychological effects, and cost-effectiveness. J Clin Neurophysiol. 2001;18:419-28.

40. Shahwan A, Bailey C, Maxiner W, Harvey AS. Vagus nerve stimulation for refractory epilepsy in children: More to VNS than seizure frequency reduction. Epilepsia. 2009;50:1220-8.

41. Osharina V, Bagaev V, Wallois F, Larnicol N. Autonomic response and Fos expression in the NTS following intermittent vagal stimulation: Importance of pulse frequency. Auton Neurosci. 2006;126127:72-80.

42. Cunningham JT, Mifflin SW, Gould GG, Frazer A. Induction of c-Fos and DeltaFosB immunoreactivity in rat brain by Vagal nerve stimulation. Neuropsychopharmacology. 2008;33:1884-95.

43. McClung CA, Ulery PG, Perrotti LI, Zachariou V, Berton O, Nestler EJ. DeltaFosB: a molecular switch for long-term adaptation in the brain. Brain Res Mol Brain Res. 2004;132:146-54.

44. De Vente J, Hopkins DA, Markerink-Van Ittersum M, Emson PC, Schmidt HH, Steinbusch HW. Distribution of nitric oxide synthase and nitric oxide-receptive, cyclic GMP-producing structures in the rat brain. Neuroscience. 1998;87:207-41.

45. Hopkins DA, Biegel D, de Vente J, Steinbusch HWM. Vagal efferent projections: viscerotopy, neurochemistry and effects of vagotomy. Progress in Brain Research. 1996;107:18.

46. Gonzalez MF, Sharp FR, Sagar SM. Axotomy increases NADPH-diaphorase staining in rat vagal motor neurons. Brain Res Bull. 1987;18:417-27. 



\section{Chapter 6}

\section{Rat vagus nerve stimulation model of seizure suppression: $\mathrm{nNOS}$ and $\triangle \mathrm{fos} B$ changes}

Rijkers K, Majoie HJM, Aalbers MW, Philippens M, Doenni VM, Vles JSH, Steinbusch HMW, Moers-Hornikx VM, Hopkins DA, Hoogland G 


\section{Abstract}

Vagus nerve stimulation (VNS) is a moderately effective treatment for intractable epilepsy. However, the mechanism of action is poorly understood. The effect of VNS in amygdala kindled rats was investigated by studying changes in $\mathrm{nNOS}$ and $\triangle \mathrm{fos} B$ expression in primary and secondary vagus nerve projection nuclei: the nucleus of the solitary tract (NTS), dorsal motor nucleus of the vagus nerve (DMV), parabrachial nucleus (PBN) and locus coeruleus (LC).

Rats were fully kindled by stimulation of the amygdala. Subsequently, when full kindling was reached and then maintained for ten days, rats received a single three-minute train of VNS starting one minute prior to the kindling stimulus and lasting until two minutes afterwards. In control animals the vagus nerve was not stimulated. They were sacrificed 48 hours later. The brain stems were stained for neuronal nictric oxide synthetase (nNOS) and $\Delta$ fos $B$.

VNS decreased seizure duration with more than $25 \%$ in $21 \%$ of rats. No changes that could be attributed to VNS in nNOS immunoreactivity were observed in the NTS and no changes in $\triangle$ fos B were observed in the NTS, PBN or LC. High nNOS immunopositive cell densities of $>300$ cells $/ \mathrm{mm}^{2}$ were significantly more frequent in the left DMV than in the right $\left(\chi^{2}(1)=26.2, p<0.0001\right)$ independent of whether the vagus nerve was stimulated.

We concluded that the observed nNOS immunoreactivity in the DMV suggests surgery-induced axonal damage. A three-minute train of VNS in fully kindled rats does not affect $\Delta$ fos $B$ expression in primary and secondary projection nuclei of the vagus nerve. 


\section{Introduction}

Vagus nerve stimulation (VNS) has been used to treat refractory epilepsy patients since 1988'. The therapy consists of prolonged cyclic electrical stimulation of the vagus nerve and has a number of anticonvulsive effects. In the first place, it has a chronic effect of reducing seizure frequency. Controlled trials have shown $>50 \%$ seizure frequency reduction in $28-31 \%$ of patients in a treatment group versus $13-15 \%$ in a placebo group ${ }^{2,3}$. In addition, VNS reduces seizure severity and duration of the post-ictal phase $\mathrm{p}^{4,5}$. Moreover, approximately $10 \%$ of patients that experience partial onset seizures or auras prior to seizure onset can abort the seizure by ondemand activation of the stimulator ${ }^{6-8}$. The moderately ameliorating effects ${ }^{9}$, in combination with the positive side effects on mood and cognition ${ }^{10}$ result in the fact that the vast majority of epilepsy patients, in spite of a moderate effect on seizure frequency, asks for replacement when the end of battery life is near.

In spite of a consensus that VNS is moderately effective ${ }^{9}$ the mechanisms by which this is achieved are unknown. Other neuromodulation therapies that are currently used in treating patients with seizures include trigeminal nerve stimulation ${ }^{11}$ and deep brain stimulation of several different targets: the anterior thalamus ${ }^{12,13}$, subthalamic nucleus and substantia nigra pars reticulata ${ }^{14}$, hypothalamus ${ }^{15}$, zona incerta ${ }^{15}$, medial temporal lobe ${ }^{16}$, and centromedian nucleus of the thalamus ${ }^{17}$. These different targets for neuromodulation treatment result in similar anticonvulsive effectiveness. This raises the question as to whether these treatments, including VNS, are effective because they cause a nonspecific imbalance in an epileptic brain resulting in seizure frequency reduction, rather than causing specific deactivation of neuronal networks involved in seizure generation.

The vagus nerve is a complex nerve with visceral afferent, and somatomotor and autonomic efferent axons. Afferent axons ending in the nucleus of the solitary tract (NTS) represent $80 \%$ of vagal axons. The cell bodies of the efferent vagus nerve fibers originate in the dorsal motor nucleus of the vagus nerve (DMV) and nucleus ambiguus. Ninety percent of the afferents and $70 \%$ of efferents are unmyelinated C-fibers ${ }^{18}$. C-fiber activation is not required for obtaining an anticonvulsive effect ${ }^{19}$. This implies that only $14 \%$ of vagus nerve fibers, consisting of myelinated $A$ and $B$ fibers that are normally involved in mediating reflexes ${ }^{20}$, are responsible for the anticonvulsive effects. The anticonvulsive effects of VNS are attributed to orthodromic activation of afferent vagus nerve fibers, but because VNS activates all vagal axons, antidromic activation of efferent vagus nerve fibers may play a role as well.

The NTS, primary projection site of vagus nerve afferents, projects to both ipsilateral and contralateral NTS ${ }^{21}$. Inside the brainstem second order NTS neurons project monosynaptically to a number of other nuclei. The parabrachial nucleus (PBN) is a major target of the NTS ${ }^{22,23}$ that, in turn, relays information from the NTS to higher levels of the CNS. The NTS is also connected monosynaptically to the locus coeruleus 
$(\mathrm{LC})^{24}$, a nucleus that appears to be crucial in the establishment of the anticonvulsive effects of VNS ${ }^{25}$.

Neuroanatomical tracing studies have further demonstrated that the vagus nerve is directly and indirectly connected to limbic structures that are involved in epileptogenesis, such as the amygdala ${ }^{26,27}$ and the hippocampus ${ }^{28}$. Neuroimaging studies in humans ${ }^{29}$ and immunohistochemical ${ }^{30,31}$ and electrophysiological ${ }^{32}$ studies in animal models have demonstrated that VNS induces changes in direct and indirect projection nuclei of the vagus nerve.

These data suggest that VNS can affect epilepsy via its afferent connections. To investigate if this is the case we applied acute VNS in an animal model for chronic epilepsy, i.e., the amygdala kindled (AK) rat $^{33}$, in which we recently confirmed the acute seizure suppressing effect of $\mathrm{VNS}^{34}$. In the current study we analyzed the brain stems of these animals using neuronal nitric oxide synthetase (nNOS) and $\Delta$ fos $B$ immunohistochemistry.

The enzyme nNOS synthesizes nitric oxide (NO) from L-arginine. Amongst its many functions in the brain NO has a neurotransmitter role in the NTS ${ }^{35}$. Previous studies have shown nicotinamide adenine dinucleotide phosphate diaphorase (NADPH-d) ${ }^{36}$ and $\mathrm{nNOS}^{37,38}$ staining in the NTS, a signal that is quickly upregulated in vagal afferents and motorneurons, after vagus nerve manipulations ${ }^{37-40}$; nNOS immunoreactivity can therefore be used to detect changes in neuronal activation ${ }^{41}$. $\triangle \mathrm{FosB}$ is a highly stable FosB isoform that persists in the brain for several weeks after an initial stimulus ${ }^{42}$. It is one of the immediate early genes that can be used as immunohistochemical marker of neuronal activity and has been shown to be present bilaterally in the NTS after chronic VNS ${ }^{31}$.

The aims of the study were:

- To investigate the degree of vagus nerve surgery and vagus nerve stimulationinduced changes in the NTS and DMV by means of nNOS immunohistochemistry.

- To determine whether VNS-induced changes in neuronal activation occur in the NTS, PBN and the LC, by means of $\triangle$ fos B immunohistochemistry.

\section{Materials and Methods}

\section{Animals}

Male 12-weeks old Sprague-Dawley (SD) rats purchased from Harlan (Horst, The Netherlands) were housed under controlled conditions $\left(21 \pm 2^{\circ} \mathrm{C}\right.$ ambient temperature, a 12 hour light/dark schedule, background noise provided by radio, and ad libitum food and water). Adequate measures were taken to minimize pain and discomfort. All experimental procedures were conducted in accordance with international standards as defined by the European Communities Council Directive 
of November $24^{\text {th }} 1986$ and approved by the Animal Ethics Committee of Maastricht University.

\section{Surgery}

In total, 63 rats were implanted with kindling/EEG electrodes. A subgroup of 33 rats was implanted with an electrode for VNS as well. In this subgroup, both procedures were performed in the same surgery session in which the VNS electrode was implanted first. Thirty minutes prior to surgery all rats received $0.1 \mathrm{ml}$ buprenorphine hydrochloride (Temgesic ${ }^{\circledR}$, Schering-Plough Inc., Amstelveen, The Netherlands) for peri-operative pain relief. All surgical procedures were performed under general isoflurane anesthesia ( $5 \%$ for induction and $2.5 \%$ for maintenance).

\section{Vagus nerve surgery}

Detailed descriptions of the custom made circular bipolar electrode (Medtronic Bakken Research Center, Maastricht, The Netherlands) and surgical procedure were published previously ${ }^{43}$. Briefly, the left carotid artery and vagus nerve were exposed in the neck. The vagus nerve was identified on the surface of the carotid artery and the electrode was wrapped around the nerve and artery, a technique successfully used by others as well $131,44,45$.

\section{Kindling/EEG surgery}

The set of electrodes for kindling/EEG was implanted stereotaxically (Dual Manipulator Lab Standard Stereotaxic, Stoelting Inc., Wood Dale, IL, USA). The amygdala stimulating/recording electrode ${ }^{46}$ (Department of Instrument Development, Engineering \& Evaluation of Maastricht University) was implanted in the left basolateral amygdala with stereotaxic coordinates relative to bregma: $-2.5 \mathrm{~mm}$ posteriorly, $4.8 \mathrm{~mm}$ laterally, and $9.6 \mathrm{~mm}$ ventrally derived from Paxino ${ }^{47}$ ). Three monopolar stainless steel electrodes were implanted in the cerebral cortex at $1 \mathrm{~mm}$ depth. One of three $3.8 \mathrm{~mm}$ laterally on the right and $2.5 \mathrm{~mm}$ posteriorly to bregma, was used for EEG, one $4.8 \mathrm{~mm}$ laterally to the left and $5 \mathrm{~mm}$ posterior to bregma for reference, and one $3.8 \mathrm{~mm}$ laterally on the right and $5 \mathrm{~mm}$ posterior to bregma for ground. Connectors for the kindling/EEG and VNS electrodes were fixed on the skull using jeweler screws and dental acrylic.

\section{Amygdala kindling}

As described previously ${ }^{34}$, ten days after surgery the pre-kindling afterdischarge threshold (pre-KADT) was assessed in all rats (Figure 6.1). The pre-KADT was defined as the stimulus amplitude necessary to elicit a two-second discharge with a high frequency and high voltage in the amygdala. For this, the amygdala was stimulated with a series of pulses delivered at an interstimulus interval of two minutes using 
steps of $10 \mu \mathrm{A}$ starting at $10 \mu \mathrm{A}(50 \mathrm{~Hz}, 0.2 \mathrm{~ms}$ square wave delivered by a WPI Accupulser A310 connected to a WPI Stimulus Isolation Unit A360 (World Precision Instruments, Sarasota, FL, USA).

Kindling was started the next day (Figure 6.1) with a two-second $50 \mathrm{~Hz}$ stimulus (400 $\mu \mathrm{A}, 0.2 \mathrm{~ms}$ square wave pulses). $400 \mu \mathrm{A}$ was chosen as stimulus intensity since it was at least $200 \%$ above pre-KADT for all rats. The amygdala was stimulated twice per day (first stimulus between 8 and 10 am, second stimulus between 2 and 4 pm; interstimulus interval at least 6 hours). Seizure stage was determined based on Racine's five-point scale ${ }^{48}$ in which stage one seizures are characterized by unilateral eye closure (mild facial clonus), stage two by bilateral eye closure and chewing (severe facial clonus), stage three by unilateral forelimb clonus, stage four by rearing and stage five by loss of balance and falling. After five consecutive stage five seizures, the animals were considered fully kindled. Subsequently, the amygdala was stimulated once per day for two more weeks. Sham-kindled rats were handled in exactly the same way as the kindled animals, but did not receive the kindling stimulus.

All rats were videotaped (Minolta DiMage G400, Konica Minolta Inc., Tokyo, Japan) during delivery of the kindling stimulus and for as long as the behavioral seizure lasted. Videos were analyzed offline by two blinded observers who assessed seizure stage based on Racine's scale.

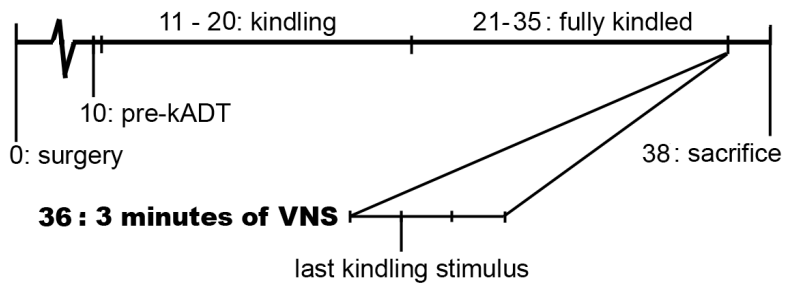

Figure 6.1 Time line in days illustrating the series of experiments.

\section{EEG analysis}

The EEG recordings from the amygdala and cortex were made using a Vangard system (Vangard Systems, Cleveland Clinic Foundation, Cleveland, USA). Recordings were made with a sample frequency of $200 \mathrm{~Hz}$, frequency band of $0.5-70 \mathrm{~Hz}$ and with a $50 \mathrm{~Hz}$ notch filter. The total seizure duration was determined by a blinded observer and defined as the duration of rhythmic activity (spikes, sharp waves or slow waves) on the EEG. A seizure was considered to have ended when these wave forms occurred less than once per ten seconds. The VNS-induced effect on total seizure 
duration was determined as follows: seizure duration during VNS was expressed as the percentage of the average seizure duration of the five preceding seizures.

\section{Vagus nerve stimulation}

For VNS, rats were connected to an external pulse generator (Pulse ${ }^{\mathrm{TM}}$ Model 102 Generator, Cyberonics Inc., Houston, Texas) and stimulated with $30 \mathrm{~Hz}, 1.0 \mathrm{~mA}$ amplitude, $0.5 \mathrm{~ms}$ square waves, using a 30s/12s ON/OFF cycle. VNS was administered for three minutes starting one minute prior to the last kindling stimulus, and continuing for two minutes thereafter (Figure 6.1). This stimulation paradigm mimics the clinical situation where a patient with partial onset seizures or an aura prior to seizure onset can acutely activate the pulse-generator to stop further seizure progression?

\section{Experimental groups}

Rats were divided into four experimental groups and were handled in exactly the same way: 1) rats that were kindled $(A K, n=12), 2)$ rats that were implanted with an amygdala electrode and in which pre-KADT was measured, but that were not kindled (sham AK; sAK, $n=8$ ), 3) kindled rats that were treated with VNS (VNS, $n=8$ ), and 4) kindled rats that were implanted with a VNS electrode, but not received actual electrical stimulations through this electrode (sham VNS, sVNS, $n=11$ ).

\section{Histology and immunohistochemistry}

Forty-eight hours after the last seizure the rats received an overdose of pentobarbital (Nembutal) followed by transcardial perfusion with tyrode buffer (in mM: $136.9 \mathrm{NaCl}$, 2.7 KCl, $0.2 \mathrm{MgCl}_{2}, 11.9 \mathrm{NaHCO}_{3}, 0.3 \mathrm{NaH}_{2} \mathrm{PO}_{4}, 5.0$ glucose, equilibrated with $5 \% \mathrm{CO}_{2} /$ $95 \% \mathrm{O}_{2}$ ), and then with fixative (4\% paraformaldehyde in $0.1 \mathrm{M}$ phosphate buffer, $\mathrm{pH}$ 7.6).

The brains were removed and postfixed in the same fixative $\left(4^{\circ} \mathrm{C}, 48 \mathrm{~h}\right)$, cryoprotected in $20 \%$ sucrose $/ 0.1 \mathrm{M}$ phosphate buffer at $\left(4^{\circ} \mathrm{C}, 24 \mathrm{~h}\right)$ and rapidly frozen and stored at $80^{\circ} \mathrm{C}$ until further processing. The vagus nerve was exposed in order to confirm the electrode position.

Coronal $10 \mu \mathrm{m}$ serial sections through the brain stem from the level of the central canal - fourth ventricle junction (bregma -13.6) caudally to the level of the inferior colliculus (bregma -9.6) rostrally were cut on a cryostat, mounted on gelatin-coated glass slides, and stored at $-20^{\circ} \mathrm{C}$.

Standard haematoxylin-eosin (Merck, Germany) staining was used to identify the location of the tip of the kindling electrode. 


\section{nNOS immunohistochemistry}

For nNOS immunohistochemistry, sections were rinsed in Tris-buffered saline containing $0.3 \%$ Triton (TBS-T) and incubated 24 hours with rabbit anti-nNOS antibody (ImmunoStar, Inc., Hudson, WI, USA) diluted 1:400 in TBS-T. The next day sections were rinsed in TBS-T and incubated for 90 minutes with donkey anti-rabbit antibody conjugated to Alexa 488 (Invitrogen Inc., Eugene, Oregon, USA) diluted 1:100 in TBS-T. Sections were rinsed with Tris-buffered saline (TBS), and coverslipped with $80 \%$ glycerol in TBS.

\section{$\triangle$ fos B immunohistochemistry}

For $\Delta$ fos $B$ immunohistochemistry, sections were rinsed in TBS-T, and incubated 48 hours at $4^{\circ} \mathrm{C}$ with rabbit polyclonal antibody against mouse fos B (sC - 48, Santa Cruz Biotechnology Inc., Santa Cruz, CA, USA) diluted 1:250 in TBS-T containing $0.5 \%$ bovine serum albumin. Next, sections were rinsed in TBS-T, and incubated overnight with the donkey-anti rabbit biotinylated secondary antibody (Jackson ImmunoResearch Laboratories Inc., West Grove, PA, USA) diluted 1:400 in TBS-T containing $0.5 \%$ bovine serum antigen. The next day, sections were rinsed, incubated for 2 hours with avidin/biotin (Vectastain ABC-kit, Vector Laboratories Inc., Burlingame, CA, USA) diluted 1:800. Immunohistochemical staining was visualized using diaminobenzidine and $0.5 \% \mathrm{NiCl}$.

The primary antibody was omitted for some sections to confirm specificity of immunohistochemical staining for both antibodies.

\section{Stereology for nNOS stained sections}

nNOS ir cell densities in the NTS and DMV were analyzed in VNS and sVNS animals using a MBG Bioscience Stereo Investigator system (MBF Bioscience; Williston, VT, USA). The system consisted of an Olympus BX50 fluorescence microscope (Olympus, Tokyo, Japan) with an Olympus UPlanApo 20x (oil; N.A. $=0.80$ ) objective, a three-axis high-accuracy computer-controlled stepping motor specimen stage (4x4 Grid Encoded Stage; Ludl Electronic Products, Hawthorne, NY, USA), a linear z-axis position encoder (Ludl Electronic Products, Hawthorne, NY, USA), a CX9000 CCD color camera (1.200x1.800 pixels; MBF Bioscience) and controlling and Stereolnvestigator software (MBF Bioscience). Every 10th section was analyzed with the Fractionator probe. The NTS ( 10 sections, 4 animals per group) and DMV ( 8 sections, 4 animals per group) were delineated in sections between bregma -12.5 and $-13.6 \mathrm{~mm}$. All nNOS immunopositive cells in the delineated areas were counted. In the NTS the following subnuclei were analyzed separately as well: central subnucleus (cNTS), medial subnucleus (mNTS), oval subnucleus (oNTS), ventrolateral subnucleus (vINTS), parvocellular subnucleus (pcNTS) and the dorsomedial subnuclei (dmNTS). These NTS subnuclei were identified according to the parcellations of 
Altschuler et al. ${ }^{21}$ and the results of differential staining after lesions of the vagus nerve ${ }^{41}$. Cell densities were calculated by dividing the number of immunopositive neurons by the cross-sectional area of the relevant parts of the NTS at 20x magnification.

\section{$\triangle$ FosB immunopositive cell counts}

$\triangle$ FosB immunopositive cell densities in the NTS (5-6 animals per group), PBN (3-6 animals per group) and LC (5-6 animals per group) of AK, sAK, VNS and sVNS rats were estimated as follows. The three regions were photographed in every $10^{\text {th }}$ section at $4 x$ magnification. The NTS was studied between bregma -11.7 and -14 ( 10 sections), the PBN between bregma -9.6 and -9.9 ( $\sim 3$ sections) and the LC between bregma -9.6 and -10.5 ( 8 sections) with an Olympus AX-70 microscope connected to a digital camera (DP70; Olympus, Tokyo, Japan). In these photographs the areas of interest were delineated and immunopositive neurons were counted using $\mathrm{NIH}$ ImageJ software (http://rsb.info.nih.gov/ij/). A cell was counted as $\Delta$ FosB positive if its density was $75 \%$ higher than background density, a method previously used for counting C-Fos positive cells ${ }^{49}$. The same black/white threshold conditions were used for all sections. Cell densities were calculated by dividing the number of immunopositive neurons by the area of the selected nuclei.

\section{Statistical analysis}

Statistical analysis was performed using SPSS v16.0 for MacOSX. Values are expressed as means \pm standard deviations.

Differences in nNOS immunopositive cell densities in the NTS and DMV between VNS and sVNS rats were analyzed using a Mann-Whitney $U$ test. Differences between left and right were calculated using a Wilcoxon signed ranks test. Pearson Chi-Square test and odds ratios were used to calculate whether a high DMV nNOS cell density of $>300$ cells $/ \mathrm{mm}^{2}$ was more frequent in either left or right DMV.

Differences in $\triangle$ FosB immunopositive neuron densities in the NTS, PBN and LC between AK, SAK, VNS and sVNS animals were analyzed using a Kruskal-Wallis test, followed by Mann-Whitney $U$ tests on selective comparisons (with adapted critical significance levels) as post-hoc tests. Differences between left and right were calculated using a Wilcoxon signed-rank test.

The correlation between $\triangle$ FosB immunopositive cell density in the NTS, PBN and LC and the response to VNS was analyzed using Spearman's correlation coefficient. 


\section{Results}

Of the 63 rats that were operated on, twenty-four rats did not complete the experiments due to surgery related, anesthesia related and hardware complications, while 39 rats completed the experiments. After implanting the VNS electrode, 20 of 33 rats had Horner's syndrome ${ }^{43}$, which has also been reported as a complication of VNS in humans ${ }^{50}$. Postmortem visual inspection confirmed that the VNS electrode was located around the vagus nerve and carotid artery in all VNS animals, while in three sVNS rats the electrode was detached from artery and nerve, although still in close proximity to these structures.

In all 39 cases that were processed for immunohistochemistry the tip of the kindling electrode was located in the left basolateral amygdala according the rat stereotaxic atlas ${ }^{47}$.

All kindled rats were fully kindled after $17 \pm 4$ stimuli, i.e. range of 7-10 days. Kindling rates did not differ significantly between VNS rats (19 \pm 4 stimuli), sVNS rats $(16 \pm 4)$ and kindled rats (16 \pm 5 stimuli).

\section{Anticonvulsive effect of VNS}

Animals with a greater than $25 \%$ reduction in total seizure duration after VNS treatment were considered responders. Responders represented $57 \%$ of VNS, $36 \%$ of sVNS, and $9 \%$ of kindled rats.

\section{Histochemistry and immunohistochemistry}

nNOS

VNS rats showed a higher density of nNOS immunopositive cells throughout the NTS (Figure 6.2) and DMV (Figure 6.3) than sVNS rats, but these differences did not reach the level of statistical significance. VNS responders did not significantly differ from non-responders either. nNOS immunopositive cells were found throughout the NTS and DMV bilaterally in all groups. The DMV contained large nNOS immunopositive cells while the nNOS immunopositive cells in the NTS were smaller. The nNOS immunopositive cells were not evenly distributed over the whole NTS. We observed a high density of clustered immunopositive cells in some subnuclei, while other subnuclei showed few scattered nNOS immunopositive cells (Figure 6.2). There were no statistically significant differences in nNOS immunopositive cell density between VNS and sVNS animals in the cNTS (Figures 6.2 A-D), mNTS, oNTS, vINTS, pcNTS and dmNTS (Figures 6.2 E-H). 

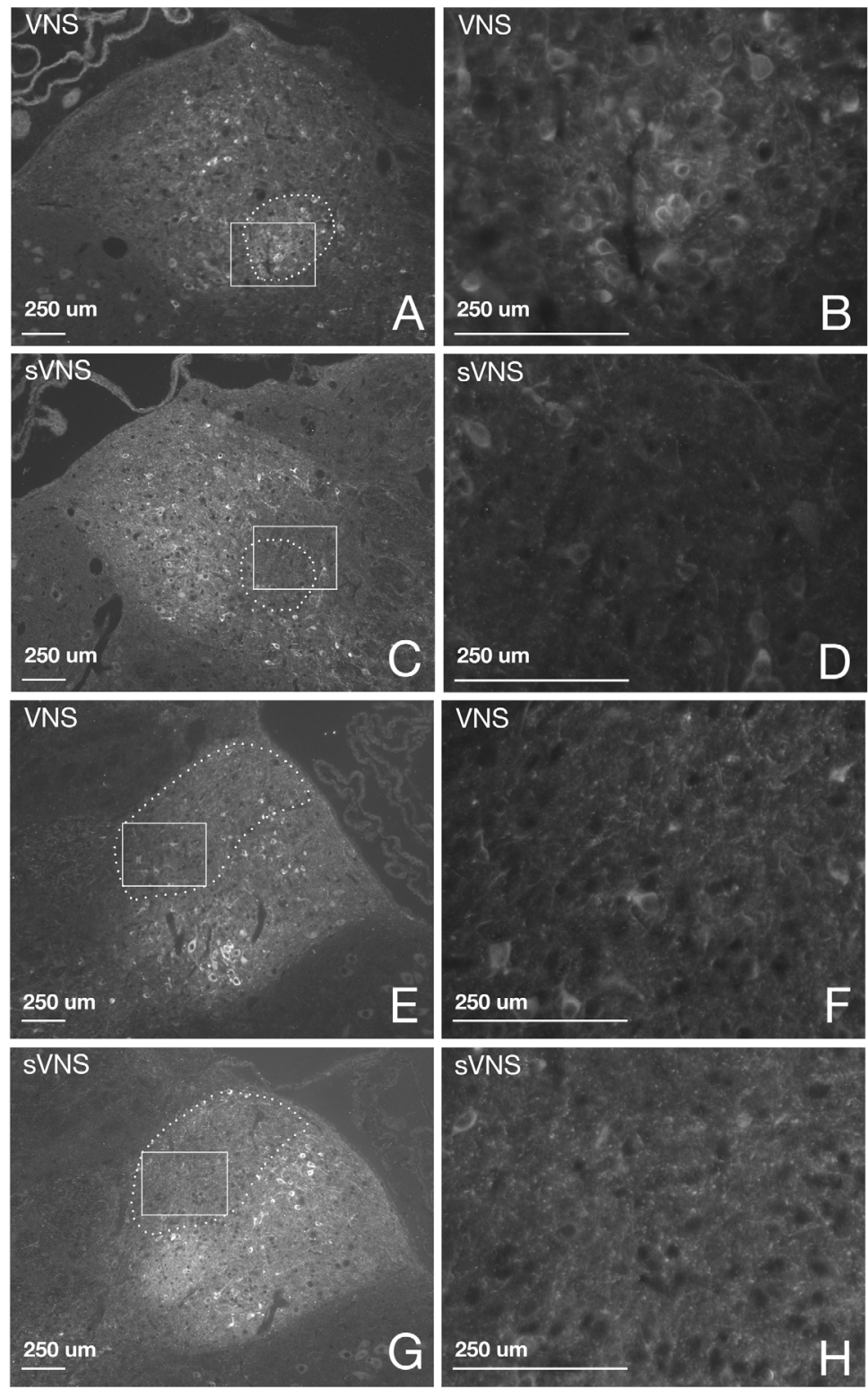

Figure 6.2 nNOS immunopositive cells in the right central subnucleus of the NTS at bregma $-13.5 \mathrm{~mm}$ (A, B, C, D) and the left dorsomedial NTS subnuclei (mediodorsal, dorsal and gelatinosous) at bregma -13.6 mm (E, F, G, H), at $10 \times(A, C, E$ and $G)$ and $40 \times(B, D, F$ and $H)$ magnification. Dotted lines indicate the $c N T S(A, C)$ and dmNTS $(E, G)$. Rectangles in $A, C, E$ and $G$ indicate the area of magnification in $B, D, F$ and $H$. 

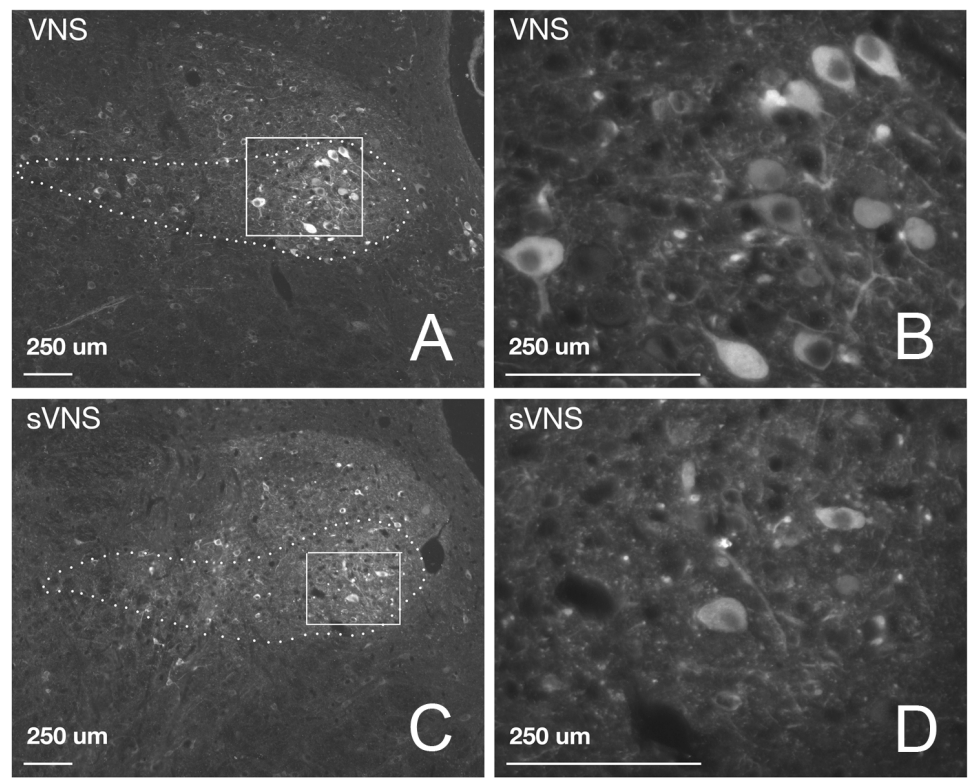

Figure 6.3 nNOS immunopositive cells in the left DMV at bregma -13.3 mm at 10x (A, C) and 40x (B, D) magnification. Dotted lines indicate the $\operatorname{DMV}(A, C)$. Rectangles in $A$ and $C$ indicate the area of magnification in $B$ and $D$, respectively.

The DMV was found medioventrally to the mNTS in the caudalmost sections, and medially to the mNTS in the rostral sections. In both VNS and sVNS rats there was a high density of large nNOS immunopositive cells (Figure 6.3 A-D) and there were no statistically significant differences between VNS and sVNS animals, nor between VNS responders and non-responders. Among both VNS and sVNS rats, nNOS immunopositive cell densities greater than 300 cells $/ \mathrm{mm}^{2}$ were found more frequently in the left DMV than in the right DMV $\left(\chi^{2}(1)=26.205, p<0.0001\right.$, Figure 6.4). Thus, based on the odds ratio it is 8.36 times more likely that cell density in the left DMV is greater than 300 cells $/ \mathrm{mm}^{2}$ compared to the right DMV. There is a trend towards a significant association between VNS treatment and a cell density larger than 300 cells $/ \mathrm{mm}^{2}$ in the left DMV $\chi^{2}(1)=3.237, \mathrm{p}=0.072$, representing the fact that based on the odds ratio it is 2.37 times more likely that cell density in the left DMV of VNS rats is greater than 300, compared to the left DMV of sVNS rats. This trend was not present in the right DMV (odds ratio 1.23). 


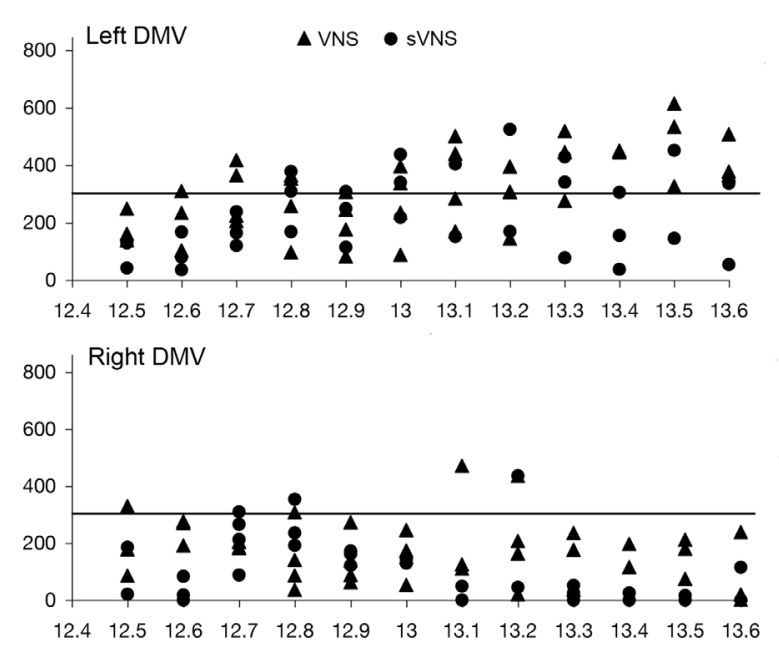

Figure 6.4 nNOS immunopositive cell density in the left and right dorsal motor nucleus of the vagus nerve (DMV). X-axis: level of investigation in $\mathrm{mm}$ posterior to bregma; $\mathrm{y}$-axis: $\mathrm{nNOS}$ immunopositive cells (cells $/ \mathrm{mm}^{2}$ ). Horizontal line marks the 300 cell $\mathrm{s} / \mathrm{mm}^{2}$ line.

\section{$\triangle F O S B$}

In both left and right NTS, VNS rats showed a trend to a higher density of $\triangle$ FosB immunopositive cells than SVNS, AK and SAK rats, but this difference did not reach the level of statistical significance (Figure 6.5A and 6.5C and Figure 6.6A and 6.6B). NTS $\triangle$ FosB immunopositive cell density was highest in the rat that responded with the largest reduction in total seizure duration, but there was not a significant correlation between $\triangle \mathrm{F}$ osB immunopositive cell density and total seizure duration reduction.

In the PBN, some rats showed scattered $\triangle \mathrm{FosB}$ immunopositive cells but most animals did not show any $\triangle F o s B$ immunopositive cells at all. The highest density of $\triangle$ FosB immunopositive cells was found in the right PBN of VNS rats (Figures $6.5 B$ and $6.5 \mathrm{E})$, but this density was not significantly higher than the $\triangle$ FosB immunopositive cell density in the other three groups (Figures 6.6C and 6.6D). The PBN $\triangle$ FosB immunopositive cell density did not correlate with VNS-induced seizure duration reduction.

In the LC, the highest densities of $\triangle$ FosB immunopositive cells were found on the right side of VNS rats (Figure 6.5B and 6.5D), but these levels were not significantly higher than those in the other groups (Figures 6.6E and 6.6F). Within-subject analysis did not reveal statistically significant differences between left and right PBN. The LC $\triangle$ FosB immunopositive cell density did not correlate with VNS-induced seizure duration reduction. 


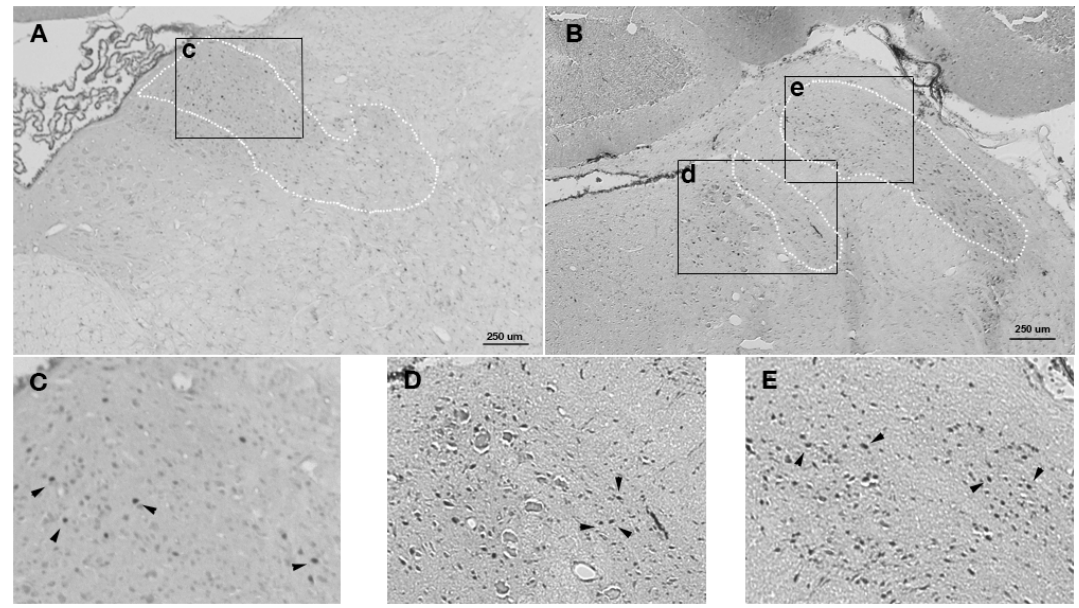

Figure 6.5 $\triangle$ fos $B$ immunopositive cells in the right NTS (A \& C), right LC (B \& D) and right PBN (B \& E) of a VNS rat. Dotted line in $1 \mathrm{~A}$ depicts the NTS, dotted lines in $1 B$ depict the PBN on the right of the picture and LC on the left of the picture. Black arrowheads in C, D and E point at $\Delta$ fos B immunopositive cells.

\section{Discussion}

This study examined the pattern of nNOS immunoreactivity in the NTS and DMV and $\triangle$ fosB immunoreactivity in the NTS, DMV, PBN and LC of epileptic rats that were treated with acute VNS. It has been suggested that VNS is effective because changes are observed in these brain stem nuclei, which are structures that are connected to hippocampus and amygdala, where seizures originate.

\section{Vagus nerve afferents}

$\triangle \mathrm{FosB}$ immunohistochemistry was used to investigate activation of the afferent vagus nerve fibers. $\triangle$ FosB is considered to be indicative of neuronal activity ${ }^{42}$. Immunohistochemical detection of neuronal activity is often done using immediately early genes such as C-Fos, FosB or $\triangle$ FosB. C-Fos staining of the primairy projection nucleus of vagus nerve afferents, the NTS, immediately after VNS in non-epileptic rats has shown that more NTS neurons are activated immediately after VNS than after sVNS $^{30,31,51}$. Chronic cyclic VNS additionally induces NTS $\triangle$ FosB expression ${ }^{31}$. In the current study epileptic rats were sacrificed 48 hours after a single train of VNS. At this time point, both C-Fos and FosB expression, which have their peaks at 2 and 6 hours after the stimulus, respectively, have returned to baseline ${ }^{42}$. In contrast, $\triangle F o s B$ is a highly stable FosB isoform that persists in the brain for several weeks after an initial stimulus ${ }^{42}$. 

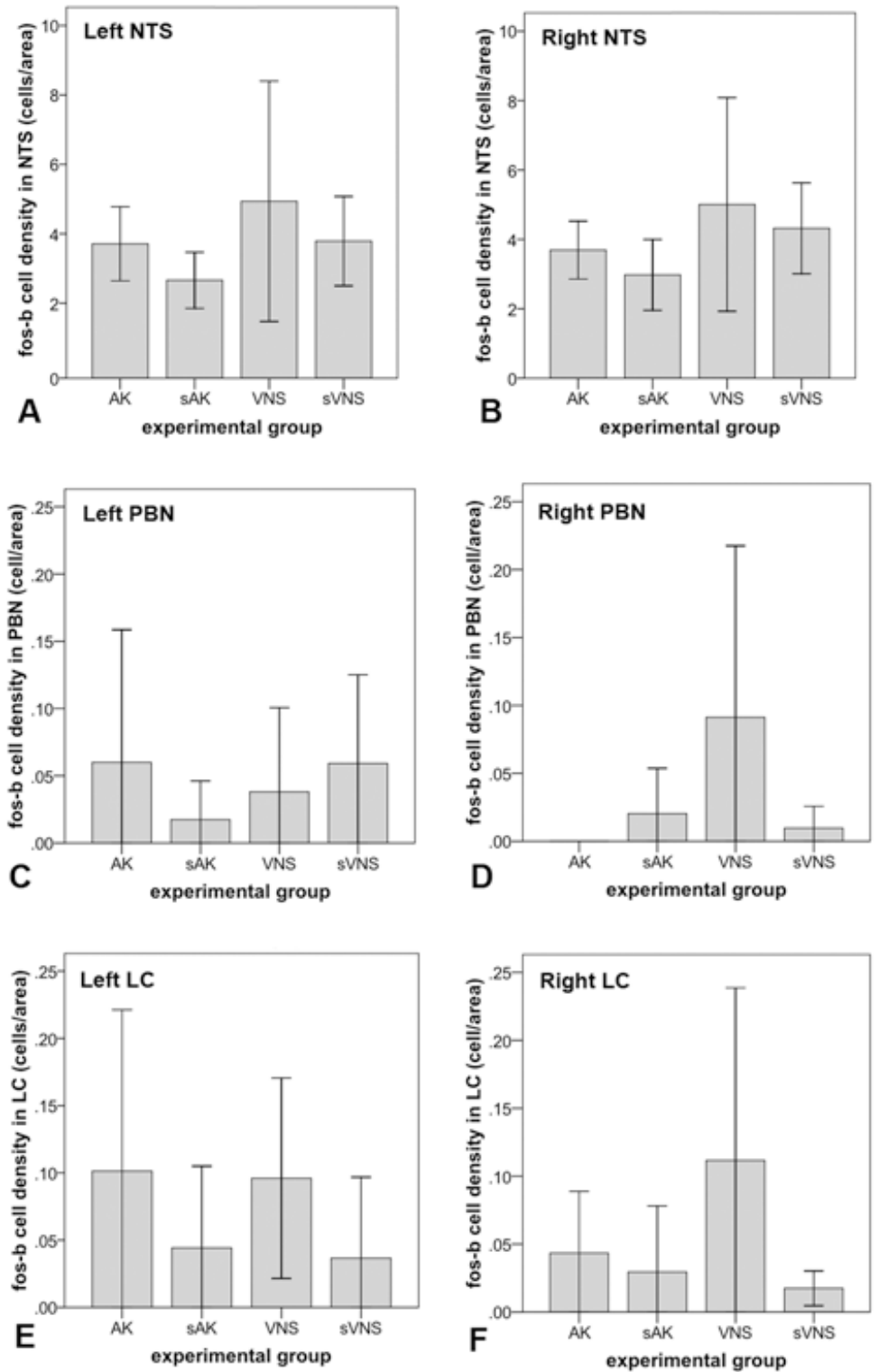

Figure 6.6 Bar diagrams showing the average number of $\triangle F o s B$ immunopositive cells per area in the NTS (A \& B), PBN (C \& D) and LC (E \& F) per experimental group. Data are expressed as average \pm standard deviation of 50-60 NTS sections from 5-6 animals per group, 9-18 PBN sections from 3-6 animals per group and 40-48 LC sections from 5-6 animals per group. The number of cells per square millimeter is the number on the $y$-axis divided by 1.5 . 
The highest density of $\triangle$ FosB ir cells was found in the NTS of VNS rats, but, in contrast to Cunningham et al., this level was not significantly higher than the $\Delta$ FosB density in the other three groups ${ }^{31}$. Several factors can account for this lack of statistically significant differences. First of all, the large variation in $\Delta$ FosB immunopositive cell density between rats, as well as the low number of rats per experimental group (five or six) may have contributed to this. Secondly, in comparison with Cunningham et al. there were important differences in stimulation protocol: we used a three-minute train of VNS while Cunningham et al. used three weeks of continuous cyclic stimulation with a duty cycle of $30 \mathrm{~s}$ on, $5 \mathrm{~min}$ off. In the third place, immunohistochemical analysis differed with regard to the number and thickness of sections that were analyzed ( 10 sections of $10 \mu \mathrm{m}$ thickness in the current study, versus 3 to 6 sections of $40 \mu \mathrm{m}$ in the study of Cunningham et al. ${ }^{31}$ ). In addition, previous studies have shown that the NTS is subdivided into several functionally and anatomically different subnuclei ${ }^{21,52}$. VNS-induced changes may be restricted to NTS subnuclei that we were unable to anatomically delineate based on the $\Delta \mathrm{FosB}$ staining. The fact that we used amygdala kindled rats may have affected the $\Delta$ FosB immunopositive cell density in the NTS as well, because the NTS receives a direct projection from the central amygdala ${ }^{26,53}$, as well as from the sensorimotor ${ }^{54}$ and motor ${ }^{55}$ cortex, areas that have been activated daily during the experiments as a result of the generalized seizure. In line with this theory one would expect high $\Delta$ FosB immunopositive cell density in the NTS of kindled animals as well, an assumption that we could not verify in our study because there was no significant difference in NTS $\triangle$ FosB immunopositive cell density between kindled rats and shams. No studies on this topic are available to compare our results with.

The PBN and LC $\triangle$ FosB studies did not reveal statistically significant differences between the four experimental groups either. Similarly to the NTS analysis, the groups were small and $\Delta$ FosB immunopositive cell density showed a large variability. Furthermore for technical reasons both nuclei were only analyzed in part. Despite all these restrictions and despite the lack of significance, when looking at Figure 6.6 it seems that a trend towards an effect of both kindling and VNS is present in the PBN and LC. These two nuclei are connected bilaterally to the NTS ${ }^{24}$, and ipsilaterally to the amygdala ${ }^{26}$, and in line with these anatomical connections the left PBN and left LC of kindled rats contained the highest density of $\triangle F o s B$ immunopositive cells, whereas on the right side the highest density was found in the VNS group.

\section{Vagus nerve efferents}

nNOS has previously been used to study the functional anatomy and connectivity of the NTS and DMV. These studies have revealed that nNOS is quickly upregulated after vagus nerve manipulations, while in healthy, untreated rats nNOS expression in the NTS is robust in some areas while in the DMV it is limited to a faint background signal $^{37-40}$. We used the nNOS staining to evaluate to what extent neurons in the NTS 
(vagal afferents) and DMV (vagal efferents) are affected by manipulation of the vagus nerve during implantation of the vagus nerve electrode and VNS itself.

To minimize damage to the vagus nerve during surgical placement of the electrode we were as careful as possible with respect to mechanical contact with the vagus nerve itself during surgery. To protect the nerve from reactive gliosis and Wallerian degeneration that may develop as a result of surgical manipulation, we implanted the circular electrode around both vagus nerve and carotid artery. Although this technique has been used previously ${ }^{31,44,45}$, in the vast majority of experimental VNS studies, the vagus nerve is first prepared free from the carotid artery after which an electrode is wrapped around it ${ }^{19,25,56-62}$. Despite our cautious surgical technique we found an important effect of vagus nerve surgery because an nNOS immunopositive cell density of $>300$ cells $/ \mathrm{mm}^{2}$ was found eight times more often in the left DMV than in the right DMV of both VNS and sVNS animals. These DMV immunopositive cells are motorneurons containing the cell bodies of efferent fibers traveling down the ipsilateral vagus nerve.

Previous studies have shown increased nNOS expression induced by vagus nerve manipulations, especially lesions, between two and at least 40 days after these manipulations $s^{41,63}$. Another study ${ }^{52}$ has shown the persistence of changes in vagal neurons for up to 90 days. In the present study, vagus nerve surgery had been performed 38 days prior to sacrifice while VNS was performed 48 hours prior to sacrificing the animals; a time-point at which, based on these previous findings, VNSinduced nNOS expression can be expected as well.

It is possible that electrical stimulation of the vagus nerve may have additionally contributed to the nNOS signal in the DMV the current study, since VNS rats were 2.4 times more likely than sVNS rats to have a nNOS cell density of $>300$ cells $/ \mathrm{mm}^{2}$ in the left DMV. If VNS has indeed contributed to the nNOS signal in the DMV, which is an efferent output nucleus of the vagus nerve, the question remains what this VNSinduced nNOS activity illustrates: antidromic activation of vagus nerve efferents or non-activation related changes in cellular functioning resulting from the electrical stimulation.

In the NTS, nNOS immunopositivity was present after VNS and sVNS in the various subnuclei as well but in contrast to the DMV, no differences in nNOS immunopositive cell density between the ipsilateral and contralateral NTS were observed. This apparently contradictory finding is most likely related to the fact that the DMV is a pure motor nucleus while the NTS is a sensory nucleus containing a large number of vagus nerve afferents. These afferents are known to express much less nNOS in response to vagus nerve manipulations than efferents ${ }^{41}$.

What manipulations (surgery, electrical stimulation or both) are responsible for the nNOS upregulation is unclear. With regard to this last question, previous studies have shown that strong increases in nNOS immunopositive neurons in the NTS and DMV were found after vagotomy ${ }^{41}$. Furthermore, these vagotomy-induced changes in nNOS immunopositivity overlap with vagus nerve injury-induced changes in the 
expression of the 27-kDA heat shock protein (Hsp27), a protein that is rapidly induced following oxidative and cellular metabolic stress ${ }^{52}$. Quantification of the nNOS immunopositive cell density in the NTS subnuclei in the current study did not reveal differences between treated and untreated animals, a finding contradicting our previous publication on VNS-treated rats $^{34}$. When we presented our previous findings we had only analyzed 5 animals per group while in the current study we were able to include one animal per group more. Apparently the findings in these animals are responsible for the lack of significance in the current study.

This lack of stimulation effect may be related to the fact that in previous studies nNOS mainly affected vagus nerve efferents ${ }^{41}$, and not afferents which are the fibers that most likely are responsible for the anticonvulsive effect of VNS. We therefore conclude that the VNS-induced effect on vagus nerve afferents can not be analyzed using this staining.

\section{Conclusion}

Vagus nerve stimulation has an anticonvulsive effect in the amygdala kindled rat. Independent of this anticonvulsive effect, significant changes that are indicative of axonal damage occur in the vagus nerve motor neurons as a result of vagus nerve electrode placement. Axonal damage may occur after human VNS surgery as well. This may contribute to two clinical observations. First of all to the lack of effectiveness in some of the VNS-refractory cases. Secondly it may contribute to the fact that in most patients, the anticonvulsive effects of VNS are not present immediately after VNS but rather after weeks to months and increase during the first year of VNS, which may be the 'healing period' of the nerve after having suffered from surgical damage. Axonal damage is likely to occur in other animal experiments as well, especially those in which the vagus nerve is dissected free from the carotid artery.

We were unable to confirm VNS-induced neuronal activation using $\triangle$ FosB immunohistochemistry in the NTS, PBN and LC. Studies with large animal groups and a VNS stimulating protocol specifically designed for immunohistochemical detection of neuronal activation must be conducted in future to investigate the VNS-induced neuronal activation in the brain stem. 


\section{References}

1. Penry JK, Dean JC. Prevention of intractable partial seizures by intermittent vagal stimulation in humans: preliminary results. Epilepsia. 1990;31 Suppl 2:S40-3.

2. A randomized controlled trial of chronic vagus nerve stimulation for treatment of medically intractable seizures. Neurology. 1995;45:224-30.

3. Handforth A, DeGiorgio CM, Schachter SC, Uthman BM, Naritoku DK, Tecoma ES, Henry TR, Collins SD, Vaughn BV, Gilmartin RC, Labar DR, Morris GL 3rd, Salinsky MC, Osorio I, Ristanovic RK, Labiner DM, Jones JC, Murphy JV, Ney GC, Wheless JW. Vagus nerve stimulation therapy for partial-onset seizures: a randomized active-control trial. Neurology. 1998;51: 48-55.

4. Majoie HJ, Berfelo MW, Aldenkamp AP, Evers SM, Kessels AG, Renier WO. Vagus nerve stimulation in children with therapy-resistant epilepsy diagnosed as Lennox-Gastaut syndrome: clinical results, neuropsychological effects, and cost-effectiveness. J Clin Neurophysiol. 2001;18:419-28.

5. Shahwan A, Bailey C, Maxiner W, Harvey AS. Vagus nerve stimulation for refractory epilepsy in children: More to VNS than seizure frequency reduction. Epilepsia. 2009;50:1220-8.

6. Ben-Menachem E, Manon-Espaillat R, Ristanovic R, Wilder BJ, Stefan H, Mirza W, Tarver WB, Wernicke JF. Vagus nerve stimulation for treatment of partial seizures: 1 . A controlled study of effect on seizures. First International Vagus Nerve Stimulation Study Group. Epilepsia. 1994;35:616-26.

7. Boon P, Vonck K, Van Walleghem P, D'Have M, Goossens L, Vandekerckhove T, Caemaert J, De Reuck J. Programmed and magnet-induced vagus nerve stimulation for refractory epilepsy. J Clin Neurophysiol. 2001;18:402-7.

8. Morris GL, 3rd. A retrospective analysis of the effects of magnet-activated stimulation in conjunction with vagus nerve stimulation therapy. Epilepsy Behav. 2003;4:740-5.

9. Privitera MD, Welty TE, Ficker DM, Welge J. Vagus nerve stimulation for partial seizures. Cochrane Database Syst Rev. 2002(1):CD002896.

10. Aldenkamp AP, Majoie HJ, Berfelo MW, Evers SM, Kessels AG, Renier WO, Wilmink J. Long-term effects of 24-month treatment with vagus nerve stimulation on behaviour in children with LennoxGastaut syndrome. Epilepsy Behav. 2002;3:475-9.

11. DeGiorgio CM, Murray D, Markovic D, Whitehurst T. Trigeminal nerve stimulation for epilepsy: longterm feasibility and efficacy. Neurology. 2009;72:936-8.

12. Fisher R, Salanova V, Witt T, Worth R, Henry T, Gross R, Oommen K, Osorio I, Nazzaro J, Labar D, Kaplitt M, Sperling M, Sandok E, Neal J, Handforth A, Stern J, DeSalles A, Chung S, Shetter A, Bergen D, Bakay R, Henderson J, French J, Baltuch G, Rosenfeld W, Youkilis A, Marks W, Garcia P, Barbaro N, Fountain N, Bazil C, Goodman R, McKhann G, Babu Krishnamurthy K, Papavassiliou S, Epstein C, Pollard J, Tonder L, Grebin J, Coffey R, Graves N; SANTE Study Group. Electrical stimulation of the anterior nucleus of thalamus for treatment of refractory epilepsy. Epilepsia. 2010;51:899-908.

13. Lim SN, Lee ST, Tsai YT, Chen IA, Tu PH, Chen JL, Chang HW, Su YC, Wu T. Electrical stimulation of the anterior nucleus of the thalamus for intractable epilepsy: a long-term follow-up study. Epilepsia. 2007;48:342-7.

14. Vesper J, Steinhoff B, Rona S, Wille C, Bilic S, Nikkhah G, Ostertag C. Chronic high-frequency deep brain stimulation of the STN/SNr for progressive myoclonic epilepsy. Epilepsia. 2007;48:1984-9.

15. Franzini A, Messina G, Marras C, Villani F, Cordella R, Broggi G. Deep brain stimulation of two unconventional targets in refractory non-resectable epilepsy. Stereotact Funct Neurosurg. 2008; 86:373-81.

16. Boon P, Vonck K, De Herdt V, Van Dycke A, Goethals M, Goossens L, Van Zandijcke M, De Smedt T, Dewaele I, Achten R, Wadman W, Dewaele F, Caemaert J, Van Roost D. Deep brain stimulation in patients with refractory temporal lobe epilepsy. Epilepsia. 2007;48:1551-60.

17. Velasco AL, Velasco F, Jiménez F, Velasco M, Castro G, Carrillo-Ruiz JD, Fanghänel G, Boleaga B. Neuromodulation of the centromedian thalamic nuclei in the treatment of generalized seizures and the improvement of the quality of life in patients with Lennox-Gastaut syndrome. Epilepsia. 2006; 47:1203-12.

18. Asala SA, Bower AJ. An electron microscope study of vagus nerve composition in the ferret. Anat Embryol (Berl). 1986;175:247-53. 
19. Krahl SE, Senanayake SS, Handforth A. Destruction of peripheral C-fibers does not alter subsequent vagus nerve stimulation-induced seizure suppression in rats. Epilepsia. 2001;42:586-9.

20. Paintal AS. Vagal sensory receptors and their reflex effects. Physiol Rev. 1973;53:159-227.

21. Altschuler SM, Bao XM, Bieger D, Hopkins DA, Miselis RR. Viscerotopic representation of the upper alimentary tract in the rat: sensory ganglia and nuclei of the solitary and spinal trigeminal tracts. $J$ Comp Neurol. 1989;283:248-68.

22. Fulwiler CE, Saper CB. Subnuclear organization of the efferent connections of the parabrachial nucleus in the rat. Brain Res. 1984;319:229-59.

23. Granata AR, Kitai ST. Intracellular study of nucleus parabrachialis and nucleus tractus solitarii interconnections. Brain Res. 1989;492:281-92.

24. Van Bockstaele EJ, Peoples J, Telegan P. Efferent projections of the nucleus of the solitary tract to peri-locus coeruleus dendrites in rat brain: evidence for a monosynaptic pathway. J Comp Neurol. 1999;412:410-28.

25. Krahl SE, Clark KB, Smith DC, Browning RA. Locus coeruleus lesions suppress the seizure-attenuating effects of vagus nerve stimulation. Epilepsia. 1998;39:709-14.

26. Hopkins DA, Holstege G. Amygdaloid projections to the mesencephalon, pons and medulla oblongata in the cat. Exp Brain Res. 1978;32:529-47.

27. Ricardo JA, Koh ET. Anatomical evidence of direct projections from the nucleus of the solitary tract to the hypothalamus, amygdala, and other forebrain structures in the rat. Brain Res. 1978;153:1-26.

28. Castle M, Comoli E, Loewy AD. Autonomic brainstem nuclei are linked to the hippocampus. Neuroscience. 2005;134:657-69.

29. Chae JH, Nahas Z, Lomarev M, Denslow S, Lorberbaum JP, Bohning DE, George MS. A review of functional neuroimaging studies of vagus nerve stimulation (VNS). J Psychiatr Res. 2003;37:443-55.

30. Naritoku DK, Terry WJ, Helfert RH. Regional induction of fos immunoreactivity in the brain by anticonvulsant stimulation of the vagus nerve. Epilepsy Res. 1995;22:53-62.

31. Cunningham JT, Mifflin SW, Gould GG, Frazer A. Induction of c-Fos and DeltaFosB immunoreactivity in rat brain by Vagal nerve stimulation. Neuropsychopharmacology. 2008;33:1884-95.

32. Groves DA, Bowman EM, Brown VJ. Recordings from the rat locus coeruleus during acute vagal nerve stimulation in the anaesthetised rat. Neurosci Lett. 2005;379:174-9.

33. Goddard GV, McIntyre DC, Leech CK. A permanent change in brain function resulting from daily electrical stimulation. Exp Neurol. 1969;25:295-330.

34. Rijkers K, Aalbers M, Hoogland G, van Winden L, Vles J, Steinbusch H, Majoie M. Acute seizuresuppressing effect of vagus nerve stimulation in the amygdala kindled rat. Brain Res. 2010;1319: 155-63.

35. Wang S, Paton JF, Kasparov S. Differential sensitivity of excitatory and inhibitory synaptic transmission to modulation by nitric oxide in rat nucleus tractus solitarii. Exp Physiol. 2007;92:37182.

36. Hope BT, Michael GJ, Knigge KM, Vincent SR. Neuronal NADPH diaphorase is a nitric oxide synthase. Proc Natl Acad Sci U S A. 1991;88:2811-4.

37. Atkinson L, Batten TF, Corbett EK, Sinfield JK, Deuchars J. Subcellular localization of neuronal nitric oxide synthase in the rat nucleus of the solitary tract in relation to vagal afferent inputs. Neuroscience. 2003;118:115-22.

38. Rodrigo J, Springall DR, Uttenthal O, Bentura ML, Abadia-Molina F, Riveros-Moreno V, MartínezMurillo R, Polak JM, Moncada S. Localization of nitric oxide synthase in the adult rat brain. Philos Trans R Soc Lond B Biol Sci. 1994; 345:175-221.

39. Lin LH, Cassell MD, Sandra A, Talman WT. Direct evidence for nitric oxide synthase in vagal afferents to the nucleus tractus solitarii. Neuroscience. 1998;84:549-58.

40. De Vente J, Hopkins DA, Markerink-Van Ittersum M, Emson PC, Schmidt HH, Steinbusch HW. Distribution of nitric oxide synthase and nitric oxide-receptive, cyclic GMP-producing structures in the rat brain. Neuroscience. 1998;87:207-41.

41. Hopkins DA, Biegel, D., de Vente, J., Steinbusch, H.W.M. Vagal efferent projections: viscerotopy, neurochemistry and effects of vagotomy. Progress in Brain Research. 1996;107:18.

42. Nestler EJ, Barrot M, Self DW. DeltaFosB: a sustained molecular switch for addiction. Proc Natl Acad Sci U S A. 2001;98:11042-6. 
43. Aalbers MW, Rijkers K, van Winden LA, Hoogland G, Vles JS, Majoie HJ. Horner's syndrome: A complication of experimental carotid artery surgery in rats. Auton Neurosci. 2009;147:64-9.

44. Follesa P, Biggio F, Gorini G, Caria S, Talani G, Dazzi L, Puligheddu M, Marrosu F, Biggio G. Vagus nerve stimulation increases norepinephrine concentration and the gene expression of BDNF and bFGF in the rat brain. Brain Res. 2007;1179:28-34.

45. Dorr AE, Debonnel G. Effect of Vagus Nerve Stimulation on Serotonergic and Noradrenergic Transmission. J Pharmacol Exp Ther. 2006;318:890-8.

46. Temel Y, Visser-Vandewalle V, van der Wolf M, Spincemaille GH, Desbonnet L, Hoogland G, Steinbusch HW. Monopolar versus bipolar high frequency stimulation in the rat subthalamic nucleus: differences in histological damage. Neurosci Lett. 2004;367:92-6.

47. Paxinos GW, C. The Rat brain in stereotaxic coordiates. fourth ed. London: Academic press; 1998.

48. Racine RJ. Modification of seizure activity by electrical stimulation. II. Motor seizure. Electroencephalogr Clin Neurophysiol. 1972;32:281-94.

49. Moers-Hornikx VM, Sesia T, Basar K, Lim LW, Hoogland G, Steinbusch HW, Gavilanes DA, Temel Y, Vles JS. Cerebellar nuclei are involved in impulsive behaviour. Behav Brain Res. 2009;203:256-63.

50. Kim W, Clancy RR, Liu GT. Horner syndrome associated with implantation of a vagus nerve stimulator. Am J Ophthalmol. 2001;131:383-4.

51. Osharina V, Bagaev V, Wallois F, Larnicol N. Autonomic response and Fos expression in the NTS following intermittent vagal stimulation: Importance of pulse frequency. Auton Neurosci. 2006;126127:72-80.

52. Hopkins DA, Plumier JC, Currie RW. Induction of the 27-kDa heat shock protein (Hsp27) in the rat medulla oblongata after vagus nerve injury. Exp Neurol. 1998;153:173-83.

53. Otake K, Reis DJ, Ruggiero DA. Afferents to the midline thalamus issue collaterals to the nucleus tractus solitarii: an anatomical basis for thalamic and visceral reflex integration. J Neurosci. 1994; 14:5694-707.

54. M'Hamed S B, Sequeira H, Poulain P, Bennis M, Roy JC. Sensorimotor cortex projections to the ventrolateral and the dorsomedial medulla oblongata in the rat. Neurosci Lett. 1993;164:195-8.

55. Ba-M'Hamed S, Viltart O, Poulain P, Sequeira H. Distribution of cortical fibers and fos immunoreactive neurons in ventrolateral medulla and in nucleus tractus solitarius following the motor cortex stimulation in the rat. Brain Res. 1998;813:411-5.

56. Dedeurwaerdere S, Gilby K, Vonck K, Delbeke J, Boon P, Mclntyre D. Vagus nerve stimulation does not affect spatial memory in fast rats, but has both anti-convulsive and pro-convulsive effects on amygdala-kindled seizures. Neuroscience. 2006;140:1443-51.

57. Krahl SE, Senanayake SS, Handforth A. Right-sided vagus nerve stimulation reduces generalized seizure severity in rats as effectively as left-sided. Epilepsy Res. 2003;56:1-4.

58. Sunderam S, Osorio I, Watkins JF, 3rd, Wilkinson SB, Frei MG, Davis RE. Vagal and sciatic nerve stimulation have complex, time-dependent effects on chemically-induced seizures: a controlled study. Brain Res. 2001;918:60-6.

59. Takaya M, Terry WJ, Naritoku DK. Vagus nerve stimulation induces a sustained anticonvulsant effect. Epilepsia. 1996;37:1111-6.

60. Woodbury DM, Woodbury JW. Effects of vagal stimulation on experimentally induced seizures in rats. Epilepsia. 1990;31 Suppl 2:S7-19.

61. Zagon A, Kemeny AA. Slow hyperpolarization in cortical neurons: a possible mechanism behind vagus nerve simulation therapy for refractory epilepsy? Epilepsia. 2000;41:1382-9.

62. Zhang JL, Zhang SP, Zhang HQ. Antiepileptic effects of electroacupuncture vs vagus nerve stimulation on cortical epileptiform activities. J Neurol Sci. 2008;270:114-21.

63. Ji J, Dheen ST, Tay SS. Molecular analysis of the vagal motoneuronal degeneration after right vagotomy. J Neurosci Res. 2002;69:406-17. 



\section{Chapter 7}

\section{Horner's syndrome: a complication of experimental carotid artery surgery in rats}

Aalbers MW, Rijkers K, van Winden LAAP, Hoogland G, Vles JSH, Majoie HJM Autonomic Neuroscience: Basic and Clinical 2009;147:64-69 


\section{Abstract}

We report on the occurrence of iatrogenic Horner's syndrome (HS) in epileptic rats after implantation of an electrode for vagus nerve stimulation and to describe the possible consequences of this new complication of carotid artery surgery in rats.

A bipolar circular electrode was placed around the left carotid artery and vagus nerve of 31 rats. The incidence of HS was evaluated by visual inspection within 24 hours after surgery.

Results: $68 \%$ of rats suffered from HS immediately after surgery. This complication did not affect epileptogenesis.

The occurrence of $\mathrm{HS}$ in the rat is a frequent complication of vagus nerve electrode implantation, which does not affect epileptogenesis in this study. However, rats affected by HS may suffer from damage to the sympathetic innervation of the gut, due to rat-specific neuroanatomy. Therefore, caution towards other research questions is warranted. 


\section{Introduction}

Horner's syndrome (HS), or oculosympathetic palsy, is a clinical syndrome characterized by four symptoms: ptosis, miosis, enopthalmos and facial anhidrosis ${ }^{1}$. The syndrome was first described in animals in 1858 by Claude Bernhard. Eleven years later Johann Friedrich Horner described it in humans as well2.

HS is caused by disruption of the oculosympathetic system. This system provides the sympathetic innervation of the eye and consists of a three neuron pathway (Figure 7.1):

1. The first order neurons originate in the posterior hypothalamus, course caudally through the mesencephalon and pons and terminate in the intermediolateral cell column of the spinal cord (the ciliospinal centre of Budge at the cervicothoracic junction).

2. The second order neurons originate in the centre of Budge, leave the spinal cord and enter the sympathetic chain to end in the superior cervical ganglion (SCG).

3. The third order neurons originate in the SCG and course cranially with the carotid artery. At the carotid bifurcation, the fibers that innervate the facial sweat glands follow the external carotid artery. All other sympathetic fibers adjoin the internal carotid artery through the carotid canal of the petrous bone, over the foramen lacerum and into the cavernous sinus. Here, the fibers that innervate the pupillodilator muscle join the ophthalmic branch of the trigeminal nerve to enter the orbita through the superior orbital fissure. They pass the ciliary ganglion and end as two ciliary nerves on the pupilodilator muscle. The fibers that innervate the tarsal muscle and lacrimal glands leave the cavernous sinus with the carotid artery, and subsequently join the opthalmic artery to enter the orbita through the foramen opticum. The tarsal muscles contribute to eye opening.

HS can be caused by a tumor, inflammatory process, trauma or surgical procedure in any of the anatomical regions described above. It also has an idiopathic variant, which can be hereditary'. The clinical diagnosis of HS is made by darkening the patient's room, which causes a normal pupil to dilate. In HS, miosis of 2-3mm will become apparent. Instillation of $4 \%$ cocaine in the eye causes a normal pupil to dilate, and can confirm the clinical diagnosis ${ }^{3}$. The partial ptosis and enophthalmos are caused by paralysis of the tarsal muscle. Ptosis is partial because the levator palpebrae muscle is unaffected.

HS has been described before in different animals ${ }^{4-8}$, but not, to our knowledge, in rats.

The oculosympathetic nervous system in rats consists of a similar three-neuron pathway as in humans. The localization of the SCG in rats, dorsally to the carotid bifurcation, is similar to that in humans as well ${ }^{9}$. There is however one important anatomical difference between the human SCG and the rat SCG: in humans the SCG consists exclusively of oculosympathetic fibers, whereas in rats a small branch of 
sympathetic fibers leaves the SCG and courses caudally with the efferent vagus nerve to contribute to the sympathetic, adrenergic innervation of the small intestine ${ }^{10}$.

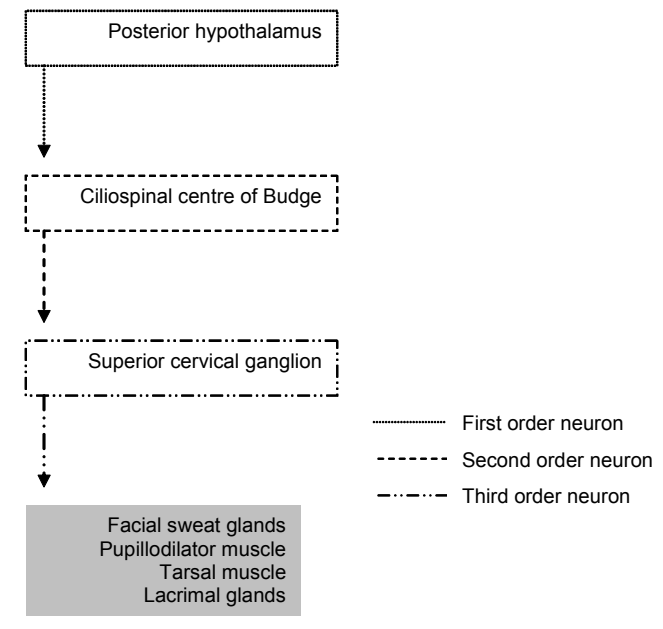

Figure 7.1 Scheme depicting the three-neuron pathway constituting the oculosympathetic pathway. The first order neurons originate in the posterior hypothalamus and course caudally to end in the ciliospinal centre of Budge at the level of the cervicothoracic junction. The second order neurons, originating in the centre of Budge, leave the spinal cord and enter the sympathetic chain to end in the superior cervical ganglion. Fibers in the third order neurons, originating in the superior cervical ganglion, course cranially with the carotid artery to reach their different targets.

We think that HS can occur in rats as well. This assumption is based on the finding of ptosis and enophthalmos in rats that were implanted with an electrode around the left carotid artery and vagus nerve for vagus nerve stimulation (VNS) (Figure 7.2). VNS was used to treat epileptic seizures provoked by amygdala kindling (AK). Moreover, we hypothesize that the occurrence of HS does not influence seizure susceptibility, because the oculosympathetic system is not involved in epileptogenesis.

The aim of the present article is, to present our series of rats in which HS occurred, and to describe the possible consequences of this new complication of carotid artery surgery in rats. 


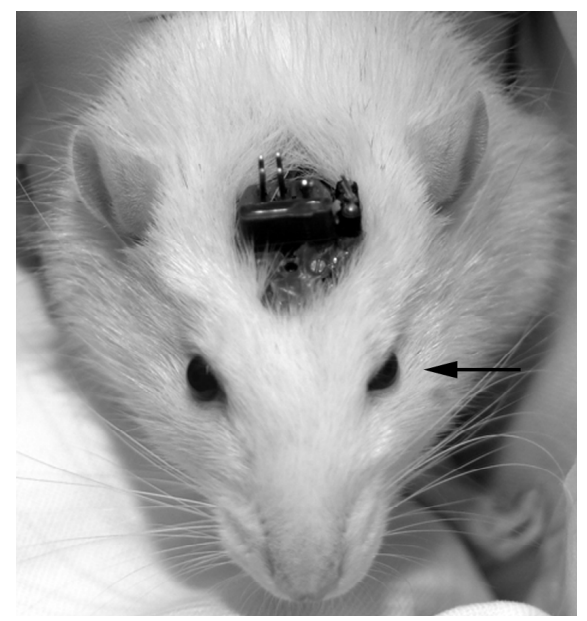

Figure 7.2 Rat with mild Horner's Syndrome. Enophthalmos and ptosis are visible at left eye (arrow).

\section{Materials and Methods}

\section{Animals}

Thirty-one male adult Sprague-Dawley rats, purchased from Harlan (Horst, The Netherlands) were kept under controlled conditions $\left(21 \pm 2{ }^{\circ} \mathrm{C}\right.$ ambient temperature, a 12 hour light/dark schedule, background noise provided by radio and food and water available ad libitum). The animals were allowed to adapt to the laboratory for one week before surgery. All experimental procedures were approved by the animal ethics committee of Maastricht University and complied with governmental legislation.

\section{Surgery}

All rats underwent surgery to implant two types of electrodes: one electrode for VNS and one set of electrodes for AK. Thirty minutes prior to surgery all rats received $0.1 \mathrm{ml}$ buprenorfine (Temgesic) subcutaneously for pain relief. All surgical procedures were performed under general isoflurane anesthesia ( $5 \%$ for induction and $2.5 \%$ for maintenance).

\section{Vagus nerve electrode}

First, the left carotid artery and vagus nerve were exposed according to the following procedure: a $3 \mathrm{~cm}$ long skin incision was made on the ventral side of the neck. After 
retracting the salivary glands and the left sternomastoid muscle laterally, the sternothyroid and omohyoid muscles were visualized. The sternohyoid muscle was left in its medial position. The carotid artery was found in the angle between the sternomastoid and sternohyoid muscles. The carotid sheath was carefully opened over a distance of approximately $7 \mathrm{~mm}$. The vagus nerve was found on the lateral surface of the carotid artery. Subsequently, a custom made circular electrode (Figure 7.3, developed by P. van Venrooij and V. Duysens, Medtronic Bakken Research Center, Maastricht, The Netherlands), was wrapped around both carotid artery and vagus nerve. The electrode lead was fixed to the surrounding tissue ventrally using a non-absorbable silk suture. The wound was closed intracutaneously using absorbable wire. The VNS electrode was implanted with assistance of an operating microscope.
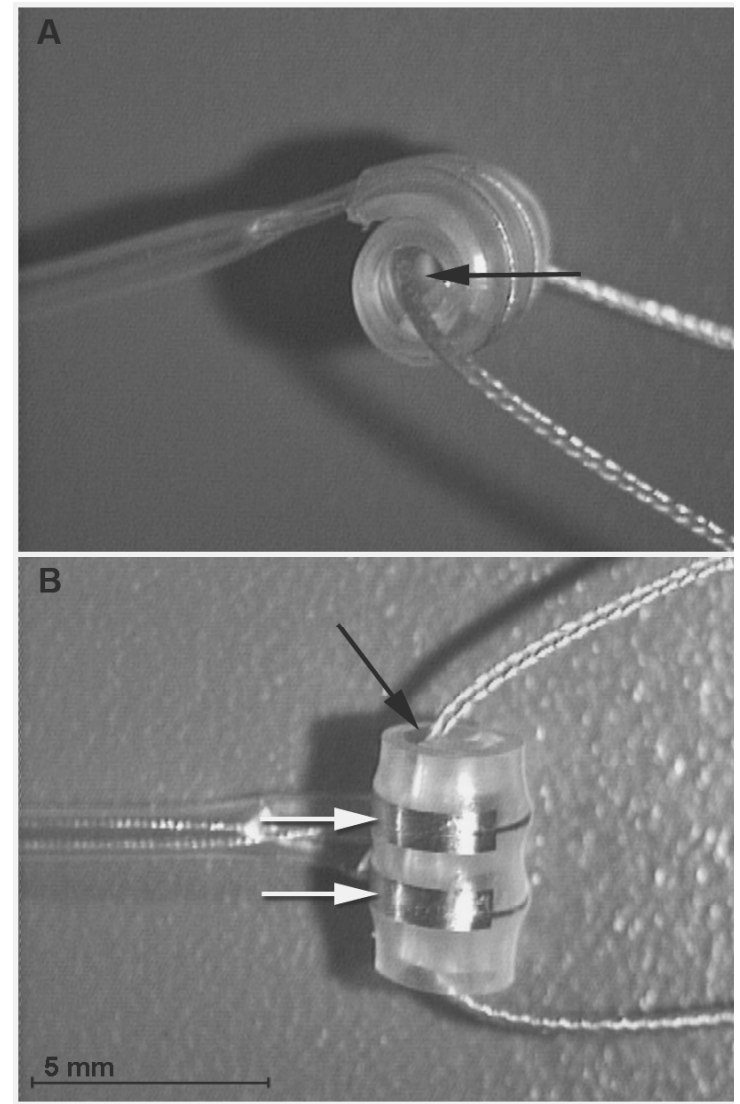

Figure 7.3 Vagus nerve electrode. A: lateral view; B: ventral view. After placement, the carotic artery and vagus nerve are both located inside the lumen of the electrode, now occupied by the green suture (black arrow). The two circular metal strips (white arrows) are the positive and negative electrodes. Scale bar illustrates the true size of the electrode. 


\section{Electrodes for kindling}

A second set of electrodes was implanted using a standard rat stereotact (Dual Manipulator Lab Standard Stereotact, Stoelting Inc., Wood Dale, III, USA). The amygdala stimulating/recording electrode was originally designed for deep brain stimulation in rats by the department of Instrument Development, Engineering \& Evaluation (Maastricht University, Maastricht, The Netherlands) in collaboration with Dr. Y. Temel (Maastricht University Medical Center, the Netherlands) ${ }^{11}$, and consisted of a bipolar platinum/iridium needle ( $200 \mu \mathrm{m}$ tip diameter) that was implanted in the left basolateral amygdala (BLA, coordinates relative to bregma: $-2.5 \mathrm{~mm}$ posteriorly, $4.8 \mathrm{~mm}$ laterally, and $9.6 \mathrm{~mm}$ ventrally) $)^{12}$. In addition, three monopolar stainless steel needles were implanted in the cortex at $\sim 1 \mathrm{~mm}$ depth. Of these electrodes, one was used for recordings, one for reference, and one for ground.

The connectors for both AK and VNS were fixed on the skull using dental acrylic cement (Paladur, Heraeus Kulzer GmbH, Wherheim, Germany).

\section{Amygdala kindling}

AK is an animal model for temporal lobe epilepsy ${ }^{13}$. It consists of electrical stimulation of the amygdala, twice daily. Initially, these stimuli induce afterdischarge (AD) activity in the amygdala, but no seizure activity. After several days of repeated stimulation, seizure activity becomes apparent, both on the EEG and behaviorally. Severity of the behavioral seizures increases with each stimulus, and is graded on a five-point scale $^{14}$. After the rats have experienced five consecutive stage five seizures they are considered to be 'fully kindled'. This fully kindled state is associated with irreversible changes in the brain and with irreversibly increased seizure-susceptibility.

Ten days after surgery the afterdischarge threshold (ADT) was assessed. ADT is defined as the stimulus amplitude necessary to elicit a high frequent, high voltage discharge with a duration of two seconds, on the amygdala electrode. It is determined by stimulating the amygdala with a series of pulses of increasing intensity starting at $10 \mu \mathrm{A}(50 \mathrm{~Hz}, 0.2 \mathrm{~ms}$ blockpulse). Stimuli were delivered through a WPI Accupulser A310 connected to a WPI Stimulus Isolation Unit A360 (World Precision Instruments, Sarasota, FL, USA). The EEG registrations from the amygdala and cortical electrodes were performed using a Vangard system (Vangard Systems, Cleveland Clinics Foundation, Cleveland, USA).

The next day, the actual AK experiment started. The amygdala was initially stimulated twice daily $(400 \mu, 50 \mathrm{~Hz}, 0.2 \mathrm{~ms}$ blockpulses). After reaching the fully kindled state, the frequency of AK stimulation was reduced to once daily. These once-a-day stimulations were continued for two weeks.

All rats were videotaped (Minolta DiMage G400, Konica Minolta Inc., Tokyo, Japan) during delivery of the AK stimulus and for as long as the behavioral seizure lasted. Seizure severity was determined offline by two blinded observers. 


\section{Statistical analysis}

To investigate the influence of HS on the development of epileptic seizures, ADT and kindling rate were compared between rats with HS and without HS by a two-tailed Mann-Whitney U test. Data are expressed as median (mdn).

\section{Results}

Nineteen of the 31 rats $(61 \%)$ reached the fully kindled stage and 12 rats dropped out due to loss of the brain electrodes (Table 7.1). Postmortem verification of the vagus nerve electrode position was performed in 26 rats; it was discovered that in four of the rats, the electrode was no longer wrapped around the carotid artery and vagus nerve. Routine histochemical evaluation of $10 \mu \mathrm{m}$ brain sections confirmed that the amygdala electrode was located in the amygdala in all fully kindled animals.

\section{Horner's syndrome}

HS, consisting of either left-sided ptosis and enophthalmos or isolated enopthalmos, was noted in $68 \%$ of rats (21 of 31 , see Table 7.1 ). In the first group of rats that was operated on (experimental group 1, $n=12$ ), 58\% suffered from HS. In experimental groups $2(n=10), 3(n=5)$ and $4(n=4)$ this percentage was 60, 100 and 75 , respectively. Of the 4 rats in which the VNS electrode was not wrapped around the carotid artery during postmortem examination, one had HS (25\%). Of the 22 other rats, 20 had HS (91\%).

\section{Epilepsy}

There was no statistically significant difference between the ADT of rats with HS (mdn $50.00 \mu \mathrm{A})$ and that of rats without HS (mdn $56.25 \mu \mathrm{A})$. There was no statistically significant difference between the kindling rate of rats with HS (mdn 17 stimulations) and that of rats without HS (mdn 17 stimulations) either. 
Table 7.1 Characteristics of the rats.

\begin{tabular}{|c|c|c|c|c|c|c|}
\hline Subject & $\begin{array}{l}\text { Horner's } \\
\text { syndrome }\end{array}$ & $\begin{array}{c}\text { Experimental } \\
\text { group }\end{array}$ & $\begin{array}{l}\text { Loss of } \\
\text { electrode }\end{array}$ & $\begin{array}{l}\text { Position of } \\
\text { vagus } \\
\text { electrode }\end{array}$ & $\begin{array}{l}\text { Kindling } \\
\text { rate }\end{array}$ & $\begin{array}{l}\text { ADT } \\
(\mu \mathrm{A})\end{array}$ \\
\hline 1 & + & 1 & + & n.d. & n.d. & 100 \\
\hline 2 & + & 1 & + & correct & n.d. & 50 \\
\hline 3 & + & 1 & + & correct & n.d. & 50 \\
\hline 4 & + & 1 & + & correct & n.d. & 75 \\
\hline 5 & - & 1 & + & correct & n.d. & 50 \\
\hline 6 & - & 2 & + & correct & n.d. & 75 \\
\hline 7 & + & 2 & - & correct & 20 & 37.5 \\
\hline 8 & + & 2 & - & correct & 26 & 62.5 \\
\hline 9 & - & 2 & - & correct & 17 & 62.5 \\
\hline 10 & + & 2 & + & correct & n.d. & n.d. \\
\hline 11 & + & 2 & - & correct & 14 & 125 \\
\hline 12 & + & 2 & - & correct & 21 & 82.5 \\
\hline 13 & + & 3 & - & correct & 20 & 50 \\
\hline 14 & + & 3 & - & correct & 17 & 112.5 \\
\hline 15 & + & 3 & + & correct & n.d. & n.d. \\
\hline 16 & + & 3 & - & correct & 15 & 37.5 \\
\hline 17 & + & 4 & + & correct & n.d. & 35 \\
\hline 18 & - & 4 & + & correct & n.d. & n.d. \\
\hline 19 & + & 4 & + & correct & n.d. & n.d. \\
\hline 20 & - & 1 & - & not correct & 13 & 75 \\
\hline 21 & + & 1 & - & correct & 13 & 50 \\
\hline 22 & - & 1 & - & n.d. & 10 & 50 \\
\hline 23 & + & 1 & - & n.d. & 20 & 50 \\
\hline 24 & - & 1 & - & correct & 22 & 75 \\
\hline 25 & - & 1 & + & n.d. & n.d. & n.d. \\
\hline 26 & + & 1 & - & n.d. & 19 & 50 \\
\hline 27 & - & 2 & - & not correct & 17 & 37.5 \\
\hline 28 & + & 2 & - & not correct & 16 & 37.5 \\
\hline 29 & - & 2 & - & not correct & 20 & 50 \\
\hline 30 & + & 4 & - & correct & 14 & 60 \\
\hline 31 & + & 3 & - & correct & 10 & 87.5 \\
\hline
\end{tabular}

Characteristics of the rats. $+=$ present; $-=$ absent; n.d. = not determined; $A D T=$ afterdischarge threshold; $\mu \mathrm{A}=$ micro Ampère

\section{Discussion}

In humans, $10 \%$ of non-idiopathic HS is reported to be iatrogenic ${ }^{15}$. Most of these cases are caused by medical interventions in the cervical area such as internal jugular vein cannulation ${ }^{16-19}$, thyroid surgery ${ }^{20,21}$, coronary artery bypass surgery ${ }^{22}$, tube thoracotomy ${ }^{23,24}$, carotid endarterectomy ${ }^{25}$, and tonsillectomy ${ }^{26-29}$. HS has also been reported as a complication of VNS electrode placement ${ }^{30}$; spontaneous recovery of symptoms occurred within 4 weeks. 
Exact data on incidence of iatrogenic HS in animals are not available. HS has been reported as a complication of surgery in the cervical area in dogs (anterior cervical spine surgery ${ }^{4,31}$ ), in a pig (aortic stenting ${ }^{5}$ ), in cats (carotid artery catheterization ${ }^{6}$ ) and in horses (intravenous injection ${ }^{7}$ ).

Fourty-four studies on VNS surgery in animals have been published so far. These include studies on healthy animals ${ }^{32-51}$ as well as on animals that model certain diseases ${ }^{52-60}$, including seizures and epilepsy ${ }^{8,38,39,41,61-74}$. In several of the abovementioned studies, the vagus nerve was transected before applying the electrode to either the proximal or distal part of the nerve. In several studies, rats were anaesthetized for the duration of the experiment and sacrificed immediately after.

Only one of these studies reports HS as a complication of VNS surgery: 2 out of 10 dogs developed HS after VNS implantation as part of a study on the safety and efficacy of VNS in dogs with medically refractory epilepsy. The symptoms resolved spontaneously within two to four weeks ${ }^{8}$.

Two of the 44 studies mentioned other complications of VNS surgery, consisting of subcutaneous inflammation in $1 \mathrm{rat}^{33}$, and unexplained death in 5 out of $57 \mathrm{rats}^{54}$.

Two of the classical symptoms of HS, enophthalmos and ptosis, were found in the rats described in the current study. Miosis was not evaluated because pupil size determination in albino rats requires dim red illumination, which could have interfered with the kindling process ${ }^{75}$. For the same reason the cocaine test was not performed. Facial anhidrosis was not evaluated either.

We hypothesized that enophtalmos and ptosis were related to damage to the oculosympathetic system caused by surgery in the area of third order neuron of the oculosympathetic system or of the SCG. These third order neurons of the oculosympathetic system in rats surround the carotid artery ${ }^{9}$, while the SCG in rats is located immediately dorsally to the carotid artery ${ }^{9}$. Both anatomical localizations are similar to those in humans and other mammals. Damage to either the SCG or the third order neurons can occur when surgery is performed in this area, and has caused $\mathrm{HS}$ in humans and other mammals. For these reasons we conclude that carotid artery surgery in rats can be accompanied by HS as well.

The oculosympathetic system has not been reported to be involved in epileptogenesis. This is supported by the findings of the current study: HS did not influence kindling rate or pre-kindling afterdischarge threshold.

All HS-affected rats suffered from HS immediately after surgery. This indicates that damage to the oculosympathetic system occurred during surgery. Perhaps postoperative edema has contributed to the symptoms as well. The finding that chronic placement of an electrode around the carotid artery is associated with HS in $91 \%$ of cases, suggests that the electrode itself may have induced secondary damage. This is supported by the absence of HS in $75 \%$ of rats in which the electrode was not 
wrapped around the carotid artery anymore during postmortem examination, although this examination has not revealed the time point at which the detachment had occurred.

More experience with the surgical technique is not associated with a lower incidence of HS in this study, since learning curve did not affect the occurrence of this complication in the current series of rats.

It is unclear why HS is reported relatively frequently in humans and other mammals, but not in rats. Over forty papers have been published on VNS in rats. None of these report HS as a complication. A much larger number of rat experiments has been conducted in which surgery of the carotid artery took place; a pubmed search using the words 'carotid artery' and 'surgery' and 'rat', resulted in over 2000 articles.

One of the reasons may be the fact that in many of these studies, acute experiments were performed, in which the rats were sacrificed immediately after finishing surgery. This means that HS could have been present, but was not diagnosed because the rat's eyes were closed throughout the experiments. Another explanation may be that the researchers did not recognize the symptoms as HS because they were not familiar with the syndrome.

Based on HS symptoms, lesions of the third order neuron cannot be distinguished from lesions of the SCG. However, this difference may be important because if damage occurred at the level of the SCG, sympathetic fibers that innervate the intestines may have been damaged as well. This is of special importance considering the growing interest in the vagal control of bowel inflammation in relation to the cholinergic anti-inflammatory reflex ${ }^{76}$, and in the role of the vagus nerve in modulating inflammation and regulation of food intake and body mass ${ }^{32,36,48}$. While these latter studies explore the effect of the efferent, parasympathetic, vagus nerve, special attention has to be paid to the possibility that by stimulating the vagus nerve, sympathetic innervation of the bowel can be influenced as well.

\section{Conclusion}

HS can occur as a complication of carotid artery surgery in rats. This complication did not influence epileptogenesis in the current study. However, considering the anatomy of the SCG in the rat, HS after carotid artery surgery in rats is a complication that should not be overlooked because the occurrence of HS in rats may coincide with damage to the sympathetic innervation of the gut. 


\section{References}

1. Adams R, Victor, M., Ropper, A. Principles of Neurology. New York: McGraw Hill; 1997.

2. $\quad$ van der Wiel HL. Johann Friedrich Horner (1831-1886). J Neurol. 2002;249:636-7.

3. Greenberg MS. Handbook of Neurosurgery. Fifth ed. New York: Thieme Medical Publishers; 2001.

4. Boydell P. Horner's syndrome following cervical spinal surgery in the dog. J Small Anim Pract. 1995; 36:510-2.

5. Lembo TM, Wright KC, Cromeens DM, Price RE. latrogenic Horner's syndrome in an experimental pig. Contemp Top Lab Anim Sci. 2001;40:33-5.

6. Kneller SK, Lewis RE, Oliver JE. Horner's syndrome following common carotid artery catheterization in cats. J Small Anim Pract. 1972;13:595-9.

7. Sweeney RW, Sweeney CR. Transient Horner's syndrome following routine intravenous injections in two horses. J Am Vet Med Assoc. 1984;185:802-3.

8. Munana KR, Vitek SM, Tarver WB, Saito M, Skeen TM, Sharp NJ, Olby NJ, Haglund MM. Use of vagal nerve stimulation as a treatment for refractory epilepsy in dogs. J Am Vet Med Assoc. 2002;221: 977-83.

9. Gabella G. Autonomic Nervous System. In: Paxinos G, editor. The Rat Nervous System. San Diego: Academic Press. 1995::81-103.

10. Gabella G. Innervation of the Gastrointestinal Tract. International Review of Cytology. 1979;59: 129-93.

11. Temel Y, Visser-Vandewalle V, van der Wolf M, Spincemaille GH, Desbonnet L, Hoogland G, Steinbusch HW. Monopolar versus bipolar high frequency stimulation in the rat subthalamic nucleus: differences in histological damage. Neurosci Lett. 2004;367:92-6.

12. Paxinos GW, C. The Rat brain in stereotaxic coordiates. fourth ed. London: Academic press; 1998.

13. Racine R. Kindling: the first decade. Neurosurgery. 1978;3:234-52.

14. Racine RJ. Modification of seizure activity by electrical stimulation. II. Motor seizure. Electroencephalogr Clin Neurophysiol. 1972;32:281-94.

15. Bell RL, Atweh N, Ivy ME, Possenti P. Traumatic and iatrogenic Horner syndrome: case reports and review of the literature. J Trauma. 2001;51:400-4.

16. Talks SJ, Shah P, Sinha PA. Horner's syndrome following central line insertion. Anaesthesia. 1994; 49:553.

17. Parikh RK. Horner's syndrome. A complication of percutaneous catheterisation of internal jugular vein. Anaesthesia. 1972;27:327-9.

18. Teich SA, Halprin SL, Tay S. Horner's syndrome secondary to Swan-Ganz catheterization. Am J Med. 1985;78:168-70.

19. Vaswani S, Garvin L, Matuschak GM. Postganglionic Horner's syndrome after insertion of a pulmonary artery catheter through the internal jugular vein. Crit Care Med. 1991;19:1215-6.

20. Smith I, Murley RS. Damage to the Cervical Sympathetic System During Operations on the Thyroid Gland. Br J Surg. 1965;52:673-5.

21. Solomon P, Irish J, Gullane P. Horner's syndrome following a thyroidectomy. J Otolaryngol. 1993; 22:454-6.

22. Barbut D, Gold JP, Heinemann MH, Hinton RB, Trifiletti RR. Horner's syndrome after coronary artery bypass surgery. Neurology. 1996;46:181-4.

23. Kahn SA, Brandt LJ. latrogenic Horner's syndrome: a complication of thoracostomy-tube replacement. N Engl J Med. 1985;312:245.

24. Fleishman JA, Bullock JD, Rosset JS, Beck RW. latrogenic Horner's syndrome secondary to chest tube thoracostomy. J Clin Neuroophthalmol. 1983;3:205-10.

25. Perry C, James D, Wixon C, Mills J, Ericksen C. Horner's syndrome after carotid endarterectomy--a case report. Vasc Surg. 2001;35:325-7.

26. Hobson JC, Malla JV, Kay NJ. Horner's syndrome following tonsillectomy. J Laryngol Otol. 2006; 120:800-1.

27. Blanco $\mathrm{Cl}$, Buznego L, Mendez M. [Horner's syndrome after tonsillectomy]. Arch Soc Esp Oftalmol. 2008;83:129-31. 
28. Novoselitskii EM. [Claude Bernard-Horner syndrome following tonsillectomy]. Zh Ushn Nos Gorl Bolezn. 1979:82-3.

29. Zollner B, Herrmann IF. [Horner's syndrome hypoglossal and laryngeal nerve paralyses as inflammatory late complications following tonsillectomy]. Monatsschr Ohrenheilkd Laryngorhinol. 1971;105:228-32.

30. Kim W, Clancy RR, Liu GT. Horner syndrome associated with implantation of a vagus nerve stimulator. Am J Ophthalmol. 2001;131:383-4.

31. Boydell P. Horner's syndrome following vertical ramus osteotomy in a dog. Vet Rec. 2001;148:113-4.

32. Laskiewicz J, Krolczyk G, Zurowski G, Sobocki J, Matyja A, Thor PJ. Effects of vagal neuromodulation and vagotomy on control of food intake and body weight in rats. J Physiol Pharmacol. 2003;54: 603-10.

33. Bohotin C, Scholsem M, Bohotin V, Franzen R, Schoenen J. Vagus nerve stimulation attenuates heatand formalin-induced pain in rats. Neurosci Lett. 2003;351:79-82.

34. Dedeurwaerdere S, Cornelissen B, Van Laere K, Vonck K, Achten E, Slegers G, Boon P. Small animal positron emission tomography during vagus nerve stimulation in rats: a pilot study. Epilepsy Res. 2005;67:133-41.

35. Dorr AE, Debonnel G. Effect of Vagus Nerve Stimulation on Serotonergic and Noradrenergic Transmission. J Pharmacol Exp Ther. 2006 May 11.

36. Sobocki J, Fourtanier G, Estany J, Otal P. Does vagal nerve stimulation affect body composition and metabolism? Experimental study of a new potential technique in bariatric surgery. Surgery. 2006;139:209-16.

37. Hosoi T, Okuma Y, Nomura Y. Electrical stimulation of afferent vagus nerve induces IL-1beta expression in the brain and activates HPA axis. Am J Physiol Regul Integr Comp Physiol. 2000;279:R141-7.

38. Zanchetti A, Wang SC, Moruzzi G. The effect of vagal afferent stimulation on the EEG pattern of the cat. Electroencephalogr Clin Neurophysiol. 1952;4:357-61.

39. Chase $M H$, Nakamura $Y$, Clemente $C D$, Sterman MB. Afferent vagal stimulation: neurographic correlates of induced EEG synchronization and desynchronization. Brain Res. 1967;5:236-49.

40. Groves DA, Bowman EM, Brown VJ. Recordings from the rat locus coeruleus during acute vagal nerve stimulation in the anaesthetised rat. Neurosci Lett. 2005;379:174-9.

41. Zagon A, Kemeny AA. Slow hyperpolarization in cortical neurons: a possible mechanism behind vagus nerve simulation therapy for refractory epilepsy? Epilepsia. 2000;41:1382-9.

42. Osharina V, Bagaev V, Wallois F, Larnicol N. Autonomic response and Fos expression in the NTS following intermittent vagal stimulation: Importance of pulse frequency. Auton Neurosci. 2006;126127:72-80.

43. Zhang $Y$, McGuire M, White DP, Ling L. Episodic phrenic-inhibitory vagus nerve stimulation paradoxically induces phrenic long-term facilitation in rats. J Physiol. 2003;551:981-91.

44. Zhang Y, McGuire M, White DP, Ling L. Serotonin receptor subtypes involved in vagus nerve stimulation-induced phrenic long-term facilitation in rats. Neurosci Lett. 2004;363:108-11.

45. Tubbs RS, Wellons JC, 3rd, Blount JP, Oakes WJ. Left-sided vagus nerve stimulation decreases intracranial pressure without resultant bradycardia in the pig: a potential therapeutic modality for humans. Childs Nerv Syst. 2004;20:309-12.

46. Nishikawa Y, Koyama N, Yoshida Y, Yokota T. Activation of ascending antinociceptive system by vagal afferent input as revealed in the nucleus ventralis posteromedialis. Brain Res. 1999;833:108-11.

47. Clark KB, Smith DC, Hassert DL, Browning RA, Naritoku DK, Jensen RA. Posttraining electrical stimulation of vagal afferents with concomitant vagal efferent inactivation enhances memory storage processes in the rat. Neurobiol Learn Mem. 1998;70:364-73.

48. Bugajski AJ, Gil K, Ziomber A, Zurowski D, Zaraska W, Thor PJ. Effect of long-term vagal stimulation on food intake and body weight during diet induced obesity in rats. J Physiol Pharmacol. 2007;58 Suppl 1:5-12.

49. Zuo Y, Smith DC, Jensen RA. Vagus nerve stimulation potentiates hippocampal LTP in freely-moving rats. Physiol Behav. 2007;90:583-9.

50. Roosevelt RW, Smith DC, Clough RW, Jensen RA, Browning RA. Increased extracellular concentrations of norepinephrine in cortex and hippocampus following vagus nerve stimulation in the rat. Brain Res. 2006;1119:124-32. 
51. Hassert DL, Miyashita T, Williams CL. The effects of peripheral vagal nerve stimulation at a memorymodulating intensity on norepinephrine output in the basolateral amygdala. Behav Neurosci. 2004;118:79-88.

52. Masada T, Itano T, Fujisawa M, Miyamoto O, Tokuda M, Matsui H, Nagao S, Hatase O. Protective effect of vagus nerve stimulation on forebrain ischaemia in gerbil hippocampus. Neuroreport. 1996;7: 446-8.

53. Miyamoto O, Pang J, Sumitani K, Negi T, Hayashida Y, Itano T. Mechanisms of the anti-ischemic effect of vagus nerve stimulation in the gerbil hippocampus. Neuroreport. 2003;14:1971-4.

54. Smith DC, Modglin AA, Roosevelt RW, Neese SL, Jensen RA, Browning RA, Clough RW. Electrical Stimulation of the Vagus Nerve Enhances Cognitive and Motor Recovery following Moderate Fluid Percussion Injury in the Rat. J Neurotrauma. 2005;22:1485-502.

55. Smith DC, Tan AA, Duke A, Neese SL, Clough RW, Browning RA, Jensen RA. Recovery of function after vagus nerve stimulation initiated 24 hours after fluid percussion brain injury. J Neurotrauma. 2006;23:1549-60.

56. Clough RW, Neese SL, Sherill LK, Tan AA, Duke A, Roosevelt RW, Browning RA, Smith DC. Cortical edema in moderate fluid percussion brain injury is attenuated by vagus nerve stimulation. Neuroscience. 2007;147:286-93.

57. Neese SL, Sherill LK, Tan AA, Roosevelt RW, Browning RA, Smith DC, Duke A, Clough RW. Vagus nerve stimulation may protect GABAergic neurons following traumatic brain injury in rats: An immunocytochemical study. Brain Res. 2007;1128:157-63.

58. Krahl SE, Senanayake SS, Pekary AE, Sattin A. Vagus nerve stimulation (VNS) is effective in a rat model of antidepressant action. J Psychiatr Res. 2004;38:237-40.

59. Krahl SE, Martin FC, Handforth A. Vagus nerve stimulation inhibits harmaline-induced tremor. Brain Res. 2004;1011:135-8.

60. Follesa P, Biggio F, Gorini G, Caria S, Talani G, Dazzi L, Puligheddu M, Marrosu F, Biggio G. Vagus nerve stimulation increases norepinephrine concentration and the gene expression of BDNF and bFGF in the rat brain. Brain Res. 2007;1179:28-34.

61. Krahl SE, Clark KB, Smith DC, Browning RA. Locus coeruleus lesions suppress the seizure-attenuating effects of vagus nerve stimulation. Epilepsia. 1998;39:709-14.

62. Krahl SE, Senanayake SS, Handforth A. Destruction of peripheral C-fibers does not alter subsequent vagus nerve stimulation-induced seizure suppression in rats. Epilepsia. 2001;42:586-9.

63. Krahl SE, Senanayake SS, Handforth A. Right-sided vagus nerve stimulation reduces generalized seizure severity in rats as effectively as left-sided. Epilepsy Res. 2003;56:1-4.

64. Dedeurwaerdere S, Vonck K, Claeys P, Van Hese P, D'Havé M, Grisar T, Naritoku D, Boon P. Acute vagus nerve stimulation does not suppress spike and wave discharges in "Genetic Absence Epilepsy Rats from Strasbourg". Epilepsy Res. 2004;59:191-8.

65. Fernandez-Guardiola A, Martinez A, Valdes-Cruz A, Magdaleno-Madrigal VM, Martinez D, FernandezMas R. Vagus nerve prolonged stimulation in cats: effects on epileptogenesis (amygdala electrical kindling): behavioral and electrographic changes. Epilepsia. 1999;40:822-9.

66. Lockard JS, Congdon WC, DuCharme LL. Feasibility and safety of vagal stimulation in monkey model. Epilepsia. 1990;31 Suppl 2:S20-6.

67. Zabara J. Inhibition of experimental seizures in canines by repetitive vagal stimulation. Epilepsia. 1992;33:1005-12.

68. Sunderam S, Osorio I, Watkins JF, 3rd, Wilkinson SB, Frei MG, Davis RE. Vagal and sciatic nerve stimulation have complex, time-dependent effects on chemically-induced seizures: a controlled study. Brain Res. 2001;918:60-6.

69. Naritoku DK, Terry WJ, Helfert RH. Regional induction of fos immunoreactivity in the brain by anticonvulsant stimulation of the vagus nerve. Epilepsy Res. 1995;22:53-62.

70. McLachlan RS. Suppression of interictal spikes and seizures by stimulation of the vagus nerve. Epilepsia. 1993;34:918-23.

71. Dedeurwaerdere S, Vonck K, De Herdt V, Waterschoot L, De Smedt T, Raedt R, Wyckhuys T, Legros B, Van Hese P, Van Laere K, Delbeke J, Wadman W, Boon P. Neuromodulation with levetiracetam and vagus nerve stimulation in experimental animal models of epilepsy. Acta Neurol Belg. 2006;106:91-7.

72. Takaya M, Terry WJ, Naritoku DK. Vagus nerve stimulation induces a sustained anticonvulsant effect. Epilepsia. 1996;37:1111-6. 
73. Woodbury DM, Woodbury JW. Effects of vagal stimulation on experimentally induced seizures in rats. Epilepsia. 1990;31 Suppl 2:S7-19.

74. Tubbs RS, Salter EG, Killingsworth C, Rollins DL, Smith WM, Ideker RE, Wellons JC 3rd, Blount JP, Oakes WJ. Right-sided vagus nerve stimulation inhibits induced spinal cord seizures. Clin Anat. 2007;20:23-6.

75. Yi PL, Tsai CH, Lin JG, Lee CC, Chang FC. Kindling stimuli delivered at different times in the sleepwake cycle. Sleep. 2004;27:203-12.

76. Tracey KJ. The inflammatory reflex. Nature. 2002;420:853-9. 



\section{Chapter 8}

General discussion and conclusion 


\section{Pathophysiology of epilepsy}

\section{Interleukin 1}

The pathophysiology of epilepsy has not been elucidated yet. Studies have repeatedly shown that febrile seizures (FS) are among the most important risk factors for development of epilepsy ${ }^{1}$, but also brain trauma ${ }^{2}$ and stroke ${ }^{3}$ predispose patients to epileptic seizures. Since all these conditions are associated with increased levels of the pro-inflammatory cytokine $\mathrm{IL}-1 \beta^{4-6}$, and since IL-1 $\beta$ can influence neuronal excitability at the cellular level $\mathrm{I}^{7-9}$, it is thought that IL-1 $\beta$ contributes to, or even initiates epileptogenesis ${ }^{10}$.

The scientific evidence supporting this hypothetical key role of IL-1 $\beta$ was reviewed and summarized in CHAPTER 2 of this thesis. In all available IL-1 $\beta$ studies, IL-1 $\beta$ levels were detemined after seizures, often in animal models that were associated with neuronal damage or in brains of epilepsy patients that suffered from an underlying brain disease, conditions that by itself are already associated with IL-1 $\beta$ expression, also in the absence of seizures. Based on these papers we stated that it could not be concluded at this point that IL-1 $\beta$ is chronically expressed in epilepsy, nor that is critically involved in epileptogenesis.

Furthermore, if seizure-susceptibility can be attributed to IL-1 $\beta$ expression, the question is why some people develop epilepsy after FS, stroke or brain trauma, while the majority does not. In CHAPTER 2 we hypothesize that individual variability in IL-1 receptor (IL-1R) upregulation may exists, possibly based on an individual balance between IL-1R type I and IL-1R type II expression. IL-1R type I is the actual functional receptor that processes the IL-1 $\beta$ signal whereas IL-1R type II is the decoy receptor. When IL-1 $\beta$ binds this receptor, signal transduction cannot take place because IL-1R II lacks an intracellular domain. Therefore we proposed that individuals that have a relatively high basal expression of IL-1RI might be more sensitive to IL-1 $\beta$ upregulation.

The findings that are presented in CHAPTER 3 elaborate on the first conclusion from CHAPTER 2, stating that proof of chronic IL-1 $\beta$ expression in epileptogenesis still lacks. The immediate seizure-induced IL-1 $\beta$ expression that has been described in several animal models for seizures and epilepsy can have a number of sources. First of all, seizures induce opening of the blood-brain barrier (BBB) leading to entrance of circulating proteins ${ }^{11}$, while IL-1 $\beta$ expressing leucocytes appear to enter the CNS too after seizure-induced changes in the expression of vascular cell adhesion molecules ${ }^{12}$. Secondly IL-1 $\beta$ upregulation occurs when Toll-like receptors are activated by heath shock proteins (HSPs), and induce expression of nuclear factor kappa B (NFKB). Since seizures induce the activation of HSPs, NFKB could be the direct stimulus for $\mathrm{IL}-1 \beta$ production after seizures ${ }^{13-15}$. NFKB activation is also associated with expression of the ceramid transfer protein (CERT, also known as the 
Goodpasture antigen binding protein ${ }^{16,17}$ ) a protein involved in intracellular transport of ceramide ${ }^{17}$.

When these cascades are taking place, other seizure-induced processes occur simultaneously. One highly important phenomenon that often occurs in experimental epilepsy is glutamate excitotoxicity. This takes place when excessive amounts of glutamate are released during status epilepticus, and leads to the influx of relatively large amounts of calcium though the NMDA-R. When intracellular calcium levels reach toxic concentrations, neurons $d_{i e}{ }^{26}$. When concentrations are high but return to normal levels before irreversible damage has taken place, sprouting can occur, a phenomenon that has been shown to be of high importance for epileptogenesis ${ }^{18}$. We therefore postulated that, in case of glutamate excitotoxicity, the effects of glutamate on the entrance of calcium into the cell via the NMDA-R are much bigger than the effects of IL-1 $\beta$.

In line with this, we investigated the degree of IL-1 $\beta$ expression in an animal model that is not associated with damage induced by glutamate excitotoxicity ${ }^{19-22}$, the amygdala kindled rat $^{23}$ (CHAPTER 3). This model is based on daily subthreshold electrical stimulation of the amygdala, leading to provoked generalized seizures of increasing severity (stage one to five), that, after five consecutive stage five seizures culminate in a chronic epileptogenic state. Chronically epileptogenic animals were sacrificed 48 hours after the last provoked seizure.

Apart from a number of IL-1 $\beta$ immunopositive cells, most likely macrophages, that were found in damaged cortex (where the kindling electrode pierced the cortex), we did not observe any IL-1 $\beta$ immunopositive cells in hippocampus or cortex of kindled rats, nor in shams (CHAPTER 3). Previous studies in the kindling model with animals that were sacrificed at similar phases in epileptogenesis, but at shorter intervals after the provoked seizure, have shown IL-1 $\beta$ upregulation immediately after a provoked generalized seizure ${ }^{24,25}$, but no other studies have been published in which IL-1 $\beta$ was determined 48 hours after a seizure.

We subsequently hypothesized that this lack of IL-1 $\beta$ may have resulted from a lack of seizure-induced NFKB upregulation in the absence of neuronal damage, and used CERT immunohistochemistry as a second readout parameter for NFKB activation. The intensity of the CERT immunopositive signal was equal among kindled animals and shams (CHAPTER 3). These results suggest that kindling does not lead to NFKB activation at all, or that NFKB activation does take place but instead of promoting chronic IL-1 $\beta$ and CERT expression, leads to upregulation of an until now unidentified protein that can lower seizure thresholds and contribute to epileptogenesis in this model. Studies are being carried out to further unravel these possible mechanisms.

\section{Calcium}

In contrast to the suspective but still non-conclusive role of IL-1 $\beta$ in epileptogenesis, research over the past 20 years has clearly shown that intracellular free calcium plays 
a key role in the process that transforms a normal brain into a hyperexcitable brain. As mentioned previously, intracellular calcium levels increase when glutamate is excessively released during a seizure, but also during other acute neurological conditions such as stroke or traumatic brain injury.

Glutamate excitotoxicity occurs in all stroke or traumatic brain injury patients. A minority of them develops epilepsy, which implies individual variability in seizure thresholds. We found individual variability in seizure thresholds in experimental seizures too. In CHAPTER 4 we described that kindled rats show variability in afterdischarge thresholds upon electrical stimulation of the amygdala and in the number of stimuli that is needed to develop a chronic epileptic state. Furthermore we described that in FS experiments of all rat pups that are exposed to hyperthermia, only $23 \%$ develop seizures.

Based on the important role for calcium in epileptogenesis we subsequently hypothesized that genetic differences in genes related to calcium homeostasis contribute to the individual variability in seizure thresholds. To investigate this we studied the occurrence of single nucleotide polymorphisms (SNPs) in two genes: the CACNA1E gene encoding the $\alpha 1$ e subunit of the voltage-gated calcium channel (VGCC) and the Camk2d gene that encodes the delta chain of calcium/calmodulin dependent kinase II (Camkll). The kindling experiments revealed an association between CACNA1E GG genotype and lower afterdischarge thresholds while the hyperthermia study showed an association between the CACNA1E G allele and hyperthermia-induced seizures. The Camk2d T allele appeared to be associated with hyperthermia-induced seizures but was not associated with kindling rate or afterdischargethresholds (CHAPTER 4).

\section{ANTICONVULSIVE EFFECTS OF VNS}

Class one evidence for the effectiveness of neuromodulation therapies in general is difficult to obtain, mostly because placebo controlled studies are not available. The effectiveness of antiepileptic treatment is classically evaluated using seizure-diaries that are kept by patients, parents or caregivers. The anticonvulsive effect of VNS has been evaluated in two randomized controlled trials in adult partial epilepsy patients where the effectiveness during the first three months of treatment was compared to 'sham' stimulation ${ }^{27,28}$. These studies showed $>50 \%$ seizure frequency reduction in $28-31 \%$ of patients in the treatment group versus $13-15 \%$ in the placebo group. Long-term effectiveness was studied in an uncontrolled fashion in both adults and children with partial epilepsy, where mean seizure frequency at baseline was compared with mean seizure frequency after 6 to 18 months. In general $30-40 \%$ of patients reported $>50 \%$ seizure frequency reduction ${ }^{29,30}$.

Besides these long-term effects VNS has an acute effect as well. Patients that have auras or partial onset seizures can acutely activate the stimulator to abort the seizure. 
This effect of VNS is only sparsely mentioned in literature, but it is estimated that $20 \%$ of these patients can abort a seizure this way, while placebo-activation aborts seizures in $10 \%{ }^{31-33}$.

Why the anticonvulsive effectiveness of VNS is limited is not known. This is related to the fact that the mechanism of action of VNS has not been studied in detail yet. Prior to its clinical use in 1997, six experimental papers, aimed at establishing the anticonvulsive effectiveness of VNS, had been published ${ }^{34-39}$. Only one of these studies study was conducted in freely moving animals suffering from experimental epilepsy ${ }^{39}$.

Since then, two studies from the same group using two different seizure models (maximum electroshock induced seizures and PTZ seizures) have been published ${ }^{40,41}$ to study the anticonvulsive mechanism of action on a cellular level. They showed that the locus coeruleus (LC) plays an important role in the anticonvulsive effect of VNS in the maximum electroshock model ${ }^{40}$ and that C-fiber activation is not required for the anticonvulsive effect of VNS in the PTZ model ${ }^{41}$. The past five years nine studies were published in which healthy animals were treated with VNS. These studies describe VNS-induced electrophysiological or immunohistochemical changes in the LC, thalamus, NTS, cortex and hippocampus ${ }^{42-50}$.

Besides these animal studies, studies in humans undergoing VNS have been published over the years as well. These studies either used imaging techniques such as SPECT ${ }^{51}$ and $\mathrm{PET}^{52}$, or biochemical analysis of plasma or cerebrospinal fluid ${ }^{53}$ and have shown that VNS induces blood flow changes in regions connected to the afferent vagus nerve projection nuclei, such as the thalamus ${ }^{51,52}$, and that cerebrospinal fluid concentrations of GABA increase $\mathrm{e}^{53}$.

In an attempt to elucidate the mechanism of action of VNS on a cellular level we developed a novel animal model: the VNS-treated kindled rat, presented in CHAPTER 5. Kindling-induced seizures mimic temporal lobe epilepsy and are often pharmacoresistant. Histopathological changes are similar to human temporal lobe epilepsy. These characterestics make the amygdala kindled rat a clinically relevant model. Our experimental VNS paradigm mimics the acute activation that is used to abort a seizure in the clinical situation. It consisted of a three-minute train of VNS. After one minute of VNS, the kindling stimulus was applied.

None of the rats stopped having a seizure. Nevertheless we observed a number of other anticonvulsive effects: $50 \%$ of VNS treated rats versus $18 \%$ of shams showed $>25 \%$ reduction in convulsive seizure duration; $57 \%$ of VNS treated rats versus $36 \%$ of shams showed $>25 \%$ reduction in total seizure duration and $38 \%$ of VNS treated rats versus none of the shams showed $>200 \%$ increase in latency. These results are in line with observations made by others in humans, namely that VNS affects more than seizure frequency alone, for instance seizure duration, duration of the post-ictal phase, mood and behavior ${ }^{54-56}$. The fact that the majority of patients including those that experience $<50 \%$ seizure frequency reduction choose to have their batteries replaced when necessary, further illustrates these positive (side) effects of VNS. 
All rats in our experiments were observed during VNS treatment and some of them coughed or scratched their necks, indicating that they felt the local stimulus. This is reported in human VNS literature as well ${ }^{27}$. No other stimulus-induced side effects were observed. As a surgical complication of VNS electrode placement we observed left sided Horner's syndrome in $68 \%$ of rats (CHAPTER 7). Horner's syndrome is a wellknown complication of neck surgery in humans (including VNS electrode placement ${ }^{57}$ ) but had not been described before in rats.

With regard to the mechanism of action of VNS, our aim was to study surgery and stimulation-induced immunohistochemical changes in the primary and secondary projection nuclei of the afferent vagus nerve in the brain stem. These data are presented in CHAPTER 6.

We used neuronal nitric oxide synthetase (nNOS) immunohistochemistry to evaluate to what extent neurons in the primary motor nucleus of the vagus nerve (dorsal motor nucleus of the vagus nerve, DMV) as well as in the primary projection nucleus of the vagus nerve afferents (nucleus of the solitary tract, NTS) are affected by manipulation of the vagus nerve during implantation, by chronic placement of the electrode and by VNS itself ${ }^{58}$. Despite a precise surgical technique we found an important effect of vagus nerve surgery and chronic electrode placement on nNOS immunopositive cell density in the DMV: a density of $>300$ cells $/ \mathrm{mm}^{2}$ was found eight times more often in the left DMV than in the right DMV of both VNS and sVNS animals. We think that electrical stimulation of the vagus nerve may have additionally contributed to the nNOS signal in the DMV the current study, since VNS rats were 2.4 times more likely than sVNS rats to have a high nNOS cell density in the left DMV. The question remains what this VNS-induced nNOS activity in the DMV illustrates: antidromic activation of vagus nerve efferents or non-activation related changes in cellular functioning resulting from the electrical stimulation.

A second immunohistochemical marker, $\triangle \mathrm{FosB}$, was used to further investigate activation of the afferents vagus nerve fibers. In contrast to nNOS, that merely indicates 'neuronal changes', $\triangle F$ FosB is considered to be indicative of neuronal activity $^{59}$. We were unable to confirm VNS-induced neuronal activation using $\triangle F o s B$ immunohistochemistry in the NTS, PBN and LC. Studies with large animal groups and a VNS stimulating protocol specifically designed for immunohistochemical detection of neuronal activation, must be conducted in future to investigate the VNS-induced neuronal activation in the brain stem.

\section{Conclusions}

Regarding epilepsy, there appears to be an important pathophysiological role for the immune system. IL-1 $\beta$ may be a player, but its key role has not been established yet. The central question remains what the role of IL-1 $\beta$ would be if excitotoxic neuronal damage is not present, a scenario that is often the case in human epilepsy. 
Furthermore, the action of IL-1 $\beta$ depends on the availability of the IL-1RI, and further research is needed to explore functioning of this receptor in epilepsy.

Besides the contribution of the immune system to seizure generation, the epileptogenic effect of high intracellular calcium continues to play an important role and genetic differences, with regard to calcium homeostasis, may contribute to the large variability in individual seizure susceptibility.

VNS is a well-established treatment option for refractory epilepsy with moderate effects on seizure frequency. A clinically relevant animal model is available now of which the effectiveness is comparable to the clinical situation: the VNS-treated kindled rat. However, the vagus nerve responds to surgical manipulation and chronic electrode placement by changes in brain stem nuclei. These reactions may affect the effectiveness of VNS in experimental epilepsy, but the effectiveness of VNS in clinical practice may be affected by similar changes induced by surgery or chronic electrode placement as well.

The first explorative mechanistic studies in the VNS-treated kindled rat suggest that the VNS signal enters the brain but also that vagus nerve damage is likely to be present. Much more research, preferably using chronic VNS, is needed to fully understand the mechanism of action. This may also lead to the discovery of a more effective target for anticonvulsive neuromodulation therapy. 


\section{References}

1. Scantlebury MH, Heida JG. Febrile seizures and temporal lobe epileptogenesis. Epilepsy Res. 2010;89:27-33.

2. Kharatishvili I, Pitkanen A. Posttraumatic epilepsy. Curr Opin Neurol. 2010;23:183-8.

3. Lossius MI, Ronning OM, Mowinckel P, Gjerstad L. Incidence and predictors for post-stroke epilepsy. A prospective controlled trial. The Akershus stroke study. Eur J Neurol. 2002;9:365-8.

4. Haspolat S, Mihci E, Coskun M, Gumuslu S, Ozben T, Yegin O. Interleukin-1beta, tumor necrosis factor-alpha, and nitrite levels in febrile seizures. J Child Neurol. 2002;17:749-51.

5. Minami M, Kuraishi Y, Yabuuchi K, Yamazaki A, Satoh M. Induction of interleukin-1 beta mRNA in rat brain after transient forebrain ischemia. J Neurochem. 1992;58:390-2.

6. Taupin V, Toulmond S, Serrano A, Benavides J, Zavala F. Increase in IL-6, IL-1 and TNF levels in rat brain following traumatic lesion. Influence of pre- and post-traumatic treatment with Ro5 4864, a peripheral-type ( $p$ site) benzodiazepine ligand. J Neuroimmunol. 1993;42:177-85.

7. Viviani B, Bartesaghi S, Gardoni F, Vezzani A, Behrens MM, Bartfai T, Binaglia M, Corsini E, Di Luca M, Galli $C L$, Marinovich $M$. Interleukin-1 beta enhances NMDA receptor-mediated intracellular calcium increase through activation of the Src family of kinases. J Neurosci. 2003;23:8692-700.

8. Zhu G, Okada M, Yoshida S, Mori F, Ueno S, Wakabayashi K, Kaneko S. Effects of interleukin-1beta on hippocampal glutamate and GABA releases associated with $\mathrm{Ca}(2+)$-induced $\mathrm{Ca}(2+)$ releasing systems. Epilepsy Res. 2006;71:107-16.

9. Zhang R, Yamada J, Hayashi Y, Wu Z, Koyama S, Nakanishi H. Inhibition of NMDA-induced outward currents by interleukin-1 beta in hippocampal neurons. Biochem Biophys Res Commun. 2008;372: 816-20.

10. Vezzani A, Balosso S, Ravizza T. The role of cytokines in the pathophysiology of epilepsy. Brain Behav Immun. 2008;22:797-803.

11. van Vliet EA, da Costa Araujo S, Redeker S, van Schaik R, Aronica E, Gorter JA. Blood-brain barrier leakage may lead to progression of temporal lobe epilepsy. Brain. 2007;130:521-34.

12. Fabene PF, Navarro Mora G, Martinello M, Rossi B, Merigo F, Ottoboni L, Bach S, Angiari S, Benati D, Chakir A, Zanetti L, Schio F, Osculati A, Marzola P, Nicolato E, Homeister JW, Xia L, Lowe JB, McEver RP, Osculati F, Sbarbati A, Butcher EC, Constantin G. A role for leukocyte-endothelial adhesion mechanisms in epilepsy. Nat Med. 2008;14:1377-83.

13. Maelfait J, Vercammen E, Janssens S, Schotte P, Haegman M, Magez S, Beyaert R. Stimulation of Tolllike receptor 3 and 4 induces interleukin-1beta maturation by caspase-8. J Exp Med. 2008;205: 1967-73.

14. Beg AA. Endogenous ligands of Toll-like receptors: implications for regulating inflammatory and immune responses. Trends Immunol. 2002;23:509-12.

15. Henshall DC, Murphy BM. Modulators of neuronal cell death in epilepsy. Curr Opin Pharmacol. 2008;8:75-81.

16. Granero F, Revert F, Revert-Ros F, Lainez S, Martinez-Martinez P, Saus J. A human-specific TNFresponsive promoter for Goodpasture antigen-binding protein. FEBS J. 2005;272:5291-305.

17. Mencarelli C, Losen M, Hammels C, De Vry J, Hesselink MK, Steinbusch HW, De Baets MH, MartínezMartínez P. The ceramide transporter (CERT) and the Goodpasture antigen binding protein (GPBP). One protein - one function? J Neurochem. 2010;113:1369-86.

18. DeLorenzo RJ, Sun DA, Deshpande LS. Erratum to "Cellular mechanisms underlying acquired epilepsy: the calcium hypothesis of the induction and maintenance of epilepsy." [Pharmacol. Ther. 105(3) (2005) 229-266]. Pharmacol Ther. 2006;111:288-325.

19. Gawlowicz M, Reichert M, Wojcierowski J, Czuczwar SJ, Borowicz KK. Apoptotic markers in various stages of amygdala kindled seizures in rats. Pharmacol Rep. 2006;58:512-8.

20. Khurgel M, Switzer RC, 3rd, Teskey GC, Spiller AE, Racine RJ, Ivy GO. Activation of astrocytes during epileptogenesis in the absence of neuronal degeneration. Neurobiol Dis. 1995;2:23-35.

21. Brandt C, Ebert U, Loscher W. Epilepsy induced by extended amygdala-kindling in rats: lack of clear association between development of spontaneous seizures and neuronal damage. Epilepsy Res. 2004;62:135-56. 
22. Osawa M, Uemura S, Kimura H, Sato M. Amygdala kindling develops without mossy fiber sprouting and hippocampal neuronal degeneration in rats. Psychiatry Clin Neurosci. 2001;55:549-57.

23. Racine RJ. Modification of seizure activity by electrical stimulation. II. Motor seizure. Electroencephalogr Clin Neurophysiol. 1972;32:281-94.

24. Plata-Salaman CR, Ilyin SE, Turrin NP, Gayle D, Flynn MC, Romanovitch AE, Kelly ME, Bureau Y, Anisman $\mathrm{H}$, Mclntyre DC. Kindling modulates the IL-1beta system, TNF-alpha, TGF-beta1, and neuropeptide mRNAs in specific brain regions. Brain Res Mol Brain Res. 2000;75:248-58.

25. Yi PL, Tsai CH, Lin JG, Lee CC, Chang FC. Kindling stimuli delivered at different times in the sleepwake cycle. Sleep. 2004;27:203-12.

26. Fujikawa DG. Prolonged seizures and cellular injury: understanding the connection. Epilepsy Behav. 2005;7 Suppl 3:S3-11.

27. A randomized controlled trial of chronic vagus nerve stimulation for treatment of medically intractable seizures. Neurology. 1995;45:224-30.

28. Handforth A, DeGiorgio CM, Schachter SC, Uthman BM, Naritoku DK, Tecoma ES, Henry TR, Collins SD, Vaughn BV, Gilmartin RC, Labar DR, Morris GL 3rd, Salinsky MC, Osorio I, Ristanovic RK, Labiner DM, Jones JC, Murphy JV, Ney GC, Wheless JW. Vagus nerve stimulation therapy for partial-onset seizures: a randomized active-control trial. Neurology. 1998;51:48-55.

29. Salinsky MC, Uthman BM, Ristanovic RK, Wernicke JF, Tarver WB. Vagus nerve stimulation for the treatment of medically intractable seizures. Results of a 1-year open-extension trial. Vagus Nerve Stimulation Study Group. Arch Neurol. 1996;53:1176-80.

30. Murphy JV. Left vagal nerve stimulation in children with medically refractory epilepsy. The Pediatric VNS Study Group. J Pediatr. 1999;134:563-6.

31. Ben-Menachem E, Manon-Espaillat R, Ristanovic R, Wilder BJ, Stefan H, Mirza W, Tarver WB, Wernicke JF. Vagus nerve stimulation for treatment of partial seizures: 1. A controlled study of effect on seizures. First International Vagus Nerve Stimulation Study Group. Epilepsia. 1994;35:616-26.

32. Boon P, Vonck K, Van Walleghem P, D'Have M, Goossens L, Vandekerckhove T, Caemaert J, De Reuck J. Programmed and magnet-induced vagus nerve stimulation for refractory epilepsy. J Clin Neurophysiol. 2001;18:402-7.

33. Morris GL, 3rd. A retrospective analysis of the effects of magnet-activated stimulation in conjunction with vagus nerve stimulation therapy. Epilepsy Behav. 2003;4:740-5.

34. Woodbury DM, Woodbury JW. Effects of vagal stimulation on experimentally induced seizures in rats. Epilepsia. 1990;31 Suppl 2:S7-19.

35. Zabara J. Inhibition of experimental seizures in canines by repetitive vagal stimulation. Epilepsia. 1992;33:1005-12.

36. McLachlan RS. Suppression of interictal spikes and seizures by stimulation of the vagus nerve. Epilepsia. 1993;34:918-23.

37. Naritoku DK, Terry WJ, Helfert RH. Regional induction of fos immunoreactivity in the brain by anticonvulsant stimulation of the vagus nerve. Epilepsy Res. 1995;22:53-62.

38. Takaya M, Terry WJ, Naritoku DK. Vagus nerve stimulation induces a sustained anticonvulsant effect. Epilepsia. 1996;37:1111-6.

39. Lockard JS, Congdon WC, DuCharme LL. Feasibility and safety of vagal stimulation in monkey model. Epilepsia. 1990;31 Suppl 2:S20-6.

40. Krahl SE, Clark KB, Smith DC, Browning RA. Locus coeruleus lesions suppress the seizure-attenuating effects of vagus nerve stimulation. Epilepsia. 1998;39:709-14.

41. Krahl SE, Senanayake SS, Handforth A. Destruction of peripheral C-fibers does not alter subsequent vagus nerve stimulation-induced seizure suppression in rats. Epilepsia. 2001;42:586-9.

42. Groves DA, Bowman EM, Brown VJ. Recordings from the rat locus coeruleus during acute vagal nerve stimulation in the anaesthetised rat. Neurosci Lett. 2005;379:174-9.

43. Ito S, Craig AD. Vagal-evoked activity in the parafascicular nucleus of the primate thalamus. J Neurophysiol. 2005;94:2976-82.

44. Zhang JL, Zhang SP, Zhang HQ. Antiepileptic effect of electroacupuncture vs. vagus nerve stimulation in the rat thalamus. Neurosci Lett. 2008;441:183-7.

45. Osharina V, Bagaev V, Wallois F, Larnicol N. Autonomic response and Fos expression in the NTS following intermittent vagal stimulation: Importance of pulse frequency. Auton Neurosci. 2006;126127:72-80. 
46. Cunningham JT, Mifflin SW, Gould GG, Frazer A. Induction of c-Fos and DeltaFosB immunoreactivity in rat brain by Vagal nerve stimulation. Neuropsychopharmacology. 2008;33:1884-95.

47. Roosevelt RW, Smith DC, Clough RW, Jensen RA, Browning RA. Increased extracellular concentrations of norepinephrine in cortex and hippocampus following vagus nerve stimulation in the rat. Brain Res. 2006 Sep 6.

48. Zhang JL, Zhang SP, Zhang HQ. Antiepileptic effects of electroacupuncture vs vagus nerve stimulation on cortical epileptiform activities. J Neurol Sci. 2008;270:114-21.

49. Biggio F, Gorini G, Utzeri C, Olla P, Marrosu F, Mocchetti I, Follesa P. Chronic vagus nerve stimulation induces neuronal plasticity in the rat hippocampus. Int J Neuropsychopharmacol. 2009;12:1209-21.

50. Revesz D, Tjernstrom M, Ben-Menachem E, Thorlin T. Effects of vagus nerve stimulation on rat hippocampal progenitor proliferation. Exp Neurol. 2008;214:259-65.

51. Vonck K, De Herdt V, Bosman T, Dedeurwaerdere S, Van Laere K, Boon P. Thalamic and limbic involvement in the mechanism of action of vagus nerve stimulation, a SPECT study. Seizure. 2008;17:699-706.

52. Henry TR, Bakay RA, Pennell PB, Epstein CM, Votaw JR. Brain blood-flow alterations induced by therapeutic vagus nerve stimulation in partial epilepsy: II. prolonged effects at high and low levels of stimulation. Epilepsia. 2004;45:1064-70.

53. Ben-Menachem E, Hamberger A, Hedner T, Hammond EJ, Uthman BM, Slater J, Treig T, Stefan H, Ramsay RE, Wernicke JF, et al. Effects of vagus nerve stimulation on amino acids and other metabolites in the CSF of patients with partial seizures. Epilepsy Res. 1995;20:221-7.

54. Shahwan A, Bailey C, Maxiner W, Harvey AS. Vagus nerve stimulation for refractory epilepsy in children: More to VNS than seizure frequency reduction. Epilepsia. 2009;50:1220-8.

55. Majoie HJ, Berfelo MW, Aldenkamp AP, Evers SM, Kessels AG, Renier WO. Vagus nerve stimulation in children with therapy-resistant epilepsy diagnosed as Lennox-Gastaut syndrome: clinical results, neuropsychological effects, and cost-effectiveness. J Clin Neurophysiol. 2001;18:419-28.

56. Aldenkamp AP, Majoie HJ, Berfelo MW, Evers SM, Kessels AG, Renier WO, Wilmink J. Long-term effects of 24-month treatment with vagus nerve stimulation on behaviour in children with LennoxGastaut syndrome. Epilepsy Behav. 2002;3:475-9.

57. Kim W, Clancy RR, Liu GT. Horner syndrome associated with implantation of a vagus nerve stimulator. Am J Ophthalmol. 2001;131:383-4.

58. Hopkins DA, Biegel, D., de Vente, J., Steinbusch, H.W.M. Vagal efferent projections: viscerotopy, neurochemistry and effects of vagotomy. Progress in Brain Research. 1996;107:18.

59. Nestler EJ, Barrot M, Self DW. DeltaFosB: a sustained molecular switch for addiction. Proc Natl Acad Sci U S A. 2001;98:11042-6. 

Summary 


\section{Summary}

Vagus nerve stimulation (VNS) is used to treat medically refractory epilepsy. Despite years of research it is still not clear why patients develop epileptic seizures and why VNS can reduce these seizures. The aims of this research were to gain more insight into the pathophysiology of epilepsy and into VNS. With regard to epilepsy, two factors that may be involved in the development of seizures were investigated: interleukin-1 beta (IL-1 $\beta$ ) and calcium. With regard to VNS a clinically relevant animal model was developed in which the mechanism of action of VNS can be studied.

\section{Pathophysiology of epilepsy}

Several mechanisms appear to play a role in the pathophysiology of epilepsy. The role of the pro-inflammatory cytokine IL-1 $\beta$ is suspected to be important, but based on the scientific literature so far available it cannot be concluded that IL-1 $\beta$ is critically involved in epilepsy or epileptogenesis (CHAPTER 2). The suspected role of IL-1 is mainly based on animal studies using different models that mimic epilepsy or seizures. The most important findings of these studies are that IL-1 $\beta$ is expressed after a seizure and that seizures can be reduced by blocking IL-1 $\beta$. In contrast to these studies we were unable to detect IL-1 $\beta$ in the brains of chronic epileptic rats (CHAPTER 3). The lack of IL-1 $\beta$ may be related to the fact that the epilepsy model we used, the amygdala kindled rat, is not associated with excitotoxic neuronal damage and associated inflammation, a phenomenon frequently encountered in the other epilepsy and seizure models.

In contrast to the suspected role of IL-1 $\beta$ in epileptogenesis, research over the past 20 years has clearly shown that intracellular free calcium plays a key role in this process that transforms a healthy brain into a hyperexcitable brain. In line with this important role, neurological conditions in which high intracellular free calcium levels are present, such as stroke and traumatic brain injury, are associated with an increased risk of epilepsy. It is still unclear why some of these stroke or brain trauma patients develop epilepsy, while the majority does not. Apparently some individuals are more vulnerable to seizures than others. We observed individual variability in seizure susceptibility in two animal models as well. We have shown in these animal models that polymorphisms in the calcium-related genes CACNA1E (encoding the $\alpha 1$ e subunit of the voltage-gated calcium channel) and Camk2d (encoding the delta chain of calcium/calmodulin dependent kinase II) may contribute to the individual variability in seizure susceptibility (CHAPTER 4).

\section{Vagus nerve stimulation}

Epilepsy patients are generally treated with antiepileptic drugs. Approximately $25 \%$ of patients does not respond to these drugs and continues to have seizures; these 
patients are considered to be pharmacoresitant. If curative resective neurosurgery (surgical removal of the part of the brain where the seizures originate) is not an option, patients can be treated with VNS resulting in $>50 \%$ seizure frequency reduction in $11.7 \%$ of patients. VNS consists of continuous cyclic stimulation of the cervical part of the vagus nerve. For this purpose, an electrode is placed around this nerve and connected to a subcutaneously placed pulse generator. Besides this chronic effect of VNS on seizure frequency, VNS has an acute seizure suppressing effect in some patients as well. VNS has been applied in a number of experimental studies in which its anticonvulsive effectiveness has been shown. However, the animal models used do not mimic the clinical situation very well. Moreover, the experimental studies that have been conducted so far have not revealed the mechanism of action of VNS. In order to develop a clinically relevant animal model in which this mechanism of action can be studied we treated amygdala kindled rats with acute VNS. This treatment affected different seizure characteristics in a subpopulation of rats, but as in the clinical situation, not all rats responded to the treatment (CHAPTER 5).

After establishing the effectiveness of VNS in this kindling model, we aimed at exploring the mechanism of anticonvulsive action by investigating the level of surgery-induced and VNS-induced changes in brain stem nuclei where vagus nerve efferents originate from and where afferents project to. We observed significant changes indicative of axonal damage in the vagus nerve motor neurons as a result of vagus nerve electrode placement. We were unable to confirm VNS-induced neuronal activation, possibly due to methodological issues (CHAPTER 6).

In humans, side effects of VNS are common but generally mild. As a side effect of vagus nerve electrode placement in our rats we observed Horner's syndrome (CHAPTER 7). This syndrome is well-known after surgery in the region of the carotid artery including after vagus nerve electrode placement, but had not been described before in rats.

\section{Conclusions}

Regarding epilepsy, there appears to be an important pathophysiological role for the immune system. IL-1 $\beta$ may be a player, but its key role has not been established yet. Besides the contribution of the immune system to seizure generation, the epileptogenic effect of high intracellular calcium plays an important role and genetic differences with regard to calcium homeostasis may contribute to the large variability in individual seizure susceptibility. VNS is a well-established treatment option for refractory epilepsy with moderate effects on seizure frequency. A clinically relevant animal model is available now in which the effectiveness is comparable to the clinical situation. The first explorative mechanistic studies in this model suggest that the VNS signal enters the brain but also that vagus nerve damage is likely to be present as a result of surgery and chronic electrode placement. Much more research, 
preferably using chronic VNS, is needed. This research must provide more insight in VNS by understanding the mechanism of action. This may also lead to the discovery of a more effective target for anticonvulsive neuromodulation therapy. 

Samenvatting 


\section{Samenvatting}

Nervus vagus stimulatie (NVS) wordt gebruikt voor de behandeling van farmacotherapieresistente epilepsiepatiënten. De afgelopen tientallen jaren is er wetenschappelijk onderzoek gedaan naar de ontstaanswijze van epilepsie en naar het werkingsmechanisme van NVS. Desondanks is het nog altijd niet duidelijk waarom mensen epilepsie krijgen, noch waarom NVS deze aanvallen kan reduceren. Doel van dit onderzoek was dan ook om meer inzicht te krijgen in de pathofysiologie van epilepsie waarbij twee verschillende factoren onderzocht werden: interleukine 1 beta (IL-1 $\beta$ ) en calcium. Daarnaast werd een klinisch relevant diermodel voor NVS ontwikkeld, waarin het werkingsmechanisme van deze behandeling verder onderzocht kan worden.

\section{Pathofysiologie van epilepsie}

Een aantal verschillende mechanismen spelen een rol in de pathofysiologie van epilepsie. Het vermoeden bestaat dat de pro-inflammatoire cytokine IL-1 $\beta$ een kritieke rol speelt. Hoewel er veel epilepsiestudies zijn waarin IL-1 $\beta$ een belangrijke rol speelt, kan deze hypothese op dit moment nog niet ondersteund worden door direkt wetenschappelijk bewijs (HOOFDSTUK 2). De hypothetische rol van IL-1 $\beta$ is voornamelijk gebaseerd op proefdierstudies. In deze studies, waarin verschillende diermodellen voor epilepsie zijn gebruikt, wordt vaak verhoogde IL-1 $\beta$ expressie gevonden kort na een epileptische aanval, of wordt de aanval geblokkeerd wanneer II-1 $\beta$ geblokkeerd wordt. In tegenstelling tot deze studies konden wij IL-1 $\beta$ in het amygdala kindling model voor epilepsie niet aantonen (HOOFDSTUK 3). Mogelijkerwijs komt IL-1 $\beta$ in onze studie niet tot expressie omdat het kindling model niet geassocieerd is met excitotoxiciteit, en daarmee ook niet met neuroinflammatie. Excitotoxiciteit en daarmee geassocieerde neuroinflammatie worden wel gezien in andere diermodellen voor epilepsie.

In tegenstelling tot de vooralsnog hypothetische rol van IL-1 $\beta$, is de rol van intracellulair vrij calcium bij het ontstaan van epilepsie de afgelopen 20 jaar duidelijk aangetoond. Neurologische aandoeningen waarbij hoge intracellulaire vrije calciumconcentraties voorkomen, zoals beroerte of traumatisch hersenletsel, zijn geassocieerd met een verhoogd risico op epilepsie. Het is niet duidelijk waarom sommige van de patiënten na een beroerte of ernstig hersentrauma epilepsie ontwikkelen, terwijl dit bij de meerderheid niet gebeurt. Blijkbaar zijn sommige individuen meer vatbaar voor het ontstaan van epileptische aanvallen dan anderen. In het dierexperimenteel epilepsie onderzoek worden ook individuele verschillen in aanvalssusceptibiliteit gezien. Polymorphismen in de twee calcium-gerelateerde genen CACNA1E (coderend voor een subunit van een calcium kanaal) en Camk2d (coderend voor een onderdeel van het calcium/calmoduline afhankelijk kinase II) 
dragen mogelijk bij aan de individuele variabiliteit in aanvalssusceptibiliteit (HOOFDSTUK 4).

\section{Nervus vagus stimulatie}

Epilepsiepatiënten worden in eerste instantie behandeld met medicijnen. Uiteindelijk reageert ongeveer $25 \%$ van de patiënten niet goed op deze medicijnen en blijft aanvallen houden. Deze patiënten zijn 'farmacotherapieresistent'. Als voor hen curatieve resectieve neurochirurgie, waarbij het epileptogene focus wordt verwijderd, geen optie is, kan deze groep behandeld worden met NVS. Dit resulteert in $>50 \%$ aanvalsfrequentiereductie in $11.7 \%$ van de patiënten. NVS bestaat uit continu cyclische elektrische stimulatie van de linker nervus vagus in de hals. Hiervoor wordt een elektrode geïmplanteerd rondom deze zenuw en verbonden met een subcutaan geplaatste pulsgenerator. Naast een chronisch effect op aanvalsfrequentie kan NVS bij sommige patiënten acuut een aanval onderdrukken. NVS is een aantal keer toegepast in diermodellen. Doel van deze studies was voornamelijk de effectiviteit van NVS aan te tonen. Fundamenteel onderzoek naar het werkingsmechanisme van NVS is schaars. Tot nu toe is dan ook nog niet duidelijk waarop dit mechanisme berust. Om een klinisch relevant diermodel voor deze anticonvulsieve behandeling te ontwikkelen, werd de amygdala kindled rat behandeld met acute NVS. Dit leidde tot afname van aanvalsduur en -ernst in een aantal dieren (HOOFDSTUK 5). Net zoals in de klinische praktijk reageerden niet alle dieren op de behandeling met NVS.

Dit klinisch relevante diermodel voor de anticonvulsieve werking van NVS werd vervolgens gebruikt voor het bestuderen van het werkingsmechanisme. Hiertoe werd een aantal hersenstamkernen onderzocht op chirurgie-gerelateerde veranderingen en op NVS-gerelateerde veranderingen. Deze hersenstamkernen bevatten ofwel de cellichamen van de efferente zenuwvezels, of ze bevatten de uitlopers van de afferente zenuwvezels. In de cellichamen van de efferente motorneuronen werden significante veranderingen gezien die mogelijk gerelateerd zijn aan axonale schade als gevolg van elektrodeplaatsing. Het was niet mogelijk om NVS-geïnduceerde neuronale activatie in een van de kernen aan te tonen, mogelijk omwille van methodologische redenen (HOOFDSTUK 6).

Onder epilepsiepatiënten komen bijwerkingen van NVS frequent voor, maar over het algemeen zijn deze niet ernstig van aard. Horner's syndroom is een zeldzame complicatie van NVS-elektrodeplaatsing in mensen. Ook bij ratten kan Horner's syndroom optreden als gevolg hiervan. Dit syndroom is bekend na chirurgie in het gebied van de arteria carotis, maar was bij ratten nog niet eerder beschreven (HOOFDSTUK 7). 


\section{Conclusies}

Het immuunsysteem lijkt een belangrijke rol te spelen in de pathofysiologie van epilepsie. IL-1 $\beta$ zou een sleutelrol kunnen spelen, maar meer onderzoek is nodig om dit aan te tonen. Naast deze relatief recent geopperde bijdrage van het immuunsysteem, blijft een verhoogde intracellulaire calcium concentratie een belangrijke rol spelen in de epileptogenese, en genetische verschillen met betrekking tot de calcium homeostase zouden kunnen bijdragen aan de individuele verschillen in aanvalssusceptibiliteit.

NVS is een geaccepteerde behandeling voor farmacotherapieresistente epilepsie met matig goede effecten op aanvalsfrequentie. De NVS-behandelde amygdala kindled rat is nu beschikbaar als klinisch relevant diermodel waarin het werkingsmechanisme van NVS verder onderzocht kan worden. De eerste exploratieve mechanistische studie suggereert dat het NVS-signaal het brein bereikt, maar ook dat schade aan de zenuw optreedt als gevolg van plaatsing en/of van chronische aanwezigheid van de elektrode. Meer onderzoek, bij voorkeur gebruik makend van chronische NVS, is nodig om het werkingsmechanisme volledig te kunnen begrijpen. Deze kennis zou ook kunnen leiden tot de ontdekking van een meer effectieve 'target' voor anticonvulsieve neuromodulatietherapie. 

List of publications 
172 


\section{List of publications}

Reduced structural and functional skin capillaries in familial combined hyperlipidemia affected men, associated with increased remnant-like lipoprotein cholesterol levels. Keulen ET, Schaper NC, Houben AJ, van Lin JM, Lutgens I, Rijkers K, Dallinga-Thie GM, de Bruin TW. Atherosclerosis 2002;163:355-62

Anticonvulsieve en psychotrope effecten van NVS. Majoie M, Berfelo W, Rijkers K, Aldenkamp B, Renier W. Ned T Epileptologie 2004;2:11-12

Cutaneous glucocorticoid receptor sensitivity and pro-inflammatory cytokine levels in antidepressant-resistant depression. Fitzgerald P, O'Brien SM, Scully P, Rijkers K. Scott LV, Dinan TG. Psychol Med 2006;36:37-43

Fatal cerebral and cerebellar hemorrhagic infarctions after thoracoscopic microdiscectomy. Cornips EMJ, Staals J, Stavast A, Rijkers K, Van Oostenbrugge RJ. J Neurosurg Spine 2007;6: 276-9

The microanatomical environment of the subthalamic nucleus. Rijkers $K$, Temel $Y$, Visser-Vandewalle V, Vanormelingen L, Vandersteen M. Adriaensen P, Gelan J, Beuls E. J Neurosurgery 2007;107:198-201

Is nervus vagusstimulatie een zinvol alternatief voor patiënten met therapieresistente epilepsie? Majoie HJM, Rijkers K, Cornips EM, Berfelo MW. T Neurol Neuroch 2007;108:80-8

Hardware failure in vagus nerve stimulation therapy: a case report. Rijkers K, Berfelo MW, Cornips EMJ, Majoie HJM. Acta Neurochirurgica 2008;150:403-5

The spinal dermal-sinus-like stalk. Van Aalst J, Beuls EA, Cornips EM, van Straaten HW, Boselie AF, Rijkers K, Weber JW, Vles JS. Childs Nerv Syst 2009;25:191-7

Spinal cord stimulation in Type I Complex Regional Pain Syndrome; instant effect on two rare cutaneous manifestations. Rijkers K, van Aalst J, Kurt E, Daemen MARC, Beuls EAM, Spincemaille GH. J Neurosurgery 2009;110:274-8

The role of Interleukin-1 in seizures and epilepsy; A critical review. Rijkers K, Majoie HJ, Hoogland G, Kenis G, de Baets M, Vles JS. Experimental Neurology 2009;216:25871 
Horner's syndrome: a complication of experimental carotid artery surgery in rats. Aalbers MW, Rijkers K, van Winden LAAP, Hoogland G, Vles JSH, Majoie HJM. Autonomic Neuroscience: Basic and Clinical 2009;147:64-9

Acute seizure-suppressing effect of vagus nerve stimulation in the amygdala kindled rat. Rijkers K, Aalbers M, Hoogland G, van Winden L, Vles J, Steinbusch H, Majoie M. Brain Research 2010;1319:155-63

Polymorphisms in CACNA1E and Camk2d are associated with seizure susceptibility of Sprague Dawley rats. Rijkers K, Mescheriakova J, Majoie M, Lemmens E, van Wijk X, Philippens M, van Kranen-Mastenbroek V, Schijns O, Vles J, Hoogland G. Epilepsy Research 2010;91:28-34

Vagus Nerve Stimulation in Refractory Epilepsy: Effects on Pro- and AntiInflammatory Cytokines in Peripheral Blood. Majoie HJM, Rijkers K, Berfelo MW, Hulsman JARJ, Myint A, Schwarz M, Vles JSH. Neuroimmunomodulation 2011;18:52-6 
Dankwoord 


\section{Dankwoord}

Hoewel mijn naam op de kaft van dit boekje staat en ik straks het proefschrift zal verdedigen zou dit boekje er helemaal niet zijn geweest zonder het initiatief, de begeleiding en aanwezigheid van heel veel mensen.

Geachte prof. dr. J.S.H. Vles, beste Hans. Na jaren van voorbereiding was het uiteindelijk door jouw steun dat ik in 2006 kon beginnen aan dit onderzoek. Allereerst dank daarvoor. Daarnaast wil ik je bedanken voor de fijne manier waarop je mij de afgelopen jaren begeleid hebt. Je gaf me veel ruimte en waar nodig werd ik bijgestuurd. Ik heb veel van je geleerd, ook als dokter en gewoon, als mens.

Geachte prof. dr. H.M.W. Steinbusch, beste Harry. Epilepsie is een aandoening die binnen het onderzoeksinstituut wat minder vaak aan bod komt dan de ziekte van Alzheimer en depressie. Desondanks heb je mij en het project altijd gesteund en heb je samen met Hans uiteindelijk de strakke planning bewaakt. Bedankt hiervoor. Jouw suggestie om Prof. dr. Hopkins bij het onderzoek te betrekken heeft het project een betere anatomische basis gegeven.

Geachte dr. H.J.M. Majoie, beste Marian. Nadat de klinische NVS studie zoveel vragen had opgeworpen heb jij de daadwerkelijke stap naar het laboratorium durven maken. Niet veel clinici kunnen de energie en het uithoudingsvermogen hiervoor opbrengen. Uithoudingsvermogen heb je hier zeker voor nodig gehad, want de eerste keer dat wij over dit project spraken was in 2002. Bijna 10 jaar later is het eerste proefschrift geschreven en het tweede onderweg. Bedankt voor je steun, hulp bij heel veel geregel, in de gaten houden van deadlines en het altijd weer terugkoppelen van onze gedachtenkronkels naar de kliniek: het moet wel klinisch relevant zijn.

Geachte dr. G. Hoogland, beste Govert. Jij was mijn dagelijks begeleider gedurende mijn tijd in het lab. En die had ik nodig! Wat ik enorm heb gewaardeerd is je aanwezigheid op cruciale momenten zoals tijdens de eerste series operaties en tijdens het 'temmen' van het EEG apparaat (of heeft hij ons getemd?). Het belangrijkste was misschien nog wel dat jij een deel van de gaten in mijn kennis van de moleculaire biologie hebt kunnen opvullen. Bovendien ben je tussen het serieuze onderzoeken door ook gewoon een gezellige collega.

Voorzitter van de beoordelingscommissie en mijn opleider prof. dr. J.J. Van Overbeeke, beste Koo. Ik wil je bedanken voor het beoordelen van het manscript, maar vooral voor de opleiding die ik krijg op de afdeling neurochirurgie. $\mathrm{Na}$ jaren met plezier in het lab te hebben gewerkt ben ik erg blij om terug te zijn. Hopelijk krijg ik nog vaak de kans om met je samen te opereren want dat is een groot plezier. 
De overige leden van de beoordelingscommissie prof. dr. F. Ramaekers, prof. dr. M. De Baets en prof. dr. O. Van Nieuwenhuizen wil ik bedanken voor het beoordelen van het manuscript en hun aanwezigheid tijdens de promotie. Dr. A. Vezzani, thank you very much for reading the manuscript and taking part in the corona. This is a big honour for me.

Prof. E.A.M. Beuls, mijn dank aan u is en blijft groot. Het is door uw vertrouwen in mij dat ik in opleiding ben tot neurochirurg. De kiem voor mijn betrokkenheid bij dit onderzoeksproject ligt ook bij u, want $u$ heeft mij in 2002 geïntroduceerd bij Dr. Berfelo en gesuggereerd dat ik NVS onderzoek zou kunnen gaan doen.

Bedankt dr. M.W. Berfelo, Willem, voor het overdragen van jouw NVS kennis op mij. Je hebt me letterlijk wegwijs gemaakt, zowel in mens als in dier. Bedankt ook voor je kritische commentaar op de manuscripten en de leuke momenten in jullie heerlijk huis in Moerslag.

Dear prof. dr. B.E. Leonard, dear Brian. In 2002 you gave me the opportunity to work in the lab in Maastricht and get experienced with several techniques and with animal work. Thank you for that and for your support and advice over the past 8 years.

Dear prof. dr. F. Onat, dear Filiz. Thank you for having me in your lab in Istanbul in 2004 and for teaching me the first principles of amygdala kindling.

Dear prof. dr. T. Dinan, dear Ted. After a pilot in Maastricht I performed my first amygdala kindling experiments under your supervision in Cork. Thank you for having me there in 2004, and for lending us the necessary equipment later on.

Beste prof. dr. D.A. Hopkins, beste David. In 2008 hebben wij kennis met elkaar gemaakt; mijn tijd in het lab zat er toen al bijna op. Als expert op het gebied van de anatomie van de nervus vagus en haar kernen in de hersenstam kwam je echter als geroepen! Het schrijven van een artikel hierover (hoofdstuk 6) is hierdoor overigens niet makkelijker geworden, maar het resultaat wordt wel veel beter. Bedankt.

Paul van Venrooij, Victor Duysens and Keith Mullet at Medtronic Bakken Research Center provided us with excellent vagus nerve electrodes and excellent service. Your problem-solving skills are impressive, as was illustrated in 2004 by the almost overnight development and production of the 'Narcose-Fixture'.

Bedankt Jos Aarts, Joeri Curfs en de mannen van de werkplaats van de afdeling 'Instrument Development, Engineering \& Evaluation' van de Universiteit Maastricht, voor het leveren van de elektrodes.

Bedankt dr. Y. Temel, Yasin, voor het mogen kopieëren van jouw elektrode ontwerp, maar ook voor je adviezen en steun de afgelopen jaren. 
Bedankt dr. V. Van Kranen-Mastenbroek, Vivianne, en de afdeling Klinische Neurofysiologie van het Maastricht Universitair Medisch Centrum voor het EEG apparaat en voor de begeleiding bij het gebruik hiervan.

Bedankt drs. Saskia Seeldrayers, Richard Frijnts en alle andere CPV medewerkers voor de samenwerking.

Bedankt Hellen Steinbusch, Marjan Phillipens en alle andere analisten voor het beantwoorden van mijn vaak onbenullige vragen, voor de hulp en voor de samenwerking.

Bedankt Tiny Wouters, voor het daadwerkelijk transformeren van een 'manuscript' tot een boekje.

Mijn nicht(je) Els Franken wil ik bedanken voor het maken van de mooie kaft.

Dr. A. Kessels, beste Fons, bedankt voor je fijne hulp. Je luistert goed en weet elke vraagstelling direkt tot haar essentie reduceren. Je hebt voor mij de statistiek begrijpelijk gemaakt (een beetje dan, want het blijft een vak apart).

Bedankt Trudy Stefess, Desirée Serpenti en Marie-Thérèse Moers voor de administratieve en secretariële hulp.

Bedankt collega's neurochirurgen, assistenten, secretaresses, verpleegkundigen en OK-assistenten van de afdelingen neurochirurgie in Maastricht en Heerlen, voor de gestelde belangstelling in mijn onderzoek. Af en toe kwam ik tussendoor even naar de afdeling of de OK. Heel fijn om dan steeds maar weer de vraag te horen 'Wanneer kom je nu eindelijk eens terug?'

Voor het mee lezen en schrijven aan de verschillende artikelen wil ik bedanken prof. dr. M. De Baets, dr. G. Kenis, C. Mencenali, dr. P. Martinez-Martinez, X. Van Wijk, O. Schijns en V.M. Moers-Hornikx.

Elk jaar waren er wel een paar studenten om mij te helpen. Bedankt Benjamin Mooij, Daniel Keszthelyi, Julia Mescheriakova, Larissa Van Winden, Maartje Huijbers, Roos Kroeders, Vienna Doenni en Sandra Schipper. Niet alleen hebben jullie mij in praktische zin geholpen, ook hebben jullie mij scherp gehouden door steeds maar kritische vragen te blijven stellen.

Mijn paranimfen Marlien Aalbers en Lisanne van den Hombergh. Lieve Marlien, jij was één van die studenten, en nu ben je 'mijn opvolger' in het lab. Je weet dat ik blij ben dat het onderzoek een vervolg krijgt. Ik ben ook blij dat jij degene bent die invulling geeft aan dit vervolg en ik ben trots op je als ik zie hoe je dat doet.

Lieve Lisanne! We hebben samen al heel wat meegemaakt. Je kent mij door en door, staat altijd voor mij klaar en maakt mij aan het lachen. Ik ben trots op je en ben erg blij dat jij mijn paranimf wilt zijn.

$\mathrm{Na}$ jaren met veel plezier in een mannen-omgeving gewerkt te hebben werd ik in het lab opeens omringd door allemaal lieve meisjes. Evi Lemmens, Eveline Stracks, 
Marijke Lemmens, Rinske Vlamings, Annerieke Sierksma, Imke Van Kooten en Eva Van Donkelaar: bedankt voor de gezelligheid, het acrobatieken, de lunchuurtjes en koffiekwartiertjes, de onvergetelijke filmpjes en toneelstukjes (zie dit niet als een aanmoediging), en de avondjes uit die wat mij betreft nog wel even door mogen gaan.

Mijn kamergenoten Lucas Ricker, Frank Dennissen, Veronique Moers en last but not least Ivona Brasnjevic (I wish you were here) en ik waren een vreemde combinatie van kolvende jonge Hollandse moeders, hard lopende en/of fietsende jonge mannen en a sweet and silly Serbian scientist. Hoe dan ook, het was een goede combinatie.

Ook mijn overige collega's in het lab wil ik bedanken voor de fijne samenwerking.

Mijn lieve vriendinnen Isabelle de Kort, Maartje Van Rij, Suzanne Grooten, Katrien Pouls, Boukje Janssen en Claudia Vernooij: in al onze levens is in de jaren dat ik aan dit proefschrift werkte zo veel veranderd. Het is mooi om te zien hoe iedereen zijn leven leidt en om dat met elkaar te kunnen delen. Hoewel de fysieke afstand vaak groot is zijn jullie stuk voor stuk kleine bakens in het gewone leven geweest waaraan ik me van tijd tot tijd even vast kon houden.

Lieve papa en mama, Amy en Wilma. Jullie zijn mijn warme nest. Toen ik jaren geleden uitvloog wist ik niet echt dat er neurochirurgen waren en wat promoveren precies inhield. Bedankt voor jullie onvoorwaardelijke liefde, hulp en steun. Daardoor ben ik nu waar ik nu ben.

Jasper en Wouter, jullie zijn mijn basis, mijn aarde. Het is zo fijn om bij jullie thuis te komen elke dag.

Liefste Jasper. Hoewel het voor mij veel belangrijker is om 'mama' genoemd te worden dan 'dokter' of 'doctor', is het heel fijn dat ik samen met jou niet hoef te kiezen en het allemaal kan zijn. Dankjewel.

Liefste Wouter. Een hele grote knuffel mèt armen.

Samen gaan we nog heel veel plezier maken en ik verheug me op de zeeën van tijd die we nu voor elkaar hebben. Ik hou van jullie. 
Curriculum Vitae 


\section{Curriculum Vitae}

Kim Rijkers werd geboren op 8 februari 1978 in Tilburg. Na haar eindexamen VWO aan het Cobbenhage College te Tilburg begon ze in aan haar geneeskundestudie aan de Universiteit Maastricht. Na het behalen van haar artsenbul in 2002 is ze gaan werken als arts-assistent op de afdeling neurochirurgie van het Ziekenhuis OostLimburg in Genk (B). In 2003 vervolgde ze haar arts-assistentschap neurochirurgie in het academisch ziekenhuis Maastricht, waar ze in 2004 aan haar opleiding tot neurochirurg begon (opleiders prof. E.A.M. Beuls en dr. H. Van Santbrink). Van 2006 tot 2009 werkte ze aan het onderzoek dat geleid heeft tot dit proefschrift aan de 'School for Mental Health \& Neuroscience' van het Maastricht Universitair Medisch Centrum onder supervisie van prof. dr. J.S.H. Vles en prof. dr. H.W.M. Steinbusch. Samen met haar partner Jasper van Aalst kreeg zij in 2008 een zoon, Wouter. In 2009 heeft zij haar opleiding tot neurochirurg hervat (opleider prof. dr. J.J. Van Overbeeke). Ze hoopt deze opleiding in 2014 af te ronden. 
